\title{
WestVirginiaUniversity
}

THE RESEARCH REPOSITORY @ WVU

Graduate Theses, Dissertations, and Problem Reports

2004

\section{Formation and characterization of metal and metal oxide nanoparticles}

\author{
Garry Glaspell \\ West Virginia University
}

Follow this and additional works at: https://researchrepository.wvu.edu/etd

\footnotetext{
Recommended Citation

Glaspell, Garry, "Formation and characterization of metal and metal oxide nanoparticles" (2004). Graduate Theses, Dissertations, and Problem Reports. 2100.

https://researchrepository.wvu.edu/etd/2100

This Dissertation is protected by copyright and/or related rights. It has been brought to you by the The Research Repository @ WVU with permission from the rights-holder(s). You are free to use this Dissertation in any way that is permitted by the copyright and related rights legislation that applies to your use. For other uses you must obtain permission from the rights-holder(s) directly, unless additional rights are indicated by a Creative Commons license in the record and/ or on the work itself. This Dissertation has been accepted for inclusion in WVU Graduate Theses, Dissertations, and Problem Reports collection by an authorized administrator of The Research Repository @ WVU.

For more information, please contact researchrepository@mail.wvu.edu.
} 


\title{
FORMATION AND CHARACTERIZATION OF METAL AND METAL OXIDE NANOPARTICLES
}

\author{
Garry Glaspell \\ Dissertation submitted to the College of Arts and Sciences \\ at West Virginia University \\ in partial fulfillment of the requirements \\ for the degree of \\ Doctor of Philosophy \\ In \\ Chemistry \\ Committee: \\ Fred L. King, Ph.D., Committee Chair \\ Paul W. Jagodzinski, Ph.D., Research Advisor \\ Larry E. Halliburton, Ph.D. \\ Ronald B. Smart, Ph.D. \\ Björn Söderberg, Ph.D. \\ C. E. Bennett Department of Chemistry \\ Morgantown, West Virginia \\ 2004
}

Keywords: SERS, LVCC, Room Temperature Ferromagnetism, Room Temperature

Synthesis, Microwave Synthesis, Titanium Dioxide, Zinc Oxide

Copyright 2004

Garry Glaspell 


\section{Abstract \\ FORMATION AND CHARACTERIZATION OF METAL AND METAL OXIDE NANOPARTICLES}

\section{Garry Glaspell}

This dissertation contains two parts. The first part is focused on Laser Vaporization Controlled Condensation (LVCC). Silver nanoparticles of controlled size were synthesized by this method in order to produce a Surfaced Enhanced Raman Scattering (SERS) active material. We have investigated the effects of particle size on SERS enhancement and how the addition of halides can further increase the limits of detection. We have also explored using LVCC to synthesize cobalt oxide nanoparticles. This is significant since a simple chemical route doesn't currently exist. Finally, we have reported the synthesis of cobalt nitrate hexahydrate by this method using cobalt metal, oxygen and nitrogen as starting materials. The second part of this dissertation focuses on synthesizing transition metal doped titanium dioxide and zinc oxide by various novel solgel techniques for applications in spintronics. Spintronics is based on the concept of carrying information due to the relative spins of electrons. Utilizing spin up and spin down allows twice as much information to be carried on the flow of the electrons. One of the key requirements for a spintronic material is that it must exhibit room temperature ferromagnetism (RTFM). Thus, we synthesized 10\% cobalt and iron doped titanium dioxide by a novel synthesis which displays RTFM. We have also explored synthesizing $5 \%$ cobalt doped zinc oxide by a room temperature process which also displays RTFM. Finally, RTFM 5\% cobalt and iron doped zinc oxide were synthesized by a novel process involving microwave irradiation. 


\section{ACKNOWLEDGEMENTS}

There are a number of people that I would like to thank. First and foremost, I would like to thank my research advisor Dr. Paul Jagodzinski. His guidance, insights, and experience have been invaluable part of my pursuit of a Ph.D. I would also like to express my sincere gratitude to Dr. Fred King who has also ensured that all my academic goals were fulfilled. I would also like to thank Dr. A. Manivannan for his inspiration, helping me carry out all the magnetic measurements, and giving me a home in the Physics Department. Special thanks go to Dr. Mohindar Seehra for his wisdom and helpful discussions. My committee must also be thanked for their advice and criticisms of the course of studies undertaken. Much gratitude is given to my lab members both past and present for their humor and encouragement. Finally, I would like to thank my parents who have taught me the meaning of hard work and integrity. 
This dissertation is dedicated to my fiancée Caroline. 


\section{TABLE OF CONTENTS}

PART I

CHAPTER 1

CHAPTER 2

\section{CHARACTERIZATION OF NANOPARTICLES PRODUCED BY LASER VAPORIZATION CONTROLLED CONDENSATION}

Surface Enhanced Raman Spectroscopy Using Silver

Nanoparticles: The Effects of Particle Size and Halide Ions on

Aggregation

1.1 Introduction

1.2 Experimental

1.3 Results and Discussion

1.4 Results of Halide Ion Addition

1.5 Conclusion

1.6 References

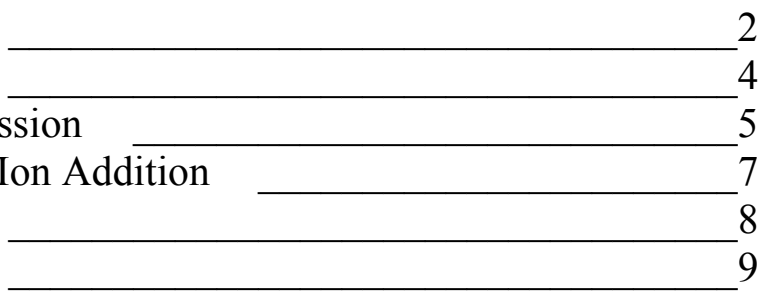

Formation of Cobalt Nitrate Hydrate, Cobalt Oxide, and Cobalt Nanoparticles Using Laser Vaporization Controlled

Condensation

2.1 Introduction

2.2 Experimental 23

2.3 Results and Discussion 23

2.4 Conclusion 24

2.5 References

SUMMARY OF PART I

PART II

VARIOUS SOL-GEL SYNTHESES OF TRANSITION METAL DOPED TITANIUM DIOXIDE AND ZINC OXIDE 42

CHAPTER 3

Controlled Transformation of Paramagnetism to RoomTemperature Ferromagnetism in Cobalt-Doped Titanium

Dioxide

3.1 Introduction 43

3.2 Experimental 44

3.3 Results and Discussion 44

3.4 Conclusion 47

3.5 References 48

CHAPTER 4

Novel Sol-Gel Synthesis and Magnetic Studies of Titanium

Dioxide Doped with 10\% M (M = Fe, Mn \& Ni)

4.1 Introduction 64

4.2 Experimental 65

4.3 Results and Discussion 66

4.4 Conclusion 68

4.5 References 
CHAPTER 5 Novel Room-Temperature Syntheis and Characterization of M-

Doped $\mathrm{ZnO}$ Nanoparticles $(\mathrm{M}=\mathrm{Co}, \mathrm{Cr}, \mathrm{Fe}, \mathrm{Mn} \& \mathrm{Ni})$

5.1 Introduction 83

5.2 Experimental

5.3 Results and Discussion 84

5.4 Conclusion 87

5.5 References

CHAPTER 6 Microwave Irradiation Synthesis and Characterization of Mdoped $\mathrm{ZnO}$ Nanoparticles $(\mathrm{M}=\mathrm{Co}, \mathrm{Cr}, \mathrm{Fe}, \mathrm{Mn} \& \mathrm{Ni})$

6.1 Introduction 107

6.2 Experimental 108

6.3 Results and Discussion 108

6.4 Conclusion 110

6.5 References 111

SUMMARY OF PART II 135

VITA 137

PUBLICATIONS 138 


\section{List of Figures}

Figure 1-1. Diagram of LVCC chamber and photograph showing 532nm light striking the metal target inside the chamber.

Figure 1-2. Raman spectra (647.1 nm excitation) of R6G $\left(3 \times 10^{-4} \mathrm{M}\right)$ on $11 \mathrm{~nm} \mathrm{Ag}$ particles as a function of time (hours). Ethanol peaks are only observed between $2900 \mathrm{~cm}^{-1}$ and $3000 \mathrm{~cm}^{-1}$. Asterisks indicate which bands are being monitored.

Figure 1-3. Plot of normalized intensities of the R6G band at $1650 \mathrm{~cm}^{-1}$ as a function of time for $15 \mathrm{~nm}(\diamond), 11 \mathrm{~nm}(\square)$ and $8 \mathrm{~nm}(\Delta)$ diameter Ag particles. Error bars indicate the standard deviation of 5 trials.

Figure 1-4. Plot of normalized intensities of the R6G band at $1523 \mathrm{~cm}^{-1}$ as a function of time for $15 \mathrm{~nm}(\diamond), 11 \mathrm{~nm}(\square)$ and $8 \mathrm{~nm}(\Delta)$ diameter Ag particles. Error bars indicate the standard deviation of 5 trials.

Figure 1-5. Plot of normalized intensities of the R6G band at $1365 \mathrm{~cm}^{-1}$ as a function of time for $15 \mathrm{~nm}(\diamond), 11 \mathrm{~nm}(\square)$ and $8 \mathrm{~nm}(\Delta)$ diameter Ag particles. Error bars indicate the standard deviation of 5 trials.

Figure 1-6. Plot of normalized intensities of the R6G band at $1310 \mathrm{~cm}^{-1}$ as a function of time for $15 \mathrm{~nm}(\diamond), 11 \mathrm{~nm}(\square)$ and $8 \mathrm{~nm}(\Delta)$ diameter Ag particles. Error bars indicate the standard deviation of 5 trials.

Figure 1-7. TEM images of $11 \mathrm{~nm} \mathrm{Ag}$ particles as a function of time (hours). Formation of aggregates is clearly visible.

Figure 1-8. Raman spectra (647.1 nm excitation) of R6G $\left(3.0 \times 10^{-4} \mathrm{M}\right)$ on $11 \mathrm{~nm} \mathrm{Ag}$ particles with the addition of chloride ions $\left(1.7 \times 10^{-4} \mathrm{M}\right)$ as a function of time (hours). Ethanol peaks are only observed between $2900 \mathrm{~cm}^{-1}$ and $3000 \mathrm{~cm}^{-1}$. Asterisks indicate which bands are being monitored.

Figure 2-1. XRD pattern showing cobalt (PDF 15-0806) as the primary product formed when the ratio of $\mathrm{O}_{2}$ to $\mathrm{N}_{2}$ is $0.3 \%$. The bracketed numbers indicate the cobalt crystal lattice planes giving rise to each line.

Figure 2-2. XRD pattern showing the decrease of cobalt $\bullet$;(PDF 15-0806) and the formation of cobalt oxide ;(PDF 43-1004) when the ratio of $\mathrm{O}_{2}$ to $\mathrm{N}_{2}$ is $2.3 \%$. 33

Figure 2-3. XRD pattern showing cobalt oxide (PDF 43-1004) as the primary product formed when the ratio of $\mathrm{O}_{2}$ to $\mathrm{N}_{2}$ is $3 \%$. 34 
Figure 2-4. TEM image of $\mathrm{CoO}$ nanoparticles. The average particle size was calculated to be $\sim 4 \mathrm{~nm}$.

Figure 2-5. XRD pattern showing Alfa Aesar 95\% CoO exhibiting mixed oxide phases referenced to $\mathrm{CoCo}_{2} \mathrm{O}_{4} \nabla$; (PDF 01-1152) and $\mathrm{CoO} \downarrow$; (PDF 431004). 36

Figure 2-6. XRD pattern showing a mixture of cobalt oxide (PDF 43-1004) and cobalt nitrate tetrahydrate (PDF 18-0425) produced when the ratio of $\mathrm{O}_{2}$ to $\mathrm{N}_{2}$ is $6.6 \%$. 37

Figure 2-7. XRD pattern showing cobalt nitrate hexahydrate (PDF 25-1219) as the primary product formed when the ratio of $\mathrm{O}_{2}$ to $\mathrm{N}_{2}$ is $50 \%$. 38

Figure 2-8. XRD pattern showing cobalt nitrate hexahydrate (PDF 25-1219) purchased from Aldrich.

Figure 2-9. Comparison of the infrared spectra of cobalt nitrate hydrate purchased from Aldrich (A) and that synthesized by LVCC (B). The nitrate normal vibrations are the $\mathrm{NO}_{3}{ }^{-}$symmetric stretching mode $\left(v_{1}\right)$, totally symmetric stretching mode $\left(v_{2}\right)$, symmetric in-plane bending mode $\left(v_{3}\right)$, antisymmetric stretching mode $\left(v_{4}\right)$, antisymmetric in-plane bending mode $\left(v_{5}\right)$ and the out of plane bending mode $\left(v_{6}\right)$. 40

Figure 3-1. X-ray diffraction patterns of the as-prepared ( $0 \mathrm{hrs})$ sample of $1 \% \mathrm{Co} / \mathrm{TiO}_{2}$ and the sample hydrogenated for 3 and $6 \mathrm{hrs}$. at $573 \mathrm{~K}$. The expected line positions for the anatase phase are shown. 49

Figure 3-2. X-ray diffraction patterns of the as-prepared ( $0 \mathrm{hrs})$ sample of $5 \% \mathrm{Co} / \mathrm{TiO}_{2}$ and the sample hydrogenated for 3 and $6 \mathrm{hrs}$. at $573 \mathrm{~K}$. The expected line positions for the anatase phase are shown. 50

Figure 3-3. X-ray diffraction patterns of the as-prepared ( $0 \mathrm{hrs})$ sample of $10 \%$ $\mathrm{Co} / \mathrm{TiO}_{2}$ and the sample hydrogenated for 1,3 and 6 hrs. at $573 \mathrm{~K}$. The expected line positions for the anatase $\bigcirc$; and rutile $\nabla$; phases are shown.

Figure 3-4. Temperature dependence of the magnetic susceptibility $(\chi)$ of the asprepared sample of $1 \% \mathrm{Co} / \mathrm{TiO}_{2}$. The solid line is fit to the equation shown. The magnetic field applied was 500 Oe. 52

Figure 3-5. Temperature dependence of the magnetic susceptibility $(\chi)$ of the asprepared sample of $1 \% \mathrm{Co} / \mathrm{TiO}_{2}$ hydrogenated at $573 \mathrm{~K}$ for 6 hours. The solid line is fit to the equation shown. 53

Figure 3-6. Temperature dependence of the magnetic susceptibility of the as-prepared sample of $5 \% \mathrm{Co} / \mathrm{TiO}_{2}$. The solid line is fit to the equation shown. 54 
Figure 3-7. Temperature variation of the magnetic susceptibility of the $5 \% \mathrm{Co} / \mathrm{TiO}_{2}$ hydrogenated at $573 \mathrm{~K}$ for $3 \mathrm{hr}$. under zero-field-cooled and field-cooled conditions.

Figure 3-8. $\quad \mathrm{M}$ vs $\mathrm{H}$ variation of $5 \% \mathrm{Co} / \mathrm{TiO}_{2}$ hydrogenated for 3 hours measured at $300 \mathrm{~K}(\mathrm{~A})$ and an expanded view (B).

Figure 3-9. Temperature variation of the magnetic susceptibility of the $5 \% \mathrm{Co} / \mathrm{TiO}_{2}$ hydrogenated at $573 \mathrm{~K}$ for $6 \mathrm{hr}$. under zero-field-cooled and field-cooled conditions.

Figure 3-10. $\mathrm{M}$ vs $\mathrm{H}$ variation of $5 \% \mathrm{Co} / \mathrm{TiO}_{2}$ hydrogenated for 6 hours measured at $300 \mathrm{~K}$ (A) and an expanded view (B). 58

Figure 3-11. Temperature dependence of the magnetic susceptibility of the as-prepared sample of $10 \% \mathrm{Co} / \mathrm{TiO}_{2}$. The solid line is fit to the equation shown. 59

Figure 3-12. $\mathrm{M}$ vs $\mathrm{H}$ variation of $10 \% \mathrm{Co} / \mathrm{TiO}_{2}$ hydrogenated for 6 hours measured at $300 \mathrm{~K} . \mathrm{A})$ and an expanded view B). 60

Figure 3-13. Temperature variation of the remanance $\left(\mathrm{M}_{\mathrm{r}}\right)$ of $10 \% \quad \mathrm{Co} / \mathrm{TiO}_{2}$ hydrogenated for 1,3 and 6 hours at $573 \mathrm{~K}$. The dotted lines are extrapolations, indicating $\mathrm{T}_{\mathrm{c}} \simeq 470 \mathrm{~K}$ where $\mathrm{M}_{\mathrm{r}}$ goes to zero.

Figure 3-14. Temperature variation of the coercivity $\left(\mathrm{H}_{\mathrm{c}}\right)$ of $10 \% \mathrm{Co} / \mathrm{TiO}_{2}$ hydrogenated for 1,3 and $6 \mathrm{hrs}$. at $573 \mathrm{~K}$. The dotted lines are extrapolations, indicating $\mathrm{T}_{\mathrm{c}} \simeq 470 \mathrm{~K}$ where $\mathrm{M}_{\mathrm{r}}$ goes to zero.

Figure 3-15. Temperature variation of the magnetic susceptibility $(\chi)$ of the $10 \%$ $\mathrm{Co} / \mathrm{TiO}_{2}$ sample hydrogenated at $573 \mathrm{~K}$ for $6 \mathrm{hr}$. under zero-field-cooled and field-cooled conditions. 63

Figure 4-1. XRD pattern showing $10 \% \mathrm{Fe} / \mathrm{TiO}_{2}$ as-prepared (A) and hydrogenated for $3 \mathrm{hr}(\mathrm{B})$ and $6 \mathrm{hr}(\mathrm{C})$. The expected line positions for the anatase, rutile, and brookite phases are shown. 72

Figure 4-2. XRD pattern showing $10 \% \mathrm{Mn} / \mathrm{TiO}_{2}$ as-prepared (A) and hydrogenated for $3 \mathrm{hr}(\mathrm{B})$ and $6 \mathrm{hr}(\mathrm{C})$. The expected line positions for the anatase, rutile, brookite, and manganese oxide phases are shown. 73

Figure 4-3. $\quad \mathrm{XRD}$ pattern showing $10 \% \mathrm{Ni} / \mathrm{TiO}_{2}$ as-prepared (A) and hydrogenated for $2 \mathrm{hr}(\mathrm{B})$ and $6 \mathrm{hr}(\mathrm{C})$. The expected line positions for the anatase, rutile, brookite, and nickel phases are shown. 
Figure 4-4. Temperature dependence of the magnetic susceptibility $(\chi)$ of the asprepared $10 \% \mathrm{Fe} / \mathrm{TiO}_{2}$. The solid line is fit to the equation shown. _ 75

Figure 4-5. Temperature dependence of the magnetic susceptibility $(\chi)$ of the asprepared $10 \% \mathrm{Mn} / \mathrm{TiO}_{2}$. The solid line is fit to the equation shown. 76

Figure 4-6. Temperature dependence of the magnetic susceptibility $(\chi)$ of the asprepared $10 \% \mathrm{Ni} / \mathrm{TiO}_{2}$. The solid line is fit to the equation shown. 77

Figure 4-7. Temperature dependence of the magnetic susceptibility $(\chi)$ of the asprepared $10 \% \mathrm{Ni} / \mathrm{TiO}_{2}$ hydrogenated for 2 hours under zero-field-cooled and field-cooled conditions.

Figure 4-8. Temperature dependence of the magnetic susceptibility $(\chi)$ of the asprepared $10 \% \mathrm{Mn} / \mathrm{TiO}_{2}$ hydrogenated for 6 hours under zero-field-cooled and field-cooled conditions.

Figure 4-9. $\quad M v s H$ variation of $10 \% \mathrm{Mn} / \mathrm{TiO}_{2}$ at $300 \mathrm{~K}(\mathrm{~A})$ and an expanded view (B).

Figure 4-10. Temperature variation of the magnetic susceptibility $(\chi)$ of $10 \% \mathrm{Fe} / \mathrm{TiO}_{2}$ hydrogenated for 6 hours under zero-field-cooled and field-cooled conditions.

Figure 4-11. $\quad M v_{s} H$ variation of $10 \% \mathrm{Fe} / \mathrm{TiO}_{2}$ at $300 \mathrm{~K}$ (A) and an expanded view (B).

Figure 5-1. X-ray diffraction patterns of the as-prepared sample of 5\% Co/ZnO (A) and hydrogenated at $573 \mathrm{~K}$ for 3 (B) and 6 hours (C) matching with the zincite phase (PDF 36-1451).

Figure 5-2. X-ray diffraction patterns of the as-prepared sample of $5 \% \mathrm{Cr} / \mathrm{ZnO}(\mathrm{A})$ and hydrogenated at $573 \mathrm{~K}$ for 3 (B) and 6 hours (C) matching with the zincite phase (PDF 36-1451).

Figure 5-3. X-ray diffraction patterns of the as-prepared sample of 5\% Fe/ZnO (A) and hydrogenated at $573 \mathrm{~K}$ for 3 hours (B). The expected lines for zincite and iron are shown below.

Figure 5-4. X-ray diffraction patterns of the as-prepared sample of $5 \% \mathrm{Mn} / \mathrm{ZnO}$ (A) and hydrogenated at $573 \mathrm{~K}$ for 3 hours (B). The expected lines for zincite and manganese are shown below.

Figure 5-5. X-ray diffraction patterns of the as-prepared sample of $5 \% \mathrm{Ni} / \mathrm{ZnO}(\mathrm{A})$ and hydrogenated at $573 \mathrm{~K}$ for 3 hours (B). The expected lines for zincite and nickel oxide are shown below. 
Figure 5-6. Temperature dependence of the magnetic susceptibility $(\chi)$ of $5 \% \mathrm{Cr} / \mathrm{ZnO}$. The solid line is fit to the equation shown above.

Figure 5-7. Temperature dependence of the magnetic susceptibility $(\chi)$ of $5 \% \mathrm{Cr} / \mathrm{ZnO}$ hydrogenated for 6 hours. The solid line is fit to the equation shown above. 95

Figure 5-8. Temperature dependence of the magnetic susceptibility $(\chi)$ of $5 \% \mathrm{Co} / \mathrm{ZnO}$. The solid line is fit to the equation shown above. 96

Figure 5-9. Temperature dependence of the magnetic susceptibility $(\chi)$ of $5 \% \mathrm{Co} / \mathrm{ZnO}$ hydrogenated at $573 \mathrm{~K}$ for 3 hours. 97

Figure 5-10. $\quad M$ vs. $H$ of $5 \% \mathrm{Co} / \mathrm{ZnO}$ hydrogenated for 3 hours (A) and an expanded view (B). 98

Figure 5-11. Temperature dependence of the magnetic susceptibility $(\chi)$ of $5 \% \mathrm{Co} / \mathrm{ZnO}$ hydrogenated at $573 \mathrm{~K}$ for 6 hours. 99

Figure 5-12. $\quad M$ vs. $H$ of $5 \% \mathrm{Co} / \mathrm{ZnO}$ hydrogenated for 6 hours (A) and an expanded view (B). 100

Figure 5-13. X-ray diffraction patterns of the as-prepared sample of $10 \% \mathrm{Co} / \mathrm{ZnO}$ and $10 \% \mathrm{Co} / \mathrm{ZnO}$ hydrogenated at $573 \mathrm{~K}$ for 6 hours matching with the zincite phase (PDF 36-1451). 101

Figure 5-14. Raman spectra of the as-prepared sample of $\mathrm{ZnO}$ and $10 \%$ doped $\mathrm{Co} / \mathrm{ZnO}$. 102

Figure 5-15. Temperature dependence of the magnetic susceptibility $(\chi)$ of $10 \%$ $\mathrm{Co} / \mathrm{ZnO}$. The solid line is fit to the equation shown above. 103

Figure 5-16. $M$ vs. $H$ of $10 \% \mathrm{Co} / \mathrm{ZnO}$ measured at $5 \mathrm{~K}(\mathrm{~A})$ and an expanded view (B).

Figure 5-17. $M$ vs. $H$ measured at $300 \mathrm{~K}$ for the $10 \% \mathrm{Co} / \mathrm{ZnO}$ hydrogenated at $573 \mathrm{~K}$ for 6 hours (A) and an expanded view (B). 105

Figure 5-18. Temperature dependence of the magnetic susceptibility $(\chi)$ of $10 \%$ $\mathrm{Co} / \mathrm{ZnO}$ hydrogenated at $573 \mathrm{~K}$ for 6 hours. 106

Figure 6-1. XRD patterns showing as-prepared samples of pure $\mathrm{ZnO}(\mathrm{A}), 1 \% \mathrm{Co} / \mathrm{ZnO}$ (B), $5 \% \mathrm{Co} / \mathrm{ZnO}(\mathrm{C})$, and $7 \% \mathrm{Co} / \mathrm{ZnO}(\mathrm{D})$ matching with the zincite phase (PDF 36-1451). The asterisks indicate contaminant peaks. 112 
Figure 6-2. $\quad \mathrm{XRD}$ patterns showing 5\% $\mathrm{Co} / \mathrm{ZnO}$ as-prepared $(\mathrm{A})$ and hydrogenated for $3 \mathrm{hrs}(\mathrm{B})$ and $6 \mathrm{hrs}(\mathrm{C})$ matching with the zincite phase (PDF 36-1451).

Figure 6-3. XRD patterns showing 5\% $\mathrm{Cr} / \mathrm{ZnO}$ as prepared (A) and hydrogenated for $3 \mathrm{hrs}(\mathrm{B})$ and 6hrs (C) matching with the zincite phase (PDF 36-1451).

Figure 6-4. XRD patterns showing 5\% Fe/ZnO as-prepared (A) and hydrogenated for 3 hrs (B) and 6hrs (C) matching with the zincite phase (PDF 36-1451).

Figure 6-5. XRD patterns showing 5\% $\mathrm{Mn} / \mathrm{ZnO}$ as-prepared (A) and hydrogenated for $3 \mathrm{hrs}(\mathrm{B})$ and $6 \mathrm{hrs}(\mathrm{C})$ matching with the zincite phase (PDF 36-1451).

Figure 6-6. XRD patterns showing 5\% Ni/ZnO as-prepared (A) and hydrogenated for $3 \mathrm{hrs}(\mathrm{B})$. The expectant lines for zincite and nickel oxide are shown below.

Figure 6-7. Temperature dependence of the magnetic susceptibility $(\chi)$ of the asprepared $5 \% \mathrm{Co} / \mathrm{ZnO}$. The solid line is fit to the equation shown.

Figure 6-8. Temperature dependence of the magnetic susceptibility $(\chi)$ of the asprepared $5 \% \mathrm{Cr} / \mathrm{ZnO}$. The solid line is fit to the equation shown.

Figure 6-9. Temperature dependence of the magnetic susceptibility $(\chi)$ of the asprepared $5 \% \mathrm{Mn} / \mathrm{ZnO}$. The solid line is fit to the equation shown.

Figure 6-10. Temperature dependence of the magnetic susceptibility $(\chi)$ of the asprepared $5 \% \mathrm{Ni} / \mathrm{ZnO}$.

Figure 6-11. Temperature dependence of the magnetic susceptibility $(\chi)$ of the asprepared $5 \% \mathrm{Fe} / \mathrm{ZnO}$.

Figure 6-12. Temperature dependence of the magnetic susceptibility $(\chi)$ of the asprepared $5 \% \mathrm{Cr} / \mathrm{ZnO}$ hydrogenated for 3 hours. The solid line is fit to the equation shown.

Figure 6-13. Temperature dependence of the magnetic susceptibility $(\chi)$ of the asprepared $5 \% \mathrm{Mn} / \mathrm{ZnO}$ hydrogenated for 3 hours. The solid line is fit to the equation shown.

Figure 6-14. Temperature dependence of the magnetic susceptibility $(\chi)$ of the asprepared $5 \% \mathrm{Co} / \mathrm{ZnO}$ hydrogenated for 3 hours under zero-field-cooled and field-cooled conditions. 
Figure 6-15. Temperature dependence of the magnetic susceptibility $(\chi)$ of the asprepared $5 \% \mathrm{Fe} / \mathrm{ZnO}$ hydrogenated for 3 hours under zero-field-cooled and field-cooled conditions.

Figure 6-16. $\quad M v s H$ Variation of $5 \% \mathrm{Co} / \mathrm{ZnO}$ at $300 \mathrm{~K}$ (A) and an expanded view (B).

Figure 6-17. $M v s H$ Variation of $5 \% \mathrm{Fe} / \mathrm{ZnO}$ at $300 \mathrm{~K}(\mathrm{~A})$ and an expanded view (B).

Figure 6-18. Temperature dependence of the magnetic susceptibility $(\chi)$ of the asprepared $5 \% \mathrm{Cr} / \mathrm{ZnO}$ hydrogenated for 6 hours. The solid line is fit to the equation shown.

Figure 6-19. Temperature dependence of the magnetic susceptibility $(\chi)$ of the asprepared $5 \% \mathrm{Mn} / \mathrm{ZnO}$ hydrogenated for 6 hours. The solid line is fit to the equation shown.

Figure 6-20. Temperature dependence of the magnetic susceptibility $(\chi)$ of the asprepared $5 \% \mathrm{Co} / \mathrm{ZnO}$ hydrogenated for 6 hours under zero-field-cooled and field-cooled conditions.

Figure 6-21. Temperature dependence of the magnetic susceptibility $(\chi)$ of the asprepared $5 \% \mathrm{Fe} / \mathrm{ZnO}$ hydrogenated for 6 hours under zero-field-cooled and field-cooled conditions.

Figure 6-22. $\quad M v s H$ Variation of $5 \% \mathrm{Co} / \mathrm{ZnO}$ at $300 \mathrm{~K}(\mathrm{~A})$ and an expanded view (B).

Figure 6-23. $\quad M v_{s} H$ Variation of $5 \% \mathrm{Fe} / \mathrm{ZnO}$ at $300 \mathrm{~K}$ (A) and an expanded view (B). 


\section{List of Tables}

Table 1-1. Slopes of the time versus intensity plots for four Raman lines of R6G as a function of size of the silver nanoparticles.

Table 1-2. Slopes of the time versus intensity plots for various Raman lines for R6G $\left(3.0 \times 10^{-4} \mathrm{M}\right)$ adsorbed on $11 \mathrm{~nm} \mathrm{Ag}$ particles for various halides. The molarities reported are the final concentrations of the halide. The addition of $0.17 \mathrm{M} \mathrm{F}^{-}$induced precipitation of R6G.

Table 1-3. Intensities of the Raman peaks measured immediately upon addition of the halide to the silver nanoparticles.

Table 2-1. Standard crystallographic peak assignments for cobalt nitrate hexahydrate produced via LVCC.

Table 2-2. Percent oxygen in the LVCC chamber related to the primary products and number of waters coordinated to the metal nitrate hydrate.

Table 4-1. Magnetic moments calculated from the Curie-constants for samples of transition metal doped $\mathrm{TiO}_{2}$. 


\section{Part I}

\section{CHARACTERIZATION OF NANOPARTICLES}

PRODUCED BY LASER VAPORIZATION

\section{CONTROLLED CONDENSATION}




\section{Chapter 1}

\section{Surface Enhanced Raman Spectroscopy Using Silver Nanoparticles: The Effects of Particle Size and Halide Ions on Aggregation}

\subsection{Introduction}

Raman spectroscopy was first observed by C.V. Raman in $1928 .^{1}$ It was not a widely accepted technique until the advent of lasers in the 1960's. In 1974 Fleischmann first observed intense Raman signals from pyridine on a silver electrode which was attributed to surface effects by Van Duyne three years later. ${ }^{2,3}$ The surface-enhanced Raman (SER) effect is currently explained using chemical (CE) and electromagnetic (EM) mechanisms. ${ }^{4}$ Chemical effects provide enhancement via an increase in the molecular polarizability of the absorbate due to the interaction of the adsorbate with the metal surface. Maximum chemical enhancement is observed when the substrate forms a monolayer on the metal of interest. Atomic scale structural features produce varying degrees of enhancement. Electromagnetic effects provide enhancement due to an increase in the electromagnetic field experienced by the molecule on the metal surface. The latter effect is paramount when investigating nanoparticles. ${ }^{5}$ The size and shape of the particles, the specific metal, and hence the nature of the surface plasmons, which can be defined as a sea of electrons with a particular resonance, contribute to the EM mechanism.

We have investigated the change in SER intensity of Rhodamine 6G (R6G) on silver nanoparticles as a function of initial particle size and as a function of aggregate formation with time. The latter work was performed both with and without the influence of halides ions. Faraday first reported that the addition of salts to metal sols resulted in aggregation of individual particles and this approach has been applied to metal 
colloids in numerous SERS studies. ${ }^{6,7}$ There are three mechanisms that describe the effect of adding salts to a metal colloid are: aggregation, co-adsorption (activation), and desorption. ${ }^{8-10}$ A possible explanation provided by Hildebrandt is that the enhancement factors are a combination of the chemical and electromagnetic mechanisms. ${ }^{11}$

Kniepp ${ }^{12-14}$, Brus ${ }^{15}$, and Nie ${ }^{16,17}$ have shown that not all particles are SER active and have reported that the aggregation of individual particles can lead to intense SER enhancement through the formation of "hot spots" that could provide enough enhancement for single molecule detection. $\mathrm{Xa}^{18}$ and Van Duyne ${ }^{19-21}$ have reported that the enhancement factors for a "hot spot" can be as high as $10^{13}$ to $10^{14}$ and that this could be responsible for single molecule detection. At low concentrations of salt the metal particles become activated showing an immediate increase in surface enhancement, but do not experience aggregation. ${ }^{11-13,15,16}$

Recently, synthesis of various semiconductor and intermetallic nanoparticles via laser vaporization controlled condensation (LVCC) has been of particular interest. This method utilizes well defined conditions to produce nanoparticles of controlled size and composition without the need for chemical precursors or heat treatments. Specifically, a laser is used to produce a supersaturated metal vapor from a target inside a chamber. Convection currents, resulting from the top plate of the chamber being cooled and the bottom plate heated, affects the rate of nucleation of the metal vapor. This can be achieved by the choice of laser power, chamber pressure, and temperature gradient. ${ }^{22-25}$ Particles generated by this procedure are predominately spherical and have significantly less fluctuation in diameter (usually $+/-3 \mathrm{~nm}$ ) compared to most reduction methods. 
Silver nanoparticles were generated and SER data were collected using Rhodamine 6G (R6G) since this adsorbate gives good enhancement on silver. ${ }^{26-28}$

\subsection{Experimental}

Silver metal (99.98\%) was purchased from Alpha Aesar (Ward Hill, MA). Nanoparticles of silver were generated via LVCC. The LVCC chamber was home built and consists of two metal plates modified to provide uniform heating and cooling. To provide convection the top plate was cooled with liquid nitrogen and the bottom plate was heated with circulating water. A Laser Photonics (Orlando, Florida) Nd / YAG laser was used to ablate the metal target. Altering the laser power, chamber pressure, and temperature gradient between the two plates results in the formation of particles of various sizes. ${ }^{29}$ The size and shape of the particles were confirmed via transmission electron microscopy (TEM) using a JEOL 1220 (Tokyo, Japan) operating at $80 \mathrm{Kev}$. Immediately after formation, the particles were placed in a test tube and mixed with a stock solution of R6G $\left(3 \times 10^{-4} \mathrm{M}\right)$ in ethanol. The R6G (99\%; Lamda Physik, Fort Lauderdale, FL) and ethanol (99.9\%; Fisher Scientific, Pittsburgh, PA) were used without further purification.

Stock solutions of aqueous $\mathrm{NaF}, \mathrm{NaCl}, \mathrm{NaBr}$ and $\mathrm{NaI}$ were prepared at various concentrations and added to the solution of particles and R6G. The concentrations of the anions in the solutions that were interrogated ranged from $1.7 \times 10^{-4} \mathrm{M}$ to $1.7 \times 10^{-1} \mathrm{M}$. The salts (99\%) were purchased from Fisher Scientific (Pittsburgh, PA) and used without further purification. 
SER spectra were obtained using a SPEX Triplemate spectrometer (Edison, NJ) equipped with 1200 grooves/mm gratings and an Oxford Instruments CCD detector cooled to $133 \mathrm{~K}$. A krypton ion laser (Lexel Laser, Fremont, CA) was used to provide excitation at $647.1 \mathrm{~nm}$. The laser power was set to $18 \mathrm{~mW}$ (at the sample) and the collection time was 5 seconds. The intensities of the SER signals were normalized relative to the well-separated ethanol peaks at $2931 \mathrm{~cm}^{-1}$ (internal intensity standard). No signals due to ethanol were observed below $2900 \mathrm{~cm}^{-1}$. Spectra were collected up to 46 hours after sample preparation after which oxidation of the silver surface obviated the possibility of obtaining reproducible data.

\subsection{Results and Discussion}

Stock solution of R6G was added to the Ag particles until a maximum SER intensity was observed (probably due to monolayer coverage since excess amounts of R6G decreased the SERS intensity). Once the optimum intensity was reached SER spectra were collected at various times for each of the initial particle sizes. Over the range of particles tested (5-50 nm in diameter) it was determined that $11 \mathrm{~nm}$ particles exhibited maximum spectral enhancement during a 46 hour period (vide infra). Figure 1-1 shows the spectra for $11 \mathrm{~nm}$ particles as a function of time through 46 hours. Plots of normalized intensities versus time for 15,11 and $8 \mathrm{~nm}$ particles for four selected aromatic ring based normal modes $\left(1650 \mathrm{~cm}^{-1}, 1523 \mathrm{~cm}^{-1}, 1365 \mathrm{~cm}^{-1}, 1310 \mathrm{~cm}^{-1}\right)$ are presented in Figures 1-2 to 1-5. It can be seen that the $11 \mathrm{~nm}$ particles exhibit the largest initial enhancement for each of the normal modes, although all three particle solutions do 
exhibit increased SER enhancement with time. Table 1-1 shows how the slopes differ among particle sizes for the four modes.

The observed enhancements could be explained via the chemical and electromagnetic effects of individual particles, hot spots of preformed clusters, or any combination of these. We can deduce that the chemical effect is minor since particles in the range of $40-50 \mathrm{~nm}$ do not exhibit a significant initial enhancement compared to the $11 \mathrm{~nm}$ particles, i.e., the initial spectra show a particle size dependent enhancement. Preformed clusters would produce varying degrees of initial enhancement due to random numbers of "hot spots" which would be independent of particle size. We have observed reproducible initial enhancements and so preformed clusters are not a major contributor to the observed enhancements. Thus we can infer that the major contribution to the initial enhancement is the electromagnetic effect. ${ }^{18,20}$

In order to show that the intensity enhancements are related to aggregate formation we collected TEM images of the $11 \mathrm{~nm}$ particles throughout the period of SER spectra collection. These images are depicted in Figure 1-6. Aggregation is also reflected in the red shift of the Raman signals with time $\left(15 \mathrm{~cm}^{-1}\right.$ shifts after 46 hours $){ }^{26}$ As aggregates form, it is possible that "hot spots" are generated where the particles come in close contact. ${ }^{18}$ Our data indicate that the energies of the "hot spots" associated with all three initial particle sizes increase their overlap with the excitation energy as the aggregates form since we observe increasing enhancement. Clearly the $11 \mathrm{~nm}$ particles do this more efficiently as evidenced by the time versus intensity slopes presented in Table 1-1. After 46 hours the relative intensities of the SER signals of the $11 \mathrm{~nm}$ particles are significantly stronger than their initial intensities. 
Another observed trend is the difference in the slopes (see Table 1-1) of the intensity versus time plots for the four Raman bands arising from totally symmetric inplane aromatic C-C stretching normal modes. ${ }^{26}$ The differences are do to the orientation of the R6G with respect to the "hot spots" where stretching modes perpendicular to the "hot spots" should exhibit the greatest enhancement. Thus, the increase in SER enhancement is dependent on the magnitude of the change of the dipole of each normal mode perpendicular to the surface. One possible explanation is that with increasing numbers of aggregates the contributions from adjacent particles perturb the orientation of the adsorbed molecule into a more rigid conformation.

\subsection{Effects of Halide Ion Addition}

Figure 1-7 shows large intensity enhancements as a function of time for the four Raman bands after the addition of chloride ions (the final concentration of $\mathrm{R} 6 \mathrm{G}$ and $\mathrm{Cl}^{-}$ are $0.003 \mathrm{M}$ and $0.0017 \mathrm{M}$ respectively) over a 7 hour period after which the particles become oxidized and intensity diminishes. ${ }^{23}$ Table 1-2 shows the slopes of intensity versus time plots for the various salt additions with $11 \mathrm{~nm}$ particles.

Again, one possible explanation of the enhancement as a function of time is the formation of "hot spots" due to aggregated particles. Comparing fluoride, chloride and bromide ions (omitting iodide because of its tendency to form $\mathrm{I}_{3}^{-}$in aqueous solution), enhancement increases proportionally with the size of anion. To elucidate the effects of co-adsorption of the anions, the intensities of the Raman bands were observed immediately after the addition of each salt. The results are reported in Table 1-3. Maximum enhancement is observed when the concentration of halide anions is 
approximately equal to the concentration of the adsorbate. The decrease in intensity when the halide concentration is high is assumed to be due to coverage of the SERS active regions by anions rather than $\mathrm{R} 6 \mathrm{G}$ as described by the chemical and electromagnetic mechanisms. Considering the trend in the slopes for the intensity versus time plots for the four aromatic modes, shown in Table 1-2, we find remarkable consistency for each anion at each concentration in reference to particles without the addition of halides. This leads to the assumption that the addition of halides to the R6G - silver nanoparticle solution does not change the orientation of the R6G. One indication is the red shift of the Raman signals as a function of time. ${ }^{21}$ In the absence of halide ions the peaks shifted approximately $15 \mathrm{~cm}^{-1}$ after 46 hours, whereas, the same red shift of $15 \mathrm{~cm}^{-1}$ was observed after 26 hours with the addition of bromide ions $\left(1.7 \times 10^{-3} \mathrm{M}\right)$.

\subsection{Conclusion}

We have observed that the range of sizes for Ag particles needed for significant SERS enhancement is relatively narrow $( \pm 3 \mathrm{~nm})$ for $647.1 \mathrm{~nm}$ excitation. The main contribution to enhancement is the electromagnetic mechanism since particles outside the range exhibit little or no enhancement. Since the excitation wavelength was invariant we attribute the increased SER enhancement with time to be due to particle aggregation. The interaction of nanoparticle aggregates could provide an increase of hot spots on the surface. The formation of aggregates is supported by TEM images as a function of time. Thus the EM mechanism must contribute significantly to the intensity although more rigorous studies of the surface morphology need to be conducted to confirm the 
dependence of this effect. Future work will involve the determination of the optimum size of Ag particles for SER enhancement at various excitation wavelengths.

We have also observed that the effect of halide concentration on SER enhacement is related to the concentration of adsorbate. Maximum enhancement is observed when the concentration of the halide is approximately equal to that of the adsorbate when monitoring the effects of aggregation and co-adsorption on the SER signal. In comparing the enhancement provided by various halides (fluoride, chloride and bromide) we have also observed a dependence on the size of the anion involved. Furthermore, no variations observed in the trends of the slopes of intensity versus time plots with and without the presence of halide ions leads to the assumption that the addition of halides does not alter the orientation of R6G on the surface. Finally, the degree of aggregation of particles

without halides present in 46 hours is approximately equal to bromide assisted aggregation $(.0017 \mathrm{M})$ in 2 hours.

\section{References}

(1) Raman, C. V; Krishnan, K. S. Nature (1928), 121, 501.

(2) "Principles of Instrumental Analysis" $5^{\text {th }}$ ed, D. A. Skoog, F. J. Holler, and T. A. Nieman, Saunders College Publishing, Philadelphia (1998).

(3) Fleischmann, M; Hendra, P. J; McQuillan, A. J. Chem. Phys. Lett.. (1974), (26) 163.

(4) "Surface Enhanced Raman Scattering" R. K. Chang and T. E. Furtak (Ed.), Plenum Press, New York (1982).

(5) Kerker, M; Wang, D; Chew, S.. Appl. Opt. (1980), 19, 3373.

(6) Faraday, M. Phil. Trans. R. Soc. London. (1857), 147145.

(7) Mie, Ann. Physik. (1908), 26377. 
(8) Wetzel, H; Gerischer, H. Chem Phys. Letters 3. (1980), 76, 460.

(9) Liang, E. J; Engert, C; Kiefer, W. Vib. Spectrosc. (1995), 8, 435.

(10) Kerker, M; Siiman, O; Wang, D. J. of Phys. Chem. (1984), 15(88) 3168.

(11) Hildebrandt, P; Kellar, S; Hoffmann, A; Vanhecke, F; Schrader, B. J. Raman Spectrosc. (1993), 24, 791.

(12) Kneipp, K; Kneipp, H; Itzkan, I; Dasari, R. R; Feld, M. S. Chem. Phys. (1999), 247(1), 155.

(13) Kneipp, K; Kneipp, H; Manoharan, R; Itzkan, I; Dasari, R. R; Feld, M. S. J. Raman Spectrosc. (1998), 29(8), 743.

(14) Kneipp, K; Kneipp, H; Deinum, G; Itzkan, I; Dasari, R. R.; Feld, M. S. Appl. Spectrosc. (1998), 52(2), 175.

(15) Michaels, A. M.; Jiang, J; Brus, L. J. Phys. Chem. B (2000), 104(50), 11965.

(16) Emory, S. R.; Nie, S. Anal. Chem. (1997), 69(14), 2631.

(17) Nie, S; Emory, S. R. Science (Washington, D. C.) (1997), 275(5303), 1102.

(18) Xu, H; Aizpurua, J; Kall, M; Apell, P. Phys. Rev. E: Stat. Phys., Plasmas, Fluids, Relat. Interdiscip. Top. (2000), 62(3-B), 4318.

(19) Hulteen, J. C; Treichel, D. A; Smith, M. T.; Duval, M. L; Jensen, T. R; Van Duyne, R. P. J. Phys. Chem. B (1999), 103(19), 3854.

(20) Jensen, T. R; Duval, M. L; Kelly, K. L; Lazarides, A. A; Schatz, G. C; Van Duyne, R. P. J. Phys. Chem. B (1999), 103(45), 9846.

(21) Malinsky, M. D; Kelly, K. L; Schatz, G. C; Van Duyne, R. P. J. Phys. Chem. B (2001), 105(12), 2343.

(22) Li, S. S; Silvers, S. J; El-Shall, M. S. J. Phys. Chem. B 1997, 101, 1794.

(23) Wang, W. Z.; Germanenko, I. N.; Glaspell, G.; El-Shall, M. S. Clusters Nanostruct. Interfaces, Proc. Int. Symp. (2000), 83.

(24) El-Shall, M. S. NASA Conf. Publ. (1999), (NASA Microgravity Materials Science Conference, 1998), 181.

(25) El-Shall, M. S; Li, S; Graiver, D; Pernisz, Udo. ACS Symp. Ser. (1996), 622(Nanotechnology), 79. 
(26) Hildebrandt, P; Stockburger, M. J. Phys. Chem. (1984), 88(24), 5935.

(27) Kneipp, K; Wang, Y; Dasari, R. R; Feld, M. S. Appl. Spectrosc. (1995), 49(6), 780 .

(28) Emory, S. R; Haskins, W. E.; Nie, S. J. Am. Chem. Soc. (1998), 120(31), 8009.

(29) El-Shall, M. S; Slack, W.; Vann, W.; Kane, D.; Hanley, D. J. Phys. Chem. (1994), 98(12), 3067. 


\begin{tabular}{|cccc|}
\hline & \multicolumn{3}{c|}{ Particle Size (/nm) } \\
\cline { 2 - 4 } SER Line/cm & \multicolumn{3}{c|}{} \\
\cline { 2 - 4 } $\mathbf{1 6 5 0}$ & 15 & 11 & 8 \\
\hline $\mathbf{1 5 2 3}$ & 23 & 198 & 48 \\
$\mathbf{1 3 6 5}$ & 63 & 243 & 88 \\
$\mathbf{1 3 1 0}$ & 38 & 238 & 77 \\
& 37 & 182 & 77 \\
\hline
\end{tabular}

Table 1-1. Slopes of the time versus intensity plots for four Raman lines of R6G as a function of size of the silver nanoparticles. 


\begin{tabular}{|c|c|c|c|c|}
\hline \begin{tabular}{|c|} 
Raman Line \\
Salt Concentration \\
\end{tabular} & $1310 \mathrm{~cm}-1$ & $1365 \mathrm{~cm}-1$ & $1523 \mathrm{~cm}-1$ & $1650 \mathrm{~cm}-1$ \\
\hline No salt & 181.8 & 238.3 & 242.7 & 197.9 \\
\hline \multicolumn{5}{|l|}{ F- } \\
\hline .00017 M & 556.5 & 607.8 & 782.6 & 554.3 \\
\hline $.0017 \mathrm{M}$ & 522.7 & 658.5 & 740.1 & 574.2 \\
\hline .017 M & 168.4 & 193.6 & 206.4 & 137.1 \\
\hline \multicolumn{5}{|l|}{ Cl- } \\
\hline $.00017 \mathrm{M}$ & 1764.5 & 2078.7 & 2947.9 & 1871.1 \\
\hline .0017 M & 2300.4 & 2716.4 & 2967.3 & 2250.3 \\
\hline $.017 \mathrm{M}$ & 663.3 & 880.6 & 914.6 & 587.4 \\
\hline $.17 \mathrm{M}$ & 643.4 & 773.5 & 835.2 & 587.7 \\
\hline \multicolumn{5}{|l|}{ Br- } \\
\hline $.00017 \mathrm{M}$ & 2564.5 & 2729.3 & 3588.6 & 2704.2 \\
\hline $.0017 \mathrm{M}$ & 2847.2 & 3268.3 & 4908.7 & 2411.8 \\
\hline $.017 \mathrm{M}$ & 1315.8 & 1337.8 & 2751.9 & 1510.1 \\
\hline $.17 \mathrm{M}$ & 1045.9 & 1227.0 & 1649.4 & 1111.8 \\
\hline \multicolumn{5}{|l|}{ I- } \\
\hline $.00017 \mathrm{M}$ & 1214.2 & 1450.4 & 1521.0 & 937.3 \\
\hline .0017 M & 1718.5 & 1928.9 & 2295.7 & 1528.2 \\
\hline $.017 \mathrm{M}$ & 490.3 & 553.5 & 595.0 & 462.2 \\
\hline $.17 \mathrm{M}$ & 475.5 & 483.8 & 512.3 & 476.3 \\
\hline
\end{tabular}

Table 1-2. Slopes of the time versus intensity plots for various Raman lines for R6G $\left(3.0 \times 10^{-4} \mathrm{M}\right)$ adsorbed on $11 \mathrm{~nm} \mathrm{Ag}$ particles for various halides. The molarities reported are the final concentrations of the halide. The addition of $0.17 \mathrm{M} \mathrm{F}^{-}$induced precipitation of R6G. 


\begin{tabular}{|c|c|c|c|c|}
\hline \begin{tabular}{|c|} 
Raman Line \\
Salt Concentration
\end{tabular} & $1310 \mathrm{~cm}-1$ & $1365 \mathrm{~cm}-1$ & $1523 \mathrm{~cm}-1$ & $1650 \mathrm{~cm}-1$ \\
\hline No salt & 73.8 & 91.4 & 109.8 & 67.2 \\
\hline \multicolumn{5}{|l|}{ F- } \\
\hline $.00017 \mathrm{M}$ & 235.5 & 299.5 & 735.9 & 331.6 \\
\hline $.0017 \mathrm{M}$ & 331.6 & 431.4 & 825.5 & 288.8 \\
\hline $.017 \mathrm{M}$ & 241.5 & 305.6 & 529.2 & 182.5 \\
\hline \multicolumn{5}{|l|}{ Cl- } \\
\hline $.00017 \mathrm{M}$ & 1163.2 & 1574.0 & 1943.2 & 673.8 \\
\hline $.0017 \mathrm{M}$ & 2095.5 & 2927.2 & 7766.2 & 1935.9 \\
\hline $.017 \mathrm{M}$ & 1673.9 & 2371.8 & 4018.3 & 1717.7 \\
\hline $.17 \mathrm{M}$ & 1170.1 & 1222.8 & 1441.3 & 981.3 \\
\hline \multicolumn{5}{|l|}{ Br- } \\
\hline $.00017 \mathrm{M}$ & 1329.2 & 1840.4 & 2464.5 & 786.8 \\
\hline $.0017 \mathrm{M}$ & 5006.3 & 6532.5 & 11290.3 & 4065.8 \\
\hline $.017 \mathrm{M}$ & 2862.7 & 4006.5 & 5752.9 & 2045.4 \\
\hline $.17 \mathrm{M}$ & 1138.1 & 1605.3 & 2425.1 & 796.2 \\
\hline \multicolumn{5}{|l|}{ I- } \\
\hline $.00017 \mathrm{M}$ & 216.6 & 342.9 & 602.3 & 156.1 \\
\hline $.0017 \mathrm{M}$ & 670.9 & 931.5 & 1668.5 & 438.7 \\
\hline $.017 \mathrm{M}$ & 267.7 & 381.8 & 616.9 & 157.4 \\
\hline $.17 \mathrm{M}$ & 118.6 & 180.4 & 429.5 & 183.0 \\
\hline
\end{tabular}

Table 1-3. Intensities of the Raman peaks measured immediately upon addition of the halide to the silver nanoparticles. 


\section{LVCC Chamber Cold Plate $\left(-150{ }^{\circ} \mathrm{C}-0{ }^{\circ} \mathrm{C}\right)$}

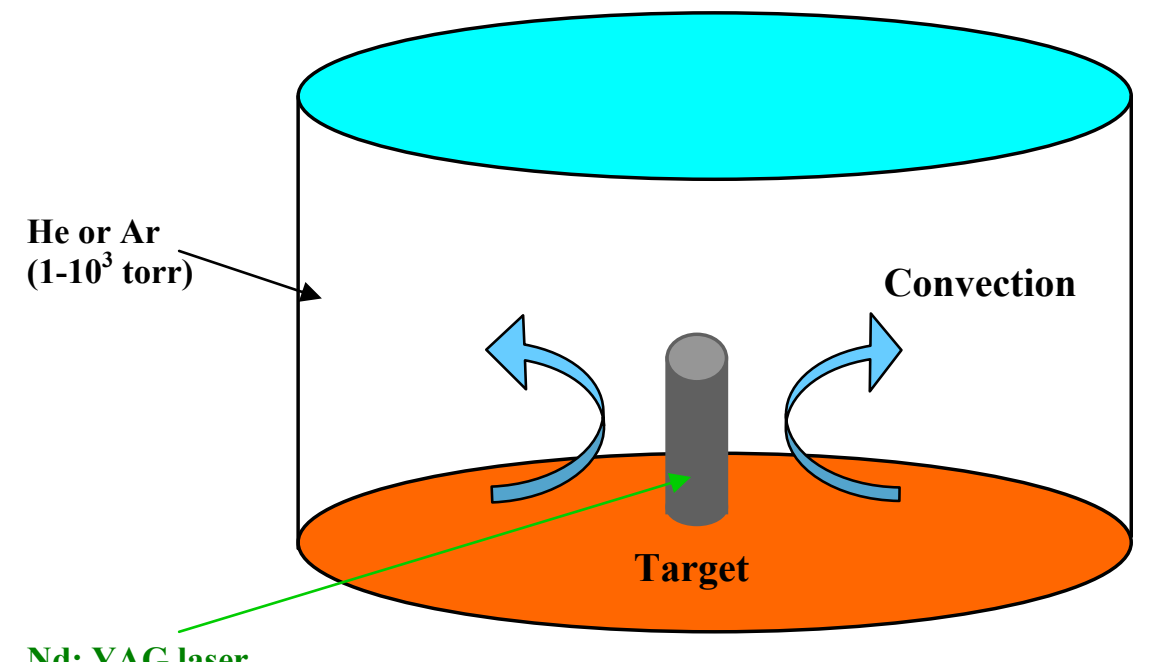

YAG laser

$\begin{array}{lll}532 \mathrm{~nm} & \text { Hot Plate }\left(20^{\circ} \mathrm{C}-150^{\circ} \mathrm{C}\right) & \begin{array}{l}\text { Height }=7.5 \mathrm{~mm} \\ \text { Width }=25 \mathrm{~mm}\end{array}\end{array}$ $10 \mathrm{~ns}$

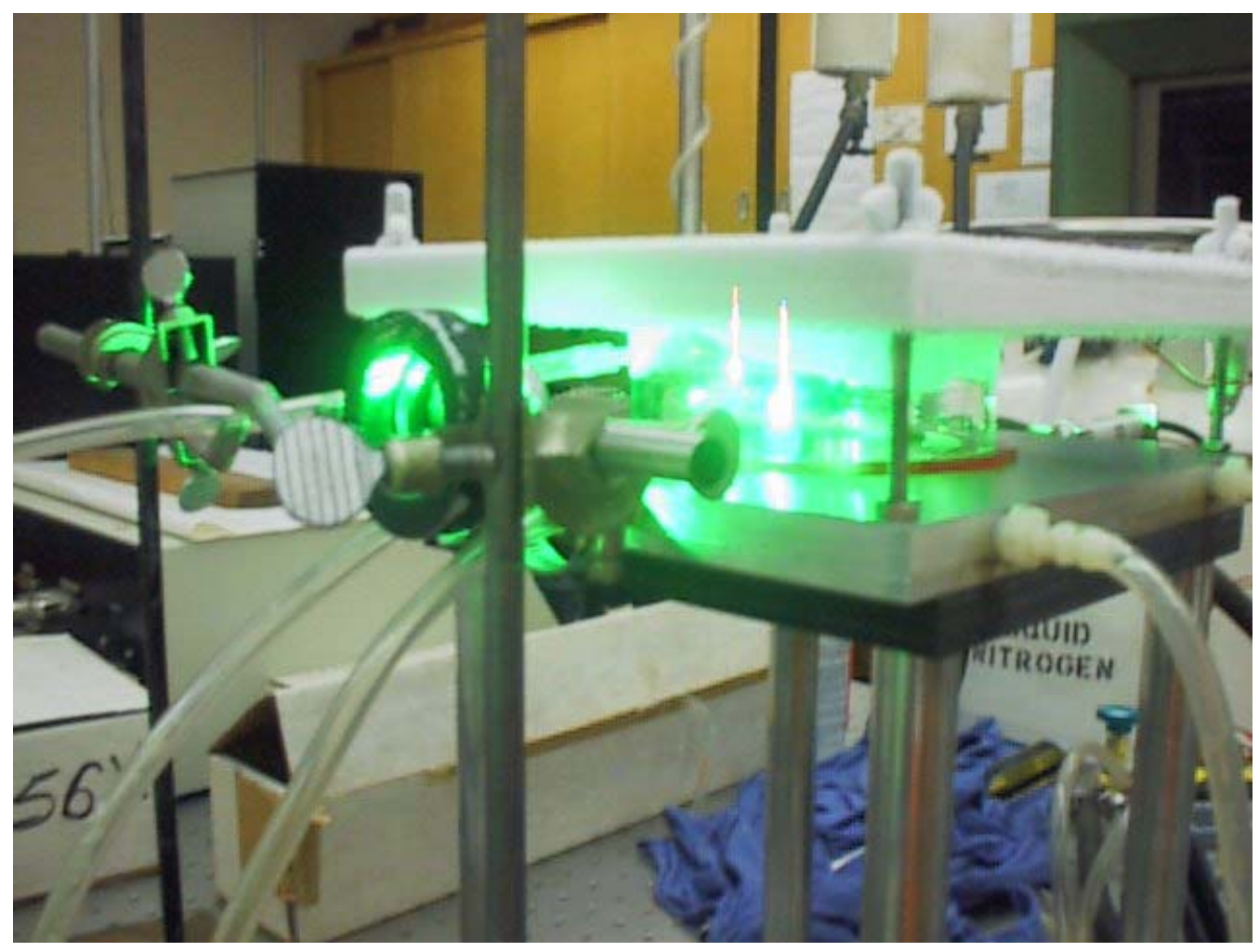

Figure 1-1. Diagram Diagram of LVCC chamber and photograph showing 532nm light striking the metal target inside the chamber. 


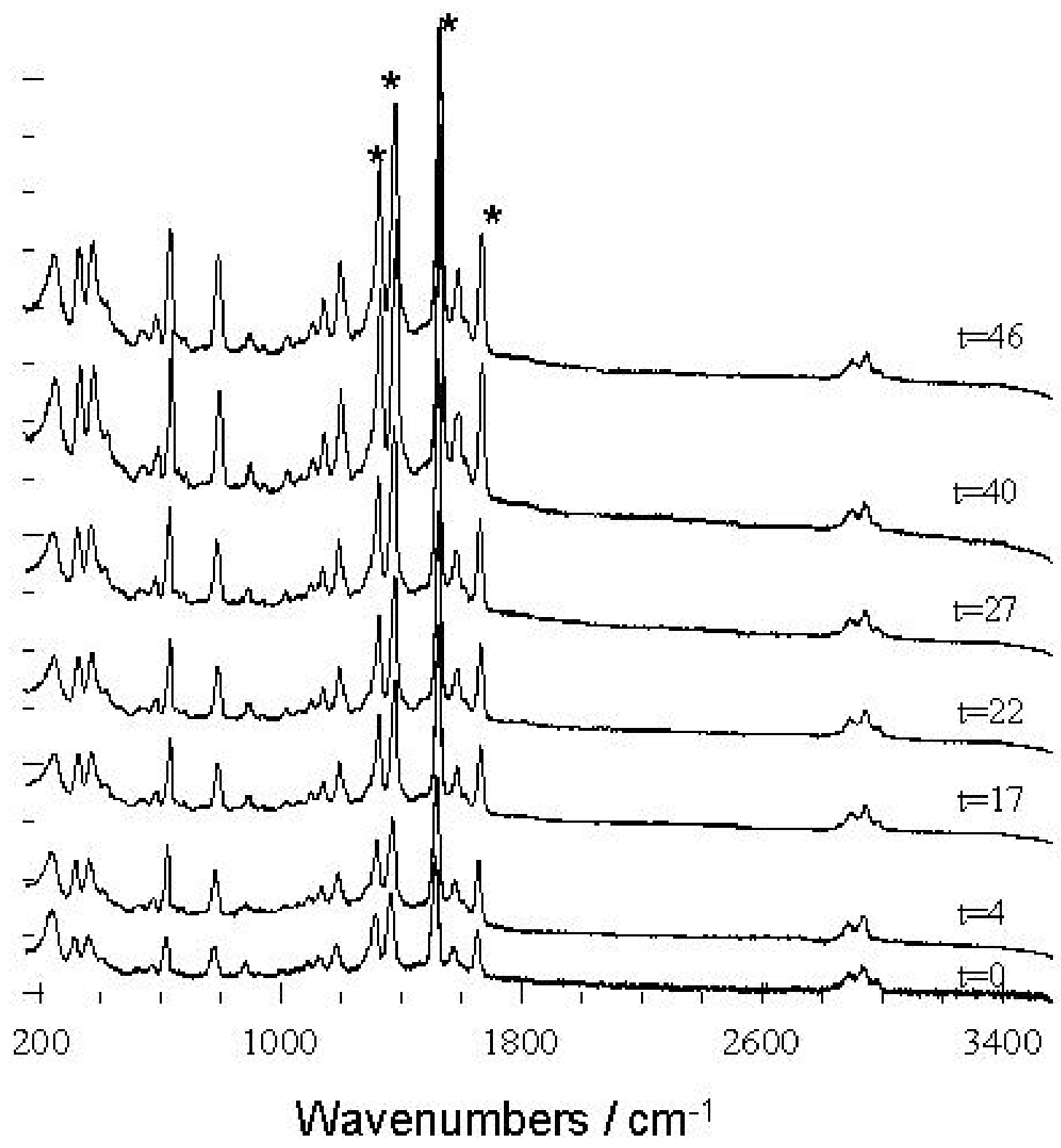

Figure 1-2. Raman spectra (647.1 nm excitation) of R6G $\left(3 \times 10^{-4} \mathrm{M}\right)$ on $11 \mathrm{~nm} \mathrm{Ag}$ particles as a function of time (hours). Ethanol peaks are only observed between 2900 $\mathrm{cm}^{-1}$ and $3000 \mathrm{~cm}^{-1}$. Asterisks indicate which bands are being monitored. 


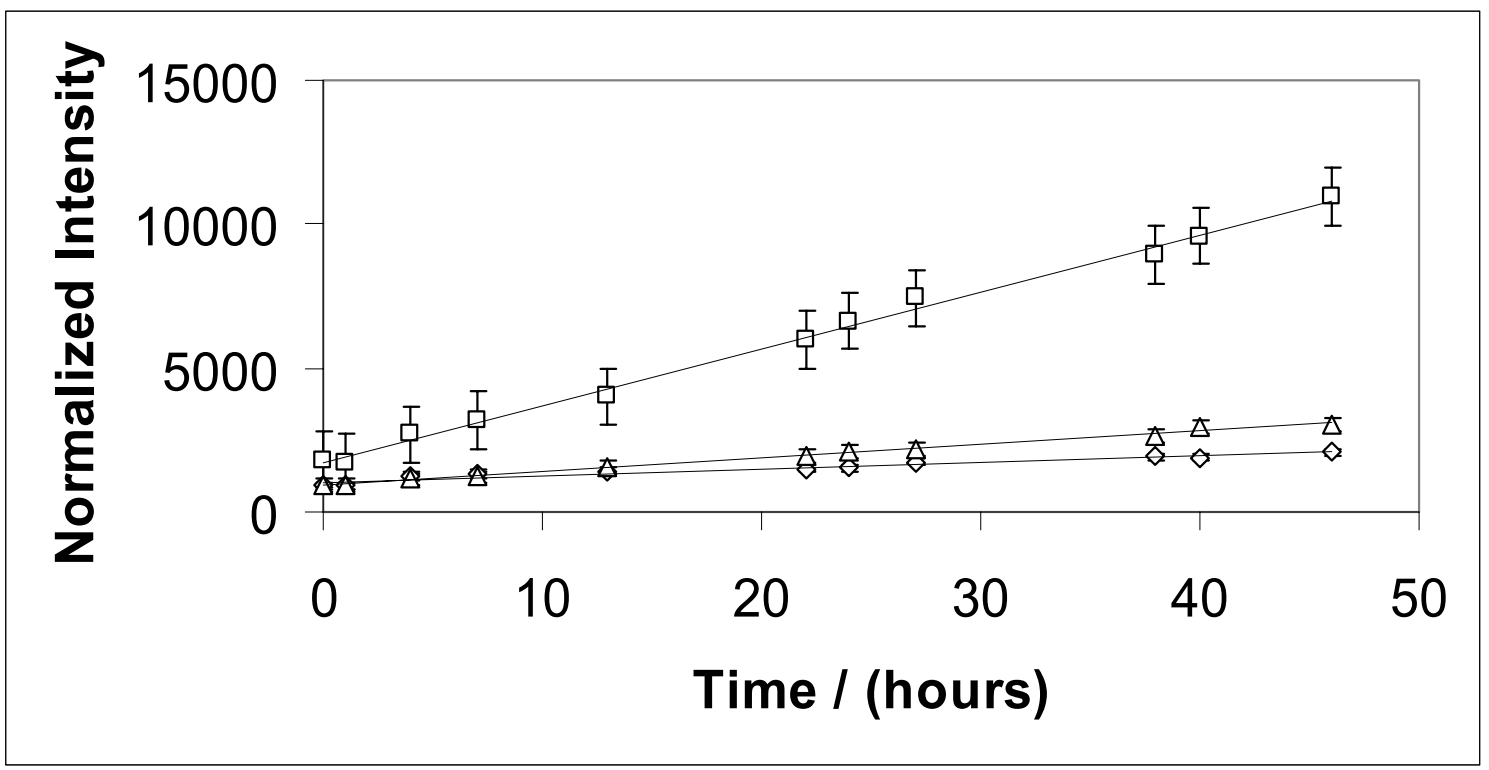

Figure 1-3. Plot of normalized intensities of the R6G band at $1650 \mathrm{~cm}^{-1}$ as a function of time for $15 \mathrm{~nm}(\diamond), 11 \mathrm{~nm}(\square)$ and $8 \mathrm{~nm}(\Delta)$ diameter Ag particles. Error bars indicate the standard deviation of 5 trials. 


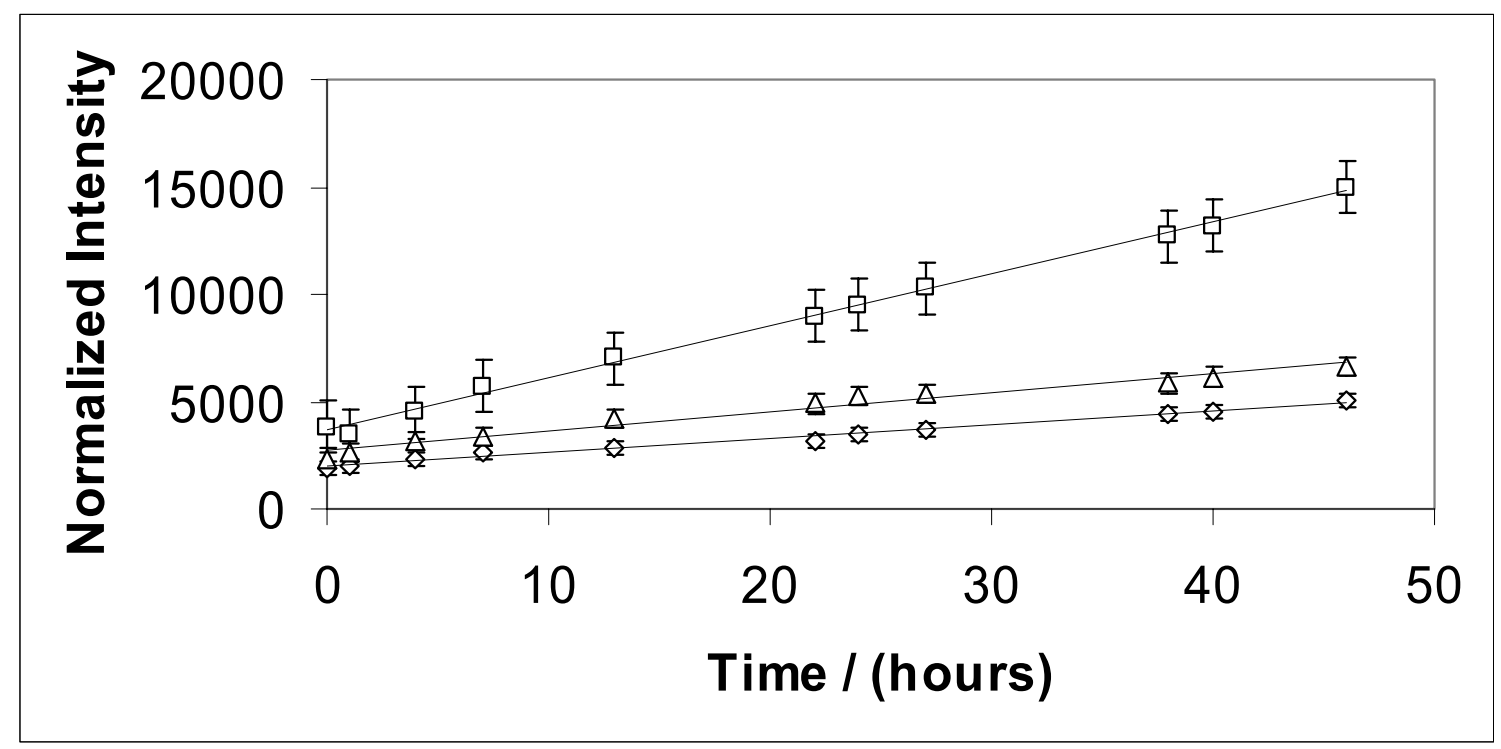

Figure 1-4. Plot of normalized intensities of the R6G band at $1523 \mathrm{~cm}^{-1}$ as a function of time for $15 \mathrm{~nm}(\diamond), 11 \mathrm{~nm}(\square)$ and $8 \mathrm{~nm}(\Delta)$ diameter Ag particles. Error bars indicate the standard deviation of 5 trials. 


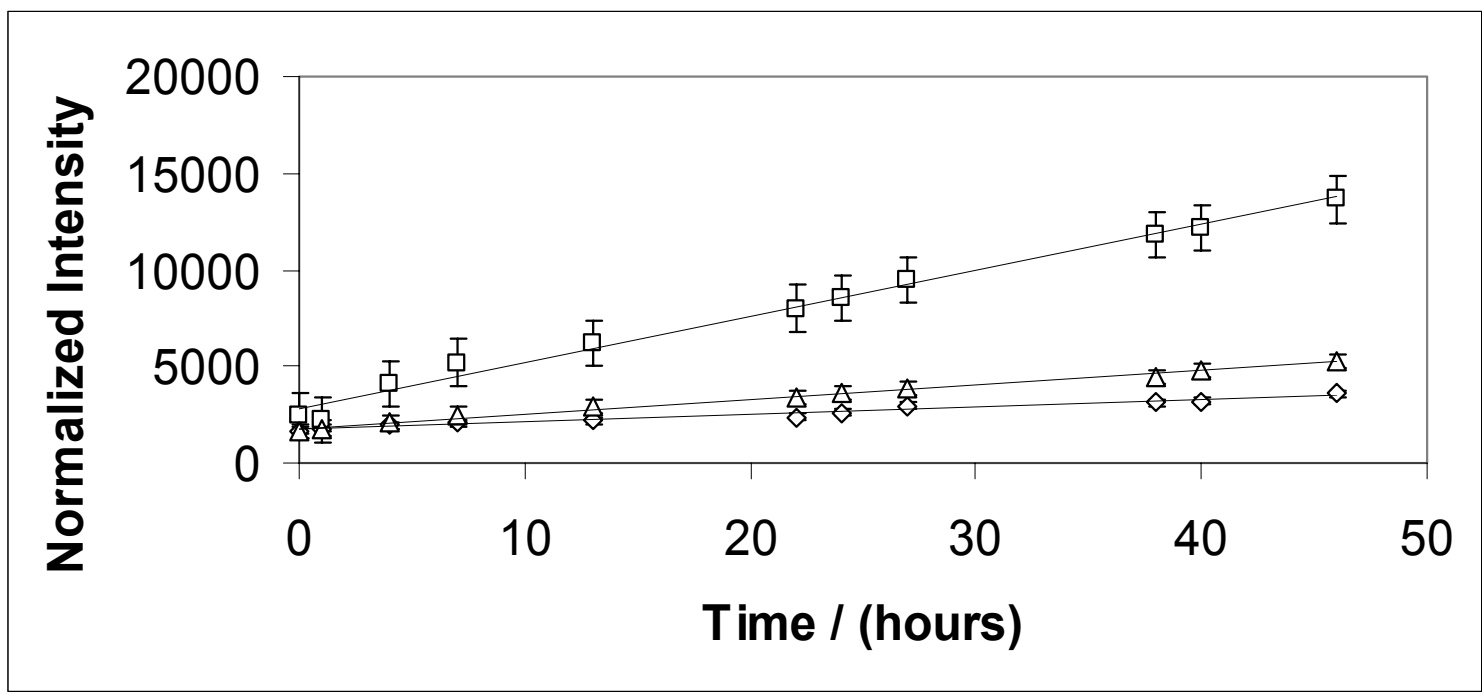

Figure 1-5. Plot of normalized intensities of the R6G band at $1365 \mathrm{~cm}^{-1}$ as a function of time for $15 \mathrm{~nm}(\diamond), 11 \mathrm{~nm}(\square)$ and $8 \mathrm{~nm}(\Delta)$ diameter Ag particles. Error bars indicate the standard deviation of 5 trials. 


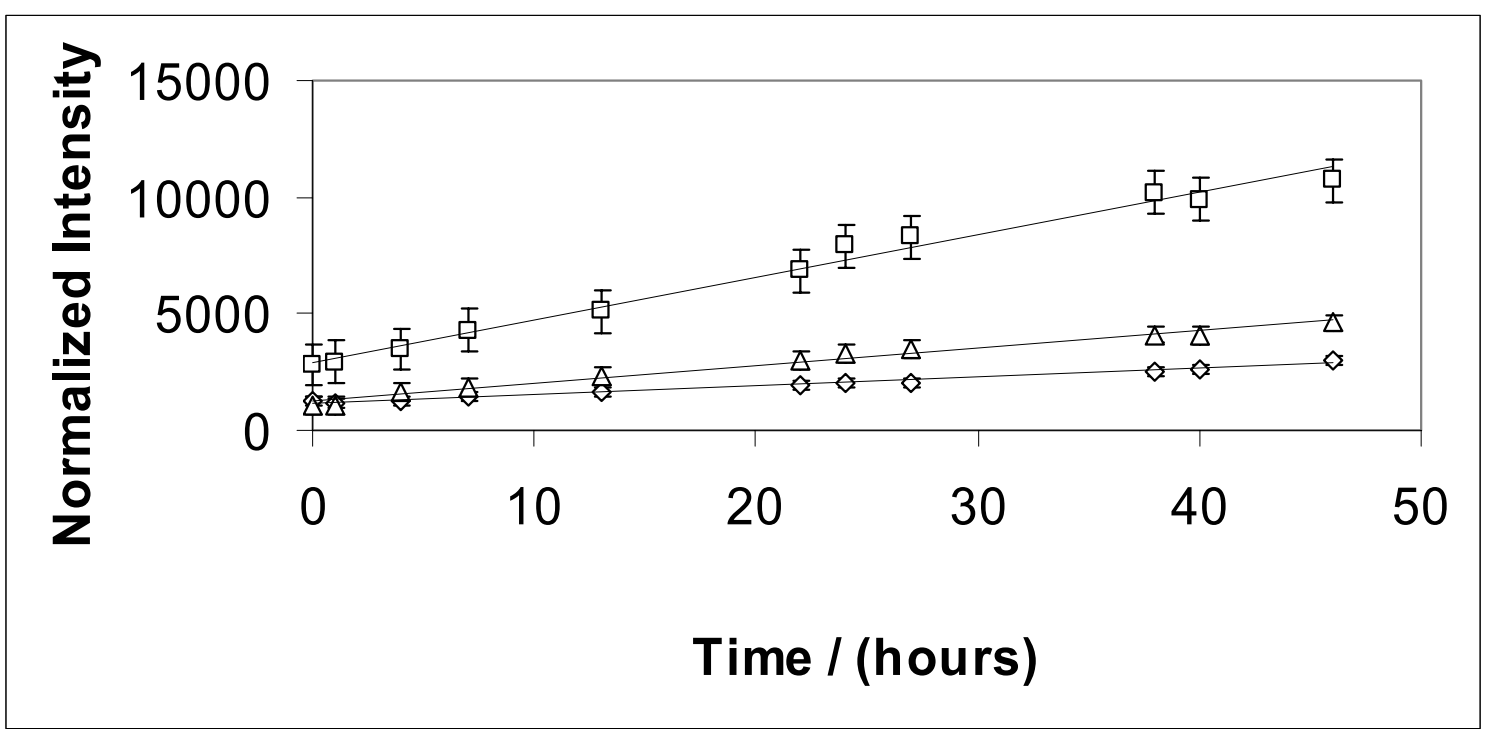

Figure 1-6. Plot of normalized intensities of the R6G band at $1310 \mathrm{~cm}^{-1}$ as a function of time for $15 \mathrm{~nm}(\diamond), 11 \mathrm{~nm}(\square)$ and $8 \mathrm{~nm}(\Delta)$ diameter Ag particles. Error bars indicate the standard deviation of 5 trials. 

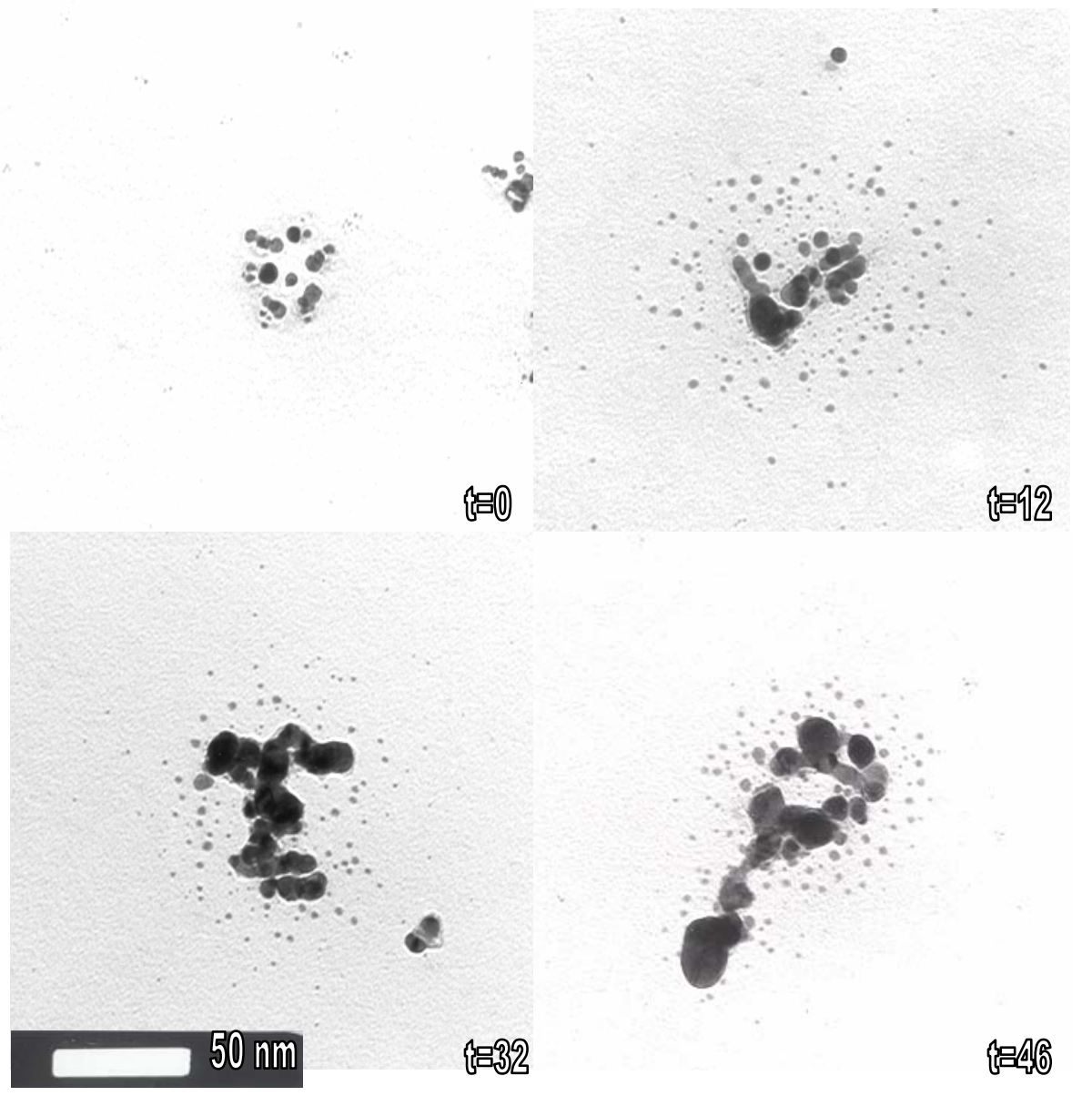

Figure 1-7. TEM images of $11 \mathrm{~nm} \mathrm{Ag} \mathrm{particles} \mathrm{as} \mathrm{a} \mathrm{function} \mathrm{of} \mathrm{time} \mathrm{(hours).} \mathrm{Formation}$ of aggregates is clearly visible. 


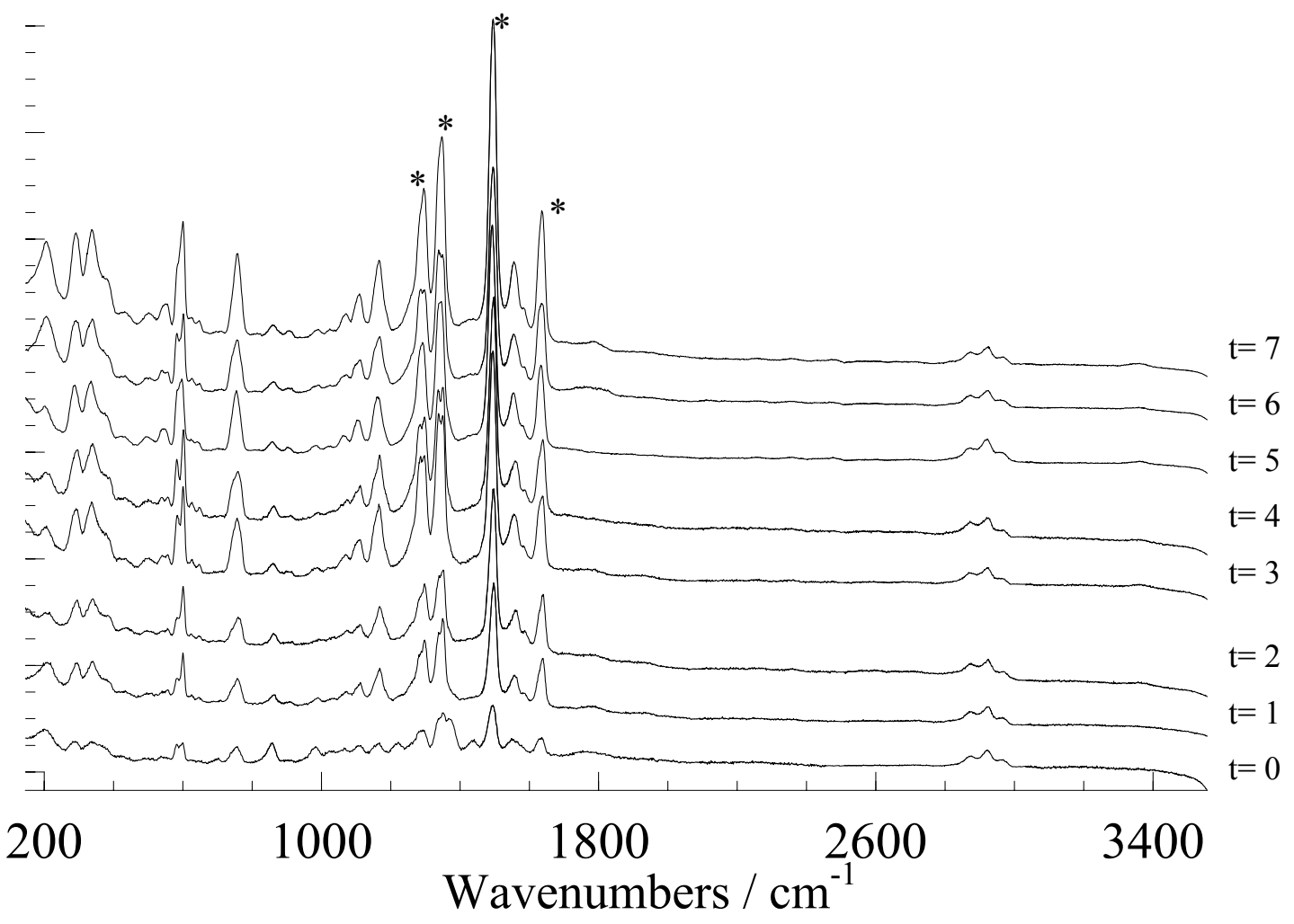

Figure 1-8. Raman spectra (647.1 nm excitation) of R6G (3.0x10 $\left.{ }^{-4} \mathrm{M}\right)$ on $11 \mathrm{~nm} \mathrm{Ag}$ particles with the addition of chloride ions $\left(1.7 \times 10^{-4} \mathrm{M}\right)$ as a function of time (hours). Ethanol peaks are only observed between $2900 \mathrm{~cm}^{-1}$ and $3000 \mathrm{~cm}^{-1}$. Asterisks indicate which bands are being monitored. 


\section{Chapter 2}

\section{Formation of Cobalt Nitrate Hydrate, Cobalt Oxide, and Cobalt Nanoparticles Using Laser Vaporization Controlled Condensation}

\subsection{Introduction}

El-Shall and coworkers have explored producing a variety of metal oxide nanoparticles using LVCC by adding oxygen to the reaction chamber. ${ }^{1-14}$ This method provides insight into the physical chemistry of the formation of these materials. In this regard, we attempted to synthesize metal nitrates from a metal target in the presence of $\mathrm{N}_{2}$ and $\mathrm{O}_{2}$ at controlled pressures.

For the first time, we have successfully synthesized cobalt nitrate hexahydrate. We have also explored how the ratio of $\mathrm{N}_{2}$ and $\mathrm{O}_{2}$ controls the physical chemistry of the various types of cobalt compounds produced. Surprisingly, we could also synthesize cobalt oxide $(\mathrm{CoO})$ nanoparticles. It is important to mention that pure $\mathrm{CoO}$ cannot be synthesized easily by a simple chemical route since this approach typically produces a mixture of $\mathrm{Co}_{3} \mathrm{O}_{4}$ with small amounts of $\mathrm{CoO}$. Our objective is to optimize the conditions to synthesize pure $\mathrm{CoO}$ nanoparticles and other related cobalt compounds. This chapter describes the LVCC method for the synthesis of cobalt nitrate hydrate, cobalt oxide, and cobalt nanoparticles produced high a purity cobalt metal target at various $\mathrm{N}_{2}$ and $\mathrm{O}_{2}$ pressures. 


\subsection{Experimental}

The cobalt metal target material (99.9\%) was purchased from Alpha Aesar (Ward Hill, MA). The $\mathrm{N}_{2}(99 \%)$ and $\mathrm{O}_{2}(99 \%)$ were obtained from Air Gas (Westover, WV) and used without any further purification. LVCC, as described in Chapter 1, was used to synthesize the various particles. Altering the laser power, chamber pressure, and temperature gradient between the two plates formed particles of various sizes. The size and shape of the particles were determined using a JEOL 1220 transmission electron microscopy (TEM) operating at $80 \mathrm{Kev}$. X-ray diffraction (XRD) patterns of the powder sample were measured at room temperature with a Rigaku Diffractometer (DMAX-B) using $\mathrm{CuK}_{\alpha}$ radiation $(\lambda=1.5418 \AA)$. The samples were mounted on a silicon plate for $\mathrm{X}$ ray measurements. IR spectra were obtained using a MIDAC M2000 series FT-IR (Costa Mesa, CA).

\subsection{Results and Discussion}

Numerous experiments were completed with various the $\mathrm{O}_{2}$ and $\mathrm{N}_{2}$ pressures in the chamber in order to obtain various compounds of cobalt. As a technique, LVCC has been used to make metal oxides of semiconductor powders. In our experiments it has been demonstrated that various compounds of cobalt are formed by simply varying the $\mathrm{O}_{2}$ and $\mathrm{N}_{2}$ ratios. Moreover the physical chemistry of the cobalt nitrate is intriguing. The cobalt metal vapor formed via the laser simply reacts with the $\mathrm{N}_{2}$ and $\mathrm{O}_{2}$ to produce cobalt nitrate.

The nanoparticles generated in pure nitrogen are primarily cobalt and are also the primary product at low concentrations of $\mathrm{O}_{2}$ (below $0.3 \%$; Figure 2-1). It is evident from 
the XRD pattern that cobalt nanoparticles are produced due to the peaks at scattering angles $(2 \theta)$ at 44.31 and 51.65 which are assigned to scattering from the 111 and 200 planes of the cobalt crystal lattice. ${ }^{15}$ This would indicate that nanoparticles having the same crystal structure as bulk cobalt have been formed. When the percentage of $\mathrm{O}_{2}$ is increased to $2.3 \%$ we begin to observe the formation of cobalt oxide $(\mathrm{CoO})$ together with trace amounts of cobalt as confirmed by XRD (Figure 2-2). The $\mathrm{CoO}$ peaks are observed at scattering angles $36.53,42.41$ and 61.64 and are assigned to scattering from the 111, 200, and 220 planes of the CoO crystal lattice. ${ }^{15}$ The trace amounts of cobalt disappear as the $\mathrm{O}_{2}$ concentration is increased to $3 \%$ (Figure 2-3). It is also observed that the nanoparticles of $\mathrm{CoO}$ possess the same crystal structure as bulk $\mathrm{CoO}$. The approximate crystallite size for the $\mathrm{CoO}$ was $4 \mathrm{~nm}$ determined via TEM (Figure 2-4). This is a significant result since the commercially available $\mathrm{CoO}$ (Alfa-Aesar) has mixed oxide phases as indicated by X-ray diffraction (Figure 2-5). Strong peaks are observed at $2 \theta$ angles $31.63,36.64,38.90,45.10,56.01,59.71$ and 65.50 that can be assigned to scattering from the $111,200,222,400,422,511$ and 533 planes, respectively, of the $\mathrm{CoCo}_{2} \mathrm{O}_{4}$ crystal lattice. $^{15}$

Formation of a mixture of cobalt nitrate tetrahydrate and cobalt oxide is observed when the percentage of $\mathrm{O}_{2}$ is raised to $6.6 \%$ (Figure 2-6). The $\mathrm{h}, \mathrm{k}$ and 1 indicies are not indicated for cobalt nitrate tetrahydrate as they are not available in the database (PDF 431004). ${ }^{15}$ It is believed that hydrates are observed due to the presence of residual moisture that is present when the nanoparticles are formed. Surface moisture probably is present in the chamber even after the chamber was evacuated and purged repetitively with nitrogen. ${ }^{16,17}$ Cobalt oxide peaks continue to diminish as the $\mathrm{O}_{2}$ concentration is increased 
to the $33-50 \%$ range. The primary product is cobalt nitrate hexahydrate in this case shown in Figure 2-7. For completeness, the standard crystallographic peak assignments for the XRD pattern are given in Table 2-1 and indicates that cobalt nitrate hexahydrate produced via LVCC possess the same crystal structure as its bulk counter part. ${ }^{15}$ For comparison, the XRD pattern of cobalt nitrate hexahydrate, purchased from Aldrich, was collected (Figure 2-8) and compared to cobalt nitrate hexahydrate produced via LVCC. It is significant to note that the two spectra possess some significant differences. Specifically, the XRD for cobalt nitrate produced via LVCC (Figure 2-7) contains a peak at $2 \theta$ angle of 19 and the presence of peaks 24.48 and $41.782 \theta$ (indicated by *'s in the XRD spectrum) in the Aldrich sample which may be due to other hydrate phases present in the sample.

We have summarized the results in Table 2-2 indicating all the reaction conditions responsible for the products that are produced at various concentrations of $\mathrm{O}_{2}$ and $\mathrm{N}_{2}$. It should be noted that the number of water molecules coordinated to the metal nitrate hydrate change as the ratio of oxygen changes. This can be explained by the amount of oxygen available in the chamber. When oxygen is present in the 3 to $33 \%$ range the amount of cobalt oxide surrounding the cobalt nitrate can vary significantly. In this range, the number of water molecules in contact with cobalt nitrate may be controlled by the amount of $\mathrm{CoO}$ which depends on the ratio of oxygen to nitrogen. Thus, oxygen plays a major role in the production of cobalt oxide and cobalt nitrate hydrate as well as the number of water molecules bound to the latter. It is important to note that (vide supra) the major product was cobalt nitrate hydrate with a maximum of six water molecules for the $33-50 \%$ oxygen range. 
Figure 9 compares the IR spectra of cobalt nitrate hexahydrate formed by LVCC and cobalt nitrate hydrate purchased from Aldrich. The nitrate group has six normal vibrations that are IR active. These are the antisymmetric stretching $v_{4}\left(\mathrm{~A}^{\prime}\right)$, symmetric stretching $v_{1}\left(\mathrm{~A}^{\prime}\right)$, totally symmetric stretching $v_{2}\left(\mathrm{~A}^{\prime}\right)$, out of plane bending $v_{6}\left(\mathrm{~A}^{\prime \prime}\right)$, antisymmetric in-plane bending $v_{5}\left(\mathrm{~A}^{\prime}\right)$ and the symmetric in-plane bending $v_{3}\left(\mathrm{~A}^{\prime}\right)$ observed at $1629,1388,1052,870,729$ and $664 \mathrm{~cm}^{-1}$ respectively. ${ }^{18,19,20}$ The broad peak at $3500 \mathrm{~cm}^{-1}$ is indicative of moisture and the cluster of peaks at $2400 \mathrm{~cm}^{-1}$ can be assigned to $\mathrm{CO}_{2}$. No significant differences were observed in the spectra which again confirm the formation of cobalt nitrate hexahydrate.

One possible explanation for the formation of the cobalt nitrate hexahydrate is the high temperature generated at the metal surface by the laser. This could provide enough energy to form $\mathrm{NO}$ from $\mathrm{N}_{2}$ and $\mathrm{O}_{2}$. The $\mathrm{NO}$ could then react with $\mathrm{O}_{2}$ to form $\mathrm{NO}_{2}$ (a brown gas; such a gas was observed in the chamber within minutes of turning on the laser). $\mathrm{NO}_{2}$ in the presence of $\mathrm{O}_{2}$ could then react with the metal vapor to produce the resulting metal nitrate. ${ }^{21}$ It is also important to indicate that the resulting product was $\mathrm{Co}_{3} \mathrm{O}_{4}$ when nitrogen was replaced by helium or argon. This is similar to chemical methods, where optimum conditions to produce $\mathrm{CoO}$ were not successful.

\subsection{Conclusion}

The results reported here clearly indicate that nanoparticles of cobalt, cobalt oxide, and cobalt nitrate hydrate were generated via LVCC by controlling the ratio of $\mathrm{N}_{2}$ to $\mathrm{O}_{2}$ present in the reaction chamber. Nanoparticles of cobalt can be synthesized in pure nitrogen and at low levels of $\mathrm{O}_{2}$ since the metal vapor produced is cooled through 
collisions with $\mathrm{N}_{2}$ before it can interact with $\mathrm{O}_{2}$. As the concentration of $\mathrm{O}_{2}$ increases $(0.3 \%-2 \%)$ the metal vapor is able to interact with oxygen before the energy necessary

for binding is quenched. The formation of only cobalt oxide $(\mathrm{CoO})$ could be achieved by keeping the $\mathrm{O}_{2}$ ratio at $2.7 \%$. When the $\mathrm{O}_{2}$ ratio was increased to the range $33-50 \%$ the resulting product was found to be cobalt nitrate hydrate with six water molecules. Work is in progress to further understand such processes with other metals such as $\mathrm{Ni}, \mathrm{Fe}$, and $\mathrm{Mn}$ and to produce various particle sizes of the metal mono oxides by varying laser power, chamber pressure, temperature gradient, etc.

\subsection{References}

(1) El-Shall, M. S; Graiver, D; Pernisz, U; Baraton, M. I. Nanostructured Materials, (1995), 6, 297.

(2) El-Shall, M. S; Li, S; Turkki, T; Gravier, D; Pernisz, U. C; and Baraton, M. I. J. Phys. Chem. (1995), 51, 17805.

(3) Jonsson, B. J; Turkki, T; Strom; El-Shall, M. S; Rao, K. V. J. Appl. Phys. (1996), 79, 5063.

(4) Li, S; Silvers, S; El-Shall, M. S. J. Phys. Chem. (1997), 101, 1794.

(5) Li, S; Germanenko, I. N; El-Shall, M. S. J. Phys. Chem. (1998), 102, 7319.

(6) Li, S; El-Shall, M. S. Nanostructured Materials (1999), 12, 215.

(7) Pithawalla, Y. B; El-Shall, M. S.; Deevi, S. C; Rao, K. V. J. Phys. Chem. B. (2001), $105,2085$.

(8) El-Shall, M. S; Abdelsayed, V; Pithawalla, Y. B; Alsharach, E; Deevi, S. C. J. Phys. Chem. B. (2003), 107, 2882.

(9) Pithawalla, Y. B; Deevi, S. C; El-Shall, M. S. Materials Science \& Engineering, A: Structural Materials: Properties, Microstructure and Processing (2002), A329-A331 92. 
(10) Pithawalla, Y. B; Deevi, S; Deevi, S. C; El-Shall, M. S. Advances in Powder Metallurgy \& Particulate Materials (2001), 9/99.

(11) Li, Shoutian; Germanenko, Igor N; El-Shall, M. S. J. of Cluster Sci. (1999), 10(4), 533.

(12) Li, Shoutian; El-Shall, M. S. Appl. Surf. Sci. (1998), 127-129 330.

(13) El-Shall, M. S; Slack, W; Vann, W; Kane, D; Hanley, D. J. Phys. Chem. (1994), 98(12), 3067.

(14) El-Shall, M. S; Li, S; Graiver, D; Pernisz, U. ACS Symp. Ser. (1996), 622 (Nanotechnology), 79.

(15) Jade X-ray database, Release 5.022, (2000) (ICDD)

(16) Get rid of water without cooking your chamber. Danielson, Philip. Danielson Assoc. Inc., USA. Res. Dev. (1986), 28(5), 101.

(17) Sugiyama, K; Ohmi, T; Morita, M; Nakahara, Y; Miki, N. J. Vac. Sci. Technol., A (1990), 8(4), 3337.

(18) Zoto, N; Petrov, K; Dimitrova-Pankova, M. J. Phys. Chem. Solids. (1990), 51, 1199.

(19) Choca, M; Ferraro J. R; Nakamoto, K. J. C. S. Dalton. (1972), 2297.

(20) Ahuja, I. S; Singh, R; Yadava, C. L. J. Mol. Struct. (1980), 68, 333.

(21) "Environmental Chemistry" Nigel Bunce, Werz Publishing Ltd. Winnipeg, Canada (1994). 


\begin{tabular}{|c|c|c|c|}
\hline 2-Theta & h & k & l \\
\hline $\mathbf{1 5 . 1}$ & 0 & 0 & 2 \\
\hline $\mathbf{1 5 . 8 4}$ & -2 & 0 & 2 \\
\hline $\mathbf{1 6 . 2 8}$ & 0 & 1 & 1 \\
\hline $\mathbf{1 9 . 1}$ & -2 & 1 & 1 \\
\hline $\mathbf{2 3}$ & 2 & 1 & 1 \\
\hline $\mathbf{2 3 . 9 1}$ & 2 & 0 & 2 \\
\hline $\mathbf{2 5 . 3 4}$ & -4 & 0 & 2 \\
\hline $\mathbf{2 6}$ & -2 & 1 & 3 \\
\hline $\mathbf{2 7 . 0 6}$ & 0 & 1 & 3 \\
\hline $\mathbf{2 8 . 1 5}$ & -2 & 0 & 4 \\
\hline $\mathbf{2 9 . 0 9}$ & 0 & 2 & 0 \\
\hline $\mathbf{3 0 . 5 4}$ & 0 & 0 & 4 \\
\hline $\mathbf{3 1 . 5 1}$ & 1 & 2 & 1 \\
\hline $\mathbf{3 2 . 1}$ & -2 & 2 & 0 \\
\hline $\mathbf{3 2 . 8 4}$ & 0 & 2 & 2 \\
\hline $\mathbf{3 3 . 2 4}$ & -2 & 2 & 2 \\
\hline $\mathbf{3 4 . 2 6}$ & 4 & 1 & 1 \\
\hline $\mathbf{3 8 . 4 2}$ & -2 & 1 & 5 \\
\hline $\mathbf{3 8 . 9 7}$ & -4 & 2 & 2 \\
\hline $\mathbf{4 0 . 4 6}$ & -4 & 1 & 5 \\
\hline $\mathbf{4 0 . 9 5}$ & -2 & 2 & 4 \\
\hline $\mathbf{4 1 . 0 7}$ & 6 & 0 & 0 \\
\hline $\mathbf{4 1 . 3 2}$ & 0 & 1 & 5 \\
\hline $\mathbf{4 2 . 7 6}$ & 0 & 2 & 4 \\
\hline $\mathbf{4 3 . 0 6}$ & -2 & 0 & 6 \\
\hline $\mathbf{4 3 . 9 3}$ & -4 & 0 & 6 \\
\hline $\mathbf{4 6 . 6 6}$ & 0 & 0 & 6 \\
\hline $\mathbf{4 8 . 4}$ & 2 & 1 & 5 \\
\hline $\mathbf{4 8 . 7 3}$ & 2 & 2 & 4 \\
\hline $\mathbf{4 9 . 6 7}$ & 6 & 0 & 2 \\
\hline $\mathbf{5 3 . 2 3}$ & -4 & 1 & 7 \\
\hline $\mathbf{5 8 . 3 7}$ & -4 & 0 & 8 \\
\hline $\mathbf{6 3 . 6 5}$ & 0 & 0 & 8 \\
\hline & & & \\
\hline
\end{tabular}

Table 2-1. Standard crystallographic peak assignments for cobalt nitrate hexahydrate produced via LVCC. 


\begin{tabular}{|c|c|c|}
\hline \% O & Products & $\begin{array}{c}\text { \# of } \\
\text { coordinated } \\
\mathbf{H}_{2} \mathbf{O} \text { 's }\end{array}$ \\
\hline $\mathbf{0 . 3}$ & $\mathrm{Co}$ & - \\
\hline $\mathbf{1 . 7}$ & $\mathrm{CoO} / \mathrm{Co}$ & - \\
\hline $\mathbf{2 . 3}$ & $\mathrm{CoO} / \mathrm{Co}$ & - \\
\hline $\mathbf{2 . 7}$ & $\mathrm{CoO}$ & - \\
\hline $\mathbf{3}$ & $\begin{array}{c}\mathrm{CoO} / \\
\mathrm{CoNO}\end{array}$ \\
\hline $\mathbf{6 . 6}$ & $\mathrm{Co}\left(\mathrm{NO}_{3}\right)_{2} /$ \\
$\mathrm{CoO}$ & 4 \\
\hline $\mathbf{2 0}$ & $\mathrm{Co}\left(\mathrm{NO}_{3}\right)_{2} /$ & 4 \\
\hline $\mathbf{C o O}$ & $\mathrm{Co}\left(\mathrm{NO}_{3}\right)_{2}$ & 6 \\
\hline $\mathbf{5 0}$ & $\mathrm{Co}\left(\mathrm{NO}_{3}\right)_{2}$ & 6 \\
\hline
\end{tabular}

Table 2-2. Percent oxygen in the LVCC chamber related to the primary products and number of waters coordinated to the metal nitrate hydrate. 


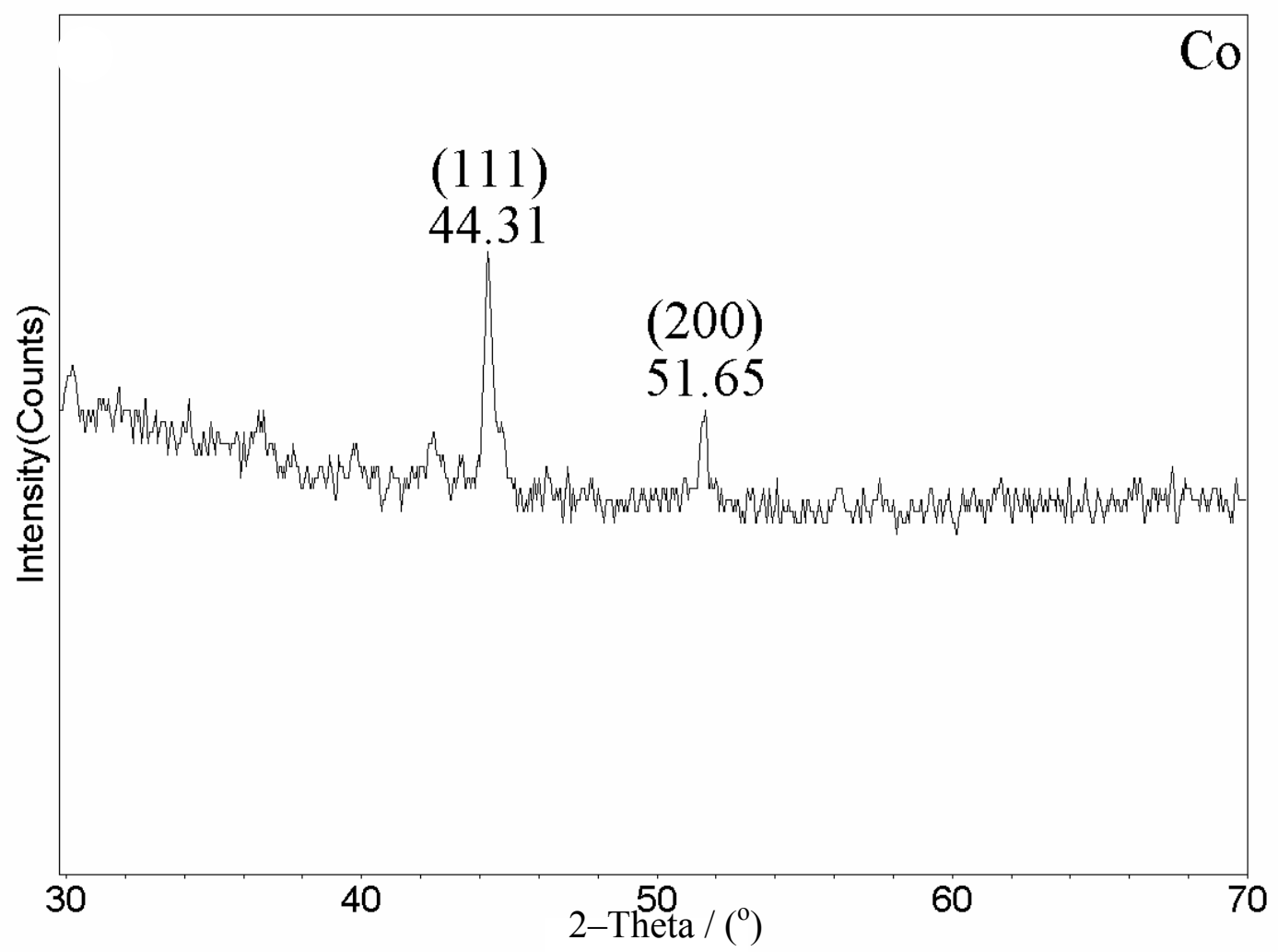

Figure 2-1. XRD pattern showing cobalt (PDF 15-0806) as the primary product formed when the ratio of $\mathrm{O}_{2}$ to $\mathrm{N}_{2}$ is $0.3 \%$. The bracketed numbers indicate the cobalt crystal lattice planes giving rise to each line. 


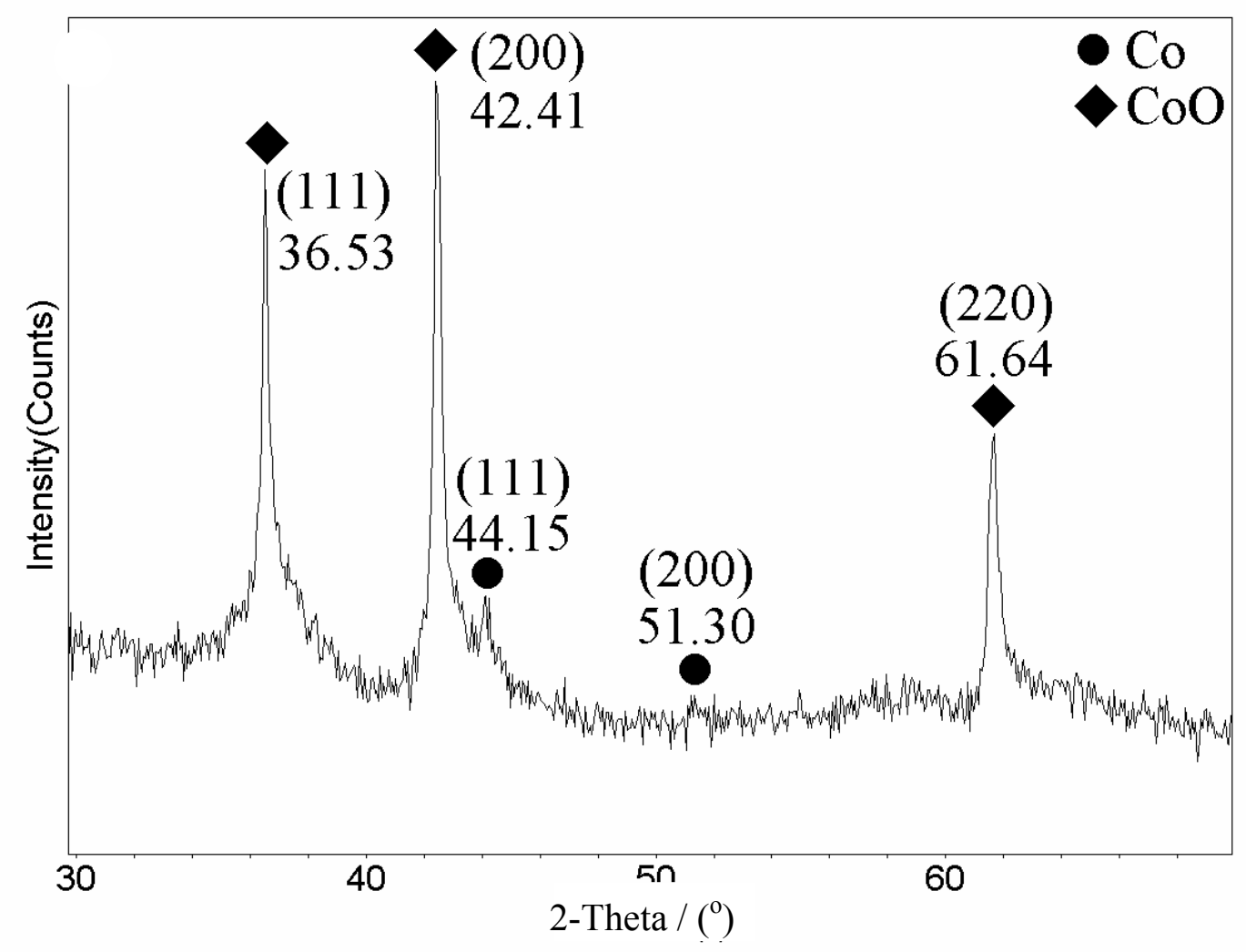

Figure 2-2. XRD pattern showing the decrease of cobalt $\bullet$;(PDF 15-0806) and the formation of cobalt oxide $\checkmark$; $\mathrm{PDF} 43-1004$ ) when the ratio of $\mathrm{O}_{2}$ to $\mathrm{N}_{2}$ is $2.3 \%$. 


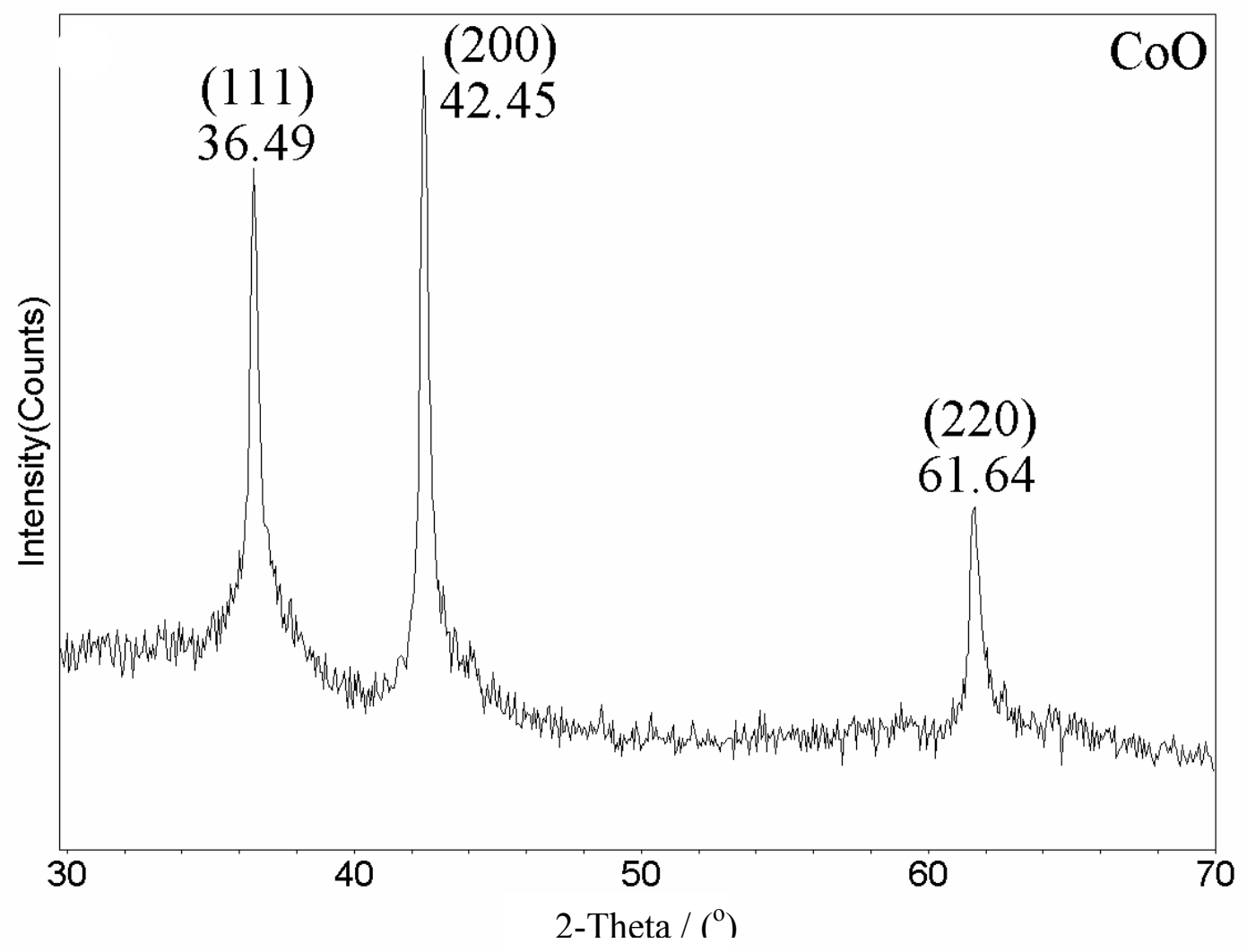

Figure 2-3. XRD pattern showing cobalt oxide (PDF 43-1004) as the primary product formed when the ratio of $\mathrm{O}_{2}$ to $\mathrm{N}_{2}$ is $3 \%$. 


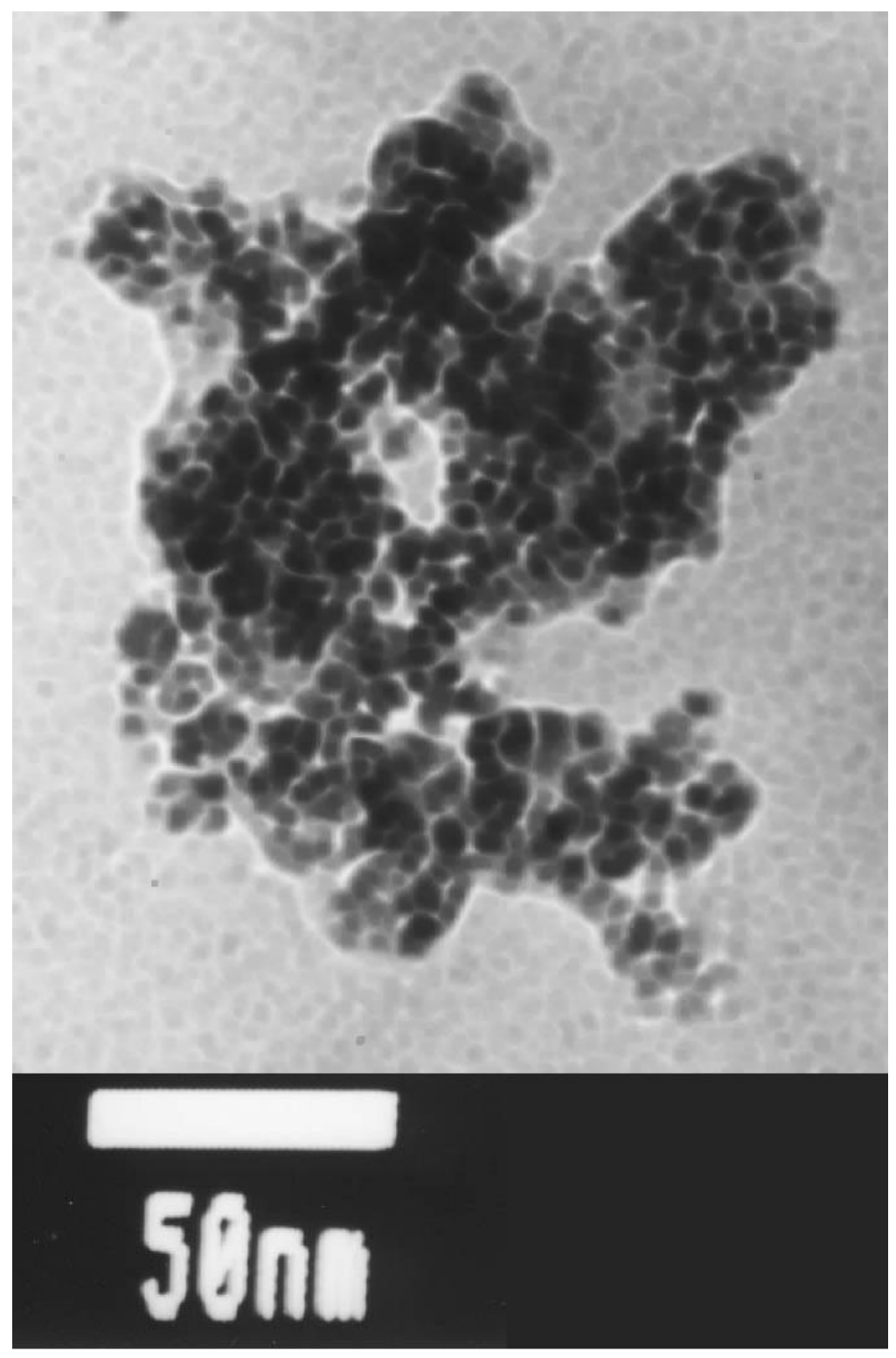

Figure 2-4. TEM image of $\mathrm{CoO}$ nanoparticles. The average particle size was calculated to be $\sim 4 \mathrm{~nm}$. 


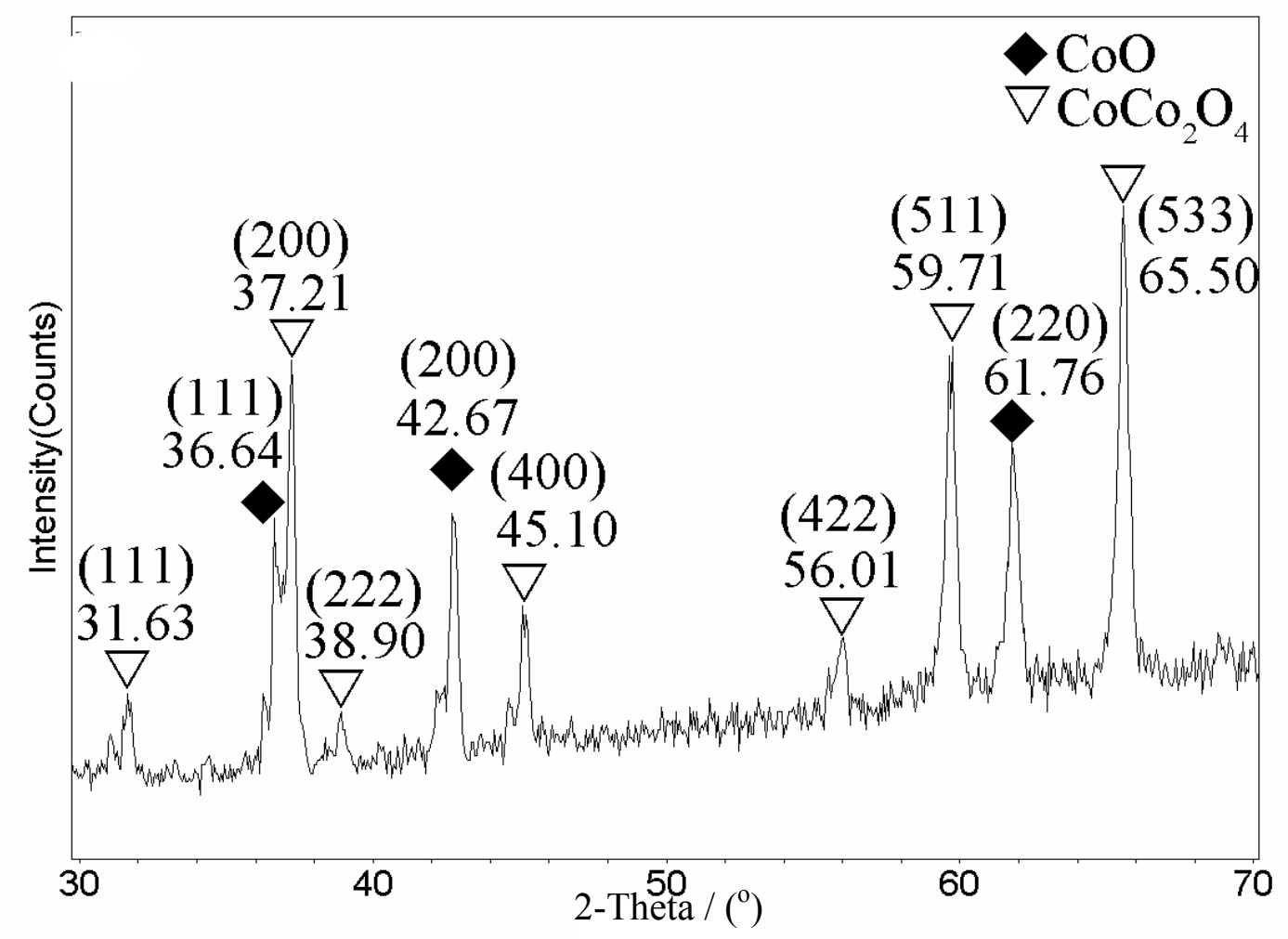

Figure 2-5. XRD pattern showing Alfa Aesar 95\% CoO exhibiting mixed oxide phases referenced to $\mathrm{CoCo}_{2} \mathrm{O}_{4} \nabla$; (PDF 01-1152) and $\mathrm{CoO} \downarrow$; (PDF 43-1004). 


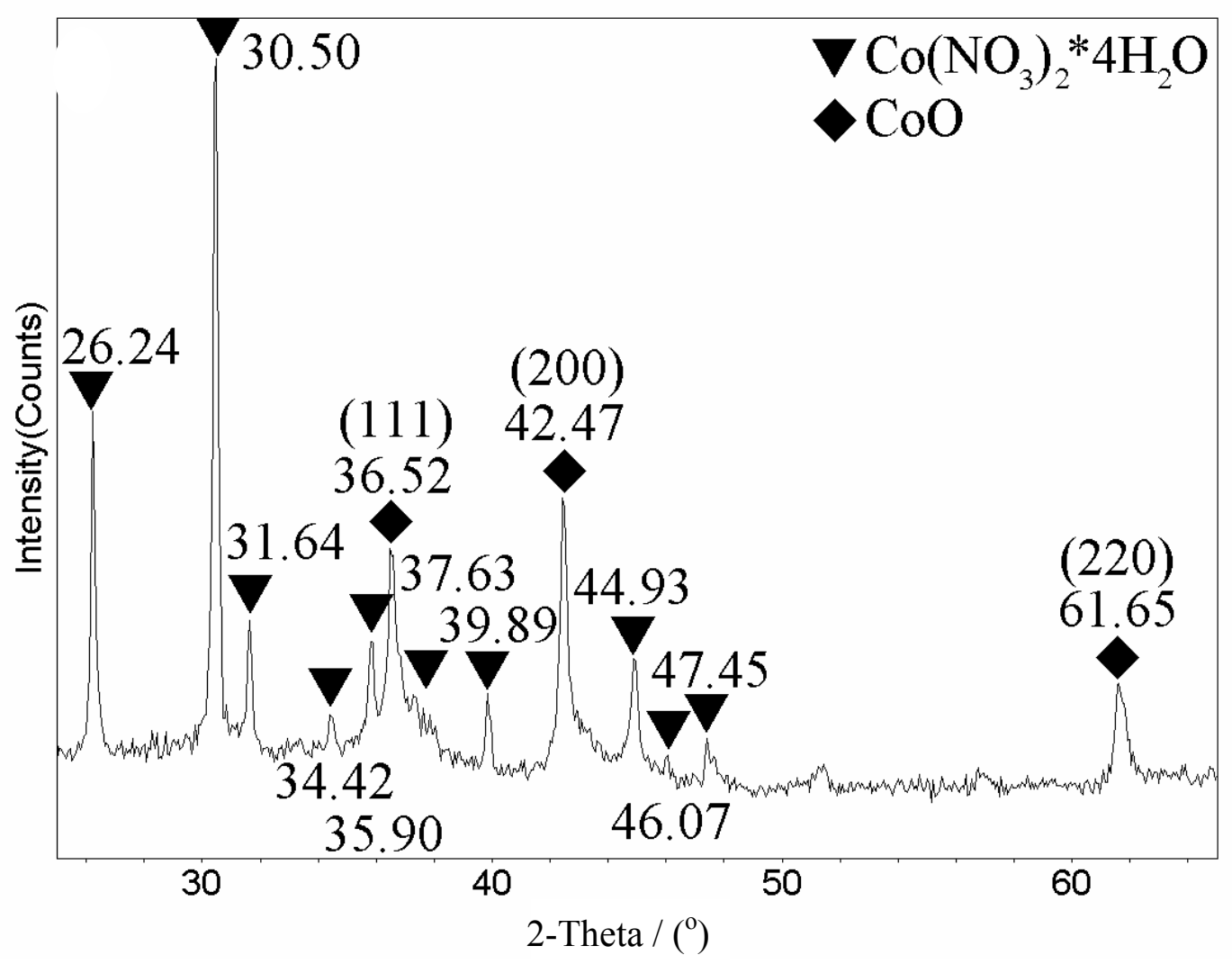

Figure 2-6. XRD pattern showing a mixture of cobalt oxide (PDF 43-1004) and cobalt nitrate tetrahydrate (PDF 18-0425) produced when the ratio of $\mathrm{O}_{2}$ to $\mathrm{N}_{2}$ is $6.6 \%$. 


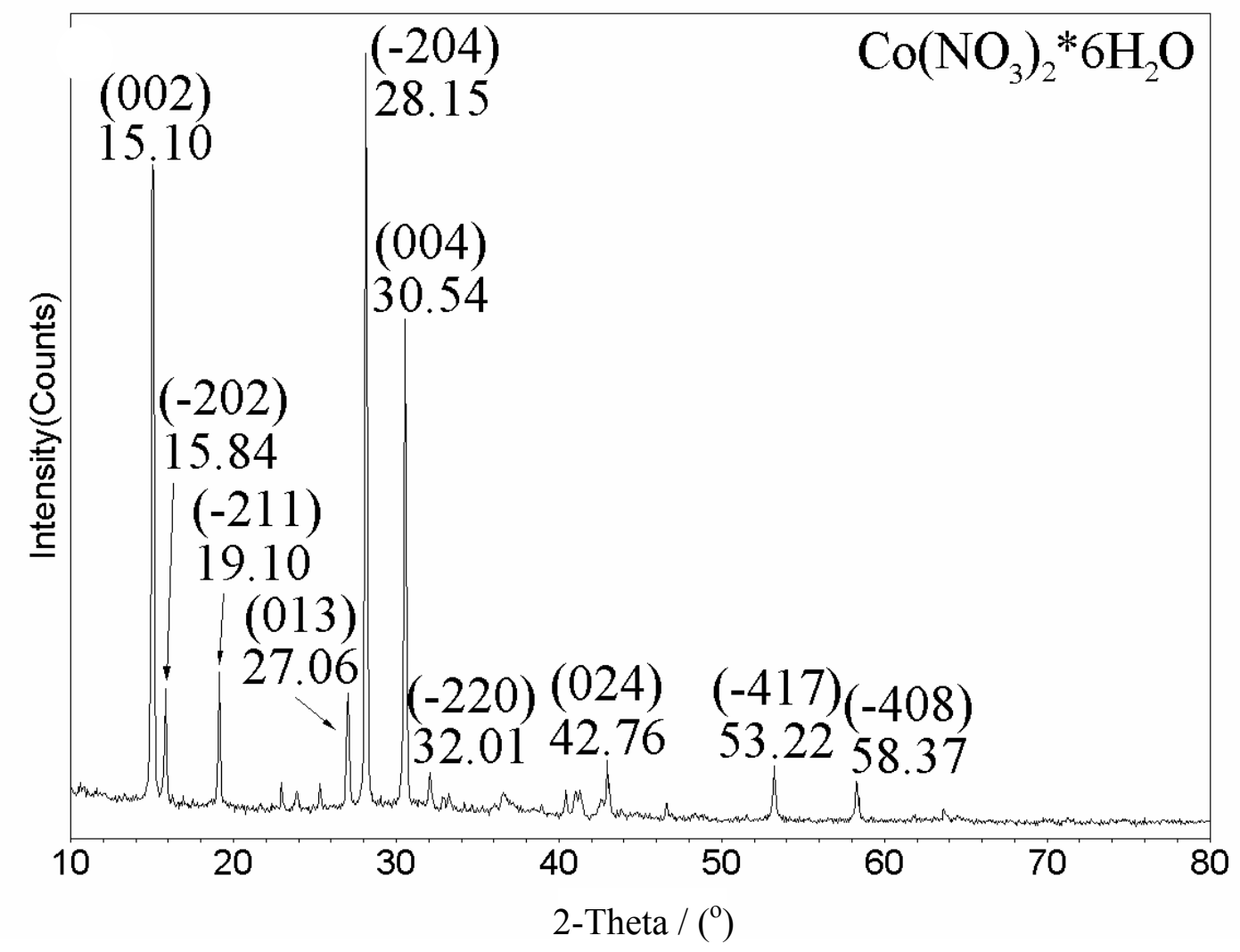

Figure 2-7. XRD pattern showing cobalt nitrate hexahydrate (PDF 25-1219) as the primary product formed when the ratio of $\mathrm{O}_{2}$ to $\mathrm{N}_{2}$ is $50 \%$. 


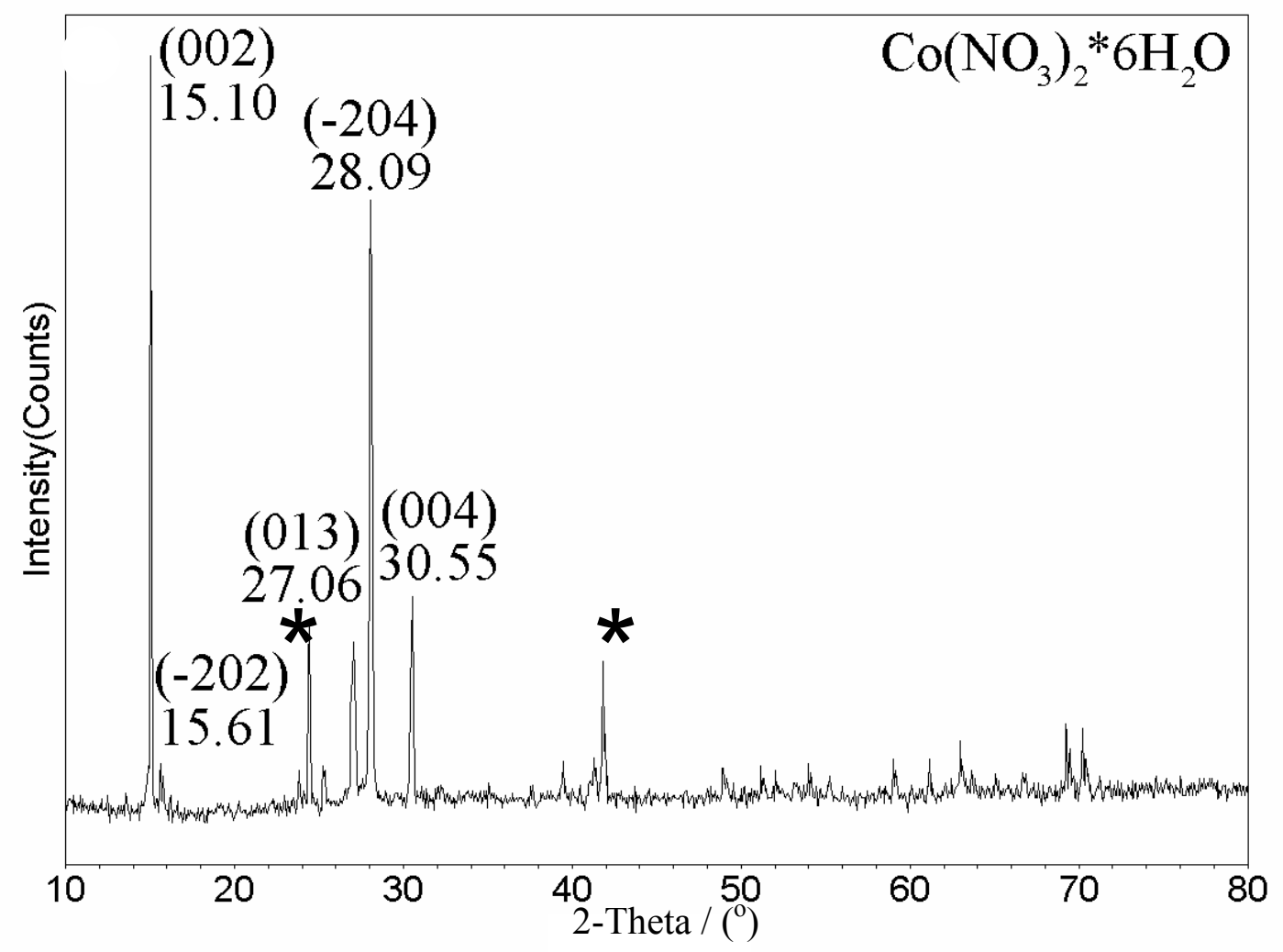

Figure 2-8. XRD pattern showing cobalt nitrate hexahydrate (PDF 25-1219) purchased from Aldrich. The asterisks indicate peaks not matching with the database. 


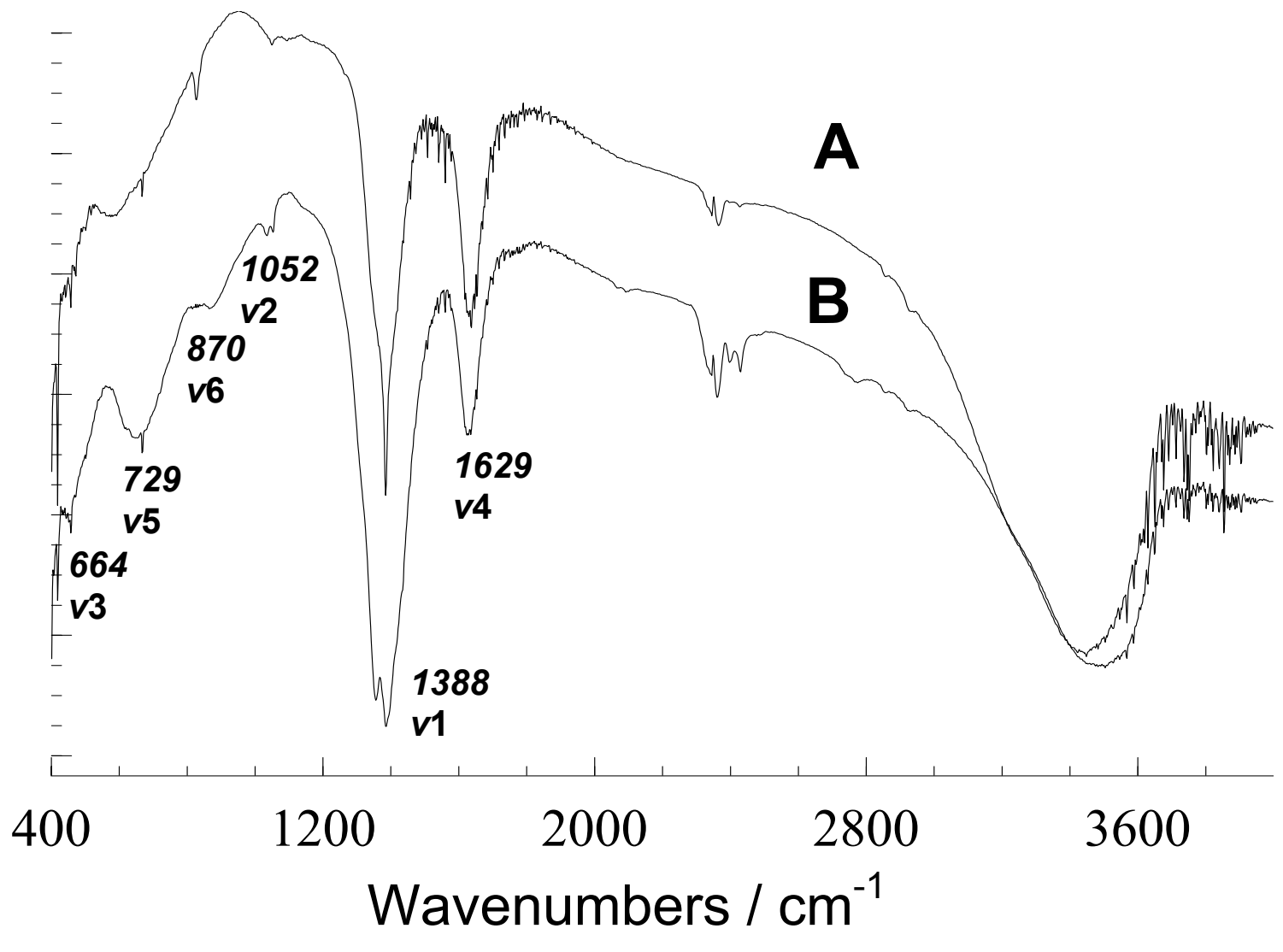

Figure 2-9. Comparison of the infrared spectra of cobalt nitrate hydrate purchased from Aldrich (A) and that synthesized by LVCC (B). The nitrate normal vibrations are the $\mathrm{NO}_{3}{ }^{-}$symmetric stretching mode $\left(v_{1}\right)$, totally symmetric stretching mode $\left(v_{2}\right)$, symmetric in-plane bending mode $\left(v_{3}\right)$, antisymmetric stretching mode $\left(v_{4}\right)$, antisymmetric in-plane bending mode $\left(v_{5}\right)$ and the out of plane bending mode $\left(v_{6}\right)$. 


\section{Summary of Part I}

A surfaced enhanced Raman spectroscopic investigation of the aggregation of silver nanoparticles formed via laser vaporization controlled condensation (LVCC) was undertaken. Using Rhodamine $6 \mathrm{G}$ as the adsorbate, nanoparticles with diameters in the range 5 to $50 \mathrm{~nm}$ were studied with the results from $8 \mathrm{~nm}, 11 \mathrm{~nm}$ and $14 \mathrm{~nm}$ diameter particles reported to highlight the effects of particle size and halide ion concentration on particle aggregation. It was found that with $647.1 \mathrm{~nm}$ excitation maximum enhancement is observed using particles with $11 \mathrm{~nm}$ diameters. Aggregates formed from particles of this size also exhibit significantly greater enhancements compared to aggregates formed from the other size particles. Upon addition of sodium salts enhancement is proportional to the size of the anion for $\mathrm{F}^{-}, \mathrm{Cl}^{-}$, and $\mathrm{Br}^{-}$. Maximum enhancement was observed when the concentration of the anion was approximately equal to the concentration of the adsorbate. These observations are explained in terms of electromagnetic contributions to the enhancement.

We also report for the first time the synthesis of cobalt nitrate hexahydrate, cobalt oxide, and cobalt particles formed from a high purity cobalt metal by a novel LVCC method under controlled pressures of $\mathrm{N}_{2}$ and $\mathrm{O}_{2}$. The metal vapor produced from a cobalt target in the presence of $50 \% \mathrm{~N}_{2}$ and $50 \% \mathrm{O}_{2}$ results in the formation of cobalt nitrate. We also explored the possibilities of forming cobalt oxide and cobalt nanoparticles by altering the ratio of $\mathrm{N}_{2}$ and $\mathrm{O}_{2}$ present. The synthesis of pure cobalt oxide $(\mathrm{CoO})$ nanoparticles is of importance and challenging since no simple chemical route is known. We believe that this work will be significant since the present method is promising as a general method for synthesis of metal mono oxides. 


\section{Part II}

\section{VARIOUS SOL-GEL SYNTHESES OF TRANSISTION METAL DOPED TITANIUM DIOXIDE AND ZINC OXIDE}




\section{Chapter 3}

\section{Controlled Transformation of Paramagnetism to Room-Temperature Ferromagnetism in Cobalt-Doped Titanium Dioxide}

\subsection{Introduction}

Recent reports ${ }^{1-4}$ of room temperature ferromagnetism (RTFM) in cobalt doped titanium dioxide thin films, for both the anatase and rutile phases, have attracted a great deal of interest primarily for the use of such materials in spintronics. However the cause of this RTFM remains controversial since more recent reports ${ }^{5-8}$ have indicated the presence of cobalt nanoparticles in the thin films prepared by sputtering and pulsed laser depositions. This raises the serious possibility that the observed RTFM could be due to undetected Co nanoparticles, which, because of the high Curie temperature of bulk cobalt $\left(\mathrm{T}_{\mathrm{c}} \simeq 1388 \mathrm{~K}\right)$, could easily account for the observations. It was recently reported ${ }^{9}$ that $10 \%$ cobalt-doped $\mathrm{TiO}_{2}$ anatase films prepared by a different technique, viz. spray pyrolysis, are paramagnetic at room temperature. The temperature dependence of the magnetic susceptibility $(\chi)$ of the sample followed the Curie-Weiss behavior, viz. $\chi=\chi_{0}$ $+\mathrm{C} /(\mathrm{T}-\theta)$, with $\theta \simeq-5 \mathrm{~K}$ and it was noted that for $\mathrm{T}<5 \mathrm{~K}$, a hysteresis loop was observed.

We have prepared a $10 \% \mathrm{Co} / \mathrm{TiO}_{2}$ (anatase) powder by a sol-gel technique. Magnetic studies show that the sample is paramagnetic at room temperature and follows a similar Curie-Weiss law. However, by controlled hydrogenation of this sample at 573 $\mathrm{K}$, the paramagnetic $10 \% \mathrm{Co} / \mathrm{TiO}_{2}$ is transformed to a ferromagnet with a Curie- 
temperature $T_{c} \simeq 470 \mathrm{~K}$. This occurs without any observable change in the crystal structure as revealed by $\mathrm{x}$-ray diffraction (XRD). High resolution transmission electron microscopy (TEM) studies of the hydrogenated sample failed to detect the presence of any cobalt nanoparticles.

\subsection{Experimental}

Samples of 1,5 , and $10 \% \mathrm{Co} / \mathrm{TiO}_{2}$ were prepared by mixing (reacting) appropriate amounts of titanium isopropoxide (Aldrich, Milwaukee, WI) and cobalt nitrate (Aldrich) in ethanol. The solution was dried at $80^{\circ} \mathrm{C}$ and the resultant powder was heated at $750 \mathrm{~K}$ for $1 \mathrm{hr}$ yielding a dark-green sample. X-ray diffraction of these powders confirmed the anatase form of $\mathrm{TiO}_{2}$, with only a trace amount of the rutile phase (Figures 3-1 to 3-3). Part of the powder was used for magnetic measurements and the remaining used for 1, 3 and $6 \mathrm{hrs}$ of hydrogenation carried out at $573 \mathrm{~K}$. The hydrogen reduction set-up consisted of a tubular furnace kept inside a continuously vented hood. The sample was contained in an open glass boat and was placed inside the tubular furnace with $\mathrm{H}_{2}$ gas passed over the sample at $573 \mathrm{~K}$ with the help of a gas flow control unit. Temperature and magnetic field variations of the magnetization (M) of these four samples were then measured using a commercial superconducting quantum interference device magnetometer (SQUID).

\subsection{Results and Discussion}

The temperature dependence of $\chi$ for the as-prepared samples (prior to hydrogenation) for $1 \% \mathrm{Co} / \mathrm{TiO}_{2}$ is shown in Figure 3-4 where the solid line is fit to the 
Curie-Weiss law: $\chi=\chi_{0}+\mathrm{C} /(\mathrm{T}-\theta)$. This dependence is similar to the one reported for the sample prepared by spray pyrolysis. ${ }^{9}$ From the Curie-constant $\mathrm{C}=2.5 \times 10^{-4}$ (emu$\mathrm{K} / \mathrm{gOe})\left(\mathrm{C}=\mathrm{N} \mu^{2} / 3 \mathrm{k}_{\mathrm{B}}\right.$ with $\mathrm{N}$ being the number of magnetic ions $/ \mathrm{g}, \mathrm{k}_{\mathrm{B}}=$ Boltzmann constant and $\mu=$ magnetic moment $), \mu\left(\mathrm{Co}^{+}\right)=4.0 \mu_{\mathrm{B}}$ is obtained. This magnitude of $\mu$ is consistent with the high spin state of $\mathrm{Co}^{2+}$, assuming that $\mathrm{Co}^{2+}$ substitutes for $\mathrm{Ti}^{4+}$ in the anatase unit cell for $1 \%$ cobalt doping with the balance of the charge compensated for by $\mathrm{O}_{2}$. After hydrogenation at $573 \mathrm{~K}$, the sample retains its paramagnetic behavior as shown in Figure 3-5 (with a similar $\mu$ ).

The as-prepared sample of $5 \% \mathrm{Co} / \mathrm{TiO}_{2}$ displays paramagnetic behavior similar to that of $1 \% \mathrm{Co} / \mathrm{TiO}_{2}$ with $\mu=4.0 \mu_{\mathrm{B}}$ (Figure 3-6). However, after hydrogenation for 3 hours at $573 \mathrm{~K}$ the sample displays room temperature ferromagnetism as indicated by $\chi$ vs $\mathrm{T}$ (Figure 3-7) and $\mathrm{M}$ vs $\mathrm{H}$ (Figure 3-8) plots. The temperature variation of the magnetic susceptibility and the magnetization are also indicative of RTFM for the sample hydrogenated for 6 hours as shown in Figures 3-9 and 3-10. The absence of a peak in $\chi$ for the zero-field cooled (ZFC) cases, which is a signature of the blocking temperature $\left(\mathrm{T}_{\mathrm{B}}\right)$ for cobalt as reported recently for the thin films of $\mathrm{Co} / \mathrm{TiO}_{2}$ prepared by sputtering ${ }^{6}$, provides additional assurance for the absence of cobalt nanoparticles in our samples. The reported $T_{B}$ values of Co nanoparticles of different sizes are: $T_{B} \simeq 20 \mathrm{~K}(3 \mathrm{~nm}), T_{B} \simeq 50$ $\mathrm{K}(6 \mathrm{~nm}), \mathrm{T}_{\mathrm{B}} \simeq 100 \mathrm{~K}(8 \mathrm{~nm})$ and $\mathrm{T}_{\mathrm{B}} \simeq 260 \mathrm{~K}(11 \mathrm{~nm})^{10,11}$. Again, it is significant to note that hydrogenation does not appear to affect the crystal structure since no significant differences are observed in the XRD patterns of the four samples (Figure 3-2). From the 
widths of the XRD lines, the average particle size of the anatase phase is $\simeq 10( \pm 2) \mathrm{nm}$, without any major changes upon hydrogenation.

The temperature variation of $\chi$ for the as-prepared samples for $10 \% \mathrm{Co} / \mathrm{TiO}_{2}$ is shown in Figure 3-11. It is significant to note that temperatures in Figure 3-11 are plotted on a log scale in order to show the details of the $\chi$ vs. T behavior at lower temperatures. After hydrogenation at $573 \mathrm{~K}$, the sample acquires RTFM. Figure 3-12 shows the hysteresis loop measured at $350 \mathrm{~K}$ for the 6 hour sample. Hysteresis loops were measured for the 1, 3 and $6 \mathrm{hr}$. hydrogenated samples. Figure 3-13 shows the temperature variation of the remanance $\mathrm{M}_{\mathrm{r}}(\mathrm{M}$ at $\mathrm{H}=0)$ from $5 \mathrm{~K}$ to $350 \mathrm{~K}$ for the 1,3 and $6 \mathrm{hrs}$. samples (measurements for $\mathrm{T}>350 \mathrm{~K}$ could not be made because of experimental limitations). The variations of $M_{r}$ vs $T$ are typical of a ferromagnet, with $T_{c} \simeq 470 \mathrm{~K}$ determined by extrapolating the $M_{r}$ data to $M_{r}=0$ (Figure 3-13). The primary effect of increasing the hydrogenation time from 1 to 6 hrs is to increase $\mathrm{M}_{\mathrm{r}}$, demonstrating a similar source of the RTFM for the three samples. This is further confirmed by the temperature variation of the coercivity which extrapolates to zero at $T_{c} \simeq 470 \mathrm{~K}$ (Figure 3-14). Thus it appears that with increase in the hydrogenation time, more of the sample is transforming to a ferromagnet. In the extrapolations shown in Figures 3-13 and 3-14, a similar $T_{c}$ is determined for the 1, 3 and $6 \mathrm{hrs}$. samples, although the extrapolations are clearly approximate since $M_{r}$ and $H_{c}$ are often non-linear on their approach to $T_{c}$. Thus an increase in $T_{c}$ with increase in hydrogenation time is not ruled out by the data in Figs. 13 and 14. Finally, we measured $\chi$ vs. T for the $6 \mathrm{hrs}$ sample under zero-field-cooled and field-cooled conditions (Figure 3-15). 
In light of the recent reports about the presence of Co nanoparticles in $\mathrm{Co} / \mathrm{TiO}_{2}$ films prepared by sputtering in different partial pressures of oxygen, ${ }^{5,8}$ we employed several characterization techniques in addition to XRD to check for Co nanoparticles in our samples. X-ray Photoelectron Spectroscopy (XPS) of the as-prepared and the $6 \mathrm{hr}$. hydrogenated samples indicated that neither Ti nor Co are in their metallic states. For the hydrogenated sample, the Ti2 $p$ peaks were observed at $457.5 \mathrm{eV}$ and $463.2 \mathrm{eV}$ and the Co $2 p$ peaks at $779.5 \mathrm{eV}$ and $795.2 \mathrm{eV}$. The corresponding values for the as-prepared samples were $458.1 \mathrm{eV}$ and $463.8 \mathrm{eV}$ for $\mathrm{Ti} 2 p$ and $780.5 \mathrm{eV}$ and $796.2 \mathrm{eV}$ for $\mathrm{Co} 2 p$. These magnitudes indicate $2+$ and/or $3+$ states of Co and $2+$ and/or $4+$ states for Ti (the metallic $\mathrm{Co} 2 p$ peak position should be at $778.3 \mathrm{eV}$ ). High resolution TEM studies of the hydrogenated samples clearly showed particles of about $10 \mathrm{~nm}$ whose Energy Dispersive X-ray (EDX) spectra yielded the presence of Co, Ti and oxygen, again ruling out the presence of metallic cobalt. Also, no exchange bias could be detected at $5 \mathrm{~K}$ for the $6 \mathrm{hrs}$ sample when cooled from $300 \mathrm{~K}$ to $5 \mathrm{~K}$ in $\mathrm{H}=20 \mathrm{kOe}$. This indicates the absence of a ferromagnetic/antiferromagnetic interface (e.g. $\mathrm{Co} / \mathrm{CoO})$ in the system ${ }^{12}$.

\subsection{Conclusion}

It has been suggested that oxygen vacancies near cobalt in Co-doped $\mathrm{TiO}_{2}$ are essential to provide the exchange coupling between cobalt ions which leads to intrinsic RTFM $^{13}$. This was the motivation for the hydrogenation experiments, since $\mathrm{H}_{2}$ is likely to extract oxygen from the sample thus producing oxygen vacancies. From the experiments described above, we were unable to detect the presence of cobalt nanoparticles, thus suggesting the intrinsic nature of RTFM in our hydrogenated samples. 
Additional experiments such as accurate measurements of electrical conductivity as a function of hydrogenation time would be useful to confirm these observations.

\subsection{References}

(1) Matsumoto, Y; Murakami, M; Shono, T; Hasegawa, T; Fukumura, T; Kawasaki, M; Ahmet, P; Chikyow, T; Koshihara, M; Koinuma, H. Science (2001), 291, 854.

(2) Chambers, S. A; Thevuthasan, S; Farrow, R. F. C; Marks, R. F; Thiele, J. W;Folks, L; Samant, M. G; Kellock, A. J; Ruzycki, N; Ederer, D. L; Diebold, U. Appl. Phys. Lett. (2001), 79, 3467.

(3) Matsumoto, Y; Takahashi, R; Murakami, M; Koida, T; Fan, X; Hasegawa, T; Fukumura, T; Kawasaki, M; Koshihara, S; Koinuma, H. Jpn. J. Appl. Phys., Part 2 (2001), 40, L1205.

(4) Park, W. K; Ortega-Hertogs, R. J; Moodera, J; Punnoose, A; Seehra, M. S. J. Appl. Phys. (2002), 91, 8093.

(5) Stampe, P. A; Kennedy, R. J; Xin, Y; Parker, J. S. J. Appl. Phys. (2003), 93, 7864.

(6) Punnoose, A; Seehra, M. S; Park, W.K; Moodera, J. S; J. Appl. Phys. (2003), 93, 7867.

(7) Kim, D. H; Yang, J. S; Lee, K. W; Bu, S. D; Kim, D; Noh, T. W; Oh, S. J; Kim, Y. J; Chung, J; Tanaka, H; Lee, H. Y; Kawai, T; Won, J. Y; Park, S. H; Lee, J. C. J. Appl. Phys., (2003), 93, 6125.

(8) Rameev, B. Z; Yildiz, F; Tagirov, L. R; Aktas, B; Park, W. K; Moodera, J. S; J. Mag. Mag. Mater. (2003), 258-259, 361.

(9) Manivannan, A; Seehra, M. S; Majumder, S. B; Katiyar, R. S; Appl. Phys. Lett. (2003), 83, 111.

(10) Chen, J. P; Sorensen, C. M; Klabunde, K. J; Hadjipanayis, G. C; Phys. Rev. B (1995), 51, 11527.

(11) Murray, C. B; Sun, S; Doyle, H; Betley, T. Mat. Res. Bull., Dec. (2001), 985.

(12) Berkowitz A. E; Takano, K. J. Magn. Magn. Mater. (1999), 200, 552.

(13) Park, M. S; Kwon S. K; Min, B. I. Phys. Rev. B (2002), 65, 161201. 


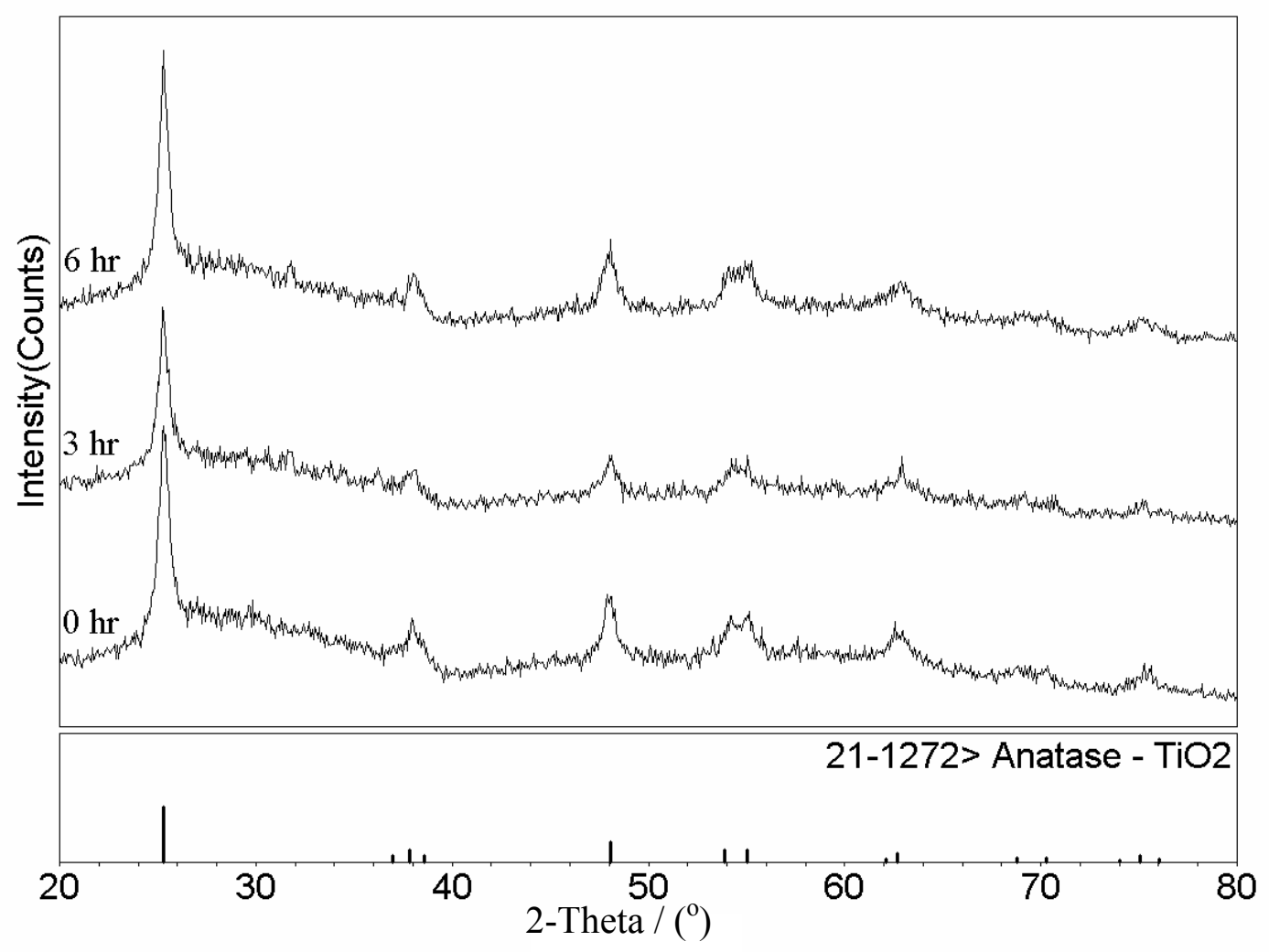

Figure 3-1. X-ray diffraction patterns of the as-prepared ( $0 \mathrm{hrs})$ sample of $1 \% \mathrm{Co} / \mathrm{TiO}_{2}$ and the sample hydrogenated for 3 and $6 \mathrm{hrs}$. at $573 \mathrm{~K}$. The expected line positions for the anatase phase are shown. 


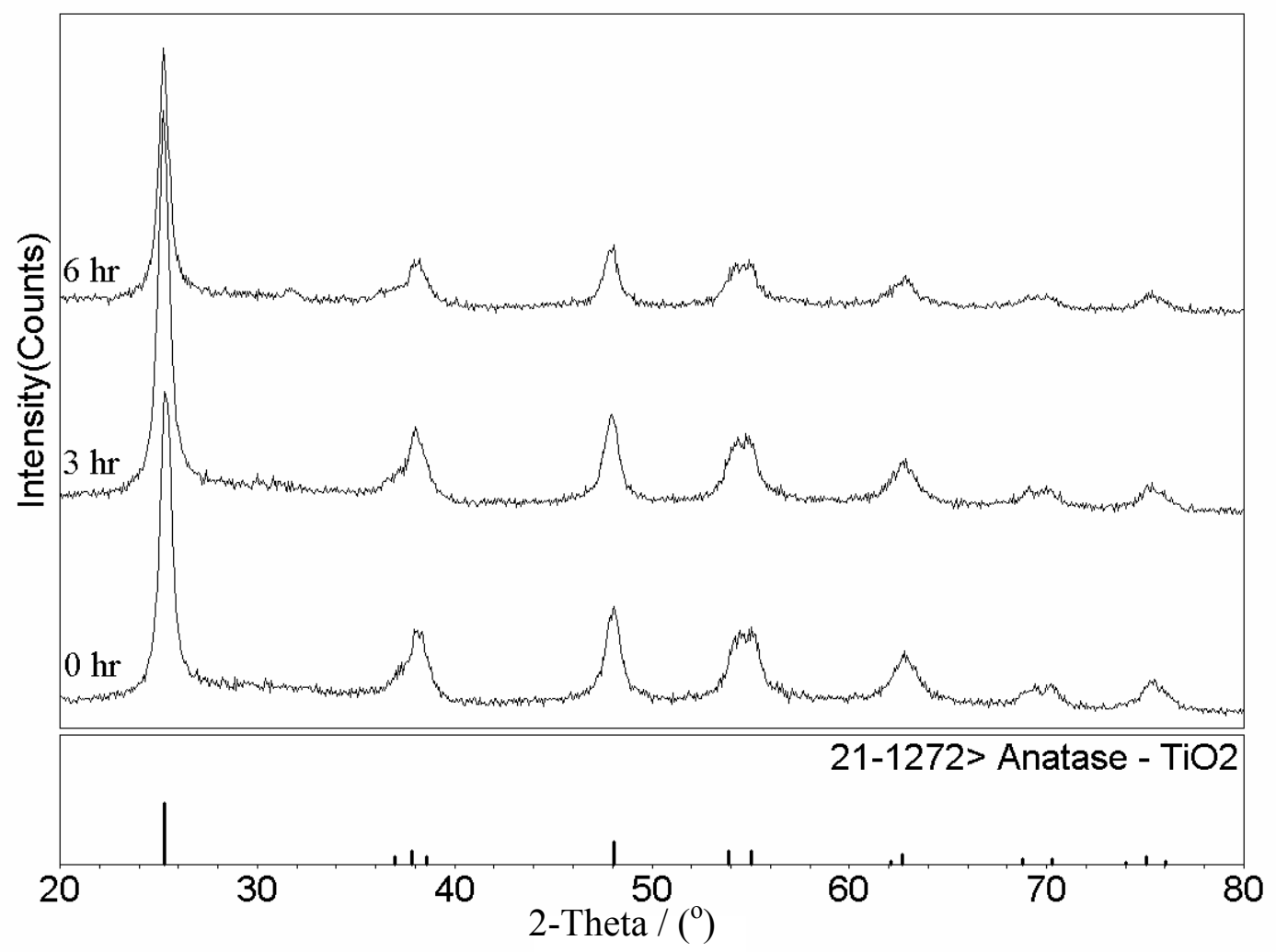

Figure 3-2. X-ray diffraction patterns of the as-prepared ( $0 \mathrm{hrs})$ sample of $5 \% \mathrm{Co} / \mathrm{TiO}_{2}$ and the sample hydrogenated for 3 and $6 \mathrm{hrs}$. at $573 \mathrm{~K}$. The expected line positions for the anatase phase are shown. 


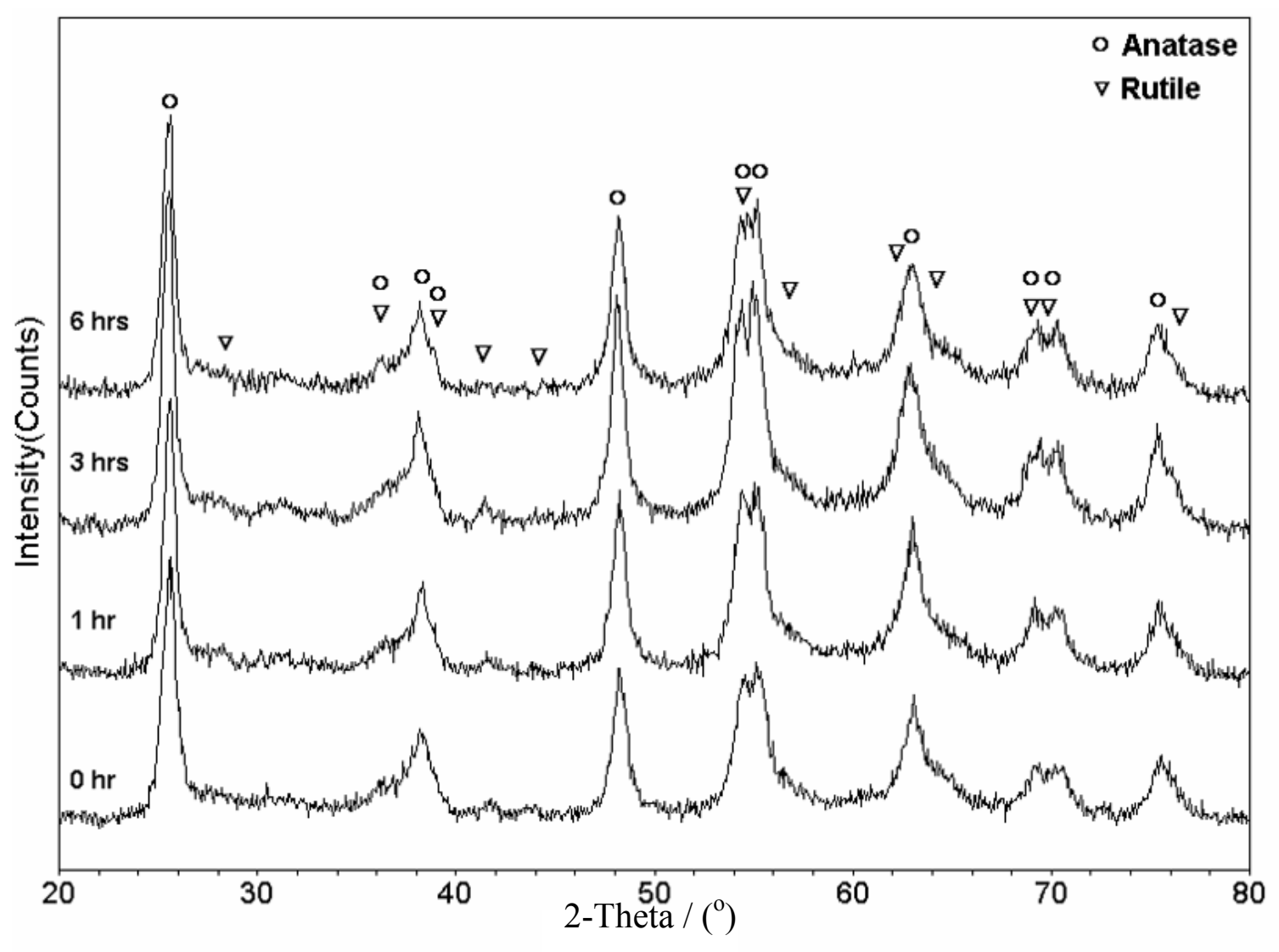

Figure 3-3. X-ray diffraction patterns of the as-prepared ( $0 \mathrm{hrs})$ sample of $10 \% \mathrm{Co} / \mathrm{TiO}_{2}$ and the sample hydrogenated for 1,3 and $6 \mathrm{hrs}$. at $573 \mathrm{~K}$. The expected line positions for the anatase $\bigcirc$; and rutile $\nabla$; phases are shown. 


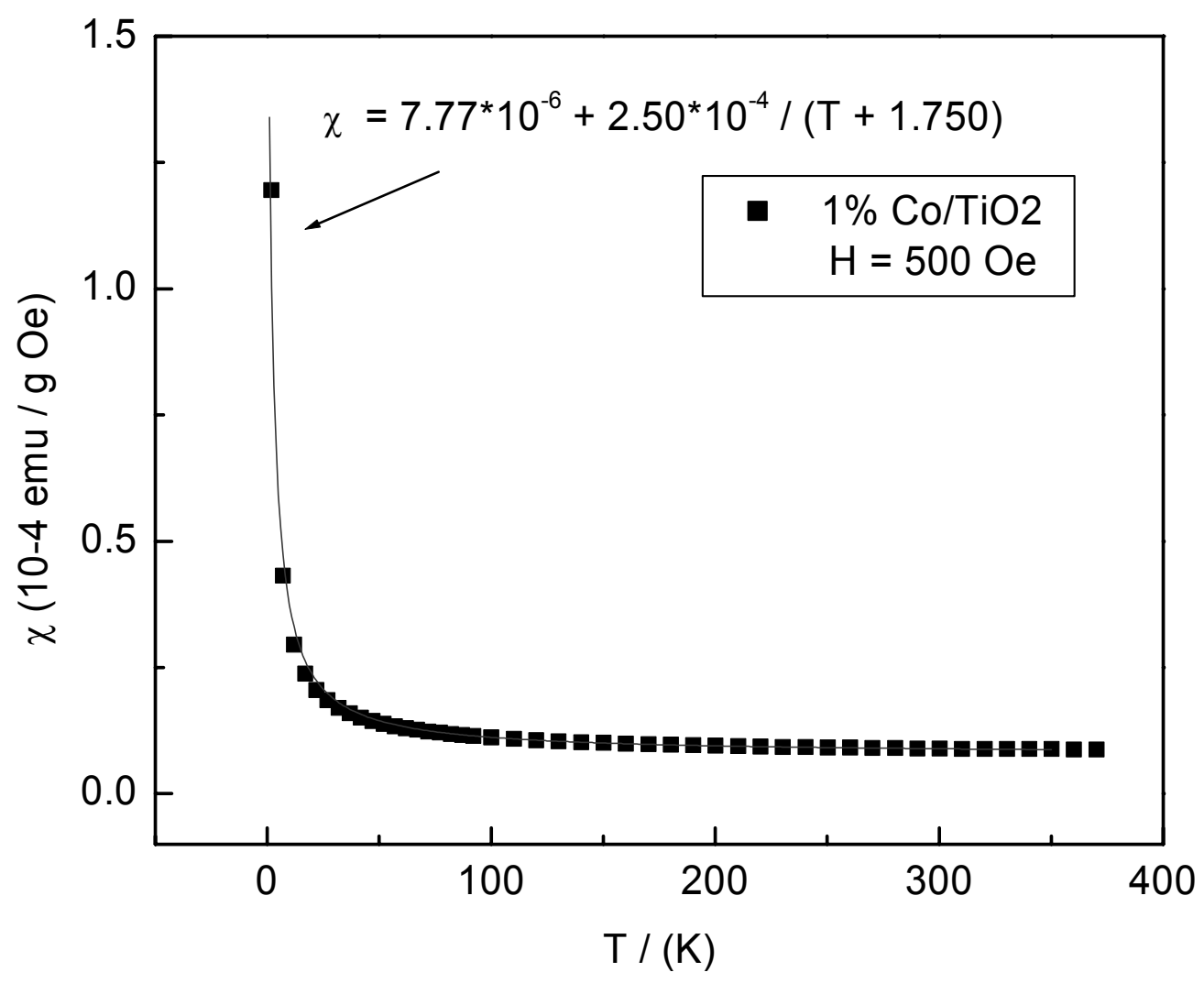

Figure 3-4. Temperature dependence of the magnetic susceptibility $(\chi)$ of the as-prepared sample of $1 \% \mathrm{Co} / \mathrm{TiO}_{2}$. The solid line is fit to the equation shown. The magnetic field applied was 500 Oe. 


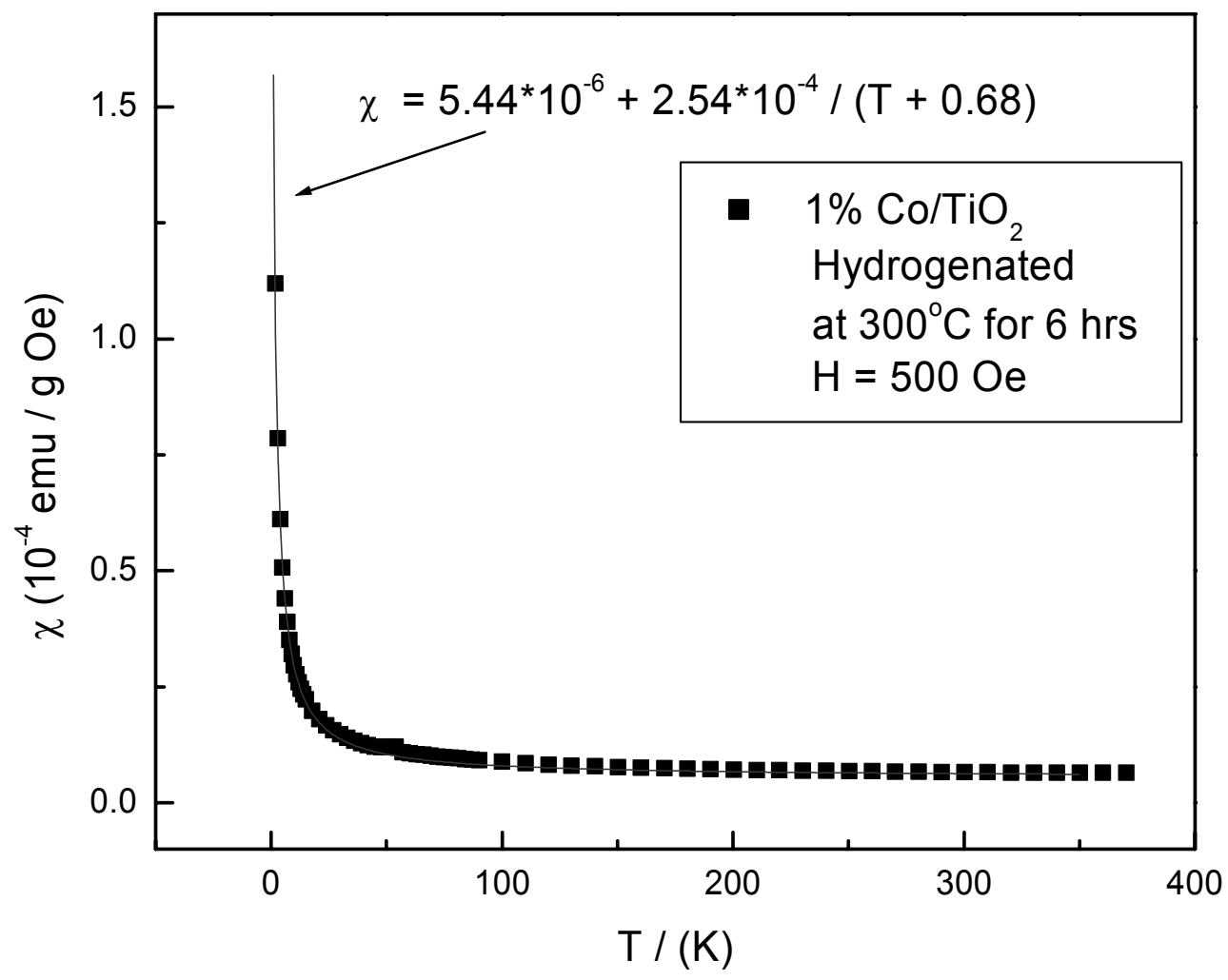

Figure 3-5. Temperature dependence of the magnetic susceptibility $(\chi)$ of the as-prepared sample of $1 \% \mathrm{Co} / \mathrm{TiO}_{2}$ hydrogenated at $573 \mathrm{~K}$ for 6 hours. The solid line is fit to the equation shown. 


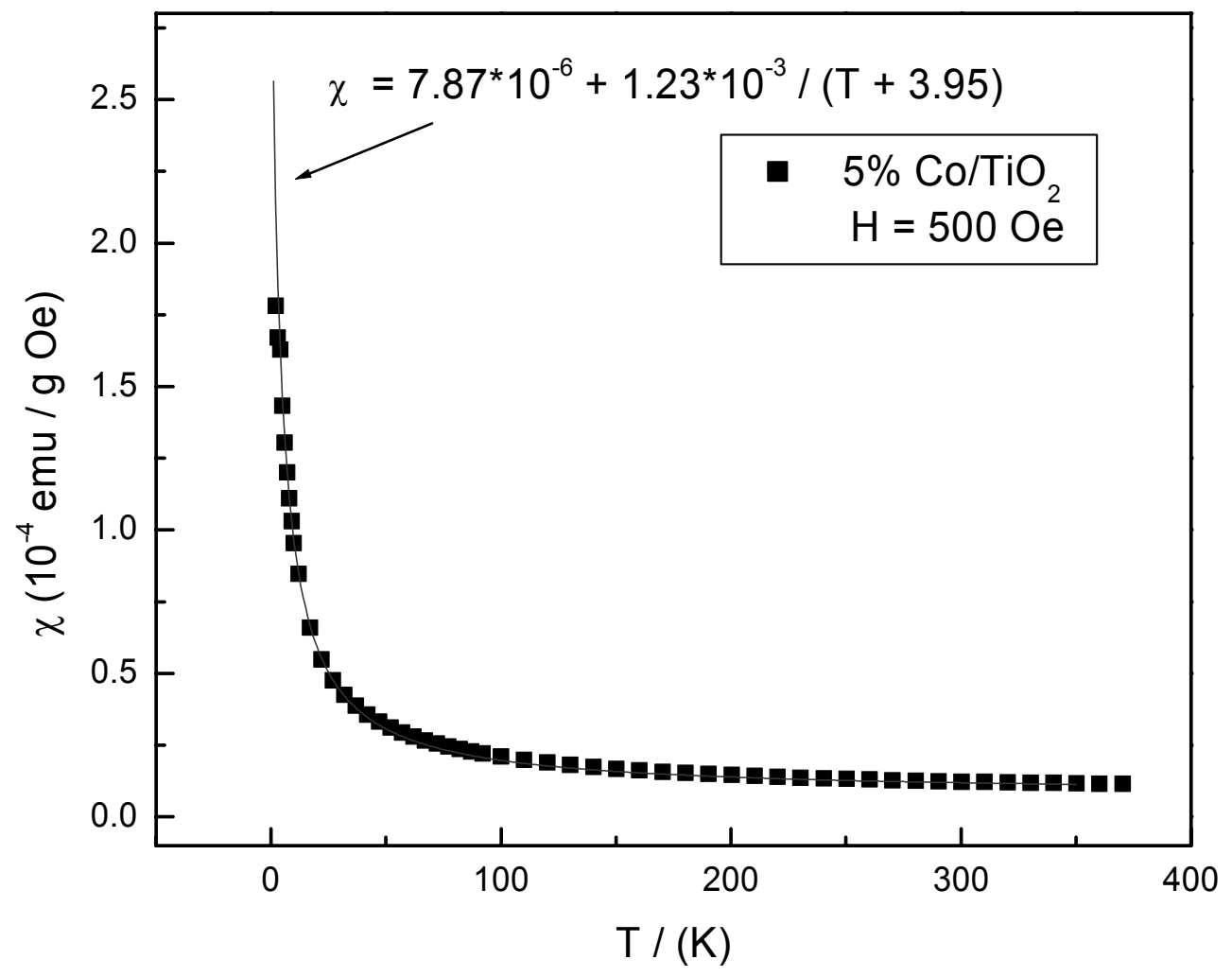

Figure 3-6. Temperature dependence of the magnetic susceptibility of the as-prepared sample of $5 \% \mathrm{Co} / \mathrm{TiO}_{2}$. The solid line is fit to the equation shown. 


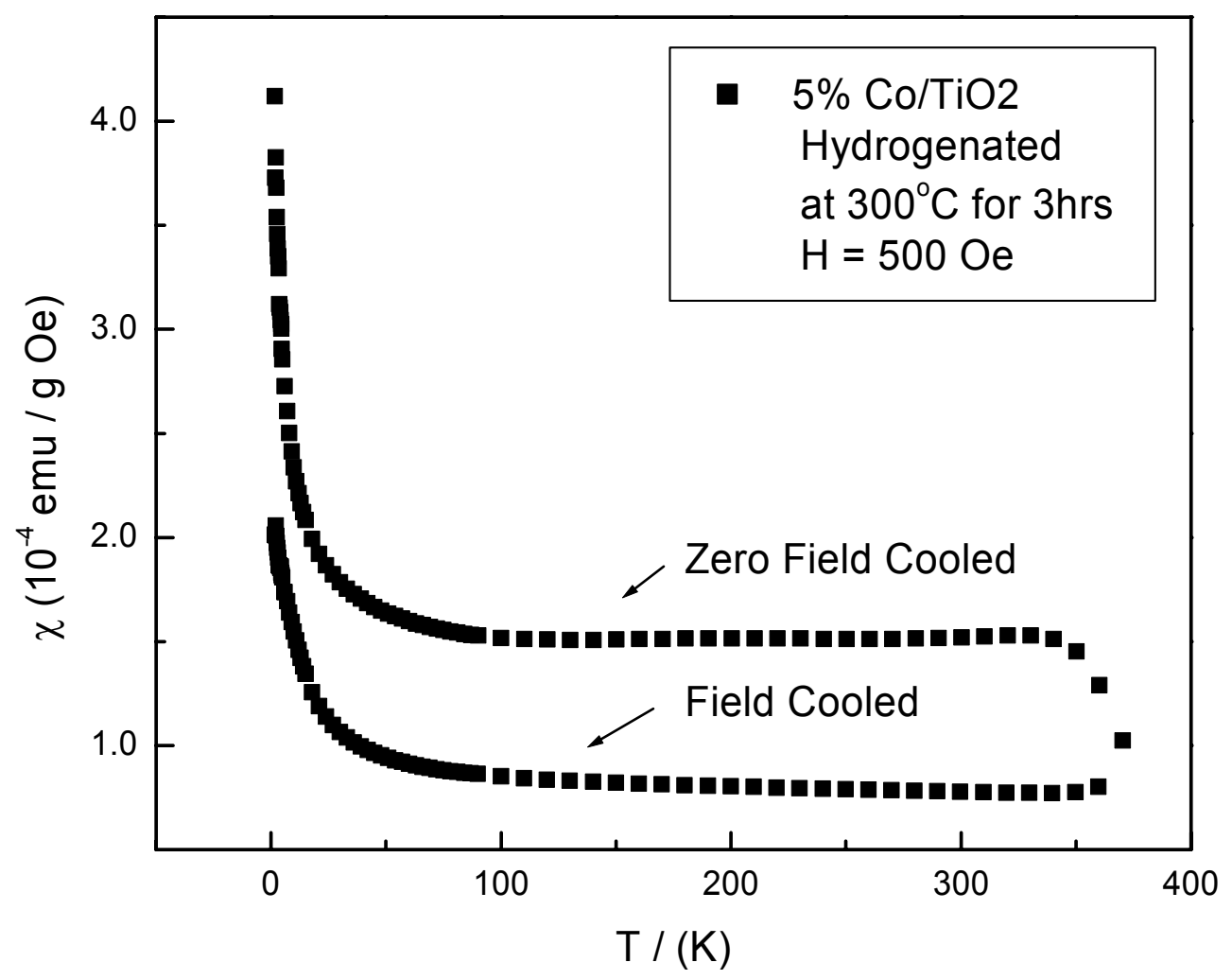

Figure 3-7. Temperature variation of the magnetic susceptibility of the $5 \% \mathrm{Co} / \mathrm{TiO}_{2}$ hydrogenated at $573 \mathrm{~K}$ for $3 \mathrm{hr}$. under zero-field-cooled and field-cooled conditions. 

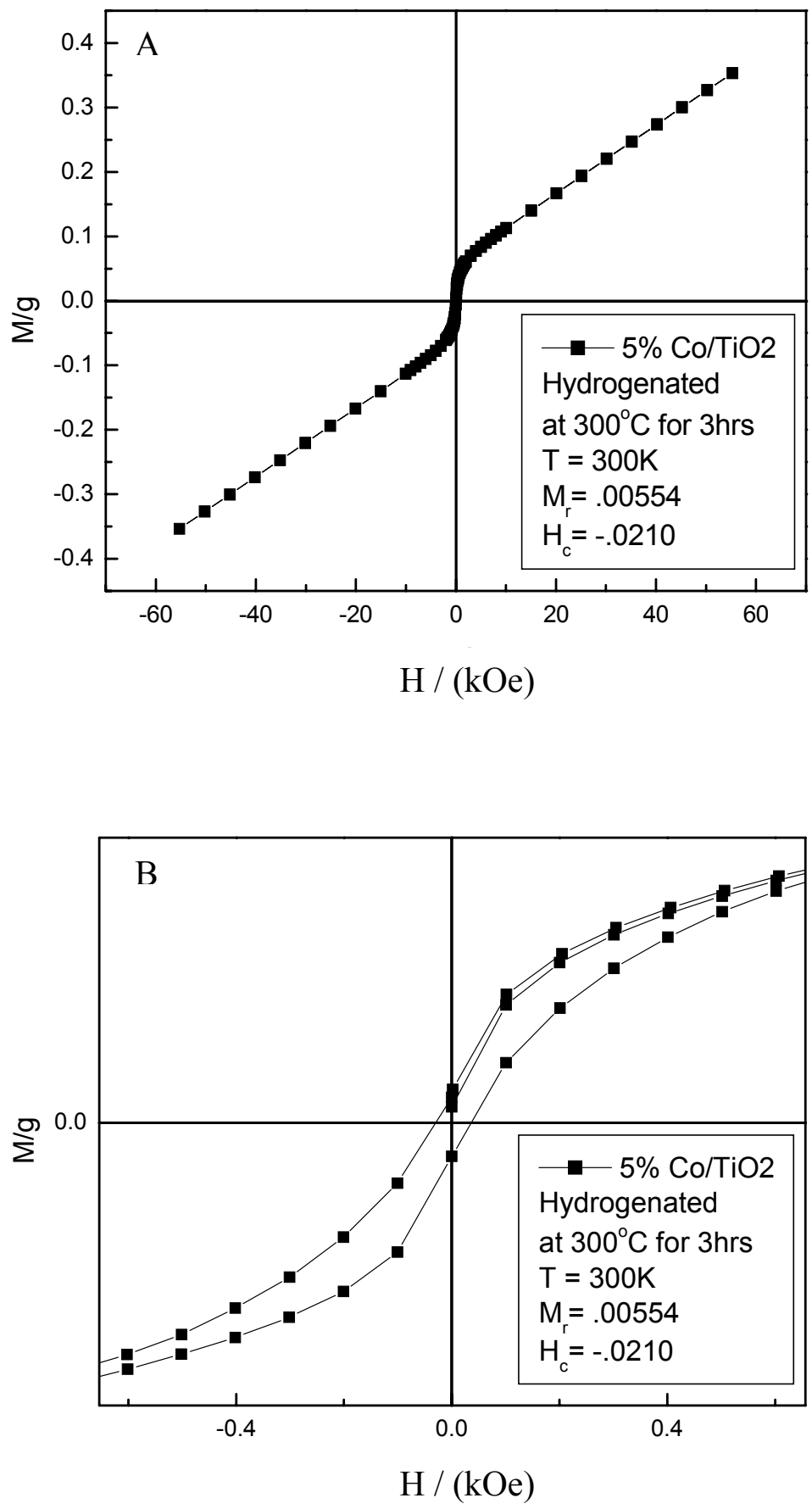

Figure 3-8. $\mathrm{M}$ vs $\mathrm{H}$ variation of $5 \% \mathrm{Co} / \mathrm{TiO}_{2}$ hydrogenated for 3 hours measured at $300 \mathrm{~K}$ (A) and an expanded view (B). 


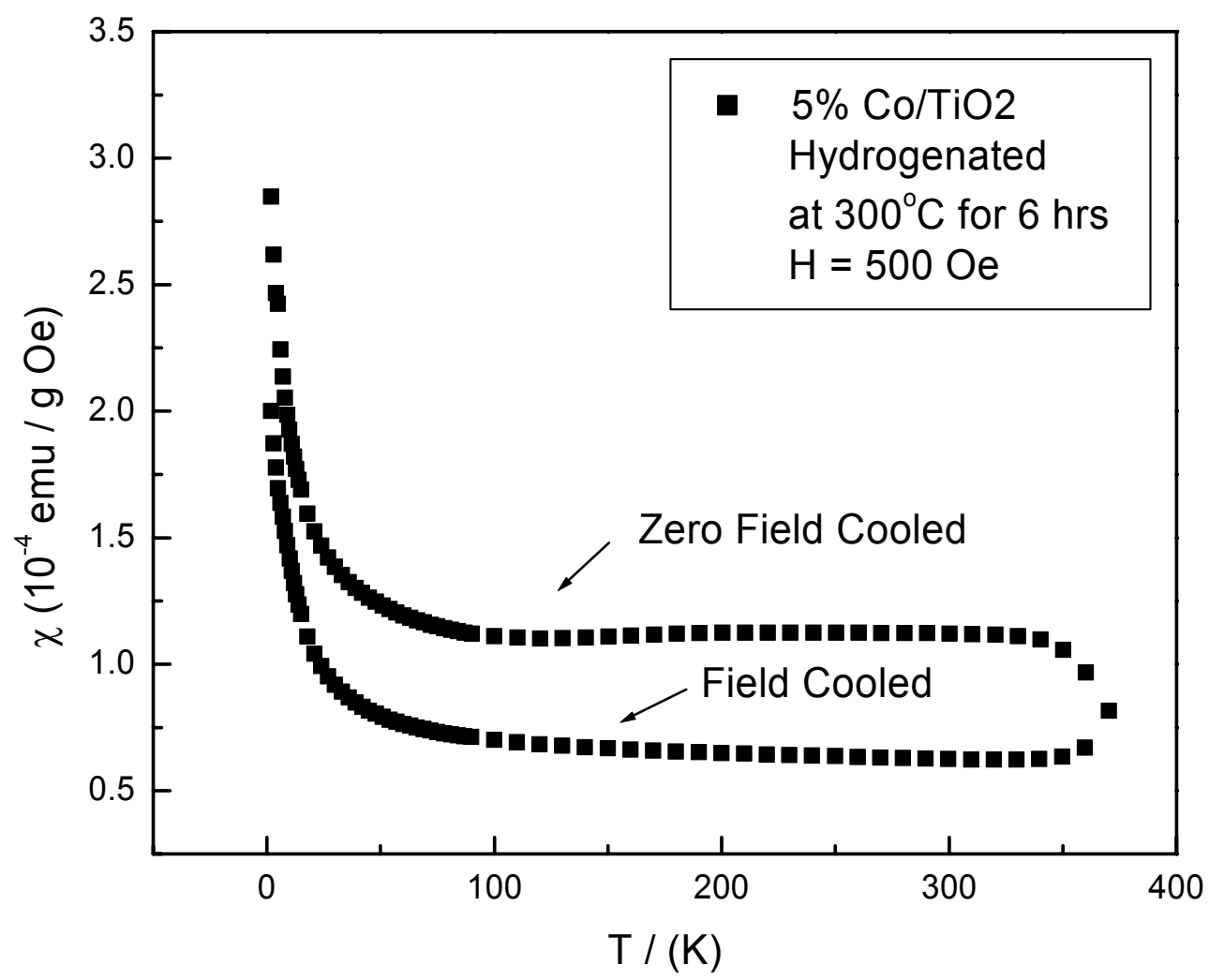

Figure 3-9. Temperature variation of the magnetic susceptibility of the $5 \% \mathrm{Co} / \mathrm{TiO}_{2}$ hydrogenated at $573 \mathrm{~K}$ for $6 \mathrm{hr}$. under zero-field-cooled and field-cooled conditions. 

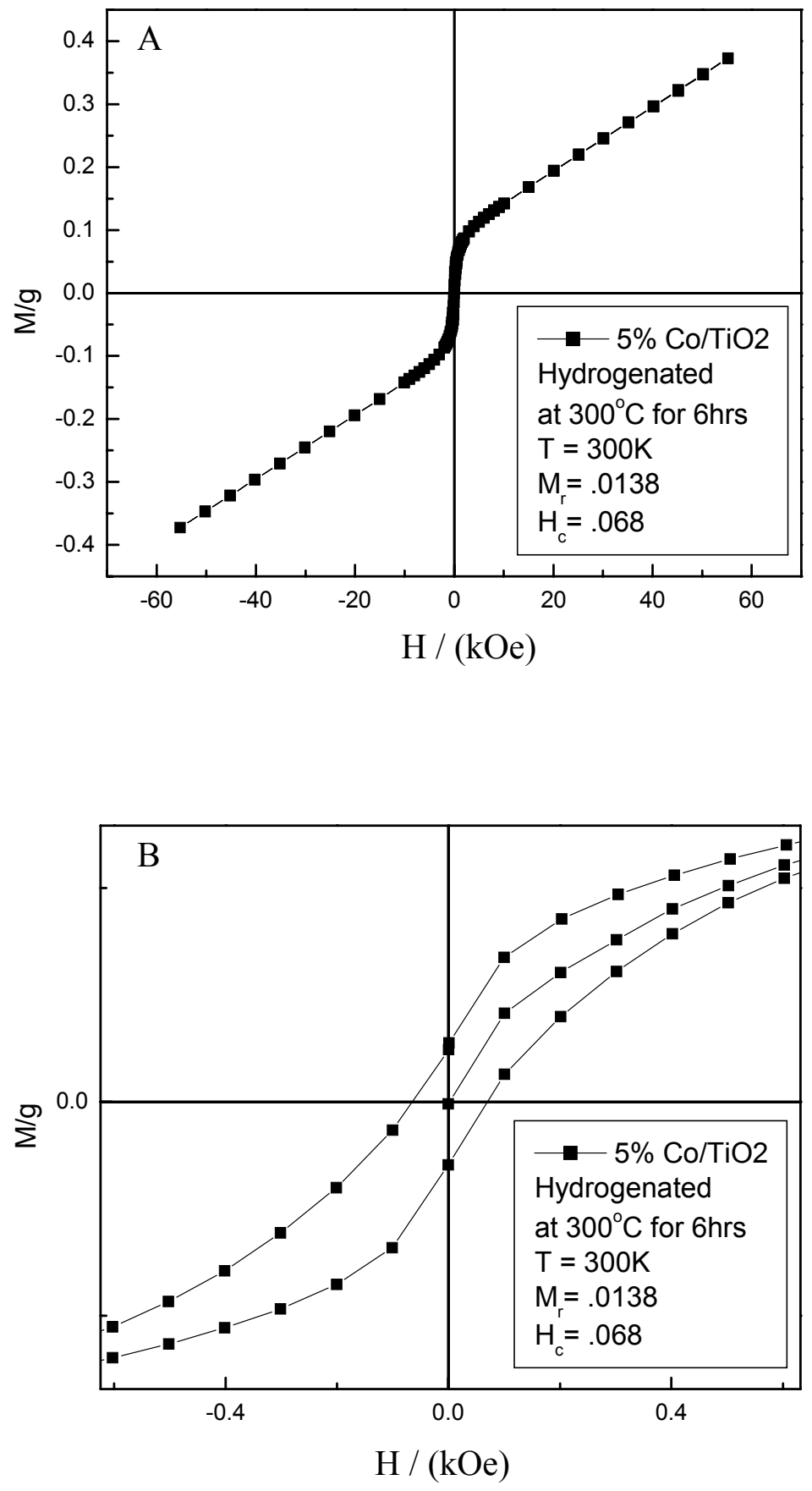

Figure 3-10. $\mathrm{M}$ vs $\mathrm{H}$ variation of $5 \% \mathrm{Co} / \mathrm{TiO}_{2}$ hydrogenated for 6 hours measured at 300 K. (A) and an expanded view (B). 


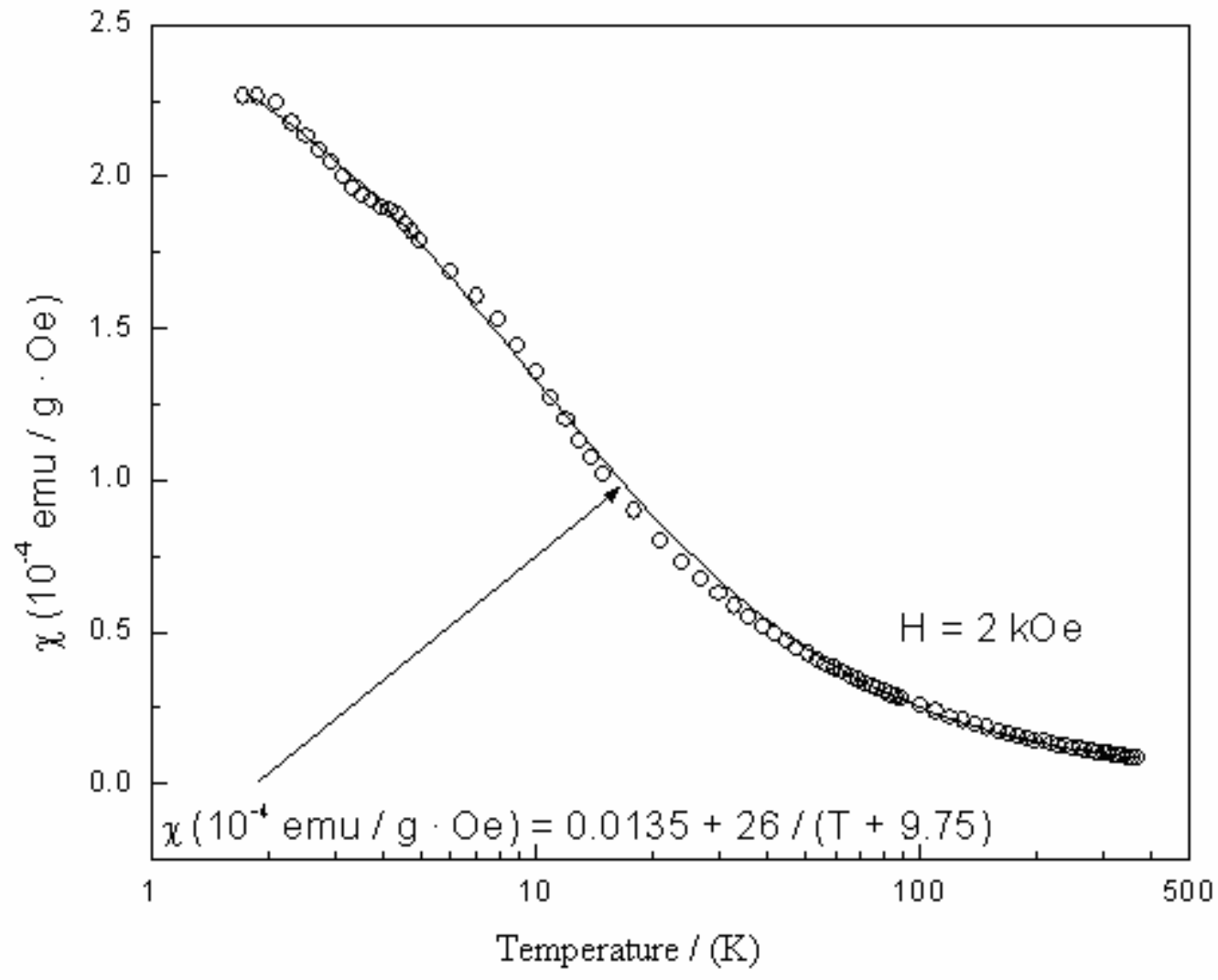

Figure 3-11. Temperature dependence of the magnetic susceptibility of the as-prepared sample of $10 \% \mathrm{Co} / \mathrm{TiO}_{2}$. The solid line is fit to the equation shown. 

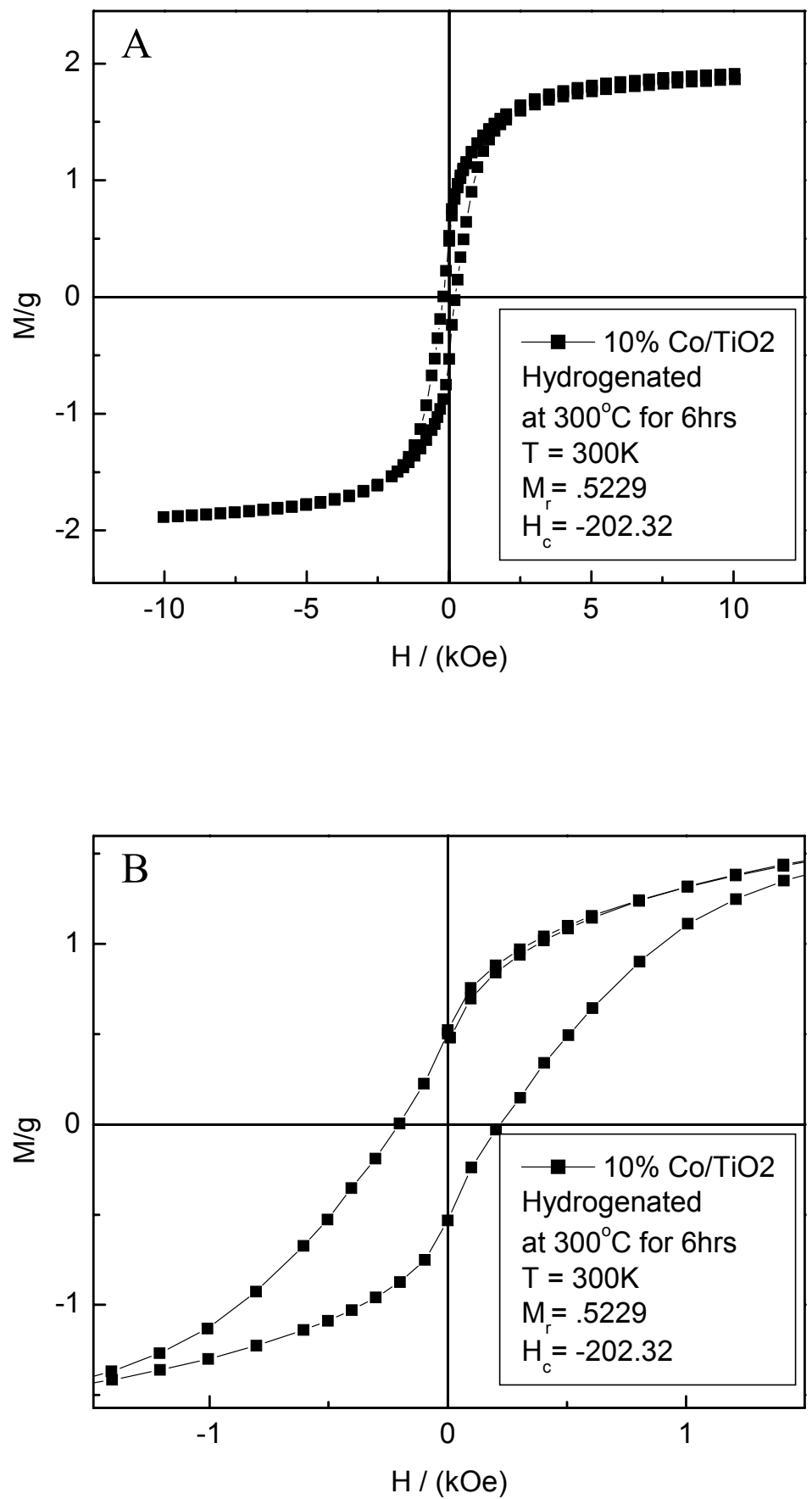

Figure 3-12. $\mathrm{M}$ vs $\mathrm{H}$ variation of $10 \% \mathrm{Co} / \mathrm{TiO}_{2}$ hydrogenated for 6 hours measured at $300 \mathrm{~K}$. (A) and an expanded view (B). 


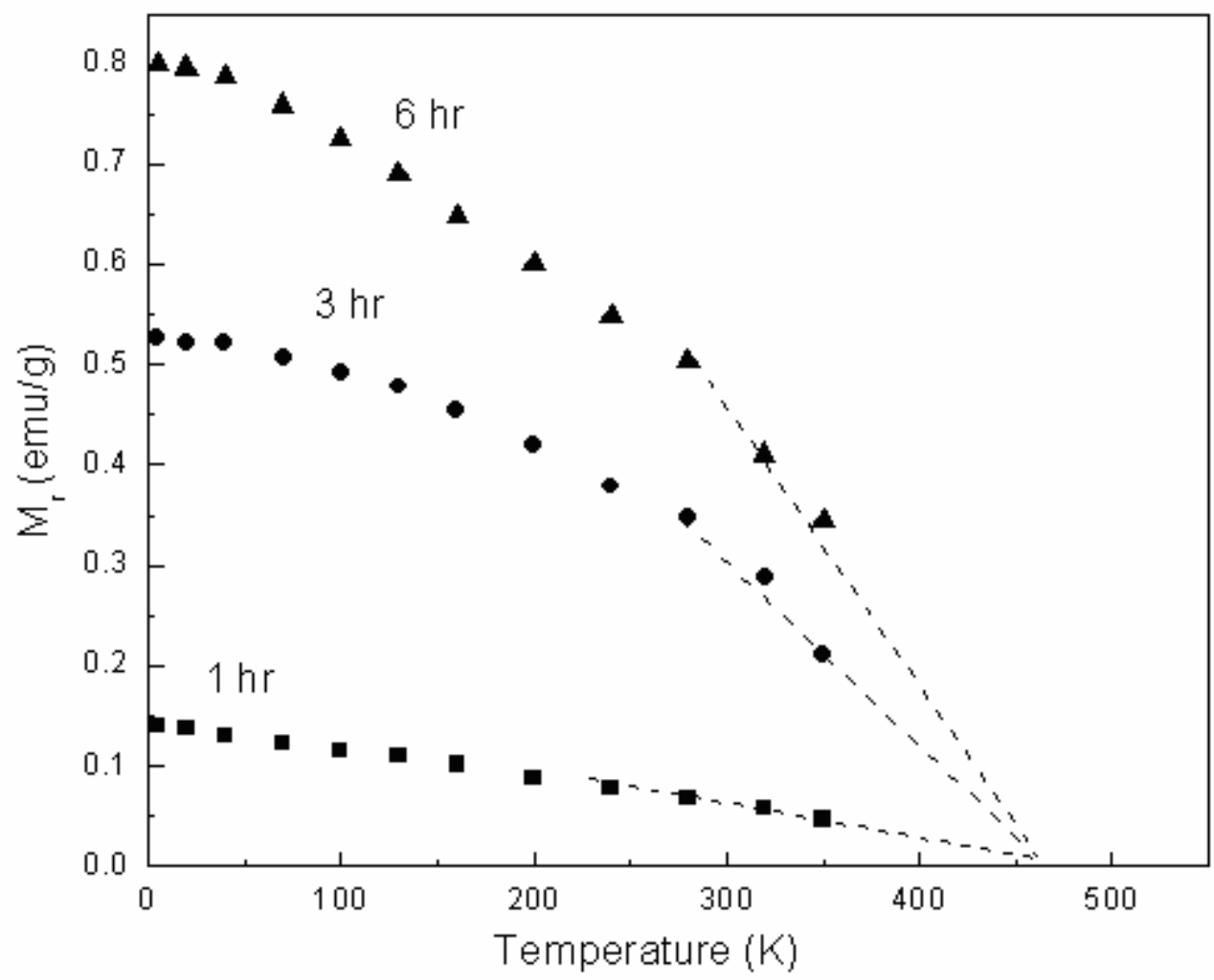

Figure 3-13. Temperature variation of the remanance $\left(\mathrm{M}_{\mathrm{r}}\right)$ of $10 \% \mathrm{Co} / \mathrm{TiO}_{2}$ hydrogenated for 1,3 and 6 hours at $573 \mathrm{~K}$. The dotted lines are extrapolations, indicating $\mathrm{T}_{\mathrm{c}} \simeq 470 \mathrm{~K}$ where $\mathrm{M}_{\mathrm{r}}$ goes to zero. 


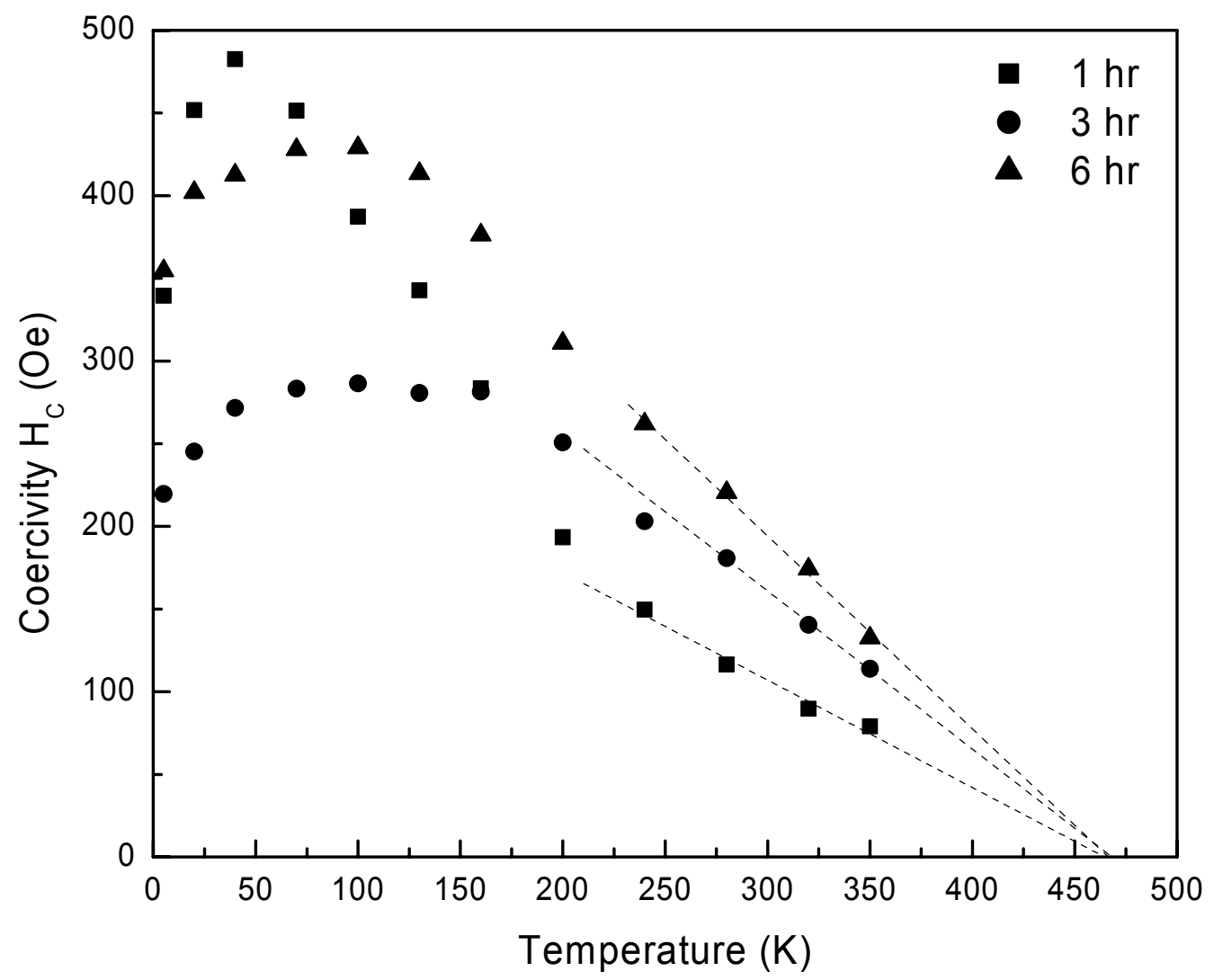

Figure 3-14. Temperature variation of the coercivity $\left(\mathrm{H}_{\mathrm{c}}\right)$ of $10 \% \mathrm{Co} / \mathrm{TiO}_{2}$ hydrogenated for 1,3 and 6 hrs. at $573 \mathrm{~K}$. The dotted lines are extrapolations, indicating $T_{c} \simeq 470 \mathrm{~K}$ where $\mathrm{M}_{\mathrm{r}}$ goes to zero. 


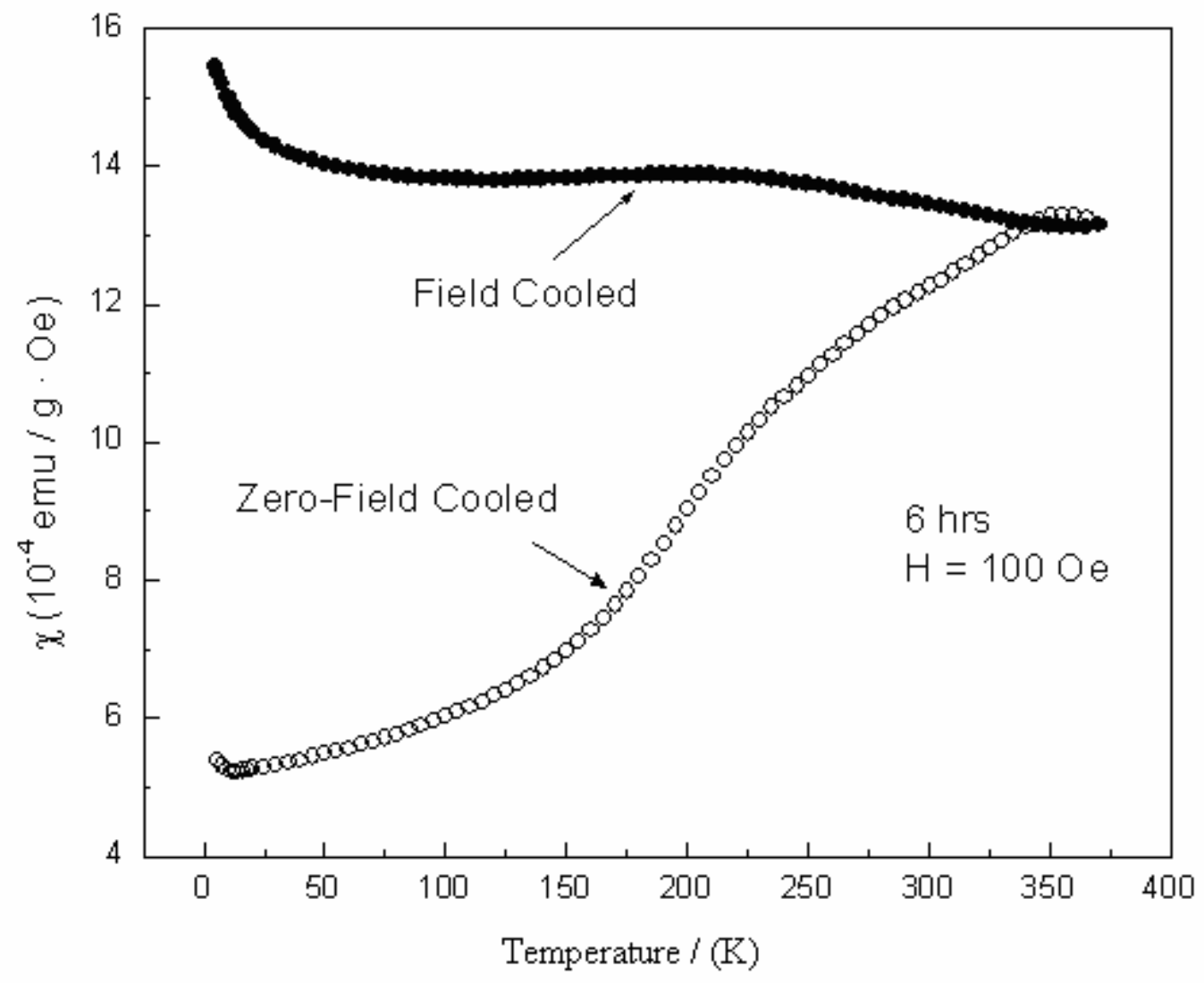

Figure 3-15. Temperature variation of the magnetic susceptibility $(\chi)$ the of $10 \% \mathrm{Co} / \mathrm{TiO}_{2}$ sample hydrogenated at $573 \mathrm{~K}$ for $6 \mathrm{hr}$. under zero-field-cooled and field-cooled conditions. 


\section{Chapter 4}

\section{Novel Sol-Gel Synthesis and Magnetic Studies of Titanium Dioxide Doped with $10 \% \mathrm{M}(\mathrm{M}=\mathrm{Fe}, \mathrm{Mn} \& \mathrm{Ni})$}

\subsection{Introduction}

Titanate nanoparticles have been extensively studied for applications in photocatalysis, optical coatings, and opto-electronic devices. ${ }^{1-7}$ The properties of the titinate nanoparticles can be tuned by adding dopants to the lattice. Experiments have shown that transition metal doped titanium dioxide can be produced in a variety of ways including pulse laser deposition, sputtering, molecular-beam epitaxy, and sol-gel techniques. Typically, sol-gel methods are employed since they offer the advantages of small particle size and high purity. ${ }^{8-11}$

Currently, room-temperature ferromagnetism (RTFM) in cobalt doped $\mathrm{TiO}_{2}$ has attracted significant attention since the cause of the RTFM is under debate. ${ }^{12-17}$ One explanation (as noted previously) is that undetected cobalt particles could readily account for the RTFM due to the high Curie temperature of bulk cobalt $(\mathrm{Tc}=1388$ K). ${ }^{18,19}$ Another possibility is that cobalt atoms substitute for titanium atoms and the exchange interaction between the substituted n-type carriers induces ferromagnetism. ${ }^{20,21}$ Lastly, ferromagnetism could be achieved by cobalt atoms occupying the interstitial positions in the lattice. $^{22}$

Recent reports have shown that $10 \% \mathrm{Co} / \mathrm{TiO}_{2}$ prepared by sol-gel synthesis is paramagnetic at room temperature with the magnetic suspectability following the CurieWeiss law. ${ }^{23,24}$ However, by controlled hydrogenation of this sample at $573 \mathrm{~K}$, the paramagnetic $10 \% \mathrm{Co} / \mathrm{TiO}_{2}$ is transformed to a ferromagnet with a Curie-temperature $\mathrm{T}_{\mathrm{c}}$ 
$\simeq 470 \mathrm{~K}$. This transformation occurs without any observable change in the crystal structure as revealed by x-ray diffraction. It has also been shown that increasing the time of hydrogenation from 1 to 6 hours increases the remanance. XPS and TEM studies of the hydrogenated sample failed to detect the presence of any cobalt nanoparticles.

That study has been extended to include other transition metals, namely Fe, Mn and $\mathrm{Ni}$ doped into $\mathrm{TiO}_{2}$. It has been suggested by Park and co-workers that when these metals dope into $\mathrm{TiO}_{2}$ the resulting material may be suitable for spintronic applications. $^{25,26}$ The present work focuses on the synthesis and characterization of various metal doped $\mathrm{TiO}_{2}$ nano-crystaline powder prepared by a simple sol-gel route.

\subsection{Experimental:}

Samples of $10 \% \mathrm{M}$ doped $\mathrm{TiO}_{2}$ (where $\mathrm{M}=\mathrm{Fe}, \mathrm{Mn}$ and $\mathrm{Ni}$ ) were prepared by mixing (reacting) appropriate amounts of titanium isopropoxide (Aldrich, Milwaukee, WI) and each metal nitrate (Aldrich) in ethanol. The solution was dried in an oven at $353 \mathrm{~K}$ and the resultant powder was placed into a furnace at 723,743 , and $723 \mathrm{~K}$ for $\mathrm{Fe}$, $\mathrm{Mn}$, and $\mathrm{Ni}$, respectively, for $5 \mathrm{~min}$. Parts of these powders were used for magnetic measurements and the remaining used for 3 and 6 hour hydrogenations carried out at 573 K. The hydrogen reduction set-up was described in Chapter 3.

X-ray diffraction (XRD) patterns of the powder sample were measured at room temperature with a Rigaku Diffractometer (DMAX-B) and $\mathrm{CuK}_{\alpha}$ radiation $(\lambda=1.5418$ $\AA$ ). The samples were mounted on a silicon plate for X-ray measurements. Temperature and magnetic field variations of the magnetization $(\mathrm{M})$ of the samples were measured using a commercial SQUID magnetometer (Quantum Design). 


\subsection{Results and Discussion:}

X-ray diffraction (XRD) of the powders confirm the anatase form of $\mathrm{TiO}_{2}$, with only a trace amount of the rutile and/or brookite phases in the as-prepared samples as shown in Figures 4-1 (A), 4-2 (A) and 4-3 (A). This is significant since other methods of producing samples of similar percentages of dopant do not show a single phase of $\mathrm{TiO}_{2}$. Optimization of the temperature used for calcination is critical since deviations from the above stated temperatures resulted in the appearance of either amorphous (lower temperatures) or rutile (higher tempatures) phases. From the widths of the XRD lines, the average particle size of the anatase phase is $10 \pm 2 \mathrm{~nm}$ without any major changes upon hydrogenation.

The results of the hydrogenation are shown in Figure 4-1 (B, C), 4-2 (B, C), and 4-3 (B,C). Figure 4-1 illustrates that $\mathrm{Fe}$ is doped into the $\mathrm{TiO}_{2}$ lattice upon calcination and remains doped within the lattice after hydrogenation. Figure 4-2 shows that $\mathrm{Mn}$ is doped within the lattice when hydrogenated for 3 hours, but that $\mathrm{MnO}_{2}$ is present after hydrogenating for 6 hours. Figure 4-3 shows that metallic Ni is detected after hydrogenation in both the 3 and 6 hour samples. Alteration of the temperature and duration of hydrogenation has yet to produce a single phase.

The temperature variation of $\chi$ for the as-prepared $10 \% \mathrm{M} / \mathrm{TiO}_{2}$ (prior to hydrogenation) is shown in Figures 4-4, 4-5, and 4-6 where the solid line is the fit to the Curie-Weiss Law. From the Curie-constant, as previously described in Chapter 3, $\mu$ values for the as-prepared $10 \% \mathrm{Fe}, \mathrm{Mn}$ and $\mathrm{Ni}$ (prior to hydrogenation) are shown in Table 4-1. 
A previous report has shown that $10 \% \quad \mathrm{Co} / \mathrm{TiO}_{2}$ acquires $\mathrm{RTFM}$ after hydrogenation at $573 \mathrm{~K}$. This was confirmed by measuring $\chi$ vs. T for the $6 \mathrm{hr}$ sample under zero-field-cooled (ZFC) and field-cooled (FC) conditions. The absence of a peak in $\chi$ for the ZFC cases, which is a signature of the blocking temperature $\left(T_{B}\right)$ for cobalt as reported recently for the thin films of $\mathrm{Co} / \mathrm{TiO}_{2}$ prepared by sputtering ${ }^{15}$, provides additional support for the absence of cobalt nanoparticles in our samples.

Hydrogenation of $10 \% \mathrm{Ni} / \mathrm{TiO}_{2}$ resulted in the presence of metallic nickel in the XRD pattern. The presence of metallic nickel was also confirmed by measuring $\chi$ vs. T under ZFC conditions. It is evident in Figure 4-7 that the ZFC condition displays a blocking temperature of $21 \mathrm{~K}$ indicative of metallic nickel. However, metallic peaks were not present in the iron and manganese samples after hydrogenation. The results of measuring $\chi$ vs. $\mathrm{T}$ can be summarized as follows. While the XRD patterns of hydrogenated $10 \%$ manganese confirmed that metallic manganese was not present in the 3 hour hydrogenated sample, $\chi$ vs. T measurements showed only paramagnetic behavior similar to the as-prepared sample. The data was fit to the Curie-Weiss Law and the calculated $\mu=2.9 \mu_{\mathrm{B}}$ for the 3 hour hydrongenated sample shows little deviation from the as-prepared samples. The $\chi$ vs. T measurements for the 6 hour hydrogenated sample exhibited significantly higher $\chi$ values and did not display Curie-Weiss behavior (Figure 4-8). The $M$ vs $H$ data indicates room temperature ferromagnetism which may arise from the presence of $\mathrm{MnO}_{2}$ as observed in the XRD pattern (Figure 4-9). The magnetic moment calculated for $10 \% \mathrm{Fe} / \mathrm{TiO}_{2}$ hydrogenated for 3 hours was $4.0 \mu_{\mathrm{B}}$, also comparable to the as-prepared sample. Conversely, $\chi$ vs. $\mathrm{T}$ measured for $10 \% \mathrm{Fe} / \mathrm{TiO}_{2}$ hydrogenated for 6 hours resulted in ferromagnetic behavior as shown in Figure 4-10. 
The absence of a peak in $\chi$ for the ZFC case, signature for the blocking temperature $\left(T_{B}\right)$ for iron, confirms that iron is doped into the lattice. It has been reported that the $T_{B}$ values of iron nanoparticles of different sizes are $\mathrm{T}_{\mathrm{B}} \approx 230 \mathrm{~K}(5 \mathrm{~nm}), \mathrm{T}_{\mathrm{B}} \approx 150 \mathrm{~K}(4 \mathrm{~nm})$ and $\mathrm{T}_{\mathrm{B}} \approx 120 \mathrm{~K}(3 \mathrm{~nm}){ }^{26}$ Figure $4-11$ shows $M$ vs $H$ for the $10 \% \mathrm{Fe} / \mathrm{TiO}_{2}$ sample. The hysteresis loop observed at room temperature is indicative of ferromagnetism. The values of $\mathrm{M}_{\mathrm{r}}$ and $\mathrm{H}_{\mathrm{c}}$ were found to be $.054(\mathrm{emu} / \mathrm{g}$ ) and -301.7 (Oe) respectively.

\subsection{Conclusion}

In summary, we have reported the $10 \% \mathrm{M}$-doped $\mathrm{TiO}_{2}$ powders successfully prepared via sol-gel synthesis and controlled calcinations. XRD for $\mathrm{M}$-doped $\mathrm{TiO}_{2}$ indicate the formation of single phase without any impurities which are paramagnetic. It has been suggested that oxygen vacancies are essential to provide the exchange coupling between the doped ions thus leading to intrinsic RTFM ${ }^{27}$ As stated in Chapter 3, we have shown that hydrogen reduction is necessary to convert the magnetic nature of $10 \%$ $\mathrm{Co} / \mathrm{TiO}_{2}$ from paramagnetic to ferromagnetic. This transformation may be due to hydrogen extracting oxygen from the sample thus producing oxygen vacancies. The generation of oxygen vacancies via hydrogenation may explain the conversion of the paramagnetic behavior for $10 \% \mathrm{Fe} / \mathrm{TiO}_{2}$ to RTFM. 


\subsection{References}

(1) Hoffmann, M. R; Martin, M. T; Choi, W; Bahnemann, D. W. Chem. Rev. (1995), $95,69$.

(2) Nishide, T; Mizukami, F. Thin Solid Films (1999), 353, 67.

(3) Gonzales, R. J; Zallen, R. In: M.F. Thorpe and M.I. Mitkova, Editors, NATOASI. Proceedings, Amorphous Insulators and Semiconductors, Kluwer, Dordrecht (1997).

(4) Plenet, J. C; Brionde, A; Bernstein, E; Lequevre, F; Dumas, J; Mugnier, J. Opt. Mater. (2000), 13, 411.

(5) Shen, Y. C; Deng, H; Fang, J. H; Lu, Z. Colloids Surf., A (2000), 175, 135.

(6) Zhou, Y; Wang, C. Y; Liu, H. J; Zhu, Y. R; Chen, Z Y. Mater. Sci. Eng., B (1999), 67, 95.

(7) Gurunathan K; Trivedi D. C. Mater. Lett. (2000), 45, 262.

(8) Li, X; Yue, P; Kutal, C. New J. Chem. (2003), 27, 1264.

(9) Wang, C; Bottcher, C; Bahnemann, D; Dohrmann, J. K. J. Mater. Chem. (2003), $13,2322$.

(10) Gratzel, M; Howe, R. J. Phys. Chem. (1990), 94, 2566.

(11) Wang, J; Limas-Ballestros, R; Lopez, T; Moreno, A; Gomez, R; Novaro, O; Bokhimi, X. J. Phys. Chem. B (2001), 105, 9692.

(12) Matsumoto, Y; Takahashi, R; Murakami, M; Koida, T; Fan, X. J; Hasegawa, T;

Fukumura, T; Kawasaki, M; Koshihara, S. Y; Koinuma, H. Jpn. J. Appl. Phys., Part 2 (2001), 40, L1205.

(13) Park, W. K; Ortega-Hertogs, R. J; Moodera, J; Punnoose, A; and Seehra, M. S. J. Appl. Phys. (2002), 91, 8093.

(14) Stampe, P. A; Kennedy, R. J; Xin, Y; Parker, J. S. J. Appl. Phys. (2003), 93, 7864.

(15) Punnoose, A; Seehra, M. S; Park, W. K; Moodera, J. S. J. Appl. Phys. (2003), 93, 7867. 
(16) Kim, D. H; Yang, J. S; Lee, K. W; Bu, S. D; Kim, D. W; Noh, T. W; Oh, S. J; Kim, Y. W; Chung, J. S; Tanaka, H; Lee, H. Y; Kawai, T; Won, J. Y; Park, S. H; and Lee, J. C. J. Appl. Phys., (2003), 93, 6125.

(17) Rameev, B. Z; Yildiz, F; Tagirov, L. R; Aktas, B; Park, W. K; Moodera, J. S. J. Mag. Mag. Mater. (2003), 258-259, 361.

(18) Kim, D. H. Appl. Phys. Lett. (2002), 81, 2421.

(19) Kim, J. Y. Phys. Rev. Lett. (2003), 90, 017401.

(20) Matsumoto, Y; Murakami, M; Shono, T; Hasegawa, T; Fukumura, Kawasaki, T. M; Ahmet, P; Chikyow, T; Koshihara S; Koinuma, H. Science (2001), 291, 854.

(21) Chambers, S. A; Thevuthasan, S; Farrow, R. F. C; Marks, R. F; Thiele, J. W; Folks, L; Samant, M. G; Kellock, A. J; Ruzycki, N; Ederer, D. L; Diebold, U. Appl. Phys. Lett. (2001), 79, 3467.

(22) Simpson, J. R; cond-mat/0205626 (unpublished).

(23) Manivannan, A; Seehra, M. S; Majumder, S. B; Katiyar, R. S. Appl. Phys. Lett. (2003), 83, 111.

(24) Manivannan, A; Glaspell, G; Seehra, M. S. J. Appl. Phys., (2003), 94, 6994.

(25) Park, M. S; Min, B. I. Phys. Rev. B (2003), 68, 033202.

(26) Gangopadhyay, S; Hadjipanayis, G. C; Dale, B; Sorensen, C. M; Klabunde, K. J; Papaefthymiou, V; Kostikas, A. Phys Rev. B. (1992), 45(17) 9778-87.

(27) Park, M. S; Kwon, S. K; Min, B. I. Phys. Rev. B (2002), 65, 161201-1. 


\begin{tabular}{|c|c|c|}
\hline Sample & $\mathrm{C} /(\mathbf{e m u}-\mathrm{K} / \mathbf{g} / \mathbf{O e})$ & $\mu / \mu_{\mathbf{B}}$ \\
\hline $\mathbf{1 0} \% \mathbf{C o} / \mathbf{T i O}_{2}$ & $2.6^{*} 10^{-3}$ & 4.1 \\
\hline $\mathbf{1 0} \% \mathbf{~ F e} / \mathbf{T i O}_{2}$ & $2.0^{*} 10^{-3}$ & 3.6 \\
\hline $\mathbf{1 0} \% \mathbf{M n} / \mathbf{T i O}_{\mathbf{2}}$ & $1.0^{*} 10^{-3}$ & 2.5 \\
\hline $\mathbf{1 0} \% \mathbf{~ N i} / \mathbf{T i O}_{2}$ & $1.6 * 10^{-3}$ & 3.2 \\
\hline
\end{tabular}

Table 4-1. Magnetic moments calculated from the Curie-constants for transition metal doped $\mathrm{TiO}_{2}$. 

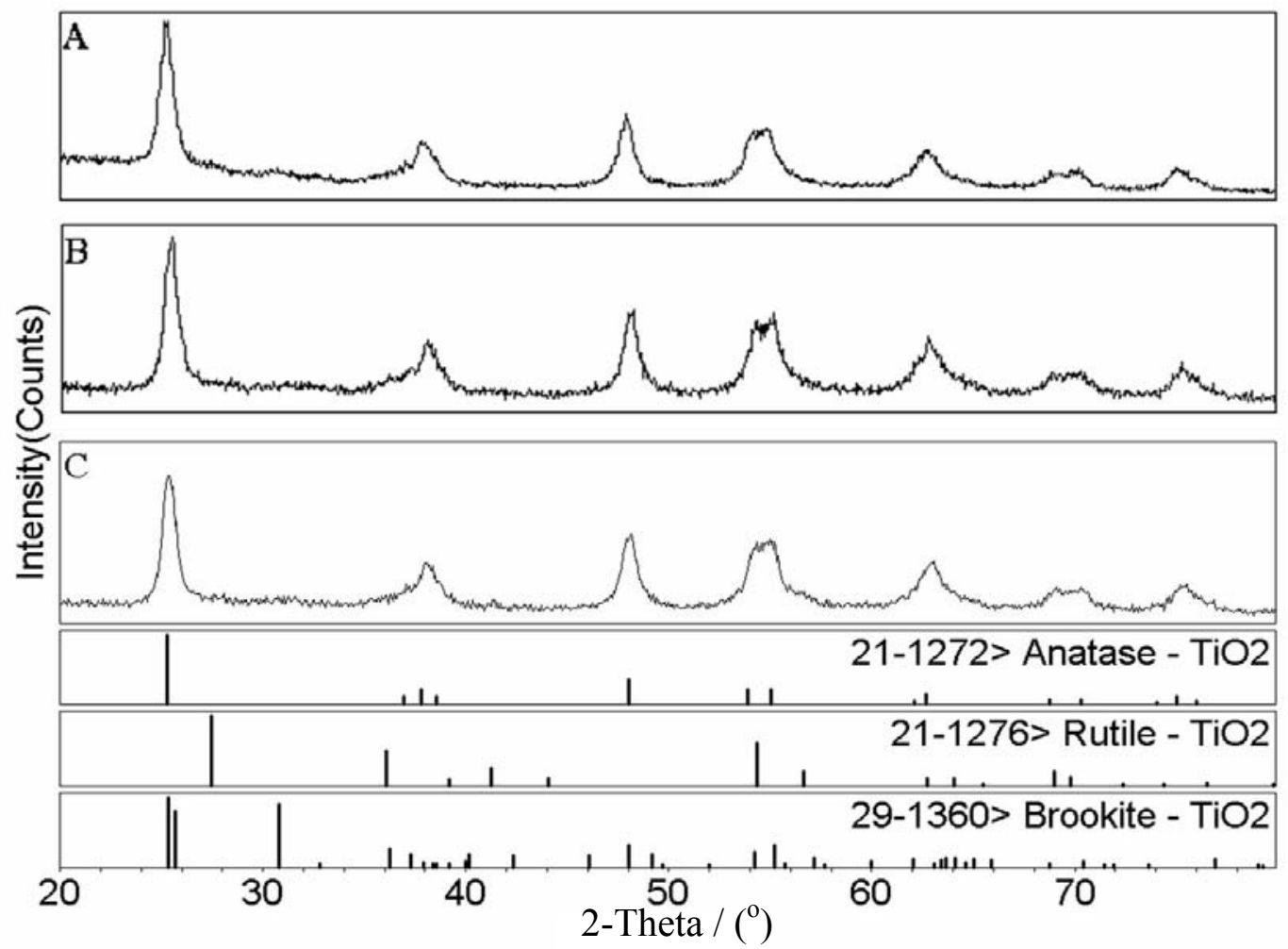

Figure 4-1. XRD pattern showing $10 \% \mathrm{Fe} / \mathrm{TiO}_{2}$ as-prepared (A) and hydrogenated for $3 \mathrm{hr}$ (B) and $6 \mathrm{hr}(\mathrm{C})$. The expected line positions for the anatase, rutile, and brookite phases are shown. 

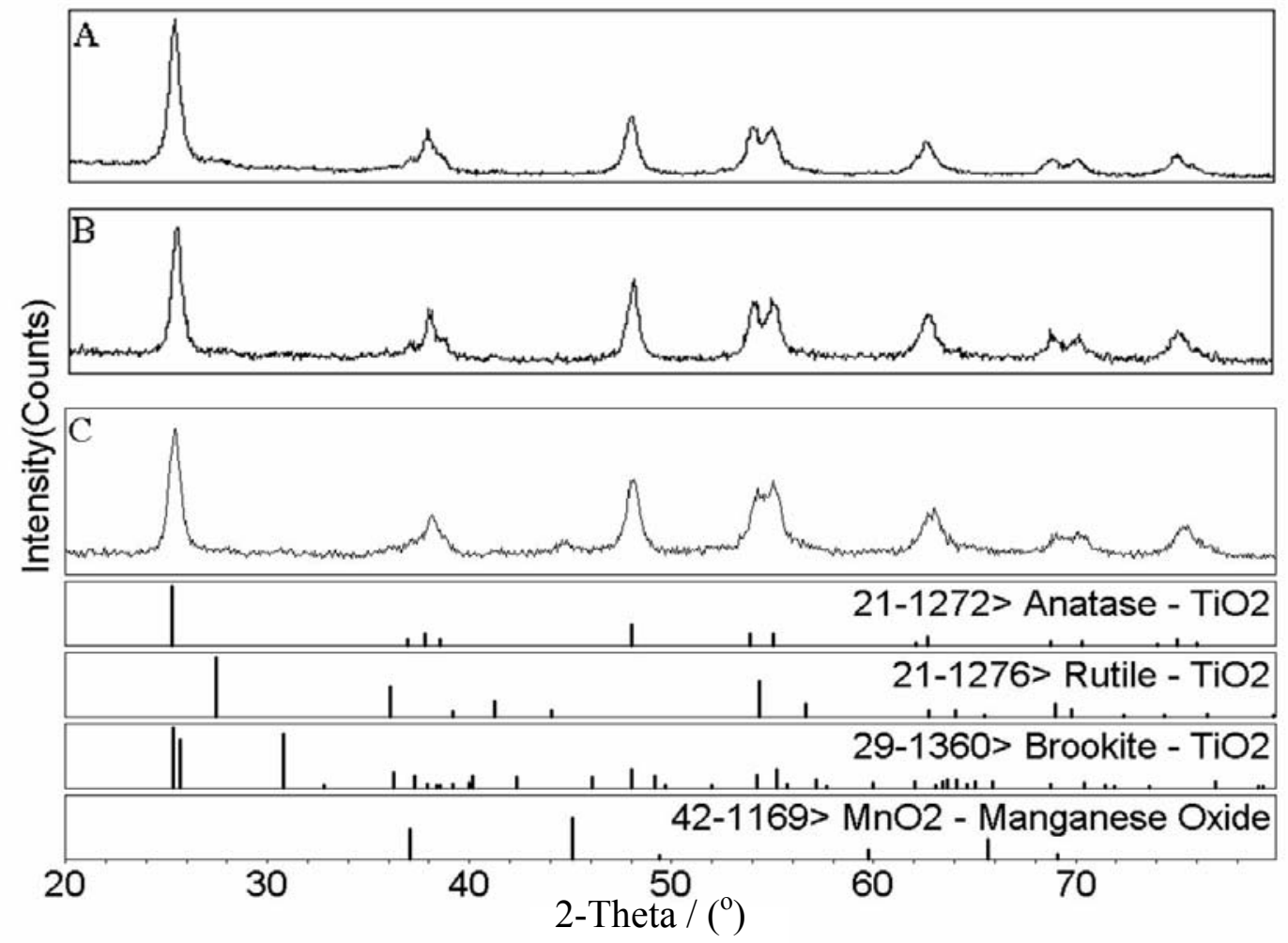

Figure 4-2. XRD pattern showing $10 \% \mathrm{Mn} / \mathrm{TiO}_{2}$ as-prepared (A) and hydrogenated for $3 \mathrm{hr}(\mathrm{B})$ and $6 \mathrm{hr}(\mathrm{C})$. The expected line positions for the anatase, rutile, brookite, and manganese oxide phases are shown. 

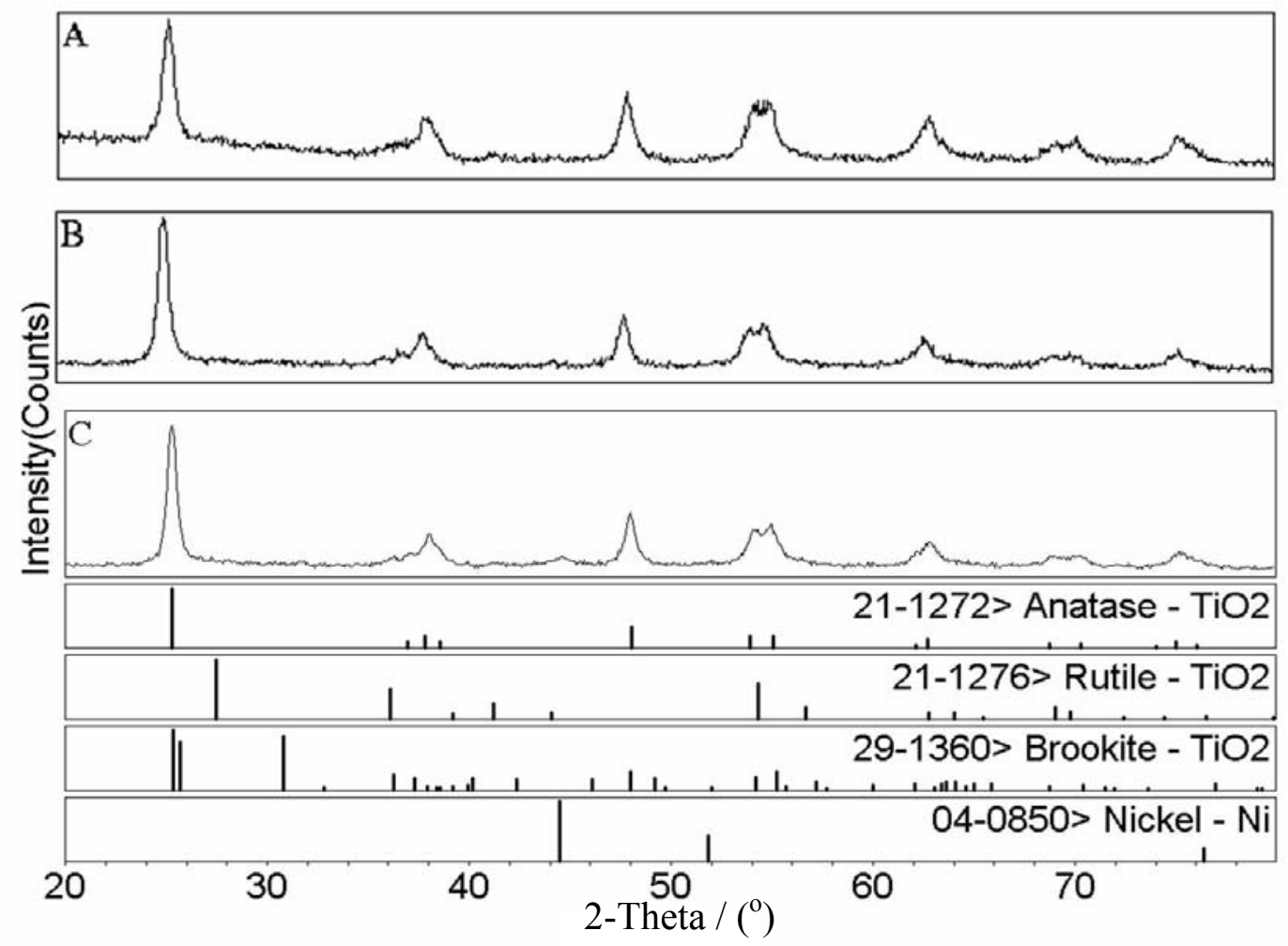

Figure 4-3. XRD pattern showing $10 \% \mathrm{Ni} / \mathrm{TiO}_{2}$ as-prepared (A) and hydrogenated for $2 \mathrm{hr}$ (B) and $6 \mathrm{hr}(\mathrm{C})$. The expected line positions for the anatase, rutile, brookite, and nickel phases are shown. 


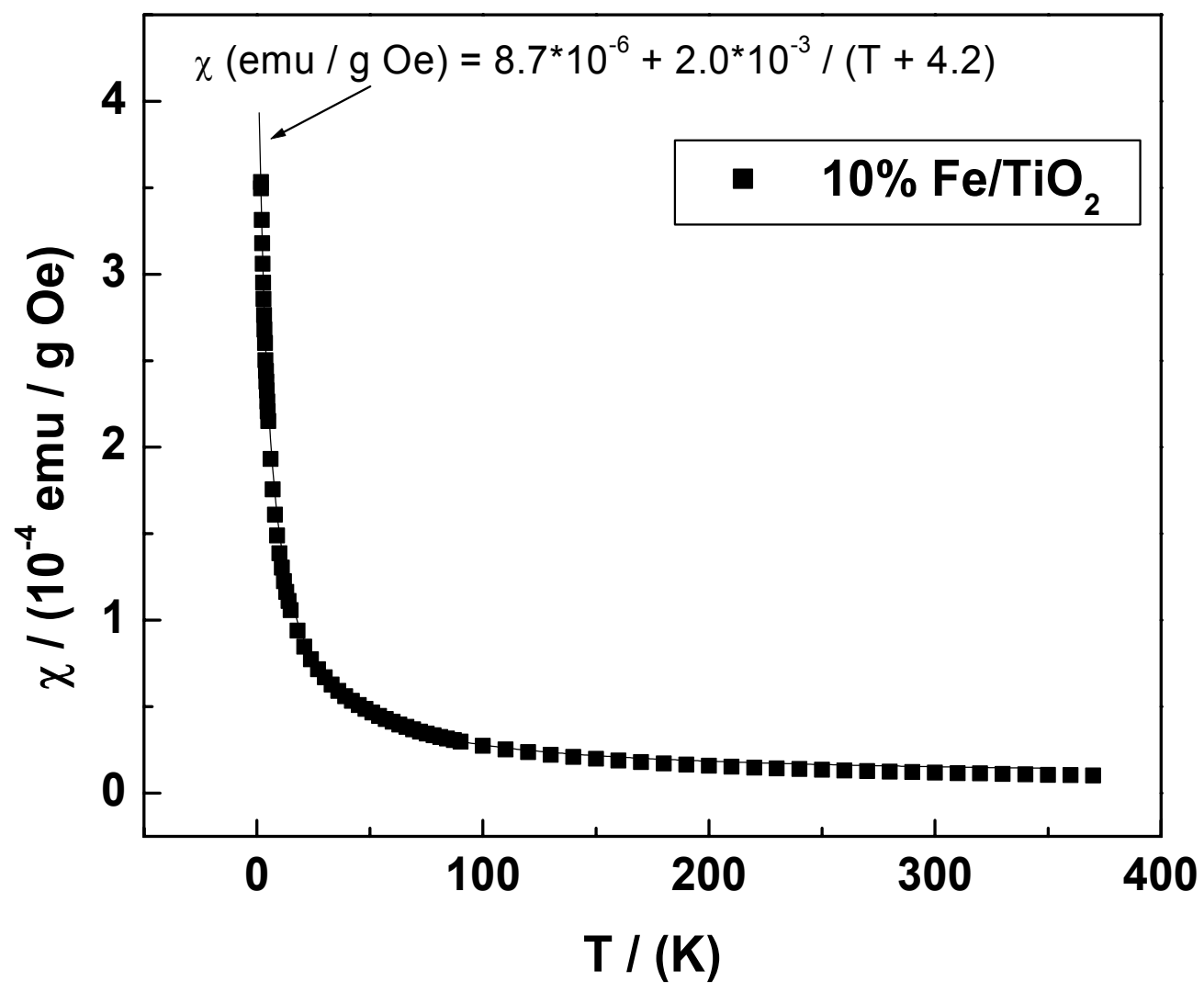

Figure 4-4. Temperature dependence of the magnetic susceptibility $(\chi)$ of the as-prepared $10 \% \mathrm{Fe} / \mathrm{TiO}_{2}$. The solid line is fit to the equation shown. 


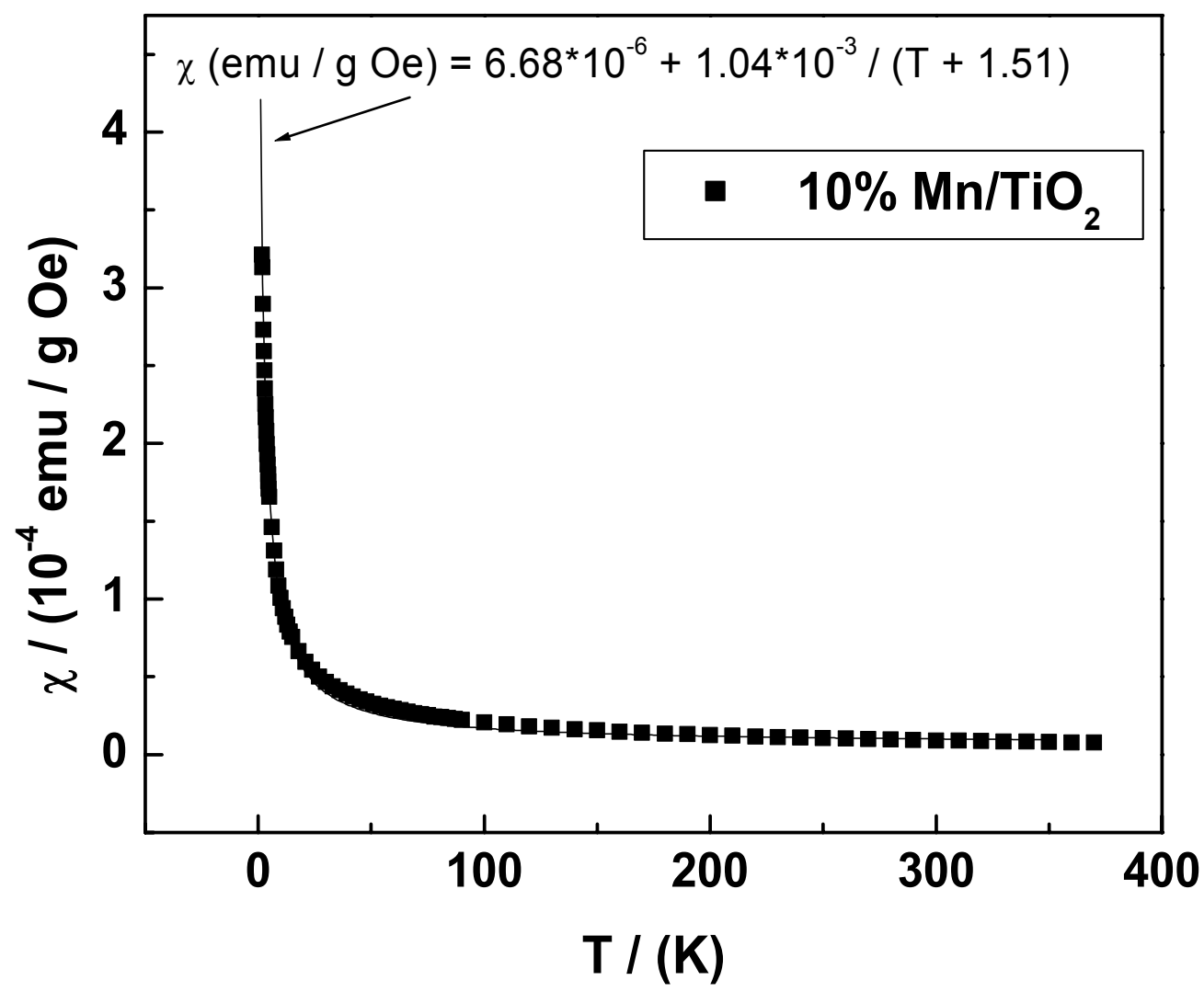

Figure 4-5. Temperature dependence of the magnetic susceptibility $(\chi)$ of the as-prepared $10 \% \mathrm{Mn} / \mathrm{TiO}_{2}$. The solid line is fit to the equation shown. 


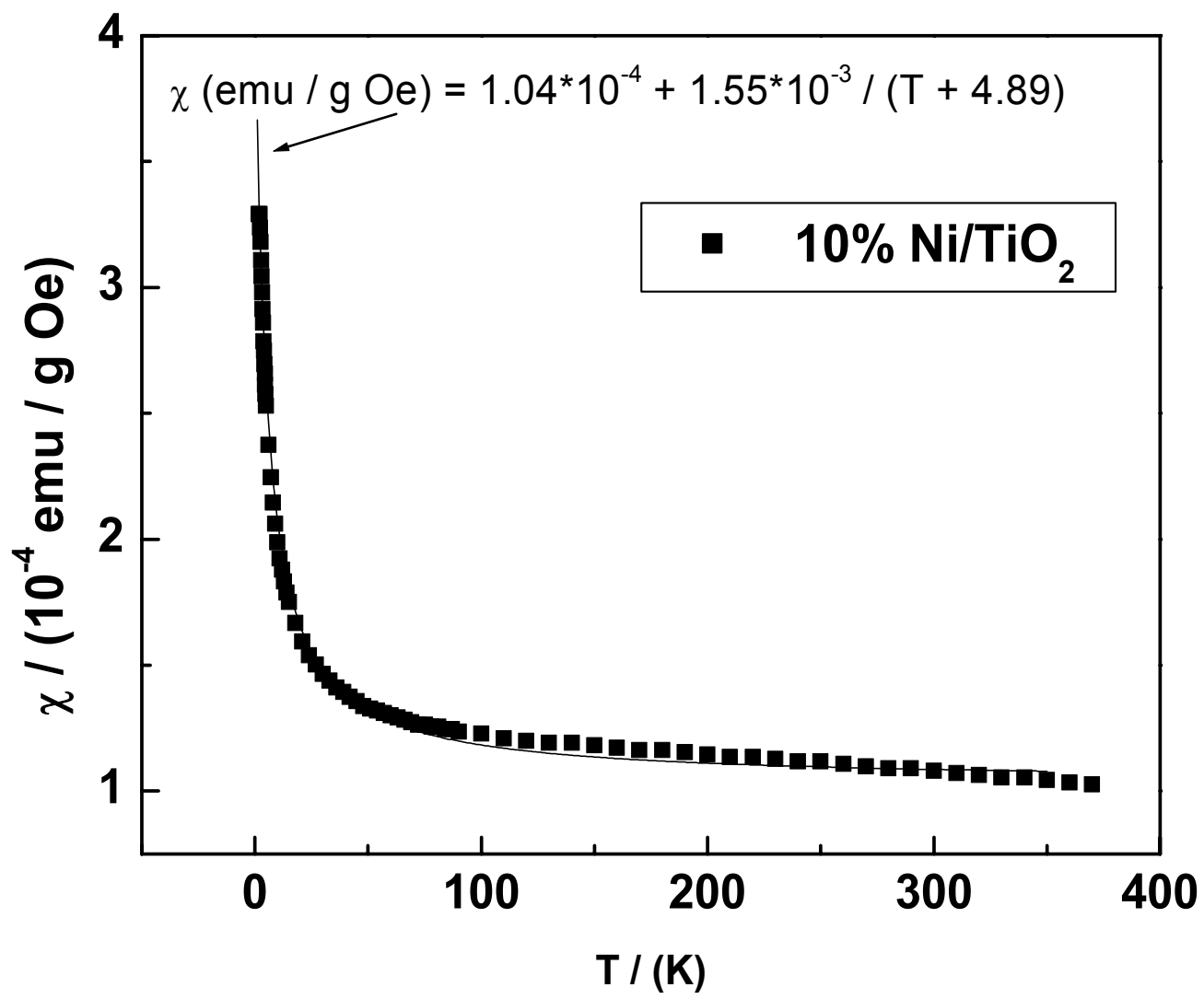

Figure 4-6. Temperature dependence of the magnetic susceptibility $(\chi)$ of the as-prepared $10 \% \mathrm{Ni} / \mathrm{TiO}_{2}$. The solid line is fit to the equation shown. 


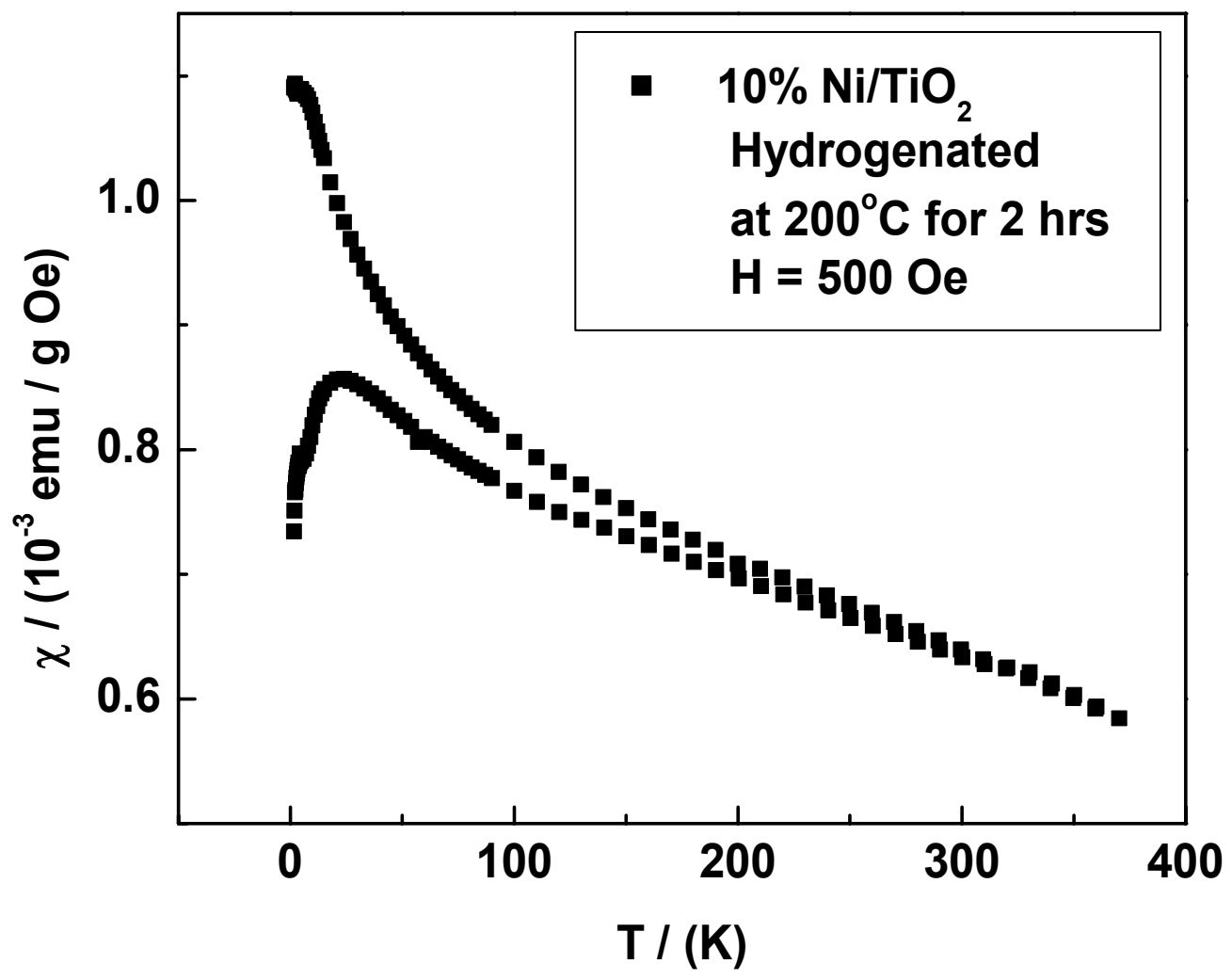

Figure 4-7. Temperature dependence of the magnetic susceptibility $(\chi)$ of the as-prepared $10 \% \mathrm{Ni} / \mathrm{TiO}_{2}$ hydrogenated for 2 hours under zero-field-cooled and field-cooled conditions. 


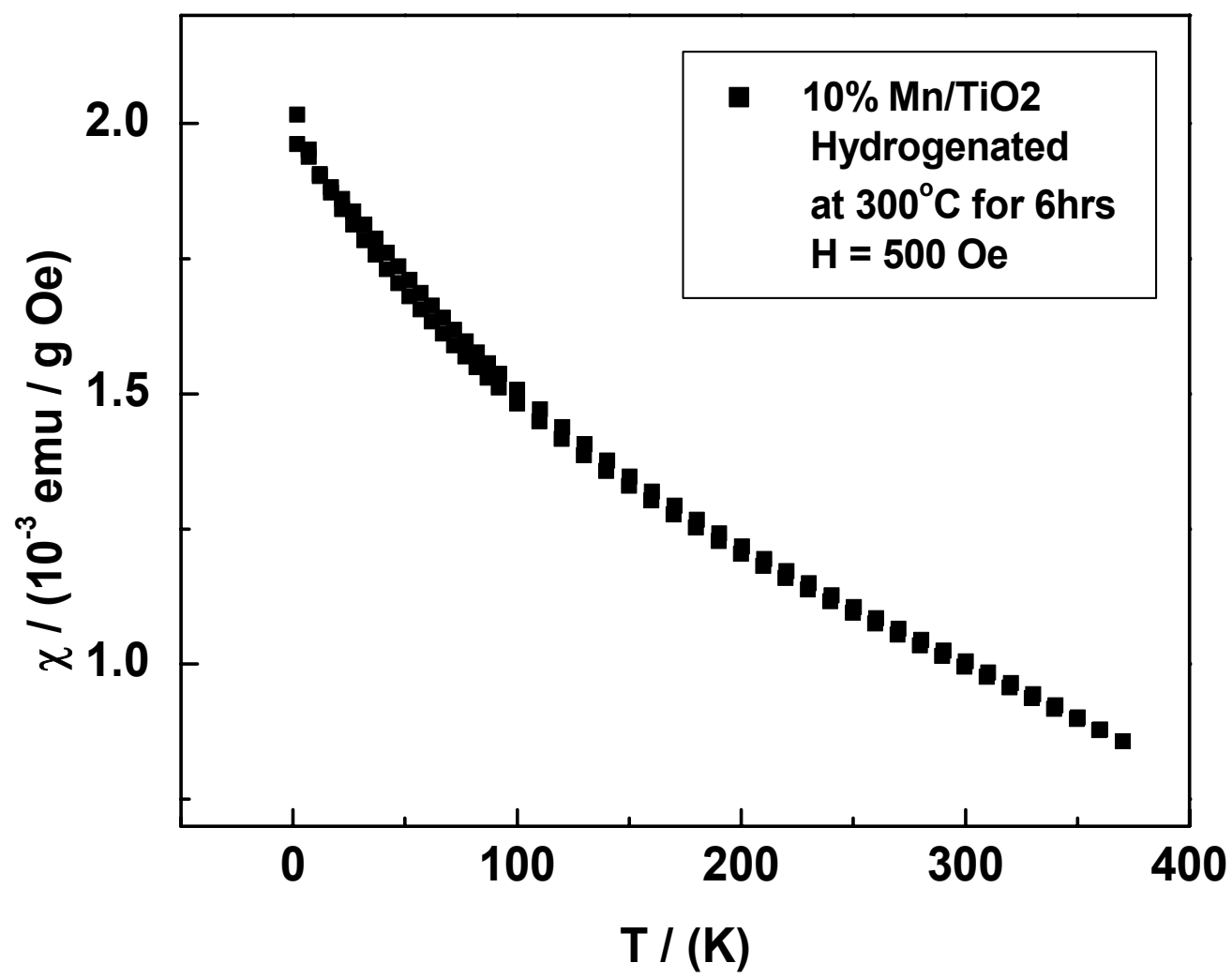

Figure 4-8. Temperature dependence of the magnetic susceptibility $(\chi)$ of the as-prepared $10 \% \mathrm{Mn} / \mathrm{TiO}_{2}$ hydrogenated for 6 hours under zero-field-cooled and field-cooled conditions. 

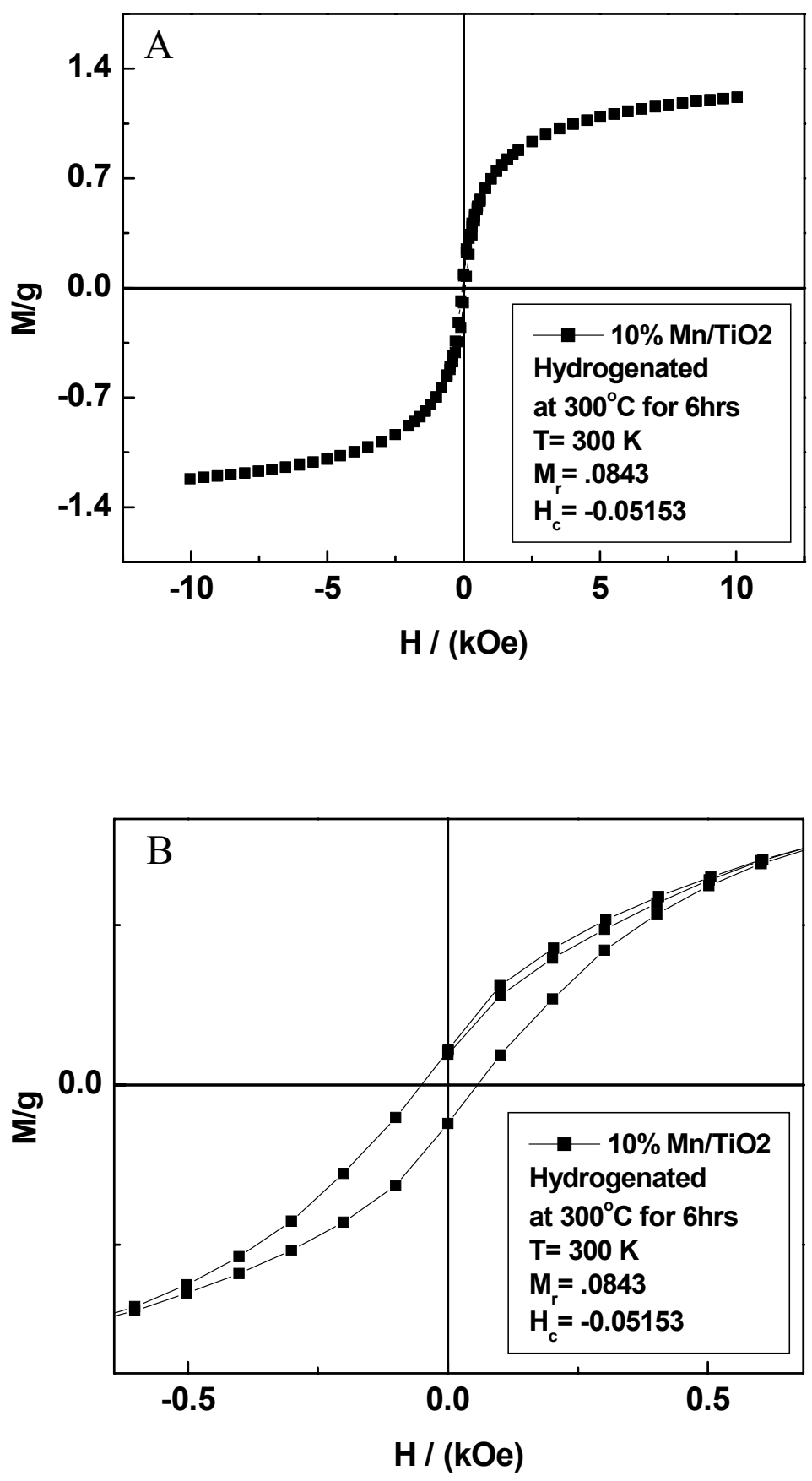

Figure 4-9. $\mathrm{M}$ vs $\mathrm{H}$ variation of $10 \% \mathrm{Mn} / \mathrm{TiO}_{2}$ at $300 \mathrm{~K}$ (A) and an expanded view (B). 


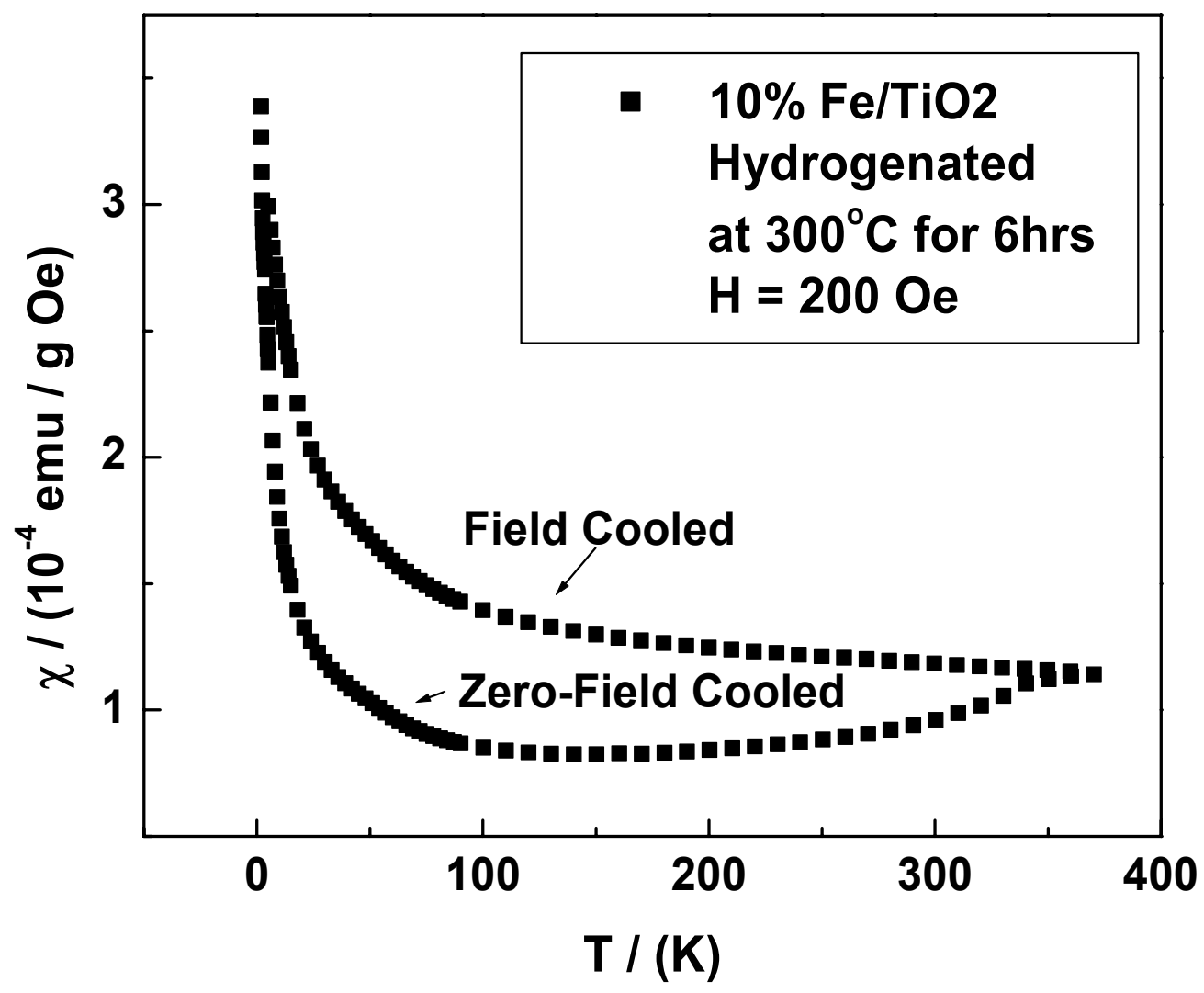

Figure 4-10. Temperature variation of the magnetic susceptibility $(\chi)$ of $10 \% \mathrm{Fe} / \mathrm{TiO}_{2}$ hydrogenated for 6 hours under zero-field-cooled and field-cooled conditions. 

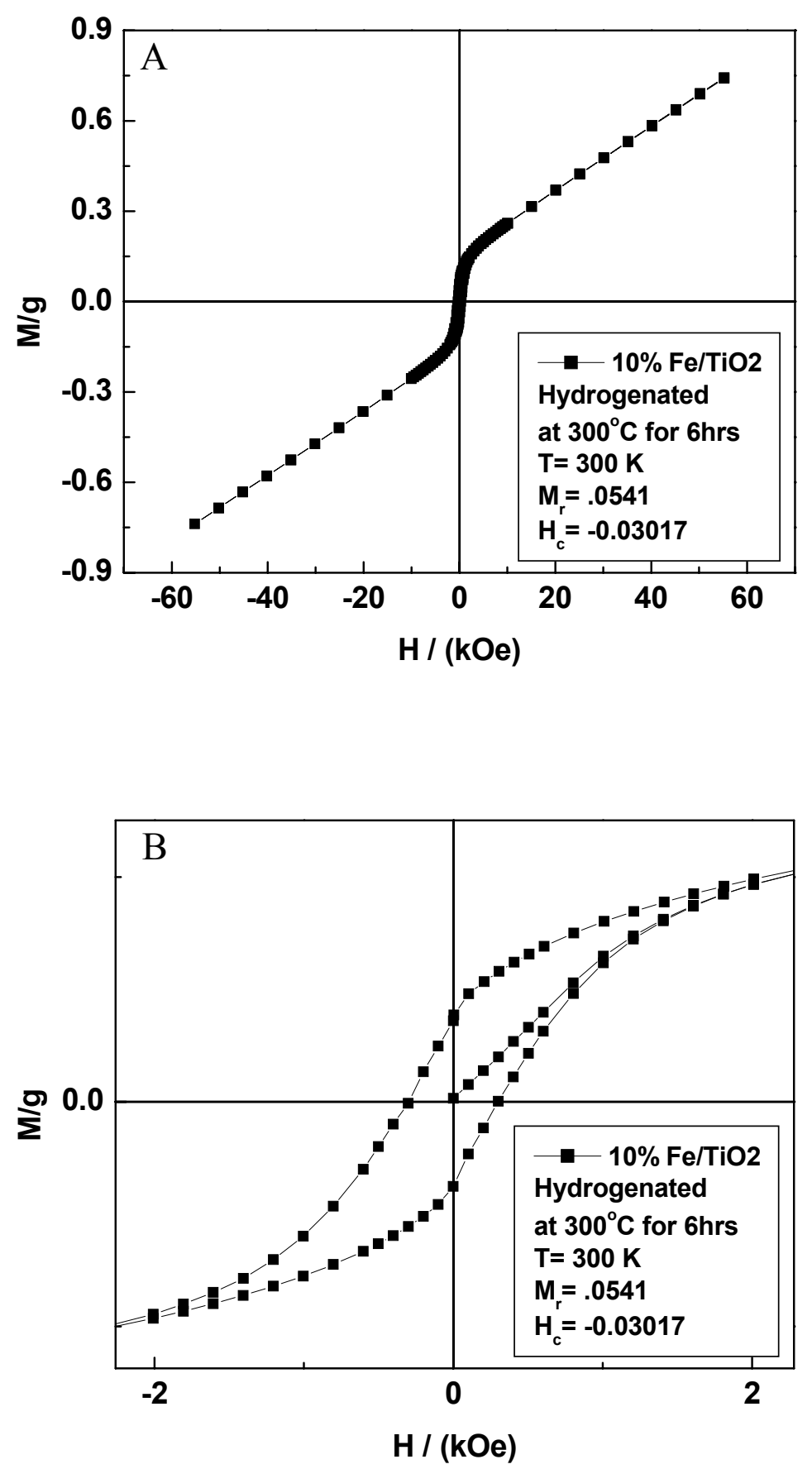

Figure 4-11. $\mathrm{M}$ vs $\mathrm{H}$ variation of $10 \% \mathrm{Fe} / \mathrm{TiO}_{2}$ at $300 \mathrm{~K}(\mathrm{~A})$ and an expanded view (B). 


\section{Chapter 5}

\section{Novel Room-Temperature Syntheis and Characterization of M-Doped \\ $\mathrm{ZnO}(\mathrm{M}=\mathrm{Co}, \mathrm{Cr}, \mathrm{Fe}, \mathrm{Mn} \& \mathrm{Ni})$}

\subsection{Introduction}

In the last decade, zinc oxide $(\mathrm{ZnO})$ has been utilized in a wide range of applications such as catalysis, optical materials, functional devices, cosmetics and UV-

absorbers. ${ }^{1-3}$ Recently, there has been a great deal of interest in cobalt-doped $\mathrm{ZnO}$ for possible applications in spintronics. ${ }^{4-11}$ A number of methods, such as sputtering, chemical vapor deposition, and sol-gel are commonly employed for preparation of these materials. In most of these methods, the nature of the produced material is amorphous and an additional high-temperature processing step is required in order to obtain crystallinity. However, high temperature processes can lead to significant side-effects such as the formation of multiple phases. Recently, mechanochemical processing has also been applied as a low temperature technique for a wide range of nanoparticulate materials involving activation of solid-state displacement reactions in a ball mill. ${ }^{12}$ We have developed a simple room temperature synthesis of pure and $\mathrm{M}$-doped crystalline $\mathrm{ZnO}$ nanoparticles (where $\mathrm{M}=\mathrm{Co}, \mathrm{Cr}, \mathrm{Fe}, \mathrm{Mn}$ and $\mathrm{Ni}$ ) by a sol-gel method.

\subsection{Experimental}

A $1 \mathrm{M}$ solution of zinc nitrate or acetate solution (Aldrich 99\%) was reacted with a $3 \mathrm{M}$ aqueous solution of $\mathrm{NaOH}$ so that the final $\mathrm{pH}$ of the solution was 12 . The reaction mixture was left overnight and the precipitate allowed to settle at the bottom. The clear 
solution was removed and replaced with water, stirred, and left for 3-5hrs. This process was repeated until the $\mathrm{pH}$ of the solution was 7. Finally, the precipitate was dispersed in ethanol and dried under vacuum. For doping, the appropriate amounts of indicated metal nitrate were added to zinc nitrate solution until the concentration of the dopant was $5 \%$. In the above reaction, a zinc hydroxy nitrate complex is first precipitated and then it slowly transforms into $\mathrm{ZnO}, \mathrm{NaNO}_{3}$ and water according to the following equations. The $\mathrm{NaNO}_{3}$ was removed by washing the sample with water.

$$
\begin{aligned}
& \mathrm{Zn}\left(\mathrm{NO}_{3}\right)_{2}+\mathrm{NaOH} \rightarrow \mathrm{Zn}\left(\mathrm{NO}_{3}\right)(\mathrm{OH})+\mathrm{NaNO}_{3} \\
& \mathrm{Zn}\left(\mathrm{NO}_{3}\right)(\mathrm{OH})+\mathrm{NaOH} \rightarrow \mathrm{ZnO}+\mathrm{NaNO}_{3}+\mathrm{H}_{2} \mathrm{O}
\end{aligned}
$$

Part of the powder samples were used for hydrogenation experiments. The hydrogen reduction set-up was described in Chapter 3. The Raman set-up used is similar to the one described in Chapter 1 with the exception of using a microscope attachment. Temperature and magnetic field variations of the magnetization $(\mathrm{M})$ of these samples were measured using a commercial SQUID magnetometer.

\subsection{Results and Discussion}

Figures 5-1 though 5-5 show the XRD patterns of 5\% M-doped $\mathrm{ZnO}$ as-prepared and hydrogenated at $573 \mathrm{~K}$. It is significant to note that only chromium and cobalt samples show a single phase of $\mathrm{ZnO}$ after hydrogenation (matching with zincite (PDF 361451) without any trace of the dopant or its respective oxide. The temperature variation

of the magnetic susceptibility $(\chi)$ for the as-prepared samples for $5 \% \mathrm{Cr} / \mathrm{ZnO}$ is shown in 
Figure 5-6 where the solid line is fit to the Curie-Weiss Law. After hydrogenation at 573 $\mathrm{K}$, the sample retains its paramagnetic behavior as shown in Figure 5-7. The as-prepared sample of $5 \% \mathrm{Co} / \mathrm{ZnO}$ displays paramagnetic behavior (Figure 5-8), but after hydrogenation for 3 hours at $573 \mathrm{~K}$ the sample displays room temperature ferromagnetism as indicated by $\chi$ vs $T$ (Figure 5-9) and $M$ vs $H$ (Figure 5-10). The temperature variation of the magnetic susceptibility and the $\mathrm{M}$ vs $\mathrm{H}$ data is also indicative of RTFM for the sample hydrogenated for 6 hours as shown in Figures 5-11 and 5-12.

Figure 5-13 shows the XRD patterns for $10 \%$ cobalt-doped $\mathrm{ZnO}$ and $10 \%$ cobaltdoped $\mathrm{ZnO}$ hydrogenated at $573 \mathrm{~K}$ for 6 hours. It is evident that the XRD patterns for the $10 \%$ doped $\mathrm{Co} / \mathrm{ZnO}$ indicate a perfect doping of $\mathrm{Co}$ into the $\mathrm{ZnO}$ lattice. We have also carried out X-ray fluorescence (XRF) measurements and found out that the amount of cobalt doped in $\mathrm{ZnO}$ was $10.4 \%$. Micro Raman spectra of the pure and cobalt-doped $\mathrm{ZnO}$ are shown in Figure 5-14. $\mathrm{ZnO}$ oxide has four atoms per unit cell resulting in $1 \mathrm{~A}_{1}, 1 \mathrm{E}_{1}$, $2 \mathrm{E}_{2}$, and $2 \mathrm{~B}_{1}$ optical phonon modes. ${ }^{13,14}$ The $\mathrm{A}_{1}+\mathrm{E}_{1}$ modes are polar and split into transverse optical (TO) and longitudinal optical (LO) phonons which are Raman and infrared active. The $\mathrm{E}_{2}$ modes are only Raman active while the $\mathrm{B}_{1}$ modes are infrared and Raman active. Significant differences have been observed between the doped and undoped spectra. Specifically, for the $10 \%$ cobalt-doped spectrum, the $2 \mathrm{E}_{2}$ modes appearing at $101 \mathrm{~cm}^{-1}$ have been downshifted to $97.4 \mathrm{~cm}^{-1}$ and the peak at $437 \mathrm{~cm}^{-1}$ is also downshifted when compared to pure $\mathrm{ZnO}$. Moreover, the intensity of the peak at 437 $\mathrm{cm}^{-1}$ is significantly reduced and broadened in the $10 \%$ cobalt-doped sample compared to the as-prepared sample of $\mathrm{ZnO}$. These observed features are clearly related to the cobaltdoping and may be used as indications for its incorporation. 
The temperature variation of the magnetic susceptibility $(\chi)$ for the as-prepared ( $10 \%$ cobalt-doped $\mathrm{ZnO}$ ) sample (prior to hydrogenation) is shown in Figure 5-15 where the solid line is fit to the Curie-Weiss Law. This variation is similar to the one reported for the sample of $10 \% \mathrm{Co} / \mathrm{TiO}_{2}$ described in Chapter 3 and prepared by spray pyrolysis ${ }^{15}$. From the Curie-constant, $\mathrm{C}=3.1 \times 10^{-3}(\mathrm{emu}-\mathrm{K} / \mathrm{gOe})$ where $\mathrm{C}=\mathrm{N} \mu^{2} / 3 \mathrm{k}_{\mathrm{B}}$, we calculated $\mu=4.465 \mu_{\mathrm{B}}$ for the $\mathrm{Co}^{2+}$ ion. This magnitude of $\mu$ is consistent with the high spin state of $\mathrm{Co}^{2+}$, assuming that $\mathrm{Co}^{2+}$ substitutes for the $\mathrm{Zn}^{2+}$ in the $\mathrm{ZnO}$ lattice. $\mathrm{M}$ vs. $\mathrm{H}$ behavior for the $10 \%$ cobalt-doped $\mathrm{ZnO}$ at $\mathrm{T}=300 \mathrm{~K}$ is shown in Figure $5-16$. There is no hysteretic behavior confirming the existence of paramagnetism.

Hydrogenation was carried out for the $10 \%$ cobalt-doped $\mathrm{ZnO}$ at $573 \mathrm{~K}$, and we find that the sample acquires RTFM. Figure 5-13 shows the XRD pattern for the sample hydrogenated for 6 hours. This pattern looks similar to the pure $\mathrm{ZnO}$ pattern and indicates no significant impurity peaks for the presence of cobalt or cobalt oxides. From the widths of the XRD lines, the average particle size of the $\mathrm{ZnO}$ phase is $10 \pm 2 \mathrm{~nm}$, without any major changes upon hydrogenation. The primary aim of hydrogenation is to induce ferromagnetism, similar to recently reported studies in the $\mathrm{Co} / \mathrm{TiO}_{2}$ system, ${ }^{16}$ where a controlled transformation of a paramagnetic cobalt-doped $\mathrm{TiO}_{2}$ into a room temperature ferromagnet was observed. $\mathrm{M}$ vs. $\mathrm{H}$ behavior at $\mathrm{T}=300 \mathrm{~K}$ for the $6 \mathrm{hr}$. hydrogenated $10 \%$ cobalt-doped $\mathrm{ZnO}$ (shown in Figure 5-17) clearly indicates ferromagnetism. Finally, we measured $\chi$ vs. T for the 6 hour hydrogenated sample under zero-field-cooled (ZFC) and field-cooled (FC) conditions (Figure 5-18). The absence of a peak in $\chi$ for the ZFC case, which is a signature of the blocking temperature $\left(T_{B}\right)$ for cobalt as reported recently for the thin films of $\mathrm{Co} / \mathrm{TiO}_{2}$ prepared by sputtering, ${ }^{9}$ provides assurance that no cobalt is 
present in the nanoparticles that we produced. The reported $T_{B}$ values of cobalt nanoparticles of different sizes are: $T_{B} \simeq 20 \mathrm{~K}(3 \mathrm{~nm}), \mathrm{T}_{\mathrm{B}} \simeq 50 \mathrm{~K}(6 \mathrm{~nm}), \mathrm{T}_{\mathrm{B}} \simeq 100 \mathrm{~K}(8$ $\mathrm{nm})$ and $\mathrm{T}_{\mathrm{B}} \simeq 260 \mathrm{~K}(11 \mathrm{~nm}) .{ }^{17-19}$

\subsection{Conclusion}

In conclusion, a straightforward method has been developed for the synthesis of both pure and cobalt-doped zinc oxide at room temperature. XRD measurements show the formation of single phase compound without any impurities and the magnetic measurements show that the as-prepared cobalt-doped zinc oxide is paramagnetic. However, hydrogen reduction at $573 \mathrm{~K}$ transforms the magnetic nature from paramagnetic to ferromagnetic. This method may possibly be extended to synthesize other doped high temperature oxides at room temperature. Work is in progress to study the effects of various doping levels of cobalt into zinc oxide.

\subsection{References}

(1) Hingorani, S; Pillai, V; Kumar, P; Multani, M. S; Shah, D. O. Materials Res. Bull. (1993), 28, 1303.

(2) Lin, H. M; Tzeng, S. J; Hsiau P. J; Tsai, W. L.Nanostruct. Mater. (1998), 10, 465.

(3) Zhao, X; Zhang, S. C; Li, C; Zheng, B; Gu, H. Mater. Synth. Process. (1997), 5, 227.

(4) Matsumoto, Y; Murakami, M; Shono, T; Hasegawa, T; Fukumura, T;

Kawasaki, M; Ahmet, P; Chikyow, T; Koshihara, S; Koinuma, H.

Science, (2001), 291, 854.

(5) Chambers, S. A; Thevuthasan, S; Farrow, R. F. C; Marks, R. F; Thiele, J. W; Folks, L; Samant, M. G; Kellock, A. J; Ruzycki, N; Ederer, D. L; Diebold, U. Appl. Phys. Lett. (2001), 79, 3467. 
(6) Matsumoto, Y; Takahashi, R; Murakami, M; Koida, T; Fan, X. J; Hasegawa, T; Fukumura, T; Kawasaki, M; Koshihara, S. Y; Koinuma, H. Jpn. J. Appl. Phys., Part 2 (2001), 40, L1205.

(7) Park, W. K; Ortega-Hertogs, R. J; Moodera, J; Punnoose, A; Seehra, M. S. J. Appl. Phys. (2002), 91, 8093.

(8) Stampe, P. A; Kennedy, R. J; Xin, Y; Parker, J. S; J. Appl. Phys. (2003), 93, 7864.

(9) Punnoose, A; Seehra, M. S; Park W. K; Moodera, J. S; J. Appl. Phys. (2003), 93, 7867.

(10) Kim, D. H; Yang, J. S; Lee, K. W; Bu, S. D; Kim, D. W; Noh, T. W; Oh, S. J; Kim, Y. W; Chung, J. S; Tanaka, H; Lee, H. Y; Kawai, T; Won, J. Y; Park, S. H; Lee, J. C. J. Appl. Phys., (2003), 93, 6125.

(11) Rameev, B. Z; Yildiz, F; Tagirov, L. R; Aktas, B; Park, W. K; Moodera, J. S. J. Mag. Mag. Mater. (2003), 258-259, 361.

(12) Tsuzuki T; McCormick, P. G. Scripta Mater. (2001), 44, 1731.

(13) Bundesman, C; Ashkenov, N; Schubert, M; Spemann, D; Butz, T; Kaidashev, E. M. Appl. Phys. Lett. (2003), 83, 1974-6.

(14) Rajalakshmi, M; Arora, K. A. K; Bendre, B. S; Mahamuni, S. J. Appl. Phys., (2000), 87, 2445.

(15) Manivannan, A; Seehra, M. S; Majumder, S. B; Katiyar, R. S. Appl. Phys. Lett. (2003), 83, 111.

(16) Manivannan, A; Glaspell, G; Seehra, M. S. J. Appl. Phys. (2003), 94, 6994.

(17) Berkowitz, A. E; Takano, K. J. Magn. Magn. Mater. (1999), 200, 552.

(18) Chen, J. P; Sorensen, C. M; Klabunde, K. J; Hadjipanayis, G. C;

Phys. Rev. B (1995), 51, 11527.

(19) Murray, C. B; Sun, S; Doyle, H; Betley, T. Mat. Res. Bull., Dec. (2001), 985. 

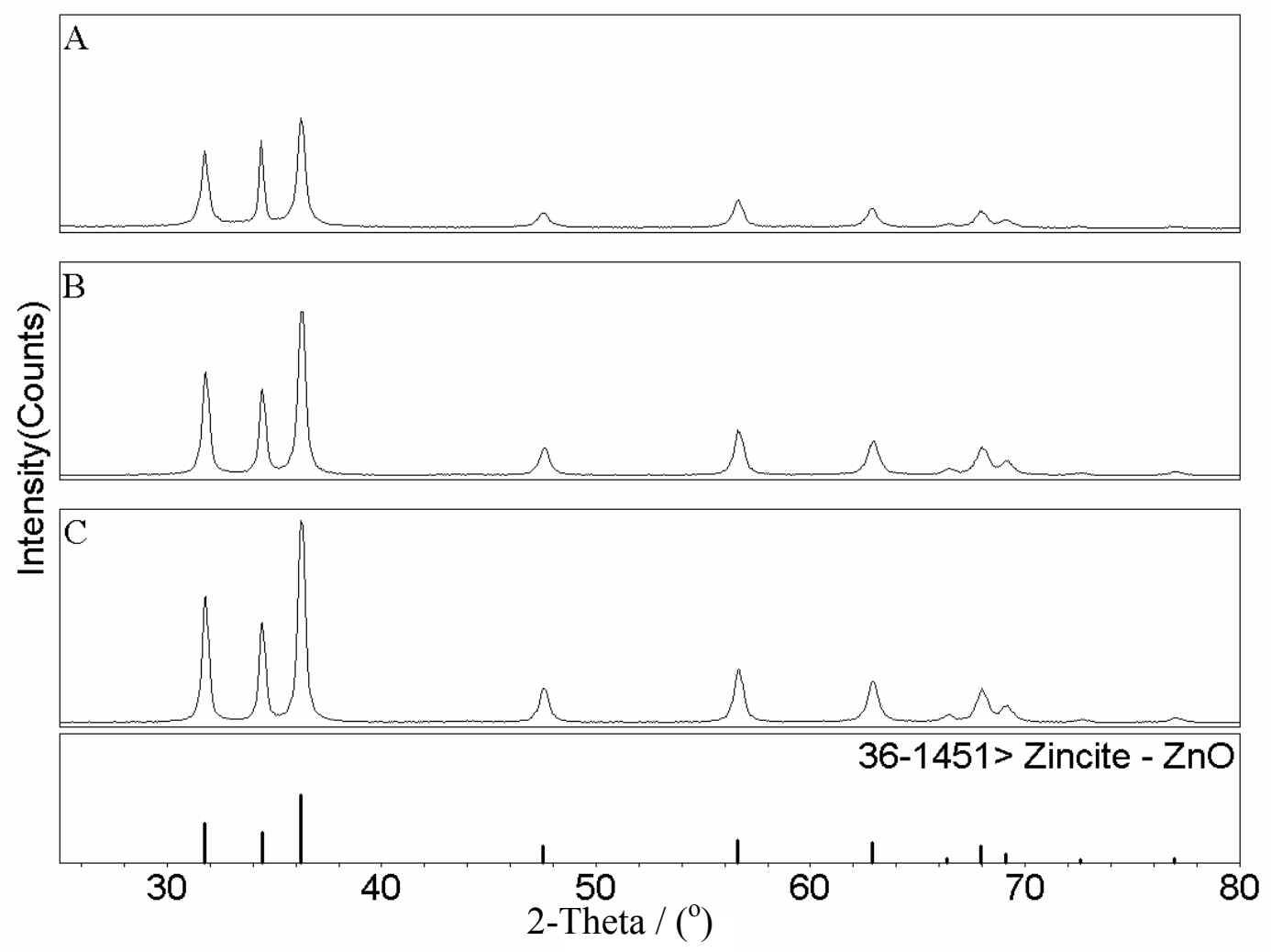

Figure 5-1. X-ray diffraction patterns of the as-prepared sample of 5\% $\mathrm{Co} / \mathrm{ZnO}(\mathrm{A})$ and hydrogenated at $573 \mathrm{~K}$ for $3(\mathrm{~B})$ and 6 hours $(\mathrm{C})$ matching with the zincite phase (PDF 36-1451). 


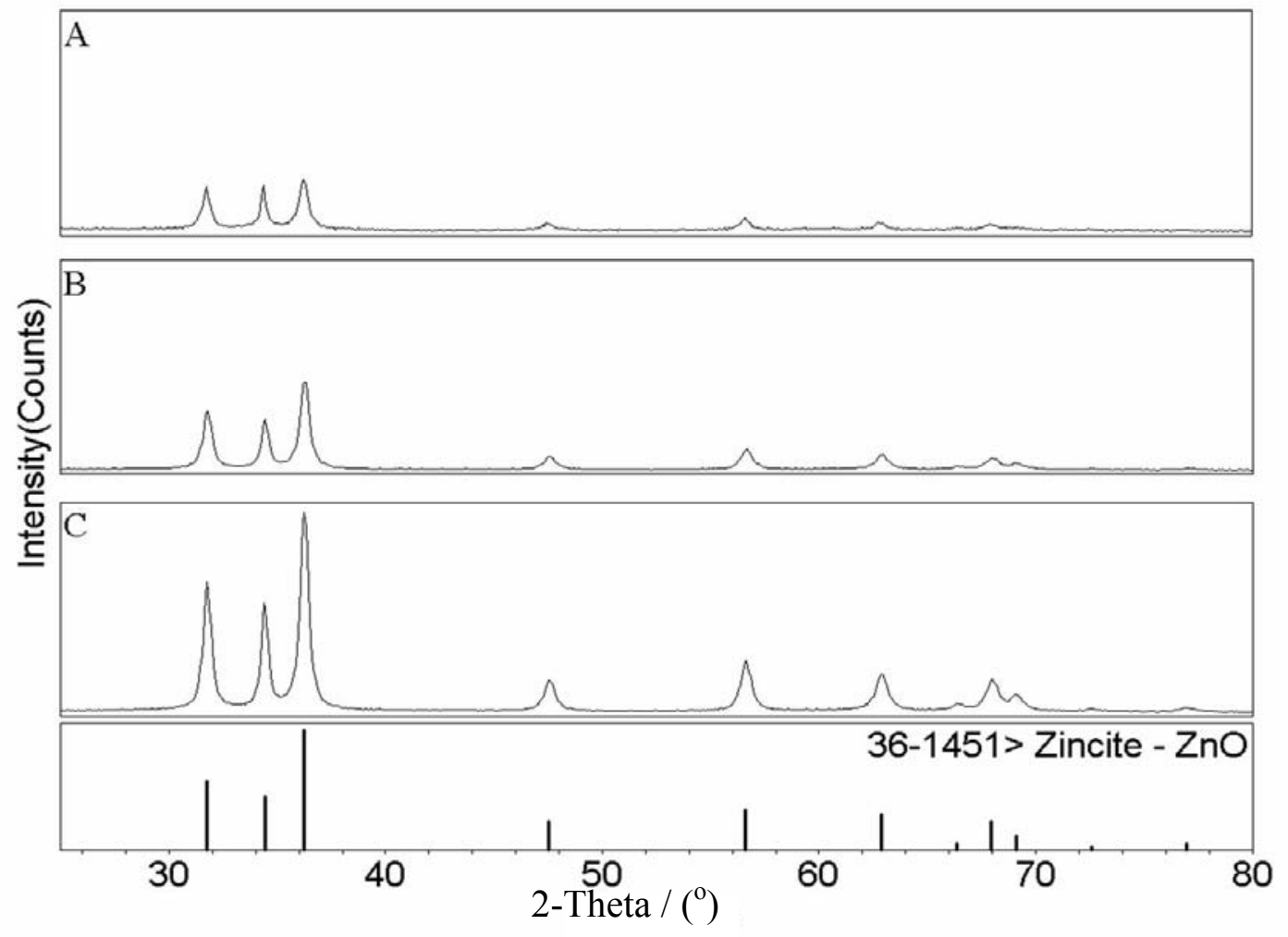

Figure 5-2. X-ray diffraction patterns of the as-prepared sample of $5 \% \mathrm{Cr} / \mathrm{ZnO}(\mathrm{A})$ and hydrogenated at $573 \mathrm{~K}$ for 3 (B) and 6 hours (C) matching with the zincite phase (PDF 36-1451). 


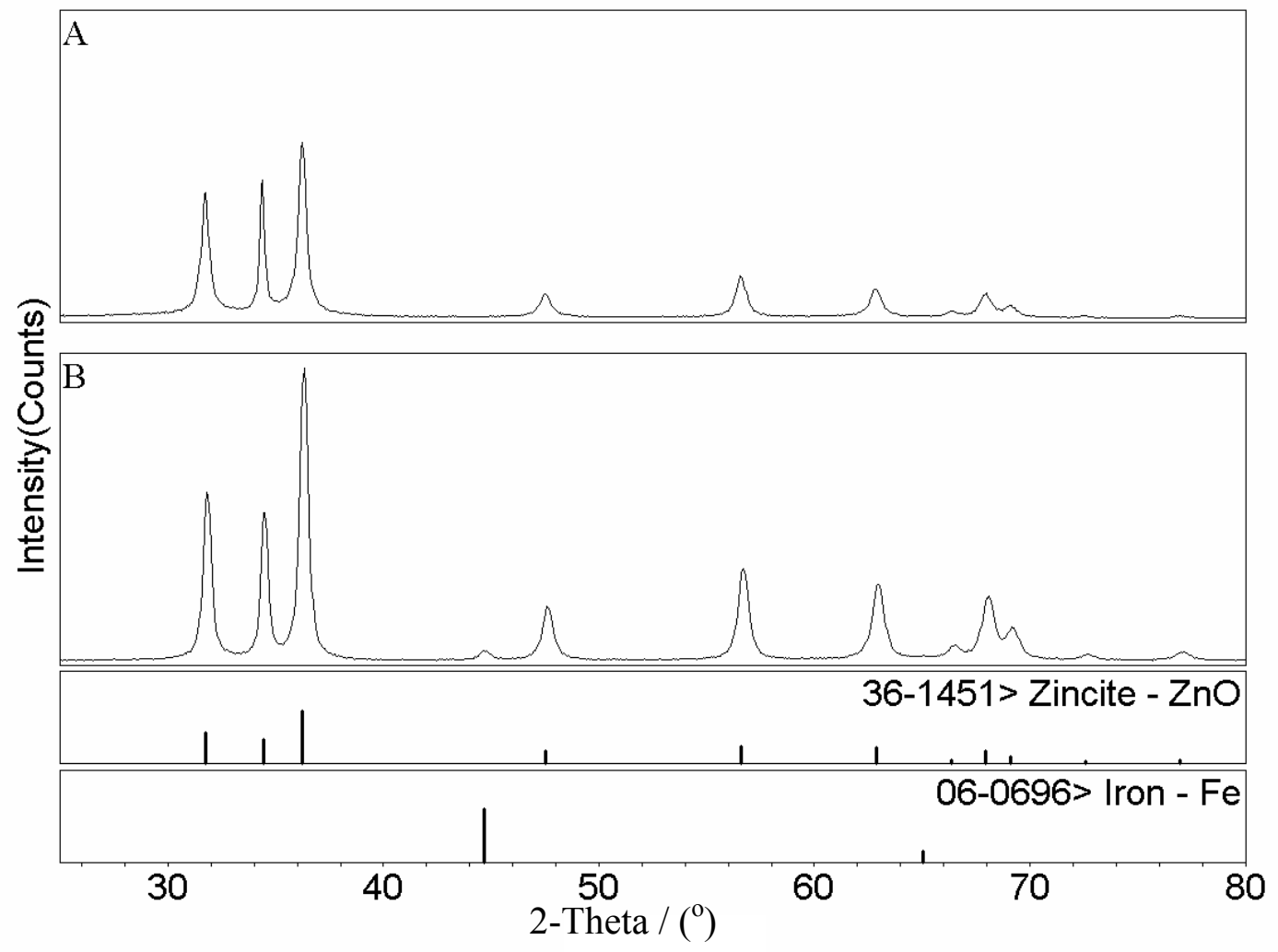

Figure 5-3. X-ray diffraction patterns of the as-prepared sample of 5\% Fe/ZnO (A) and hydrogenated at $573 \mathrm{~K}$ for 3 hours (B). The expected lines for zincite and iron are shown below. 


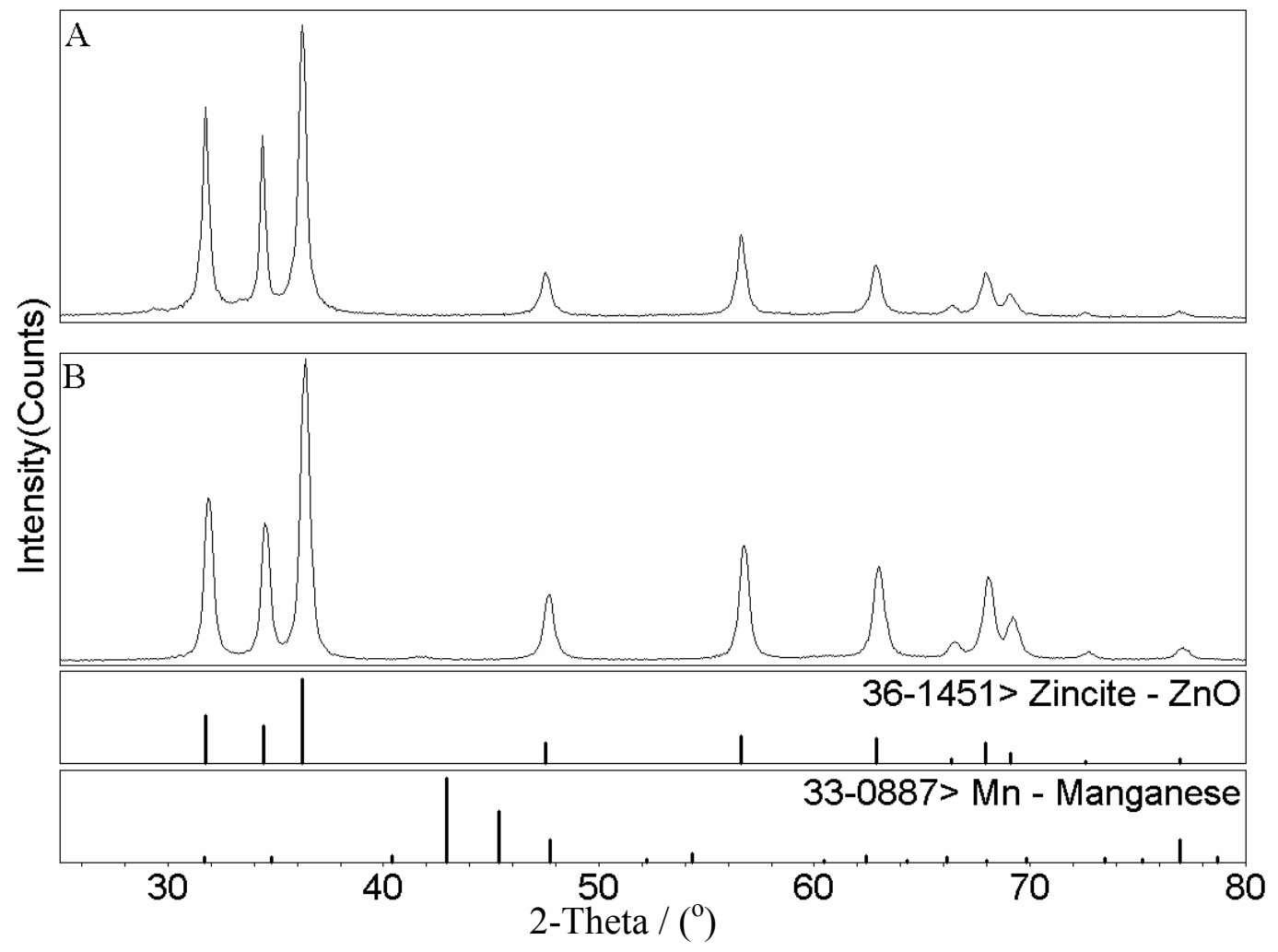

Figure 5-4. X-ray diffraction patterns of the as-prepared sample of 5\% $\mathrm{Mn} / \mathrm{ZnO}$ (A) and hydrogenated at $573 \mathrm{~K}$ for 3 hours (B). The expected lines for zincite and manganese are shown below. 


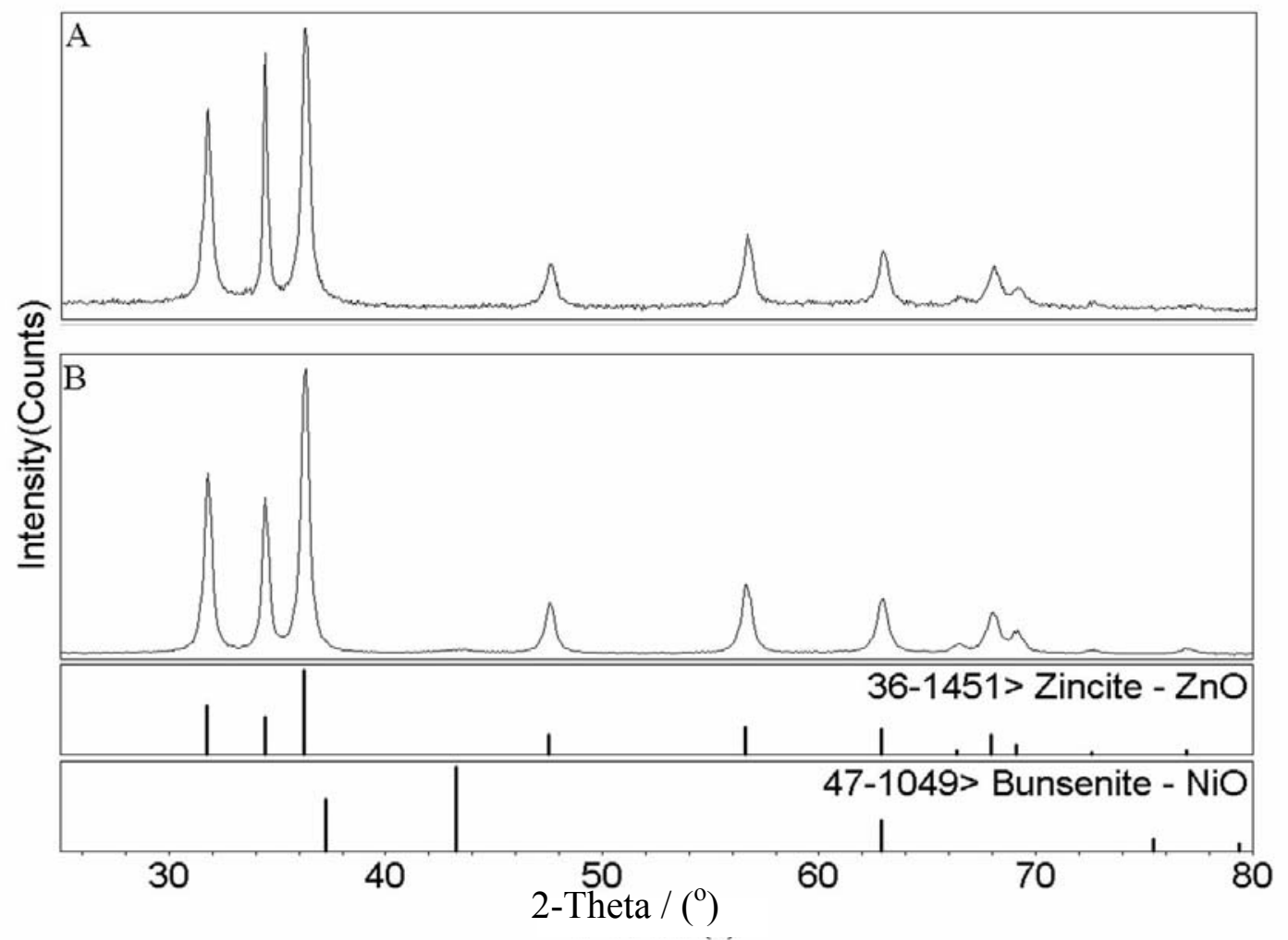

Figure 5-5. X-ray diffraction patterns of the as-prepared sample of $5 \% \mathrm{Ni} / \mathrm{ZnO}(\mathrm{A})$ and hydrogenated at $573 \mathrm{~K}$ for 3 hours (B). The expected lines for zincite and nickel oxide are shown below. 


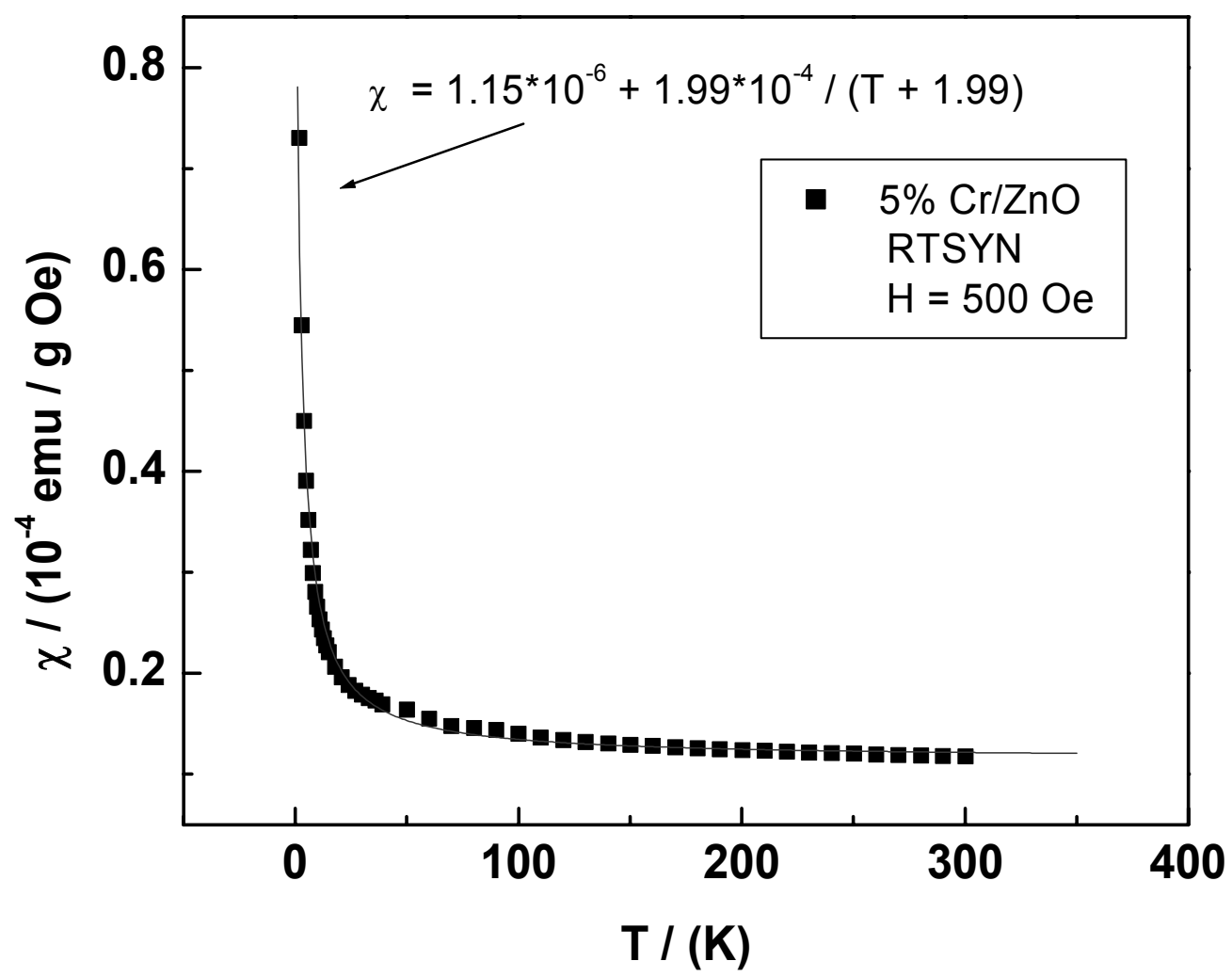

Figure 5-6. Temperature dependence of the magnetic susceptibility $(\chi)$ of $5 \% \mathrm{Cr} / \mathrm{ZnO}$. The solid line is fit to the equation shown above. 


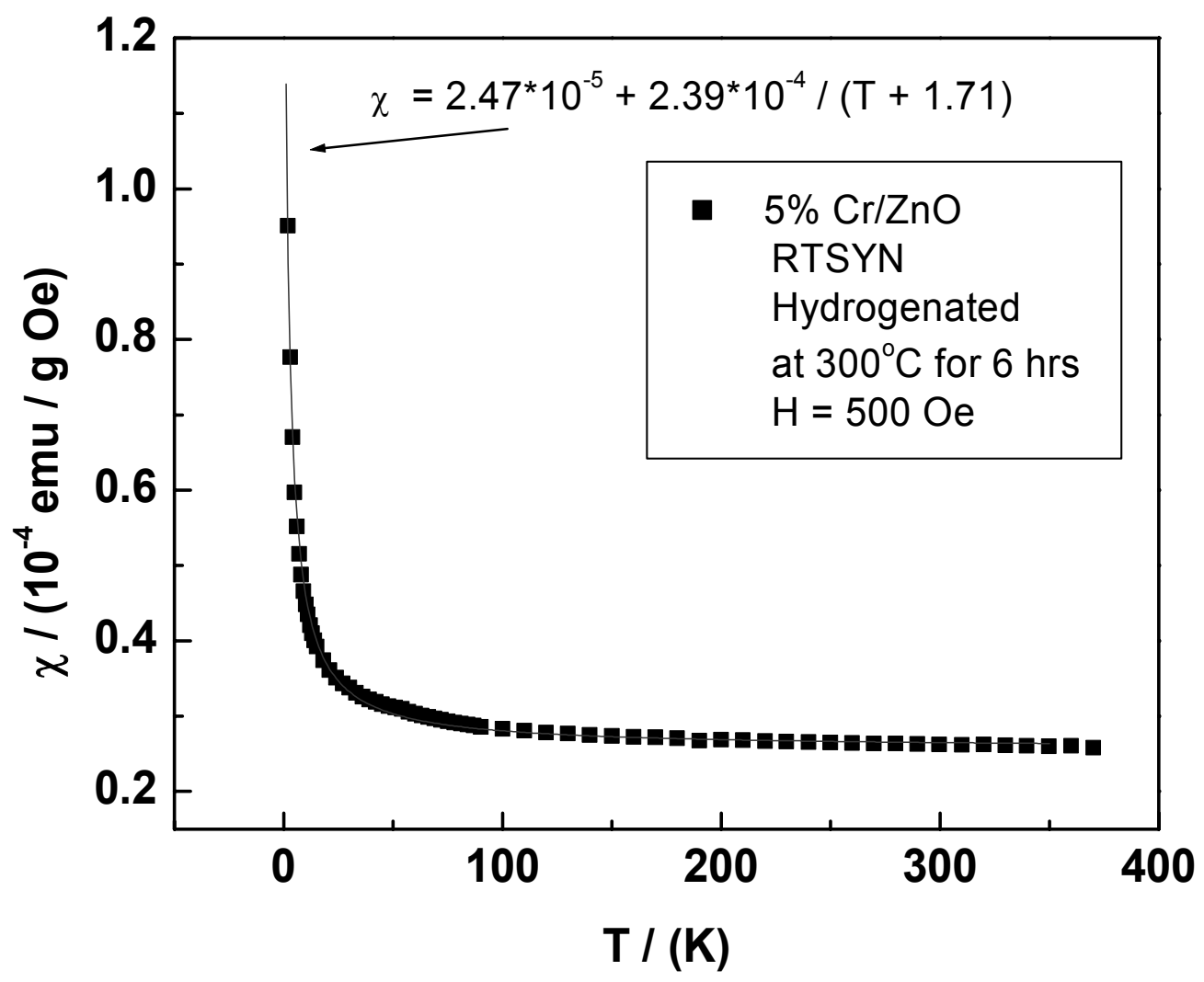

Figure 5-7. Temperature dependence of the magnetic susceptibility $(\chi)$ of $5 \% \mathrm{Cr} / \mathrm{ZnO}$ hydrogenated for 6 hours. The solid line is fit to the equation shown above. 


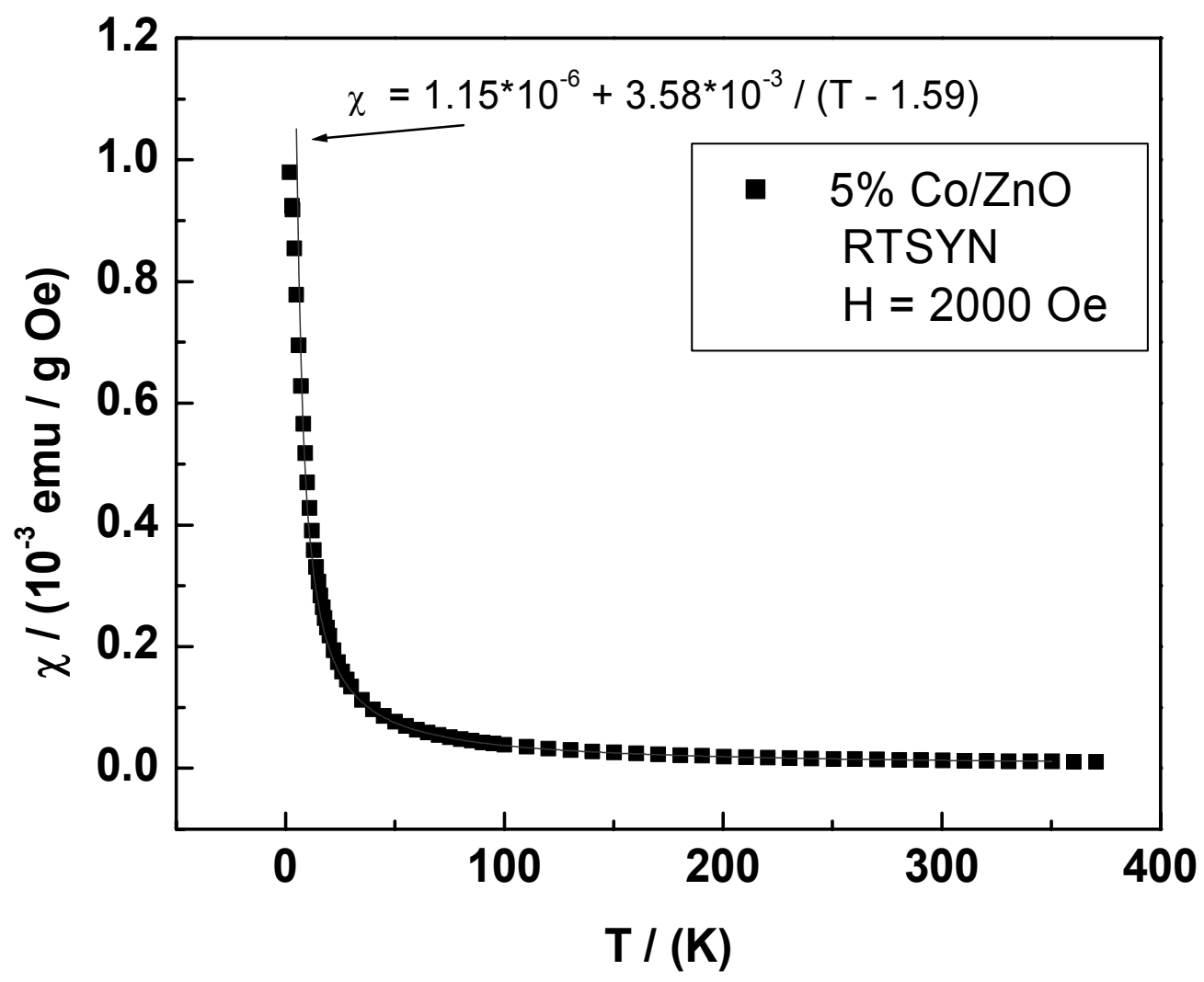

Figure 5-8. Temperature dependence of the magnetic susceptibility $(\chi)$ of $5 \% \mathrm{Co} / \mathrm{ZnO}$. The solid line is fit to the equation shown above. 


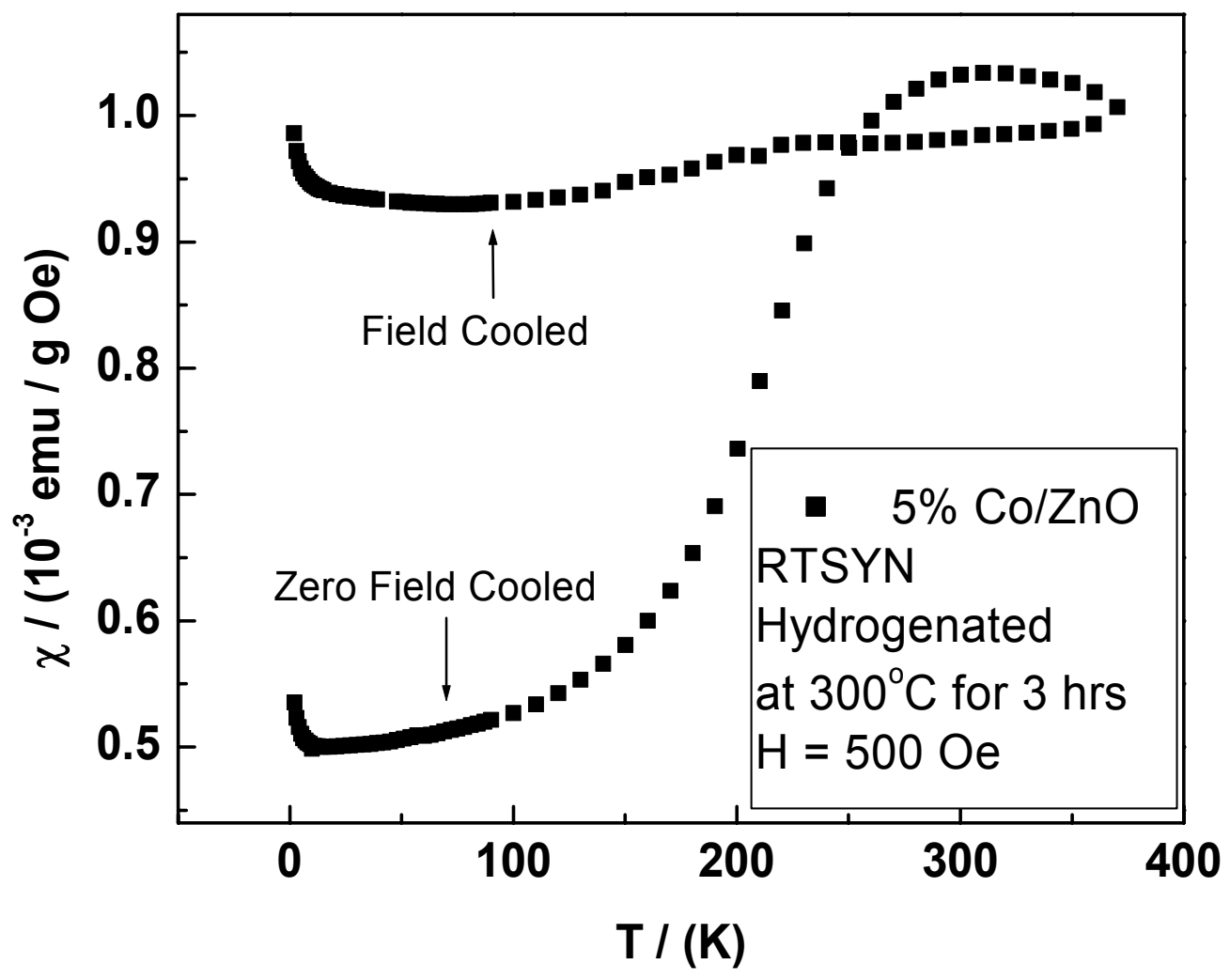

Figure 5-9. Temperature dependence of the magnetic susceptibility $(\chi)$ of $5 \% \mathrm{Co} / \mathrm{ZnO}$ hydrogenated at $573 \mathrm{~K}$ for 3 hours. 

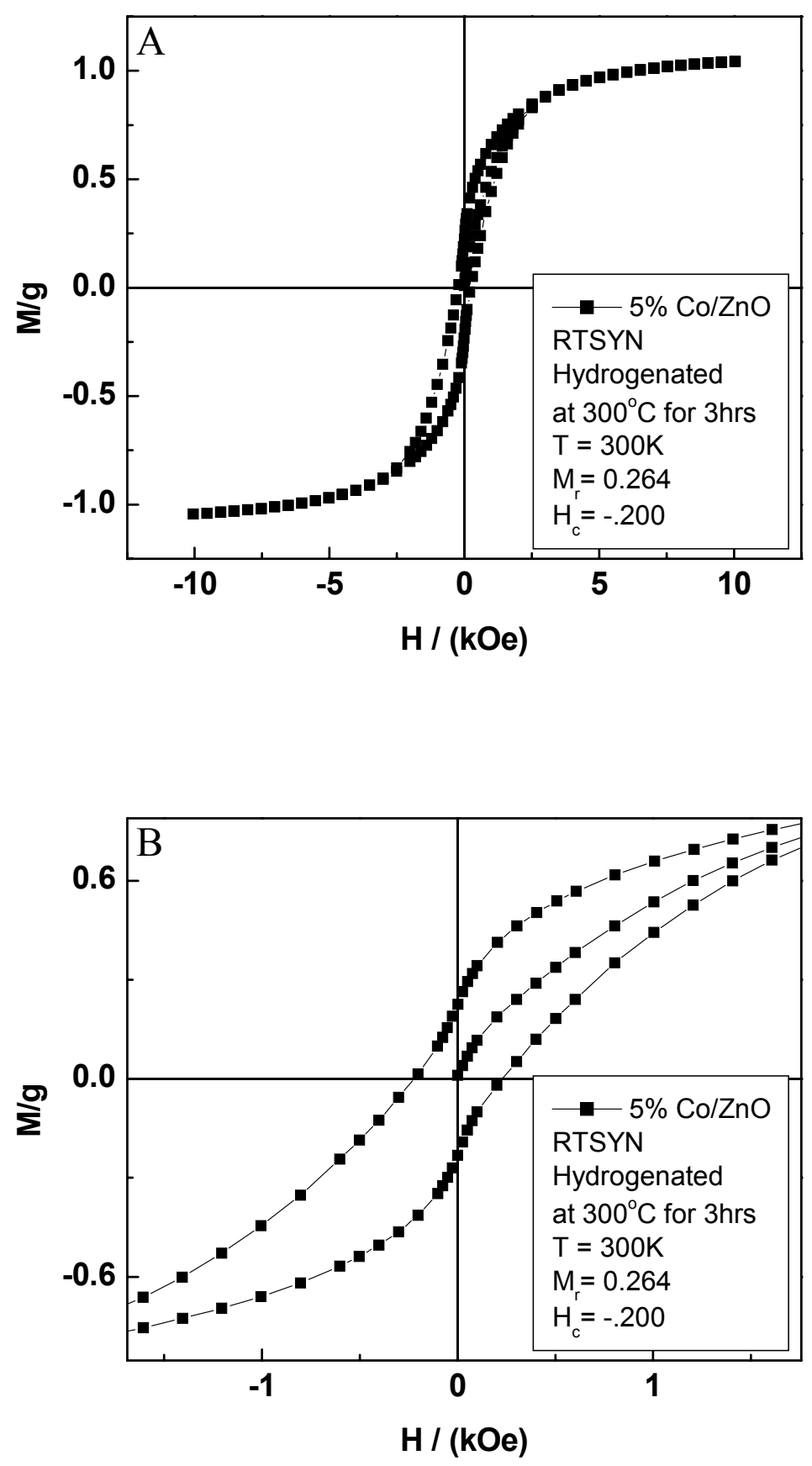

Figure $5-10 . M$ vs. $H$ of $5 \% \mathrm{Co} / \mathrm{ZnO}$ hydrogenated for 3 hours (A) and an expanded view (B). 


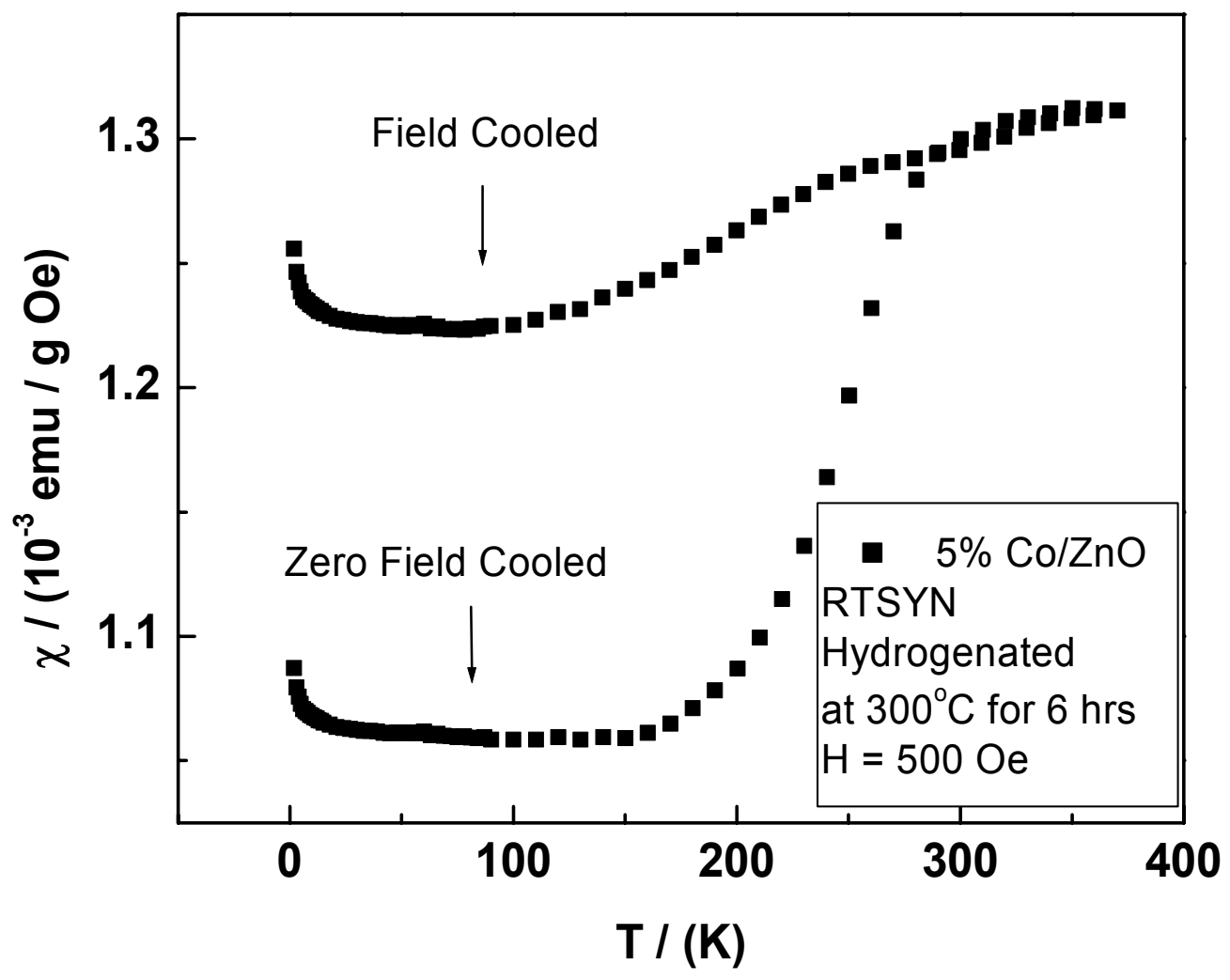

Figure 5-11. Temperature dependence of the magnetic susceptibility $(\chi)$ of $5 \% \mathrm{Co} / \mathrm{ZnO}$ hydrogenated at $573 \mathrm{~K}$ for 6 hours. 

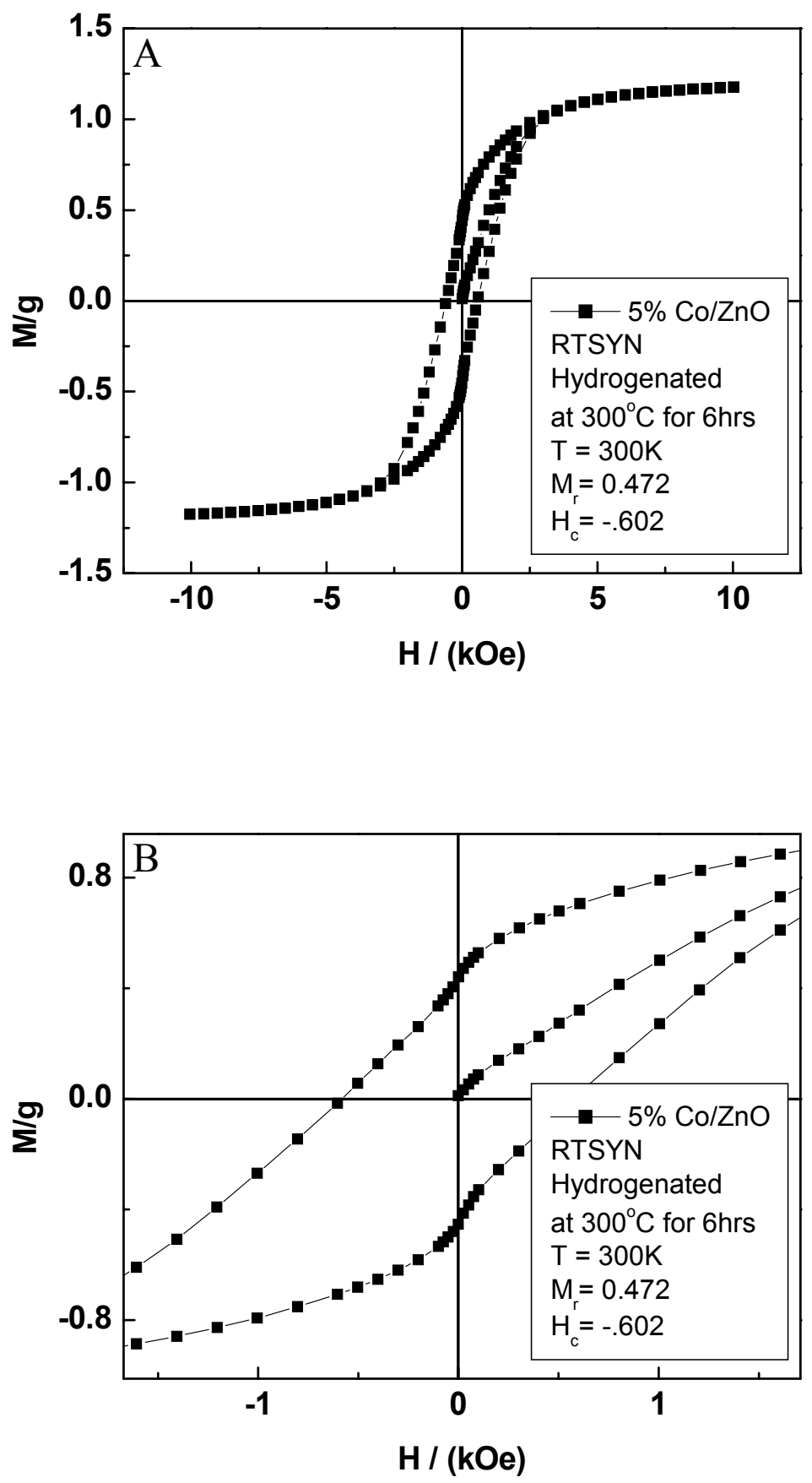

Figure $5-12 . M$ vs. $H$ of $5 \% \mathrm{Co} / \mathrm{ZnO}$ hydrogenated for 6 hours (A) and an expanded view (B). 


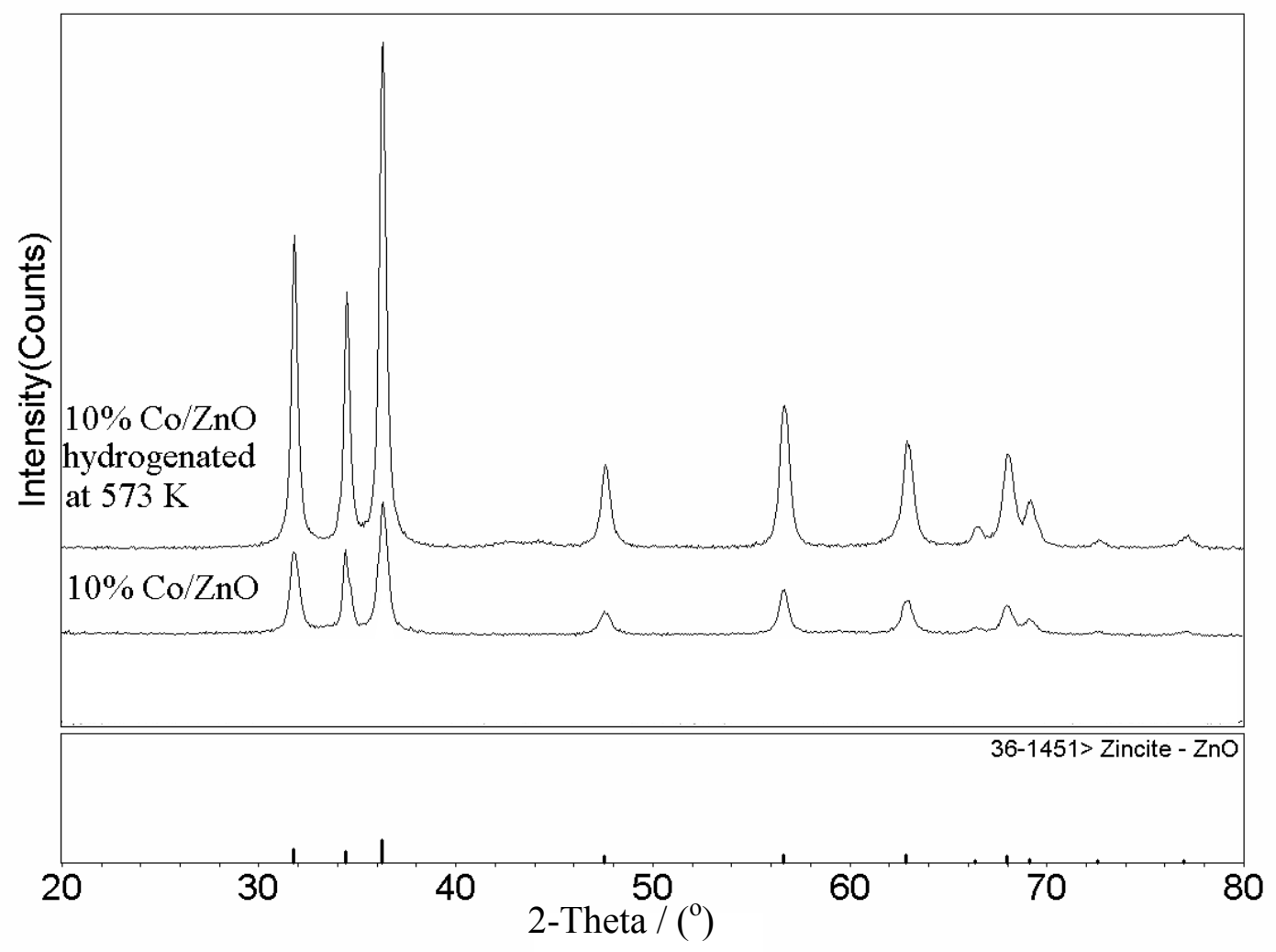

Figure 5-13. X-ray diffraction patterns of the as-prepared sample of $10 \% \mathrm{Co} / \mathrm{ZnO}$ and $10 \% \mathrm{Co} / \mathrm{ZnO}$ hydrogenated at $573 \mathrm{~K}$ for 6 hours matching with the zincite phase (PDF 36-1451). 


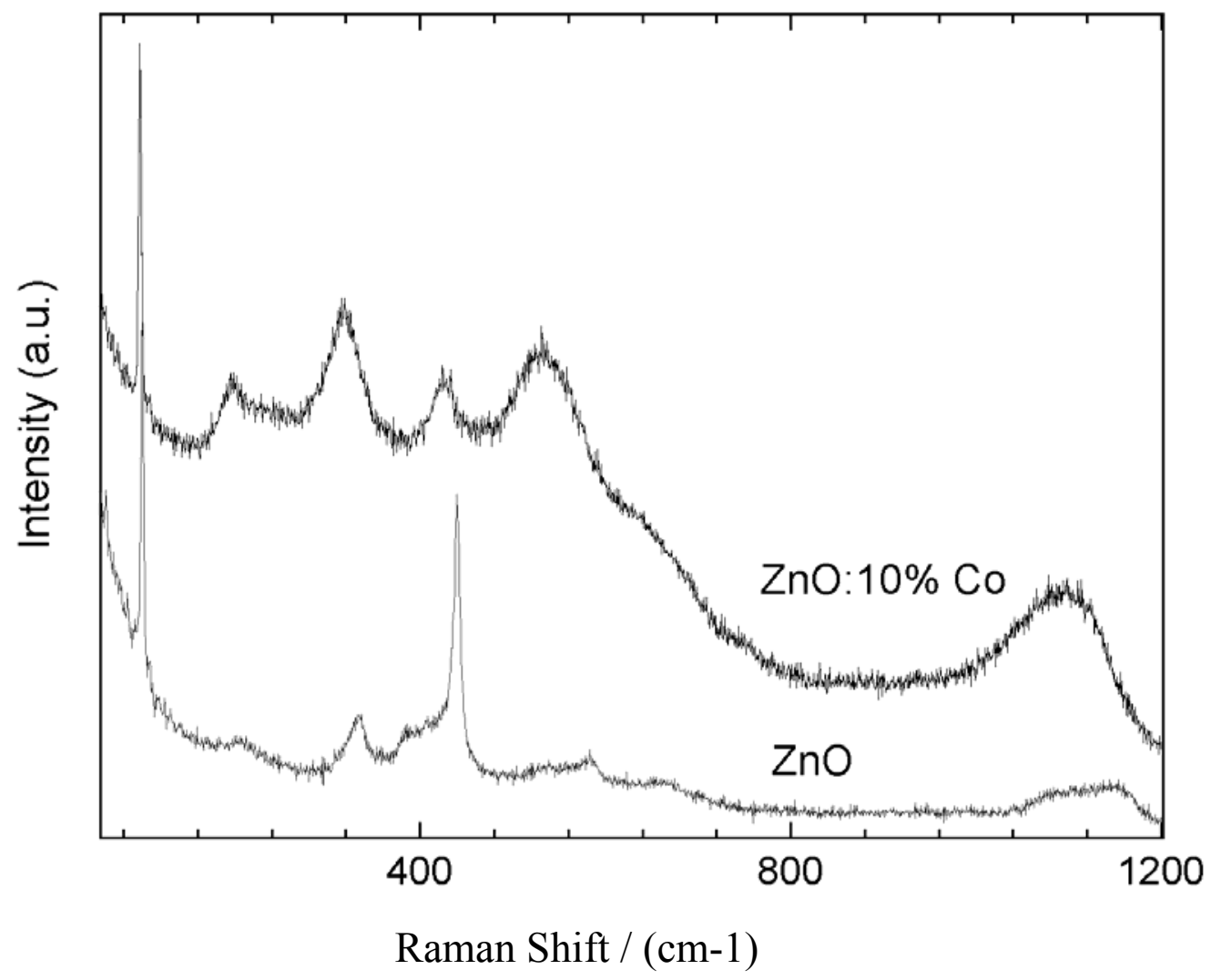

Figure 5-14. Raman spectra of the as-prepared sample of $\mathrm{ZnO}$ and $10 \%$ doped $\mathrm{Co} / \mathrm{ZnO}$. 


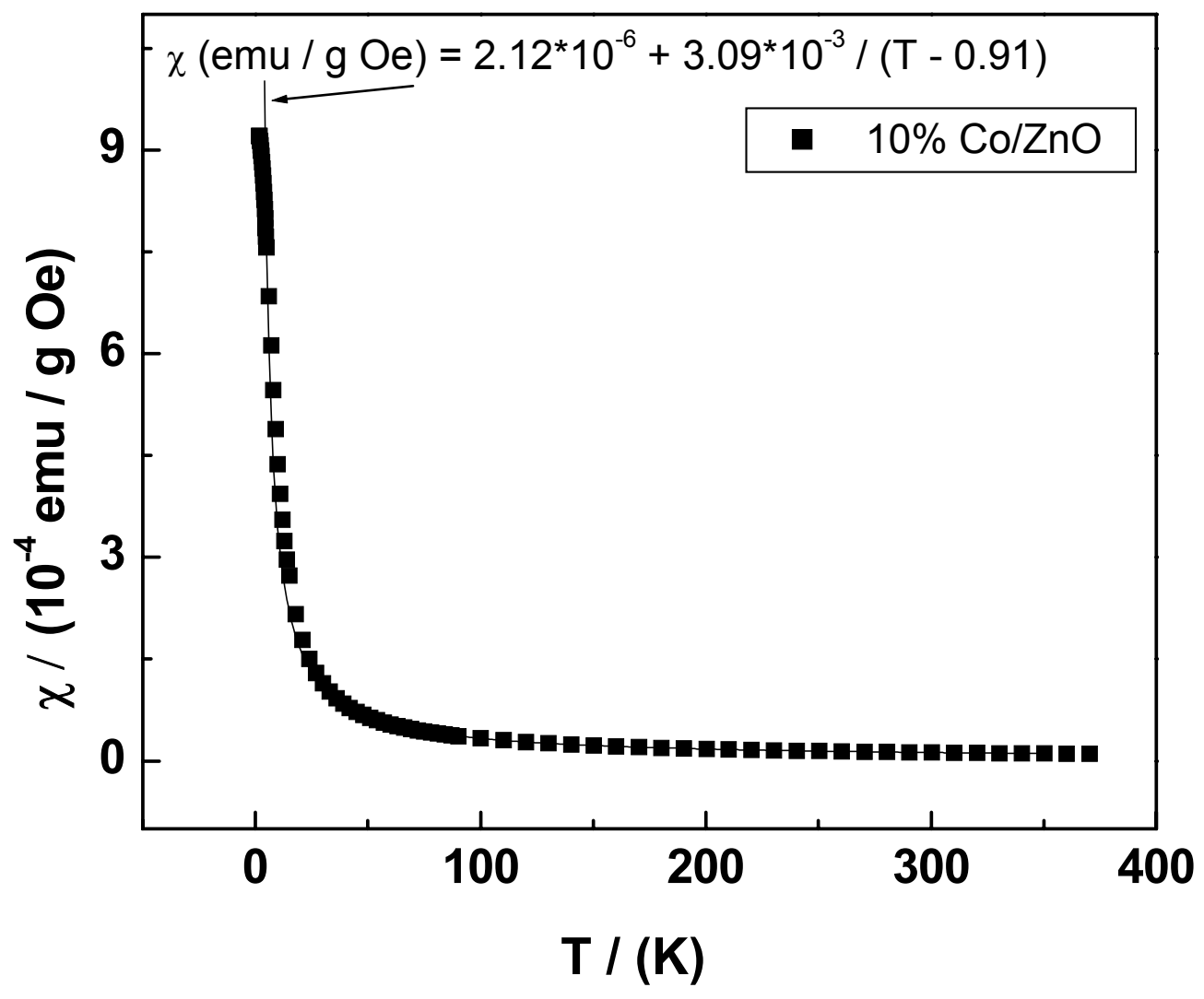

Figure 5-15. Temperature dependence of the magnetic susceptibility $(\chi)$ of $10 \% \mathrm{Co} / \mathrm{ZnO}$. The solid line is fit to the equation shown above. 

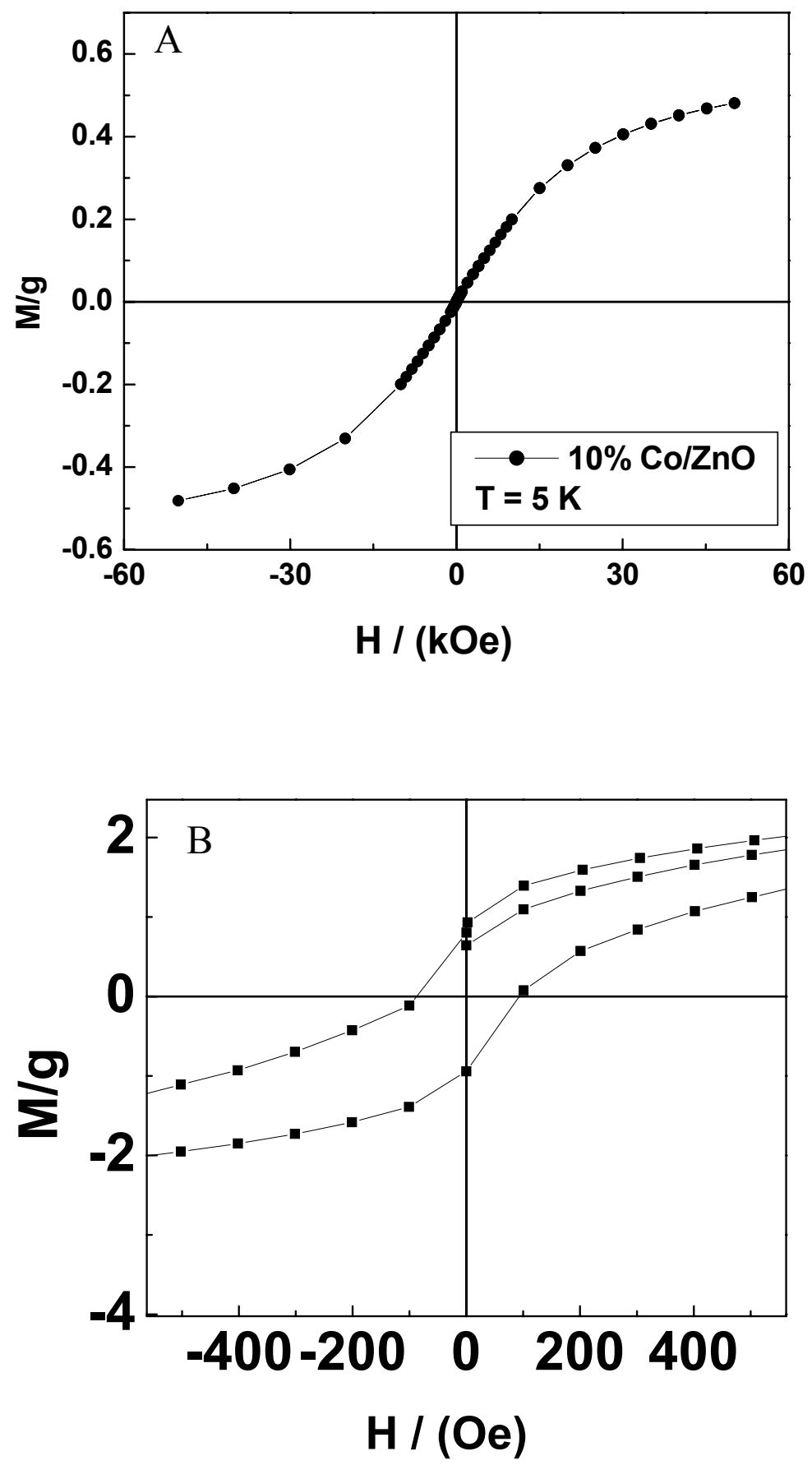

Figure 5-16. $M$ vs. $H$ of $10 \% \mathrm{Co} / \mathrm{ZnO}$ measured at $5 \mathrm{~K}(\mathrm{~A})$ and an expanded view (B). 

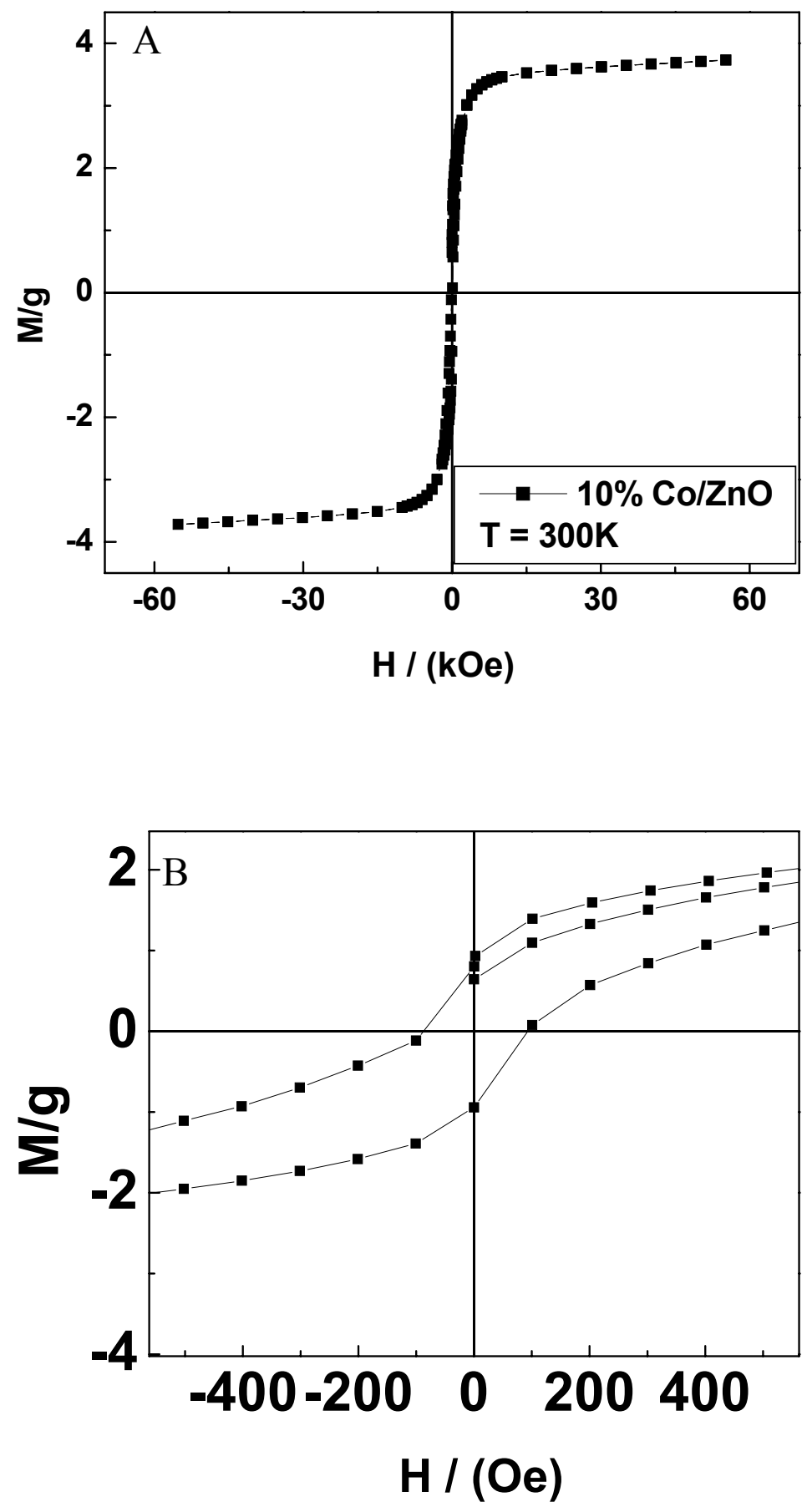

Figure $5-17 . M$ vs. $H$ measured at $300 \mathrm{~K}$ for the $10 \% \mathrm{Co} / \mathrm{ZnO}$ hydrogenated at $573 \mathrm{~K}$ for 6 hours A) and an expanded view B). 


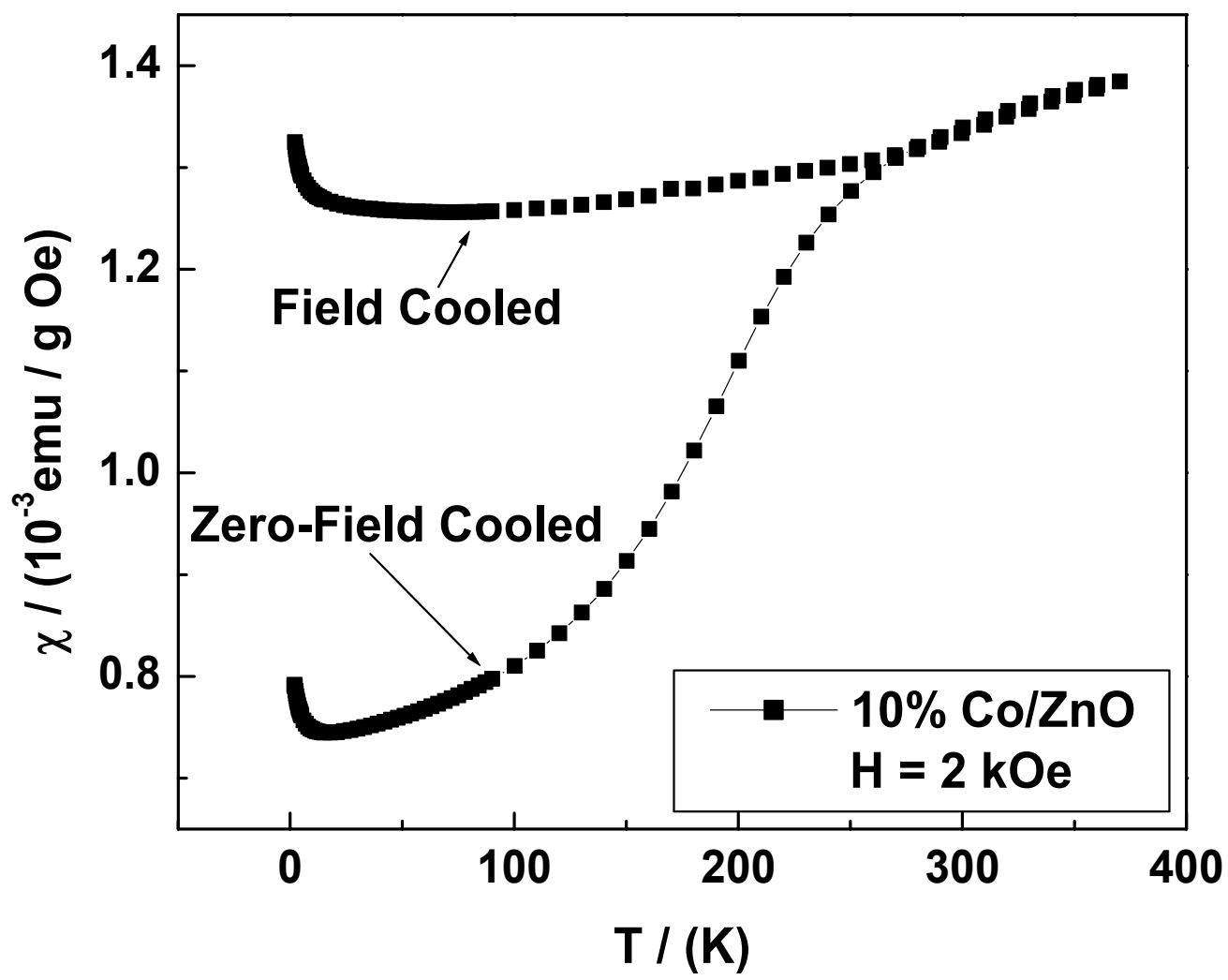

Figure 5-18. Temperature dependence of the magnetic susceptibility $(\chi)$ of $10 \% \mathrm{Co} / \mathrm{ZnO}$ hydrogenated at $573 \mathrm{~K}$ for 6 hours. 


\section{Chapter 6}

\section{Microwave Irradiation Synthesis and Characterization of M doped ZnO Nanoparticles $(\mathrm{M}=\mathrm{Co}, \mathrm{Cr}, \mathrm{Fe}, \mathrm{Mn} \& \mathrm{Ni})$}

\subsection{Introduction}

Development of new applications for zinc oxide $(\mathrm{ZnO})$ has been an integral part of research for the last decade. Current applications for zinc oxide include catalysis, cosmetics, and optical devices. ${ }^{1-3}$ Recently, $\mathrm{Co}$, Mn and $\mathrm{Ni}$ doped $\mathrm{ZnO}$ have been investigated for possible applications as spintronic materials. ${ }^{4-11}$ Synthesis of these materials is often accomplished by sputtering, chemical vapor deposition and sol-gel techniques.

Previous chapters have reported synthesis of $10 \% \mathrm{Co} / \mathrm{ZnO}$ by a sol-gel method at room temperature. Magnetic studies of the as-prepared $10 \% \mathrm{Co} / \mathrm{ZnO}$ sample show it to be paramagnetic. However, hydrogenation of the sample at $573 \mathrm{~K}$ for 6 hours changes the sample to a room temperature ferromagnet.

This chapter will focus on the synthesis of 5\% M-doped zinc oxide $(\mathrm{M}=\mathrm{Co}, \mathrm{Cr}$, $\mathrm{Fe}, \mathrm{Mn}$ and Ni) using microwave irradiation. This approach has several advantages over conventional methods including short reaction time, small particle size, narrow size distribution, and high purity. ${ }^{4-13}$ The synthesis and magnetic properties of these samples will be discussed. 


\subsection{Experimental}

Synthesis of $\mathrm{ZnO}$ was achieved by dissolving approximately $4 \mathrm{~g}$ of zinc nitrate (Alfa Aesar) in ethanol. While stirring, $10 \mathrm{ml}$ of $10 \mathrm{~N} \mathrm{NaOH}$ (Alfa Aesar) was added dropwise. Finally, $2 \mathrm{~g}$ of polyethyleneglycol MW $\sim 2,000$ (Avocado) was added. The resulting solution was then placed in a microwave. The microwave power was set to $33 \%$ of $650 \mathrm{~W}$ and operated in 30 second cycles (on for $10 \mathrm{~s}$ off $20 \mathrm{~s}$ ) for $10 \mathrm{~min}$. The resulting powder was washed with ethanol, distilled water, and acetone and left to dry. M-doped $\mathrm{ZnO}(\mathrm{M}=\mathrm{Co}, \mathrm{Cr}, \mathrm{Fe}, \mathrm{Mn} \& \mathrm{Ni})$ was prepared as above, but with the addition of the appropriate amounts of the metal nitrate to was mixed with the zinc nitrate solution until the concentration of the dopant was $5 \%$.

Particles generated by this method have an average size of $10 \pm 2 \mathrm{~nm}$. This was confirmed by anlysis of the peak widths of the X-ray diffraction patterns (XRD). The XRD patterns of the powder sample were measured at room temperature with a Rigaku Diffractometer (DMAX-B) and $\mathrm{CuK}_{\alpha}$ radiation $(\lambda=1.5418 \AA)$. The samples were mounted on a silicon plate for X-ray measurements.

The hydrogen reduction set-up is discussed in Chapter 3. Temperature and magnetic field variations of the magnetization $(\mathrm{M})$ of these samples were measured using a commercial SQUID.

\subsection{Results and Discussion}

X-ray diffraction of pure zinc oxide formed via microwave irradiation is shown in Figure 6-1 (A). Figure 6-1 (B, C, and D) show 1, 5 and 7\% Co doped $\mathrm{ZnO}$ respectively. It 
is significant to note that $7 \%$ Co doped $\mathrm{ZnO}$ shows impurity phases. Thus, $5 \%$ was considered an upper limit for useful synthesis via microwave irradiation. Figures 6-2 (A), 6-3 (A), 6-4 (A), 6-5 (A) and 6-6 (A) show the XRD patterns of as-prepared samples of 5\% $\mathrm{Co}, \mathrm{Cr}, \mathrm{Fe}, \mathrm{Mn}$ and $\mathrm{Ni}$ doped $\mathrm{ZnO}$ correspondingly indicating a single phase of $\mathrm{ZnO}$ matching with zincite (PDF 36-1451) with no impurity phases of the dopant or their relevant oxides indicating perfect doping of the dopant metals into the $\mathrm{ZnO}$ lattice. Figures 2-6 (B and C) show the results of hydrogenation for 3 hours and 6 hours, respectively. XRD indicates that hydrogenation does not affect the composition of the sample except for one case where peaks due to $\mathrm{NiO}$ were observed as shown in Figure 6$6(\mathrm{~B})$.

The temperature variation of the magnetic susceptibility $(\chi)$ for the as-prepared samples of 5\% $\mathrm{Co}, \mathrm{Cr}, \mathrm{Mn}, \mathrm{Ni}$ and $\mathrm{Fe}$ doped $\mathrm{ZnO}$ are shown in Figures 6-7 though 6-11 respectively where the solid line in Figures 6-7, 6-8 and 6-9 are the fit to the Curie-Weiss Law. Figures 6-10 and 6-11 show $\chi$ versus $\mathrm{T}$ for the as-prepared samples of $\mathrm{Ni}$ and $\mathrm{Fe}$, neither of which display Curie-Weiss behavior.

As shown in a previous chapter, as-prepared $10 \% \mathrm{Co} / \mathrm{TiO}_{2}$ displays paramagnetic behavior. Upon hydrogenation of the sample at $573 \mathrm{~K}$, ferromagnetism is induced at room temperature. It has been reported that oxygen vacancies are essential to provide the exchange coupling between cobalt ions, ultimately leading to intrinsic room temperature ferromagnetism (RTFM). ${ }^{13}$ The results of hydrogenating the as-prepared samples can be described as follows. Hydrogenation of $5 \% \mathrm{Ni} / \mathrm{ZnO}$ resulted in the presence of metallic nickel in the XRD pattern. However, metallic peaks were not present in the chromium, manganese, cobalt and iron samples after hydrogenation. When hydrogenated for 3 hours 
the chromium and manganese samples still retain Curie-Weiss behavior as shown in Figures 6-12 and 6-13. The $\chi$ vs. T measurements for the 3 hour hydrogenated samples of cobalt-doped and iron-doped are shown in Figures 6-14 and 6-15. The absence of a peak in $\chi$ for the zero-field-cooled cases, which is a signature of the blocking temperature $\left(T_{B}\right)$ for cobalt and iron, provides assurance that cobalt and iron nanoparticles are not present in our samples. The $M$ vs $H$ data for these two samples indicates a controlled transformation from paramagnetism to room temperature ferromagnetism indicated by the hystersis loops (shown in Figures 6-16 and 6-17). Hydrogenation for 6 hours did not alter the paramagnetic behavior observed for the chromium and manganese samples as shown in Figures 6-18 and 6-19. The $\chi$ vs. T measurements for the 3 hour hydrogenated samples of cobalt and iron are shown in Figures 6-20 and 6-21. The $M$ vs $H$ data indicates RTFM with an increase in the coercivity as shown in Figures 6-22 and 6-23.

\subsection{Conclusion}

In conclusion, we have demonstrated a one step synthesis of $\mathrm{M}$ doped $\mathrm{ZnO}$ nanoparticles via microwave irradiation. To the best of our knowledge this is the first report of a metal being doped into a zinc oxide lattice using microwave irradation. This method offers extremely short reaction times and produces high purity nanoparticles. The magnetic measurements show that the as-prepared samples of $5 \% \mathrm{M}$ doped $\mathrm{ZnO}$ are paramagnetic. However, hydrogen reduction at $573 \mathrm{~K}$ for the cobalt and iron doped samples transforms the magnetic nature from paramagnetic to ferromagnetic. This method may possibly be extended to synthesize other transition metal doped oxides quickly and efficiently. 


\subsection{References}

(1) Hingorani, S; Pillai, V; Kumar, P; Multani, M. S; Shah, D. O. Materials Res. Bull. (1993), 28, 1303.

(2) Lin, H. M; Tzeng, S. J; Hsiau. P. J; Tsai, W. L; Nanostruct. Mater. (1998), 10, 465.

(3) X. Zhao, S. C. Zhang, C. Li, B. Zheng and H. Gu, Mater. Synth. Process. (1997), 5, 227.

(4) Rao, K. J; Vaidhyanathan, B; Gaguli, M; Ramajrishnan, P. A. Chem. Mater. (1999), 11,882 .

(5) Xue-Hong, L. Chem. Commun. (2001), 937.

(6) Liang, J; Deng, ZX; Jiang, X; Li, F; Li, Y. Inorg. Chem. (2002), 41, 3602.

(7) Wang, H; Jin-Zhong, X; Jun-Jie, Z; Hong-Yuan, C. J. of Crystal Growth. (2002), 244, 88 .

(8) Gallis, K; Landry C; Adv. Mater. (2001), 13(1), 23.

(9) Palchik, O; Zhu, J; Gedankan, A. J. Mater. Chem. (2000), 10, 1251.

(10) Boxall, D; Lukehart, C. Chem. Mater. (2001), 13, 806.

(11) Zhu, J; Palchik, O; Chen, S; Gedanken, A; J. Phys. Chem. B. (2000), 104, 7344.

(12) Tu, W; Liu, H. J. Mater. Chem. (2000), 10, 2207.

(13) Boxall, D; Lukeart, C. Chem. Mater. (2001), 13, 891. 

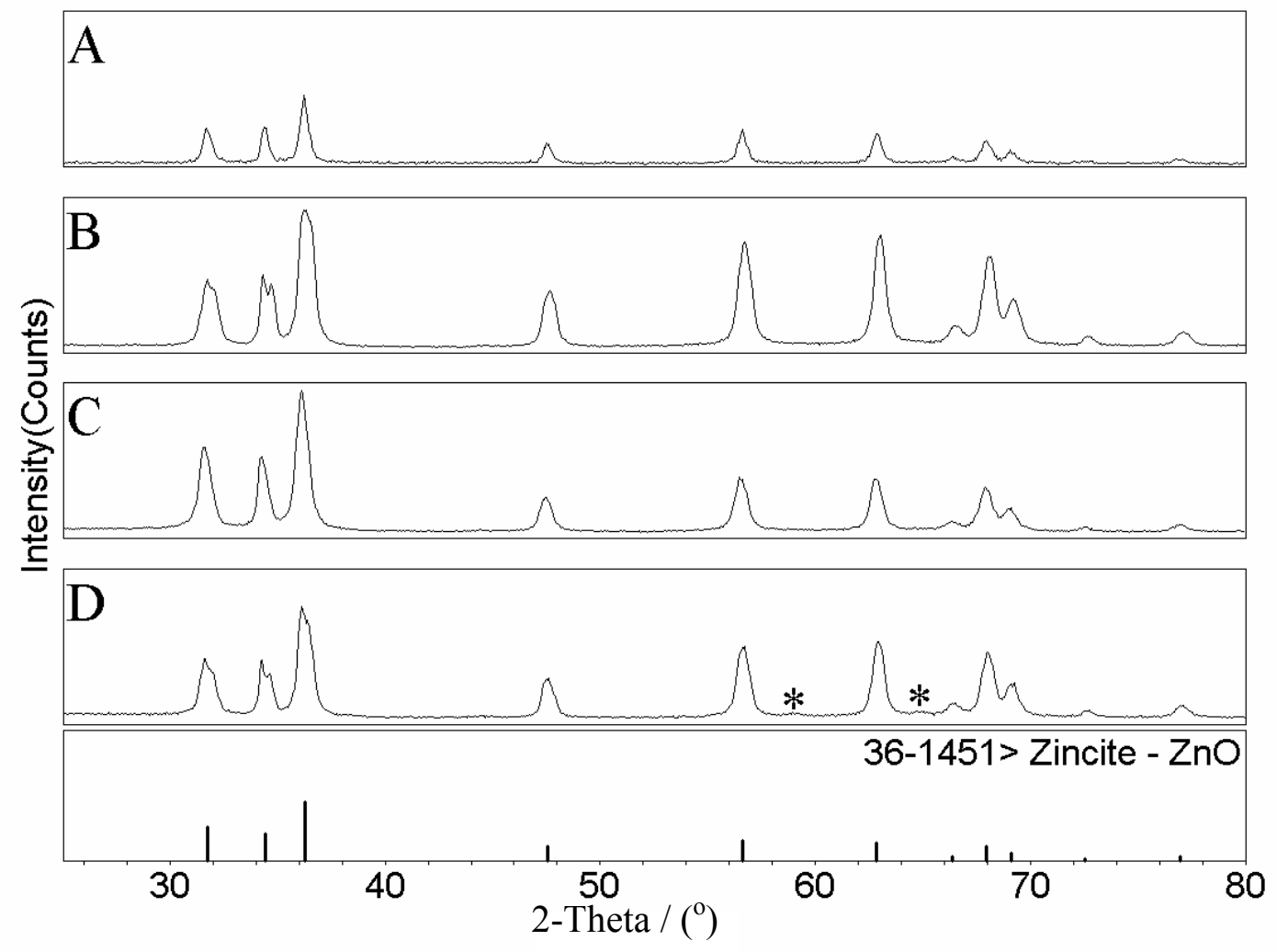

Figure 6-1. XRD patterns showing as-prepared samples of pure $\mathrm{ZnO}(\mathrm{A}), 1 \% \mathrm{Co} / \mathrm{ZnO}$ (B), $5 \% \mathrm{Co} / \mathrm{ZnO}(\mathrm{C})$, and $7 \% \mathrm{Co} / \mathrm{ZnO}(\mathrm{D})$ matching with the zincite phase (PDF 361451). The asterisks indicate contaminant peaks. 

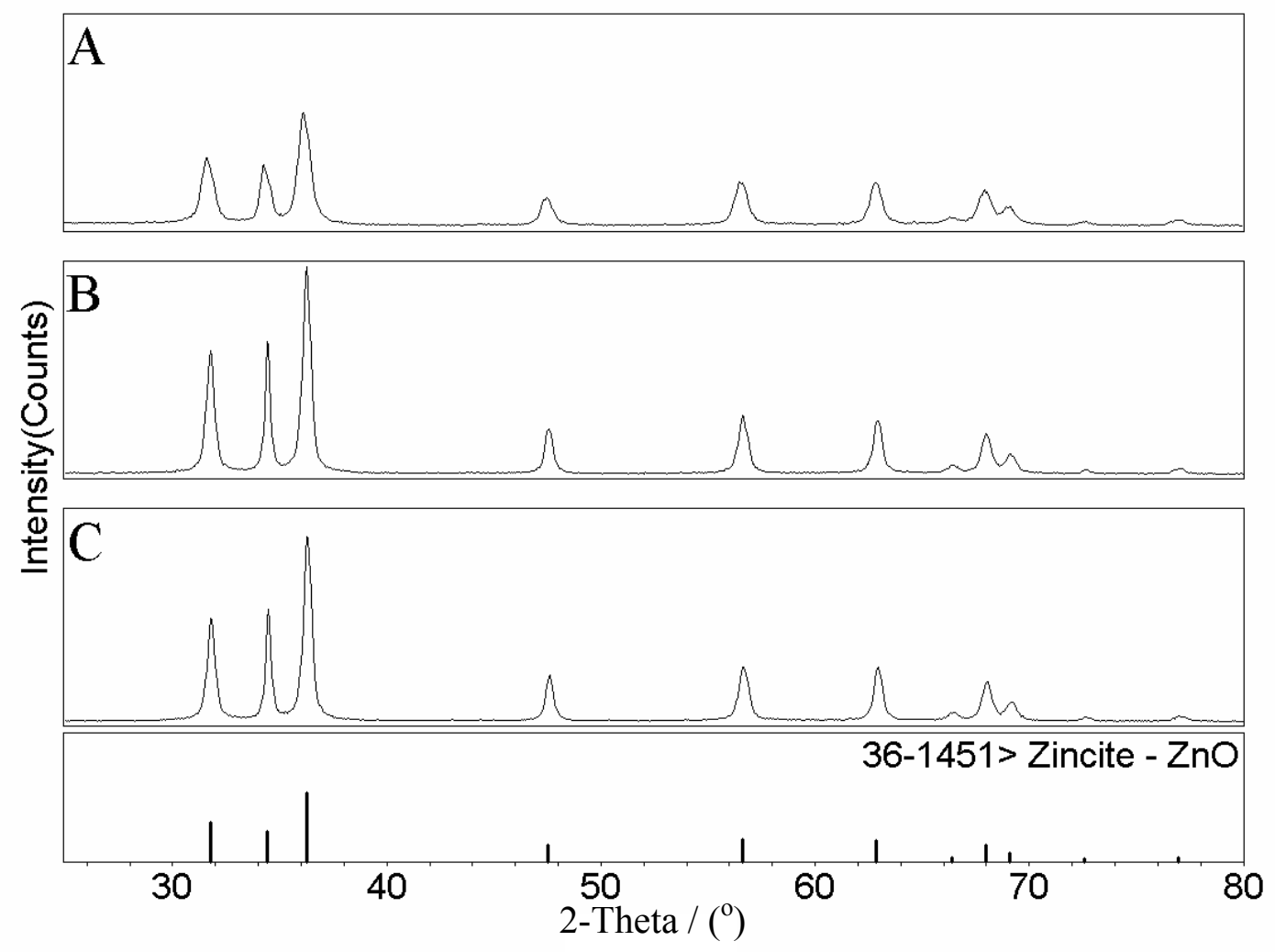

Figure 6-2. XRD patterns showing 5\% $\mathrm{Co} / \mathrm{ZnO}$ as-prepared (A) and hydrogenated for $3 \mathrm{hrs}(\mathrm{B})$ and $6 \mathrm{hrs}(\mathrm{C})$ matching with the zincite phase (PDF 36-1451). 

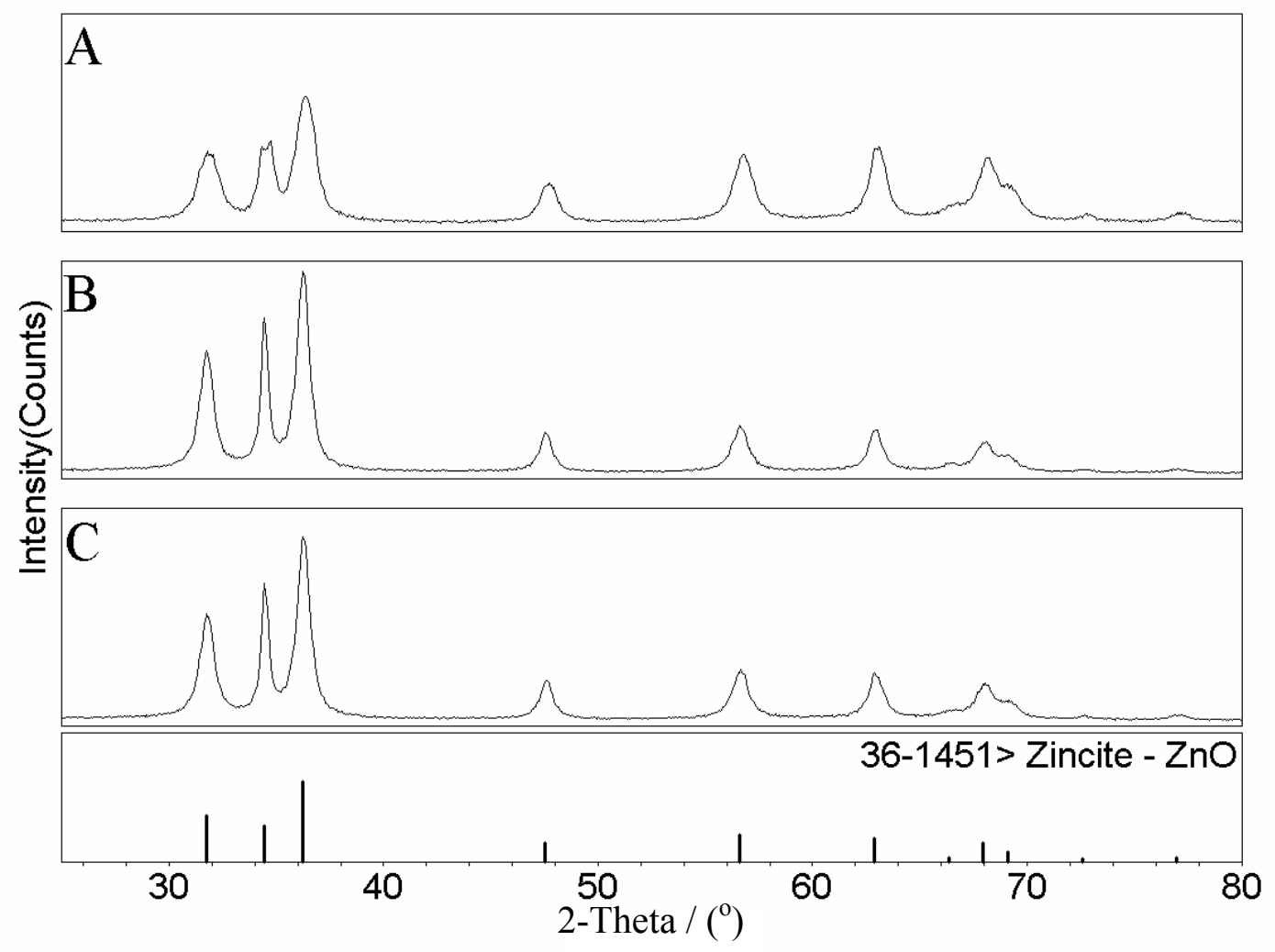

Figure 6-3. XRD patterns showing 5\% $\mathrm{Cr} / \mathrm{ZnO}$ as prepared (A) and hydrogenated for $3 \mathrm{hrs}(\mathrm{B})$ and $6 \mathrm{hrs}(\mathrm{C})$ matching with the zincite phase (PDF 36-1451). 

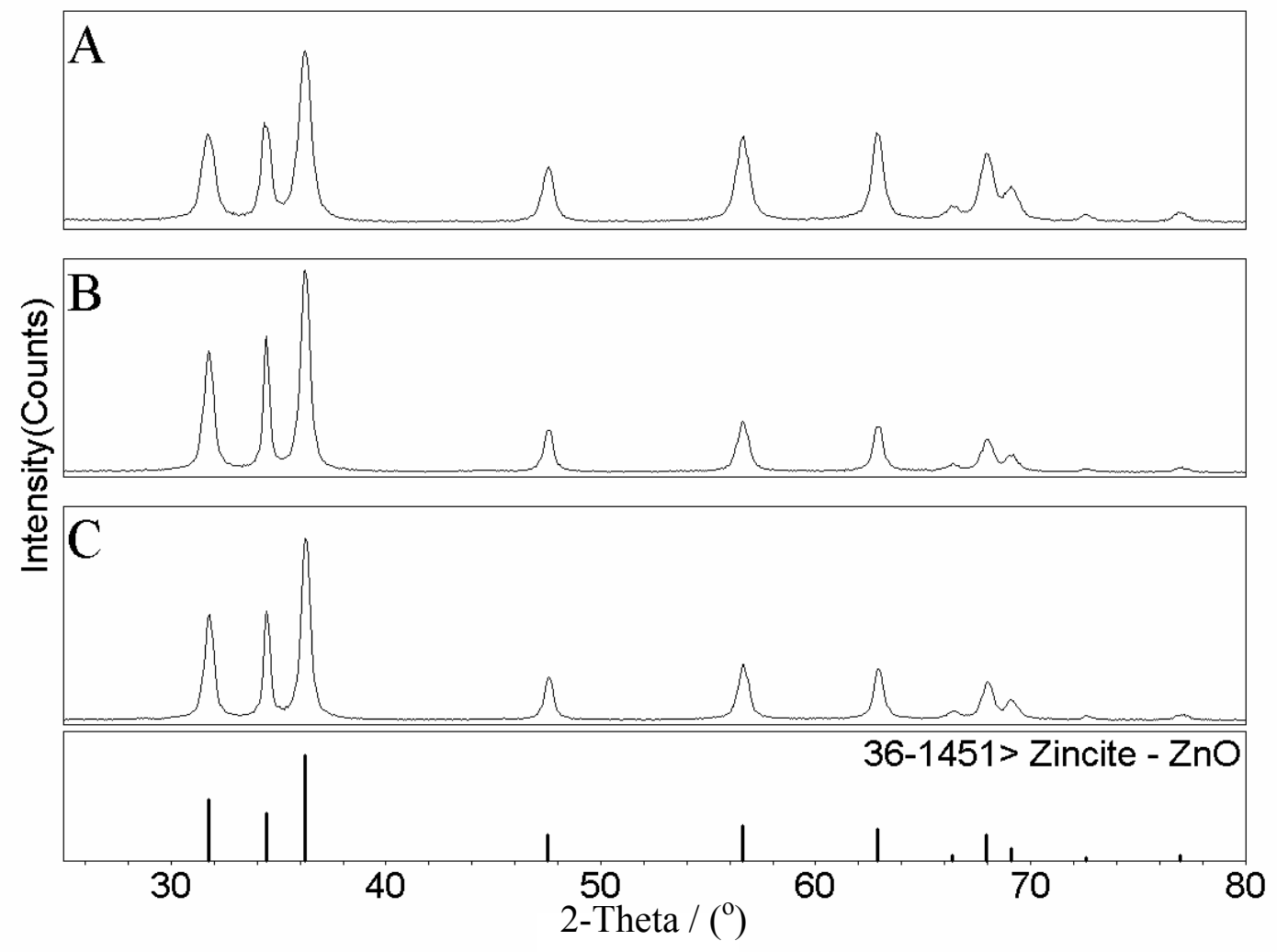

Figure 6-4. XRD patterns showing 5\% Fe/ZnO as-prepared (A) and hydrogenated for $3 \mathrm{hrs}(\mathrm{B})$ and $6 \mathrm{hrs}(\mathrm{C})$ matching with the zincite phase (PDF 36-1451). 

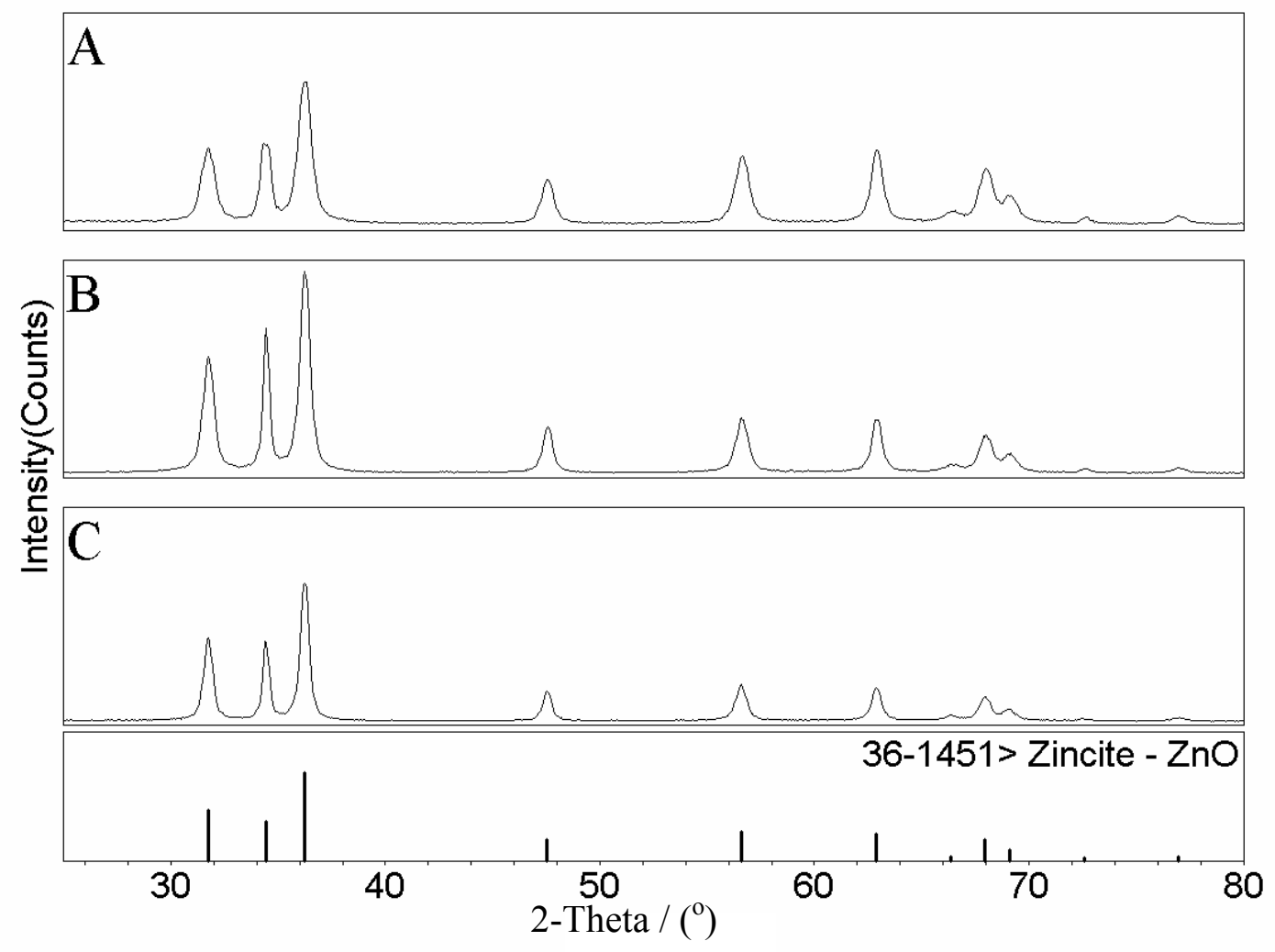

Figure 6-5. XRD patterns showing 5\% $\mathrm{Mn} / \mathrm{ZnO}$ as-prepared (A) and hydrogenated for $3 \mathrm{hrs}(\mathrm{B})$ and $6 \mathrm{hrs}(\mathrm{C})$ matching with the zincite phase (PDF 36-1451). 


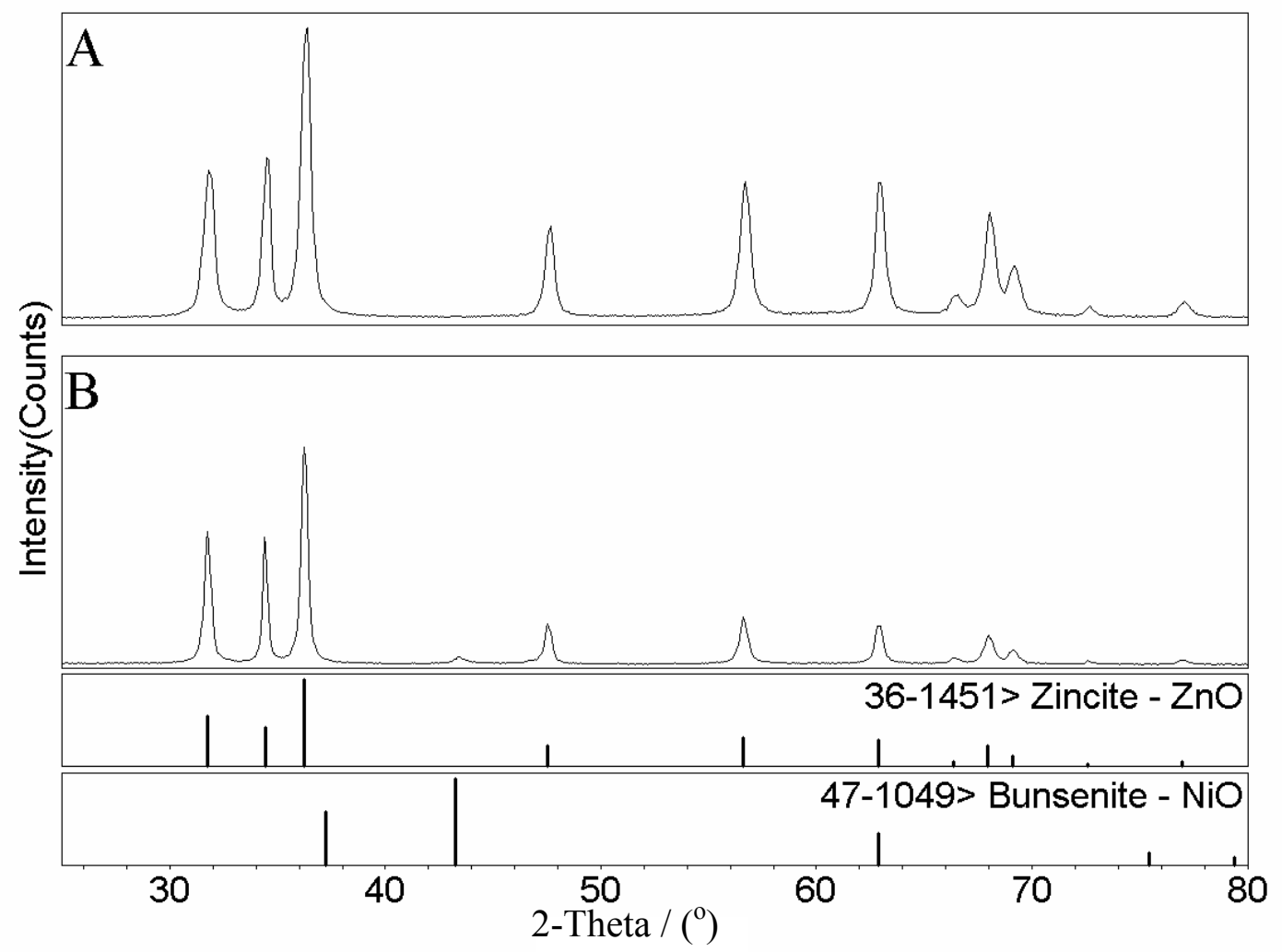

Figure 6-6. XRD patterns showing 5\% Ni/ZnO as-prepared (A) and hydrogenated for $3 \mathrm{hrs}(\mathrm{B})$. The expectant lines for zincite and nickel oxide are shown below. 


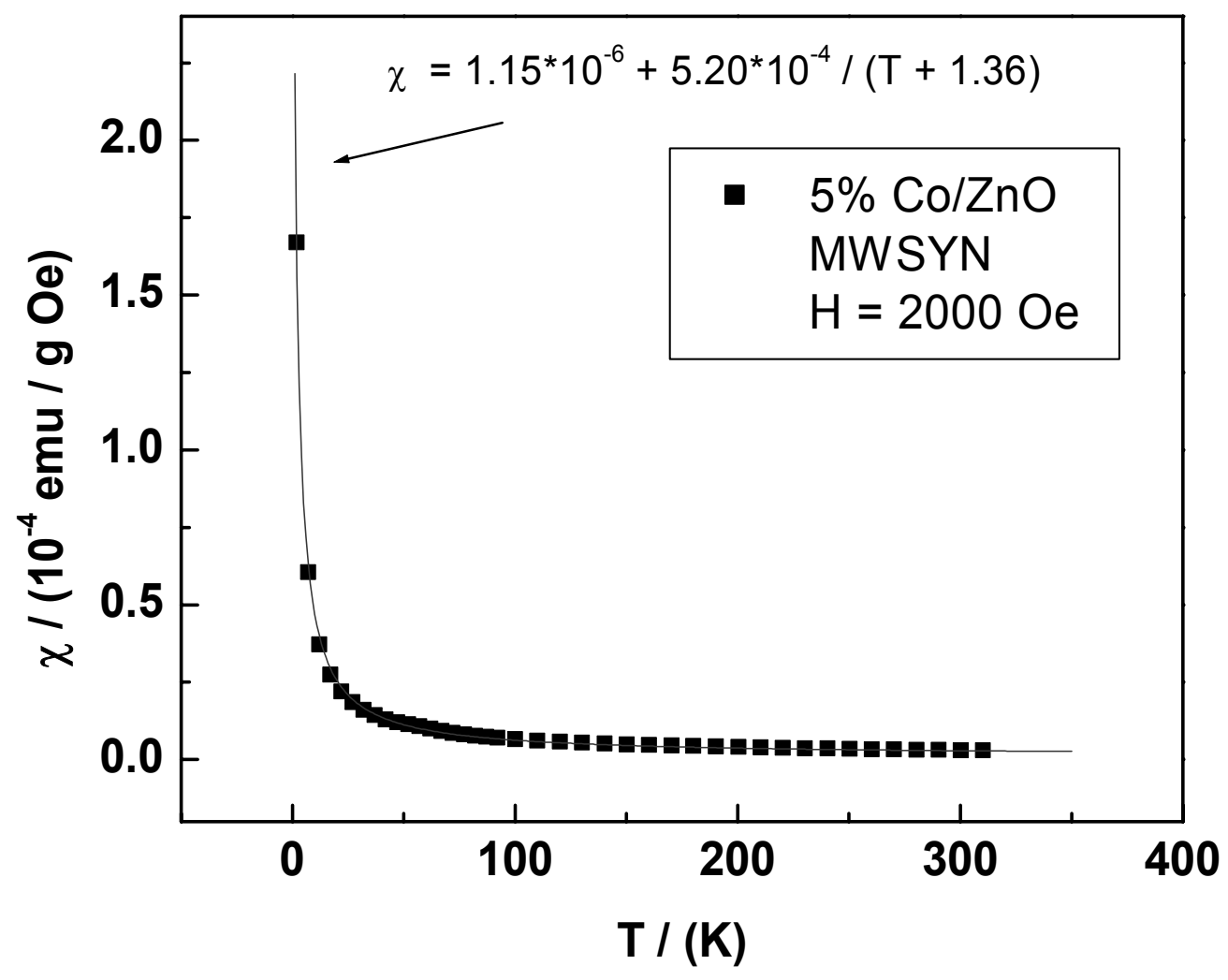

Figure 6-7. Temperature dependence of the magnetic susceptibility $(\chi)$ of the as-prepared $5 \% \mathrm{Co} / \mathrm{ZnO}$. The solid line is fit to the equation shown. 


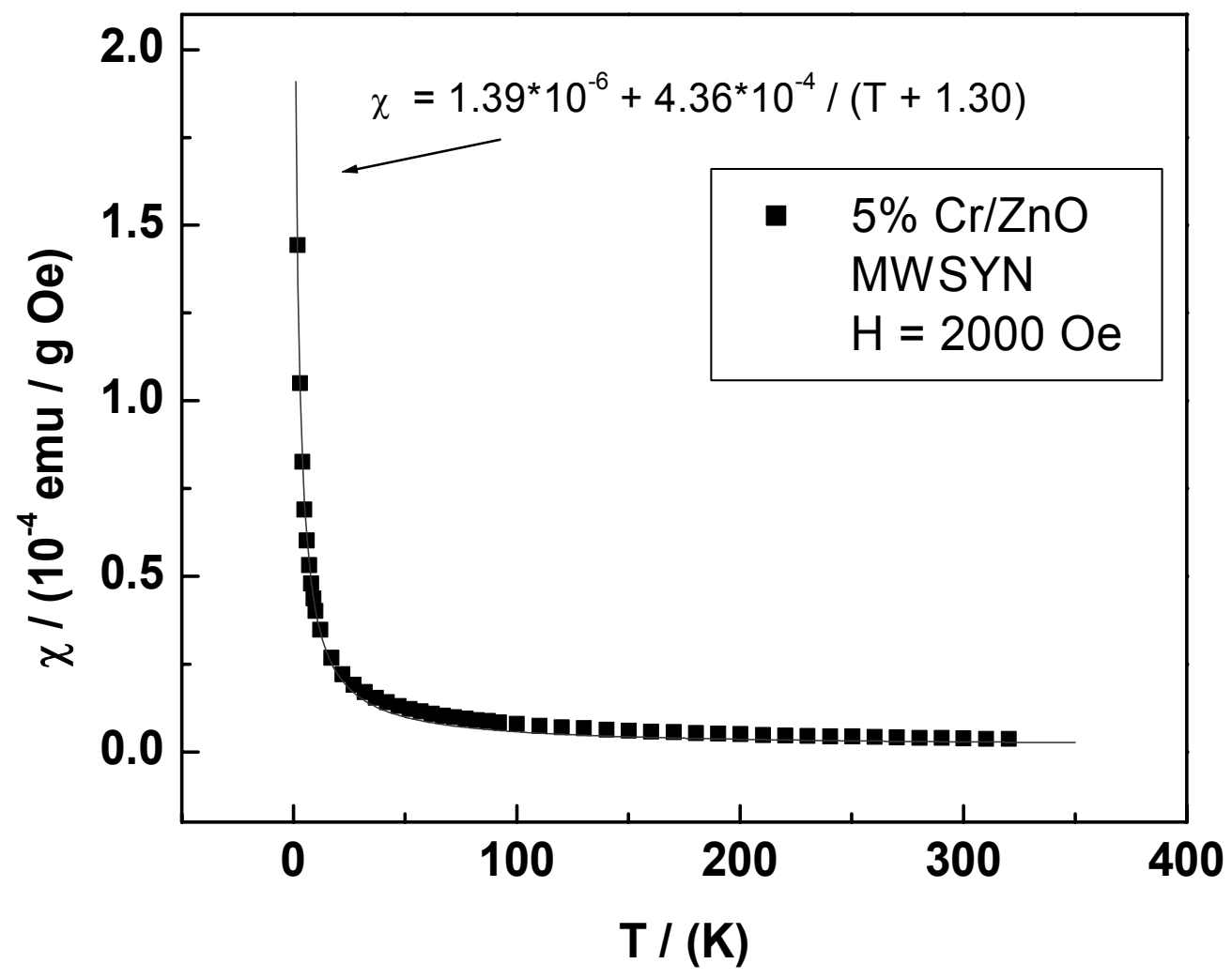

Figure 6-8. Temperature dependence of the magnetic susceptibility $(\chi)$ of the as-prepared $5 \% \mathrm{Cr} / \mathrm{ZnO}$. The solid line is fit to the equation shown. 


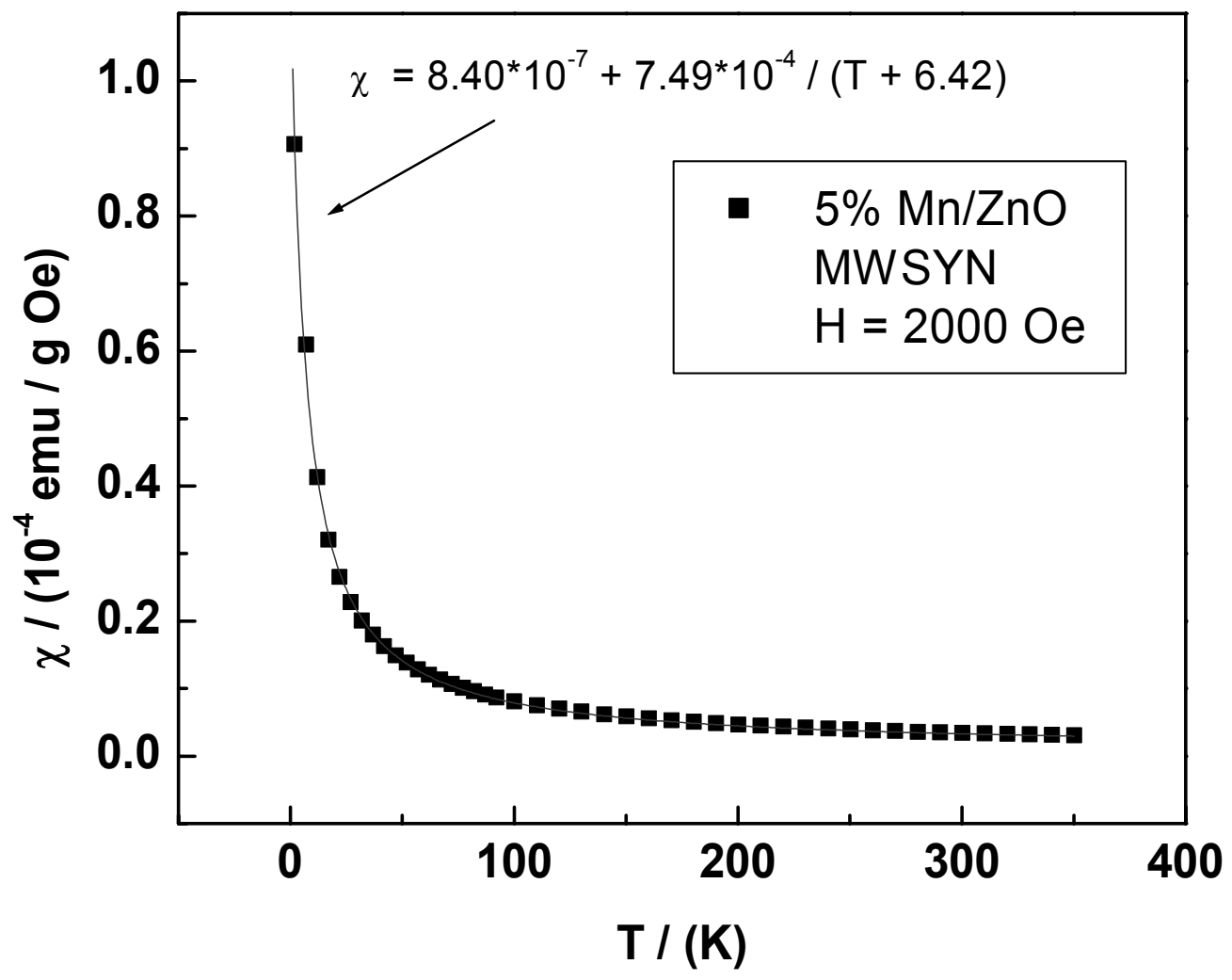

Figure 6-9. Temperature dependence of the magnetic susceptibility $(\chi)$ of the as-prepared $5 \% \mathrm{Mn} / \mathrm{ZnO}$. The solid line is fit to the equation shown. 


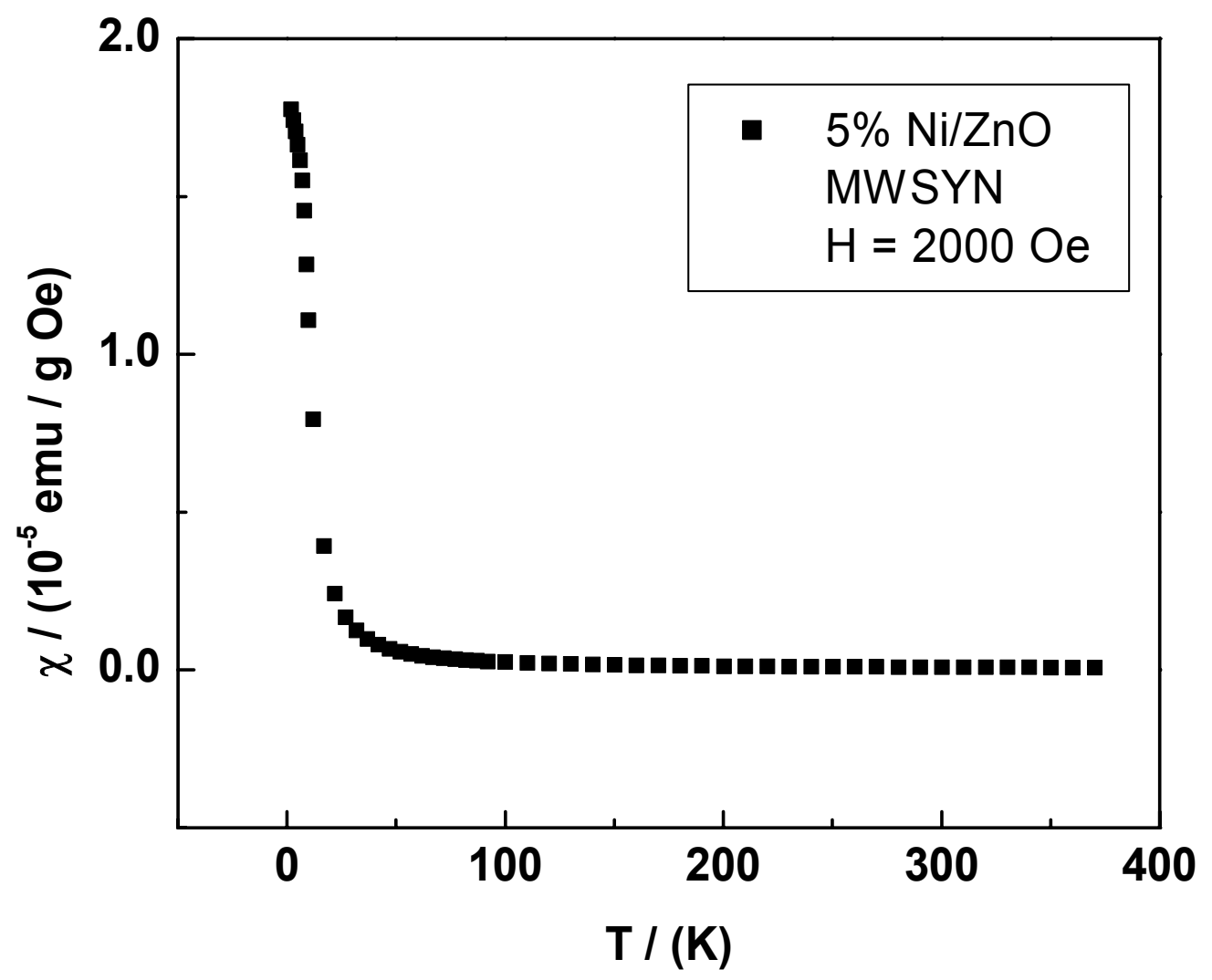

Figure 6-10. Temperature dependence of the magnetic susceptibility $(\chi)$ of the asprepared $5 \% \mathrm{Ni} / \mathrm{ZnO}$. 


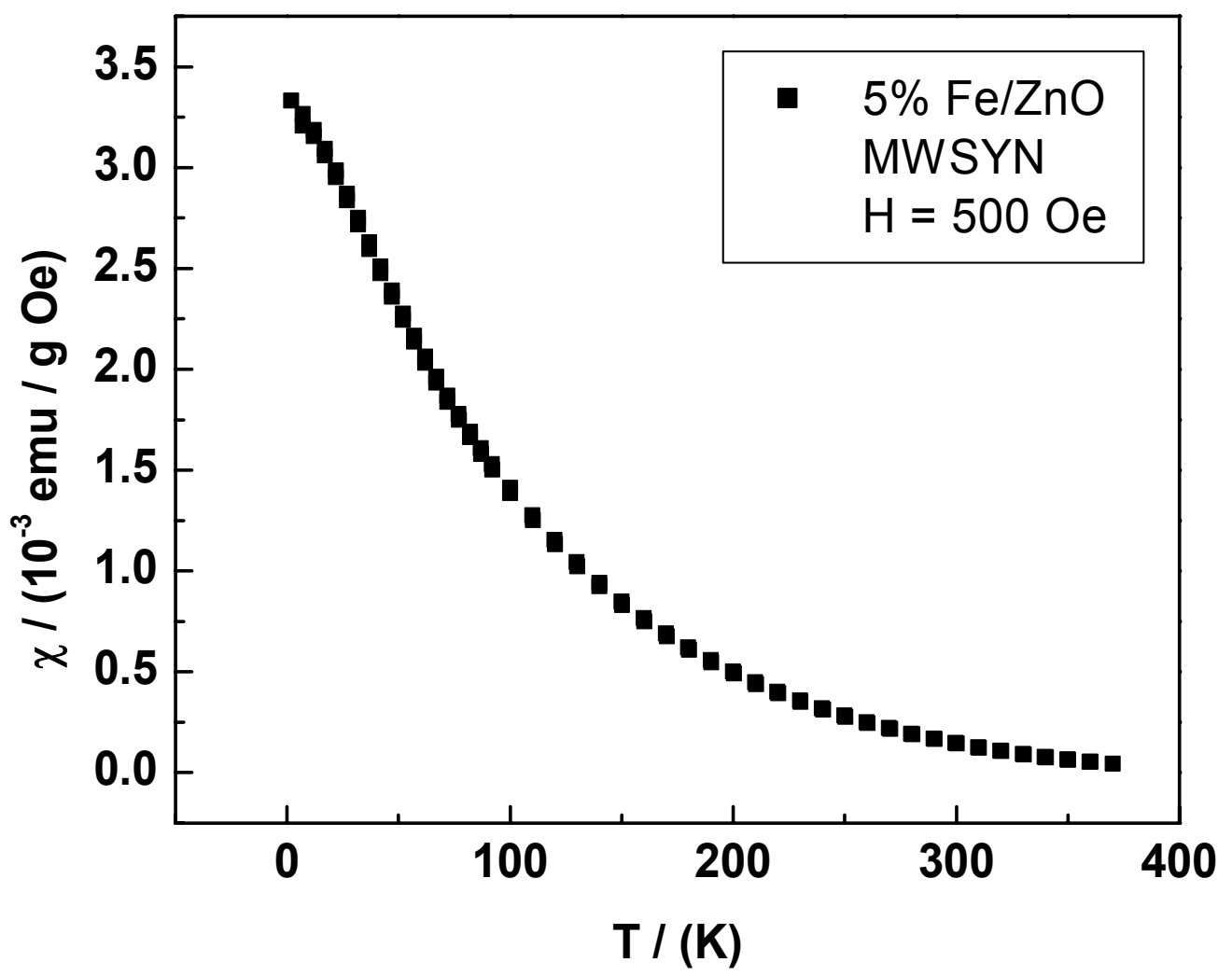

Figure 6-11. Temperature dependence of the magnetic susceptibility $(\chi)$ of the asprepared $5 \% \mathrm{Fe} / \mathrm{ZnO}$. 


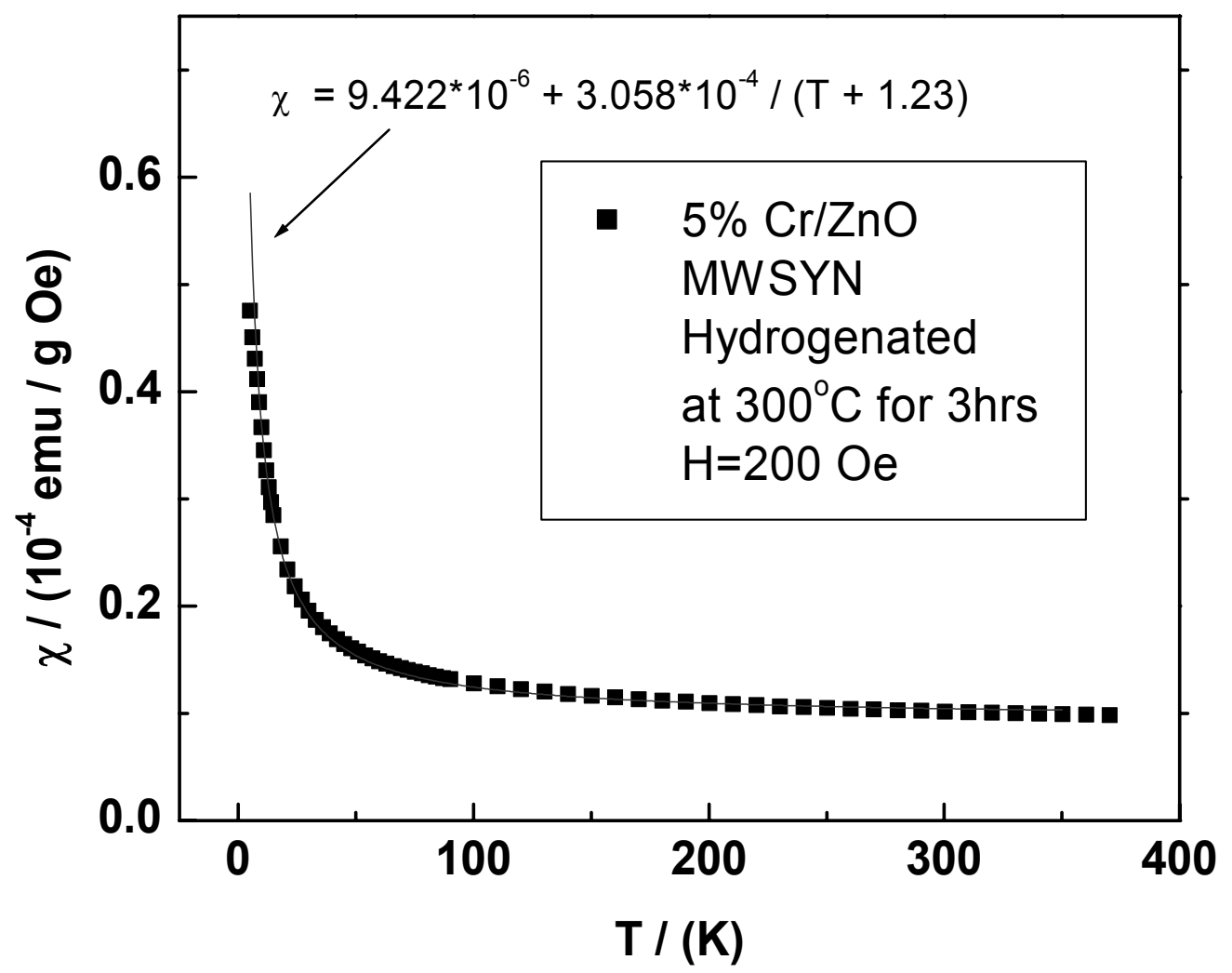

Figure 6-12. Temperature dependence of the magnetic susceptibility $(\chi)$ of the asprepared $5 \% \mathrm{Cr} / \mathrm{ZnO}$ hydrogenated for 3 hours. The solid line is fit to the equation shown. 


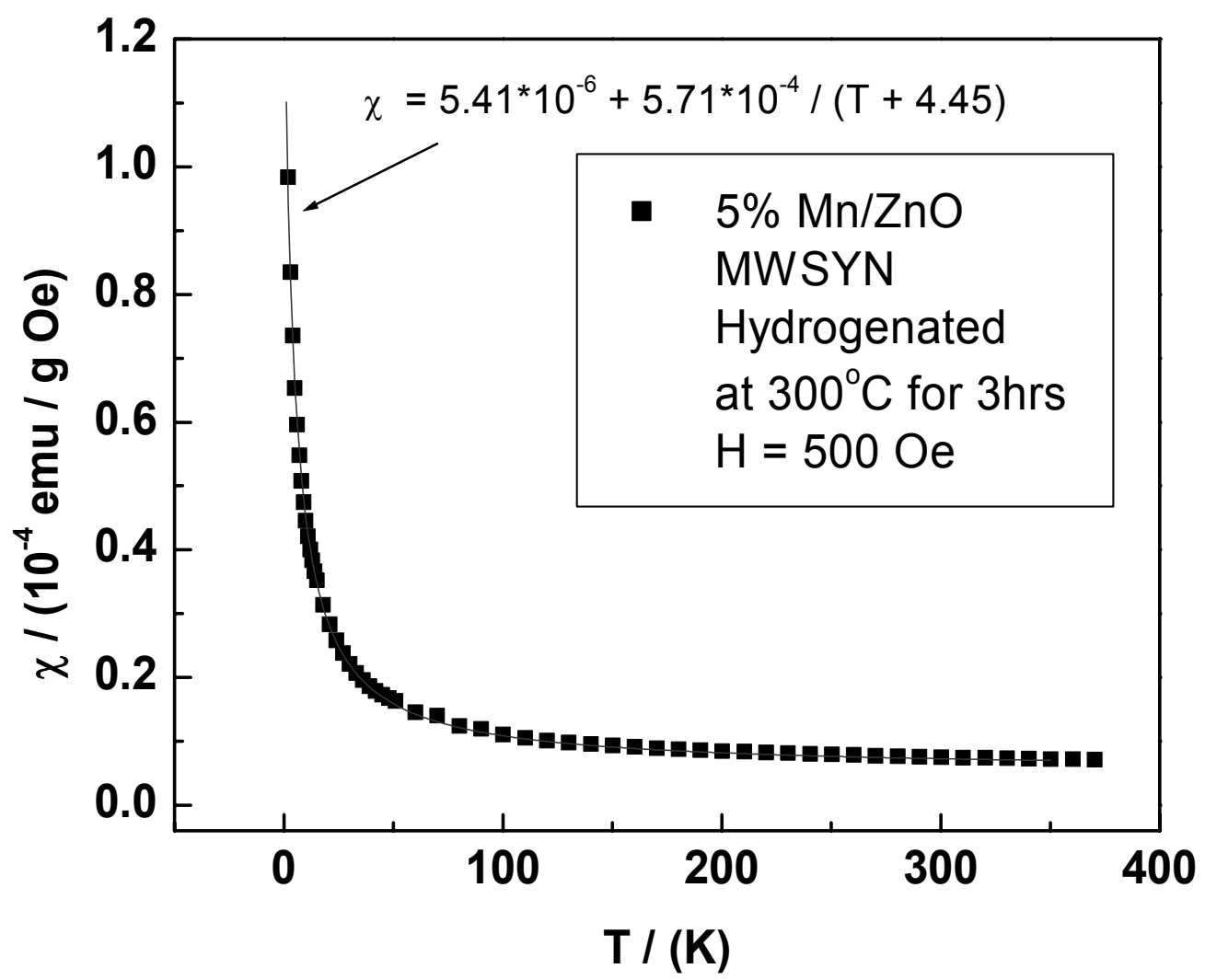

Figure 6-13. Temperature dependence of the magnetic susceptibility $(\chi)$ of the asprepared $5 \% \mathrm{Mn} / \mathrm{ZnO}$ hydrogenated for 3 hours. The solid line is fit to the equation shown. 


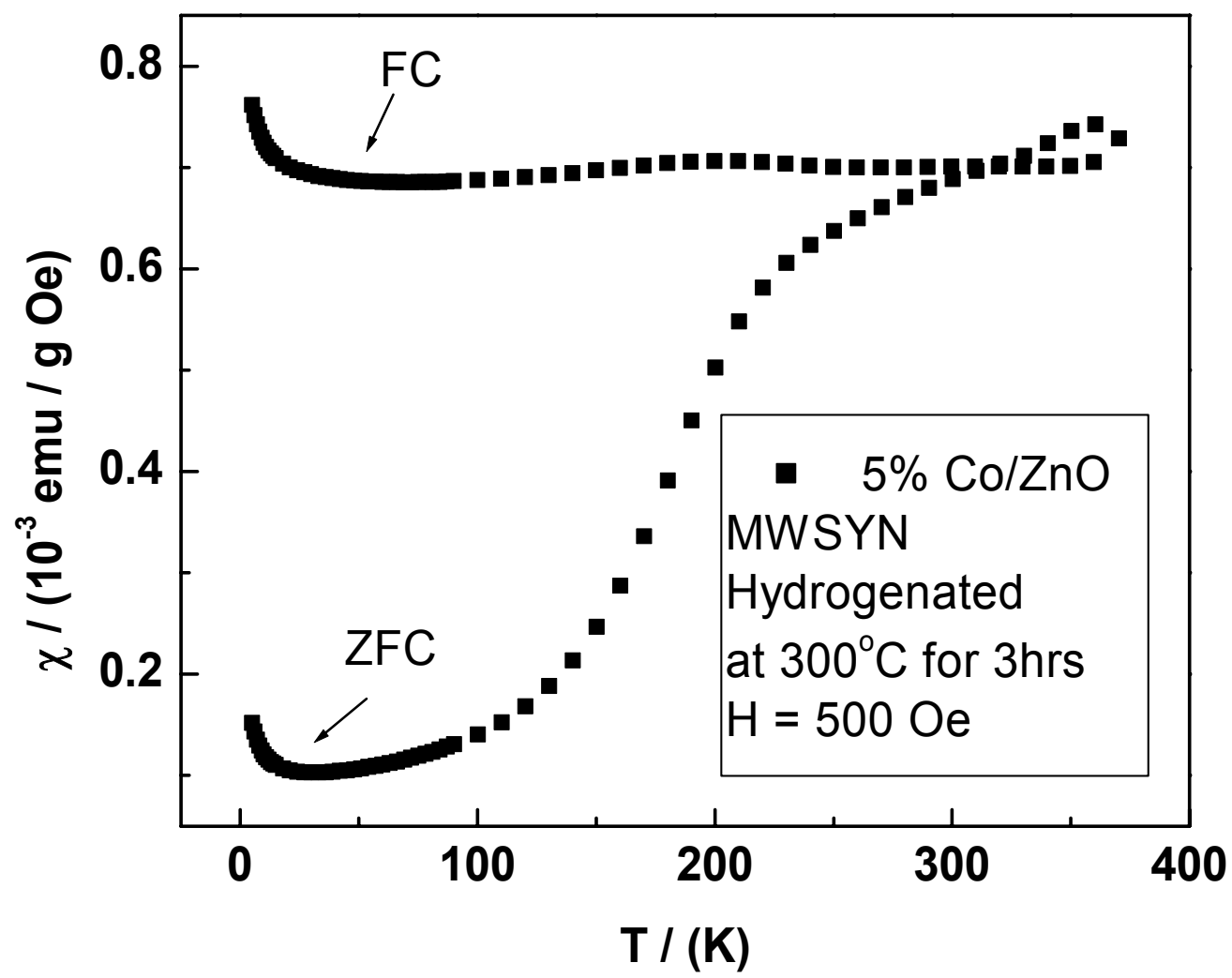

Figure 6-14. Temperature dependence of the magnetic susceptibility $(\chi)$ of the asprepared $5 \% \mathrm{Co} / \mathrm{ZnO}$ hydrogenated for 3 hours under zero-field-cooled and field-cooled conditions. 


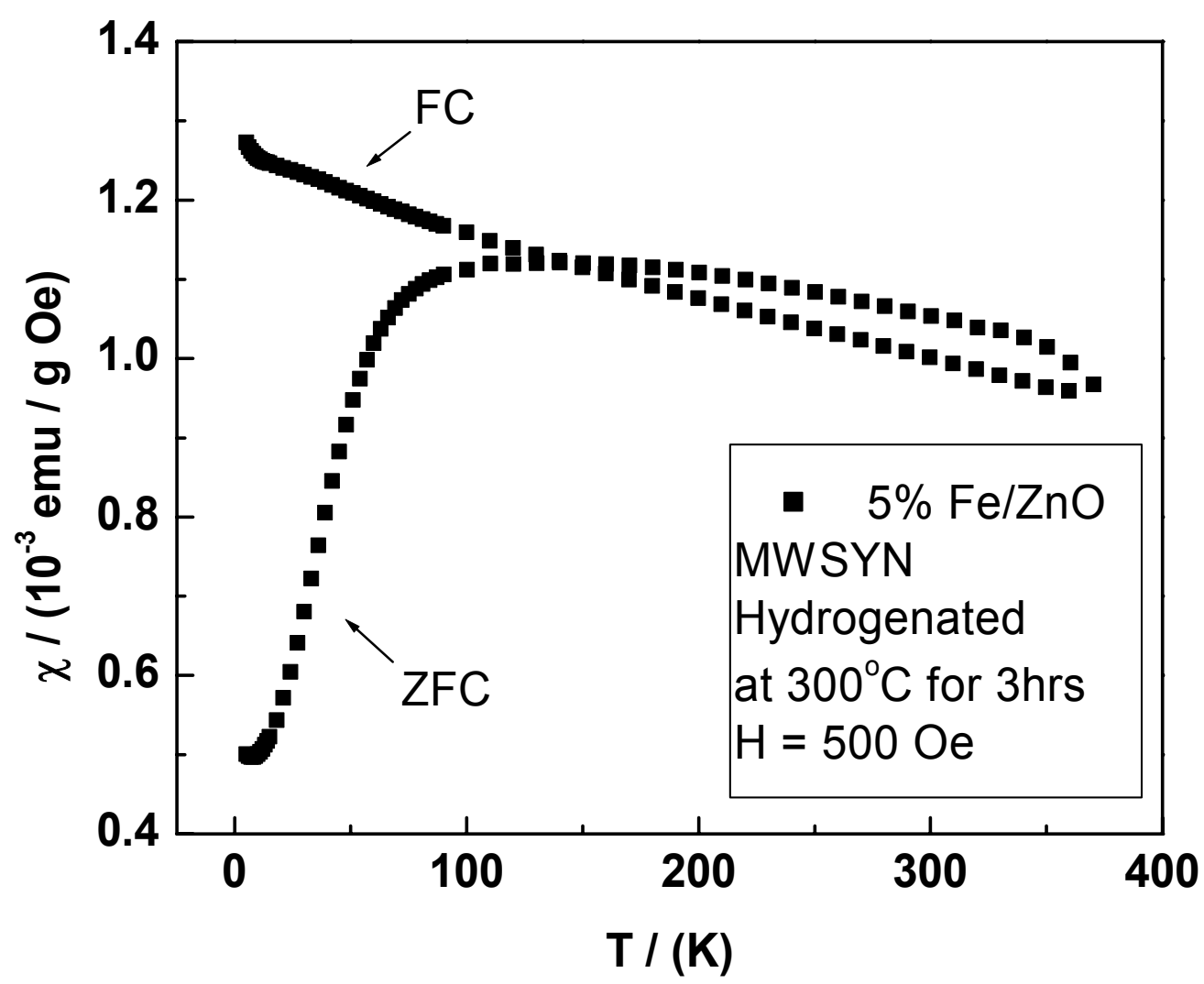

Figure 6-15. Temperature dependence of the magnetic susceptibility $(\chi)$ of the asprepared $5 \% \mathrm{Fe} / \mathrm{ZnO}$ hydrogenated for 3 hours under zero-field-cooled and field-cooled conditions. 

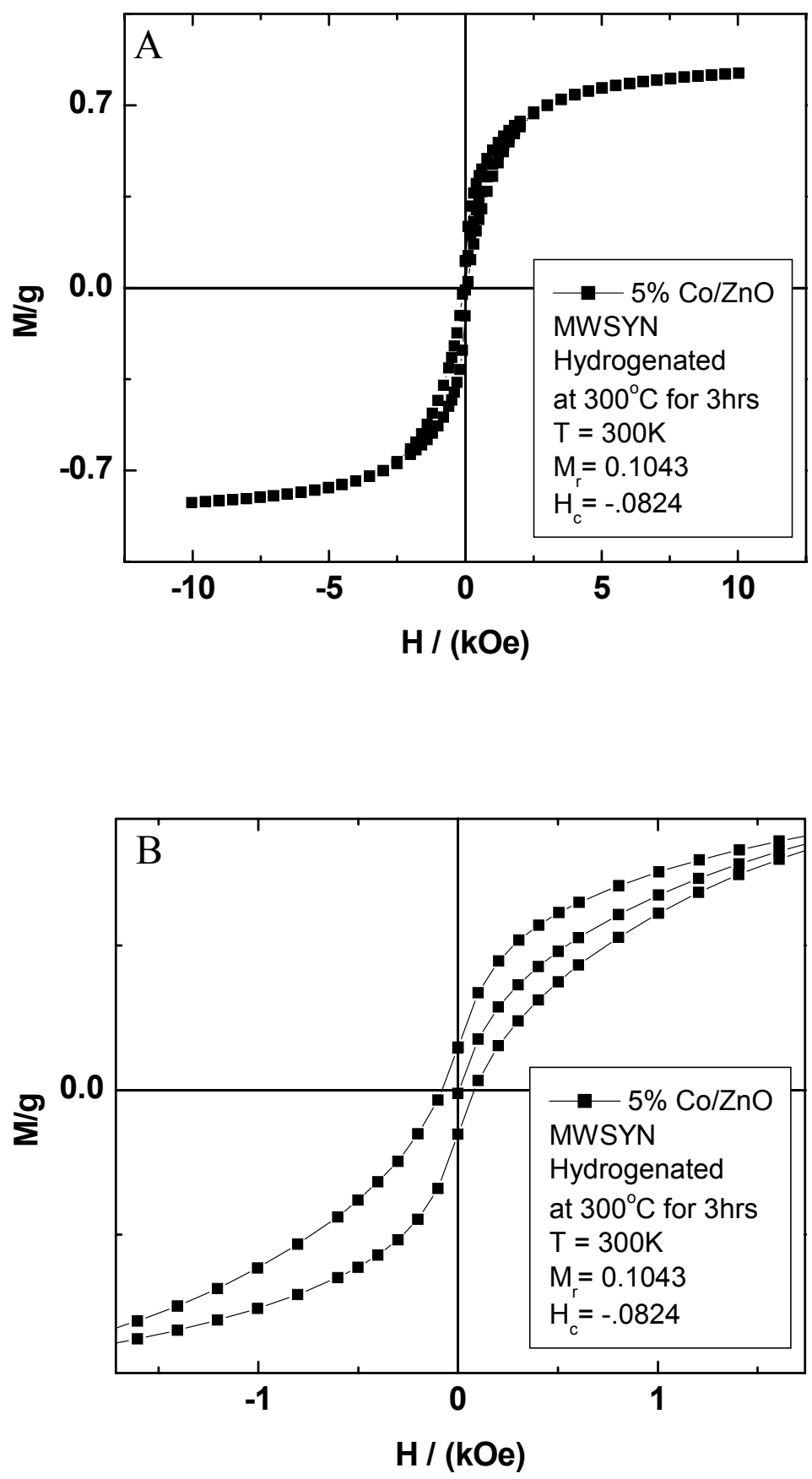

Figure 6-16. $M v s H$ Variation of $5 \% \mathrm{Co} / \mathrm{ZnO}$ at $300 \mathrm{~K}(\mathrm{~A})$ and an expanded view (B). 

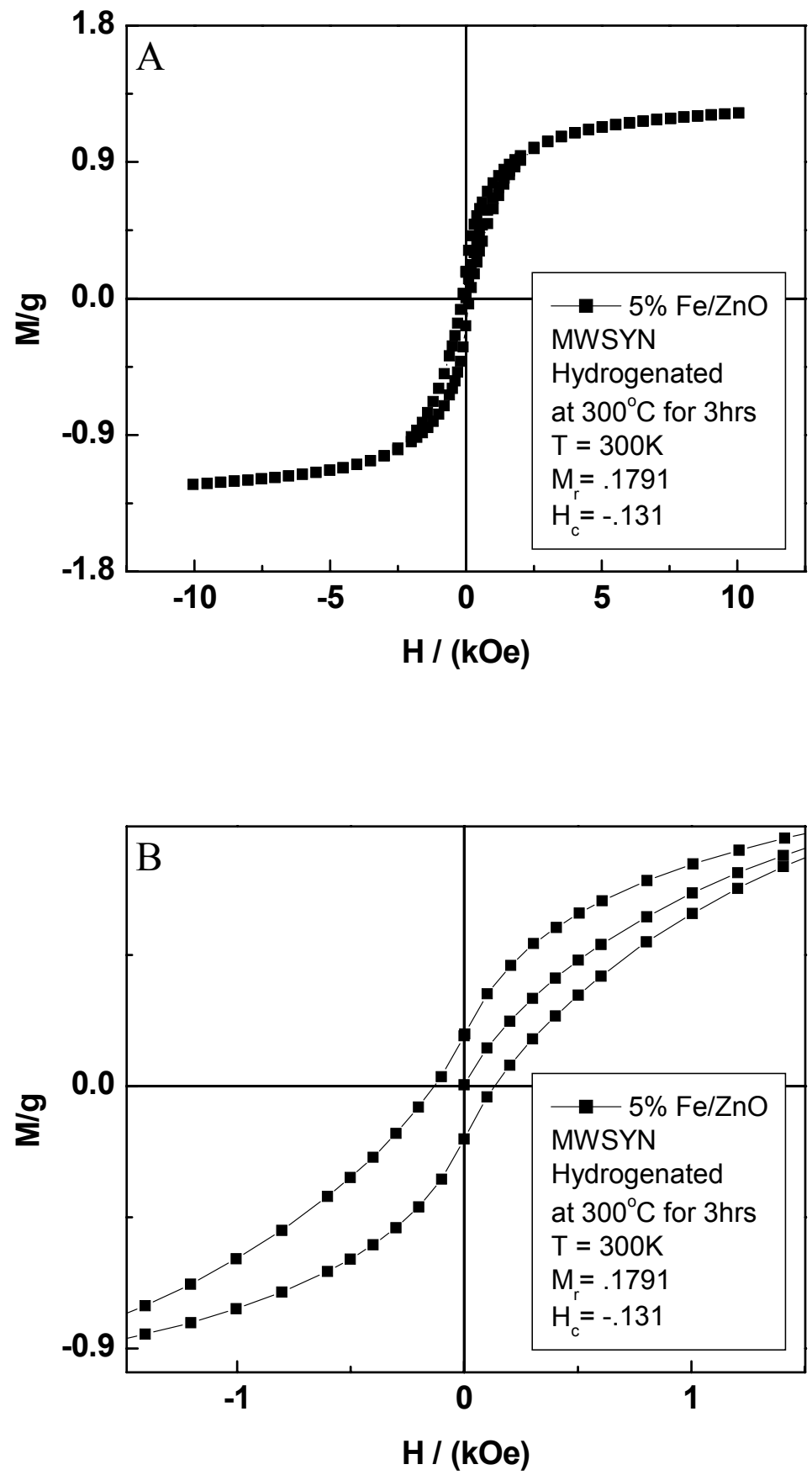

Figure 6-17. $M v s H$ Variation of $5 \% \mathrm{Fe} / \mathrm{ZnO}$ at $300 \mathrm{~K}$ (A) and an expanded view (B). 


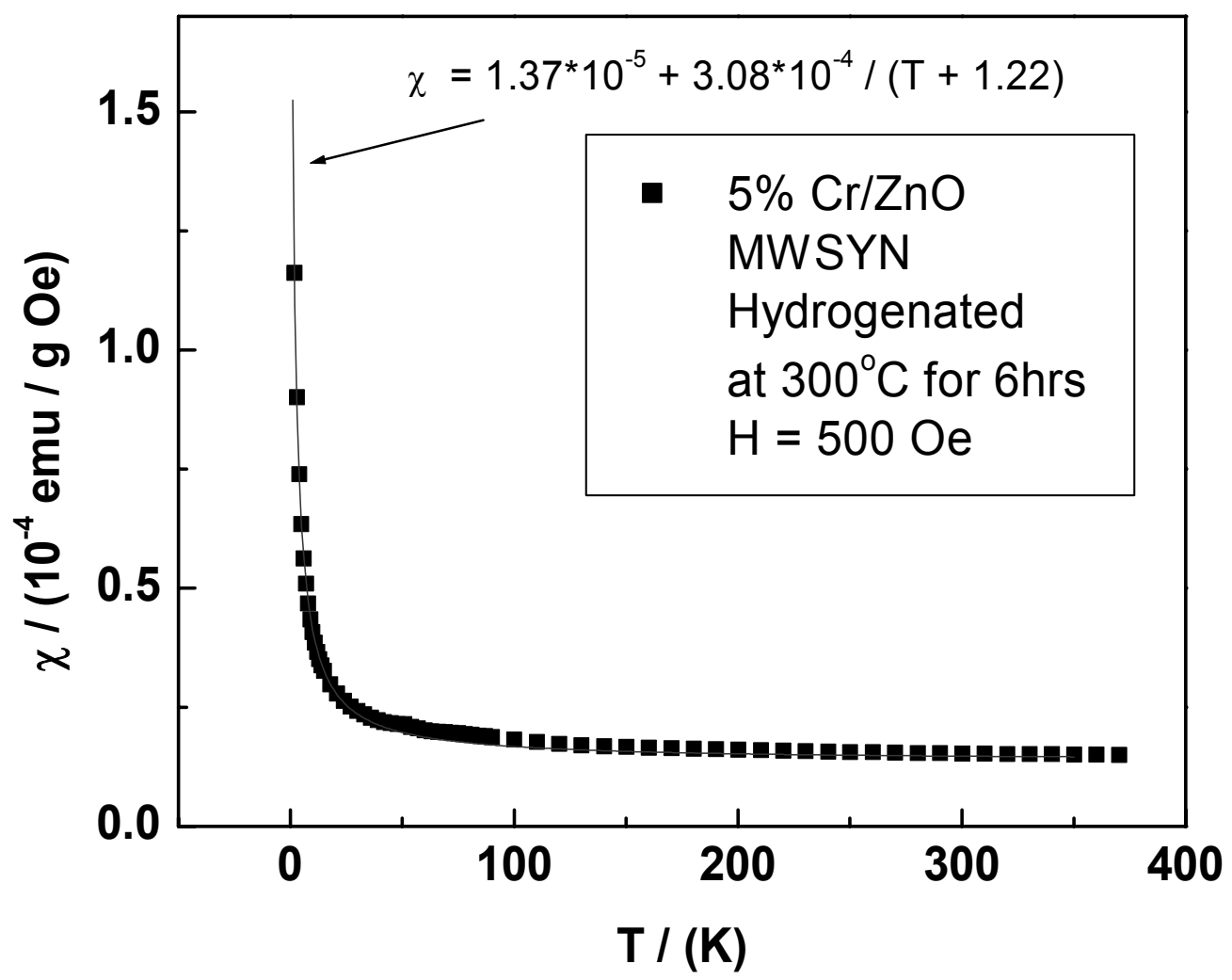

Figure 6-18. Temperature dependence of the magnetic susceptibility $(\chi)$ of the asprepared $5 \% \mathrm{Cr} / \mathrm{ZnO}$ hydrogenated for 6 hours. The solid line is fit to the equation shown. 


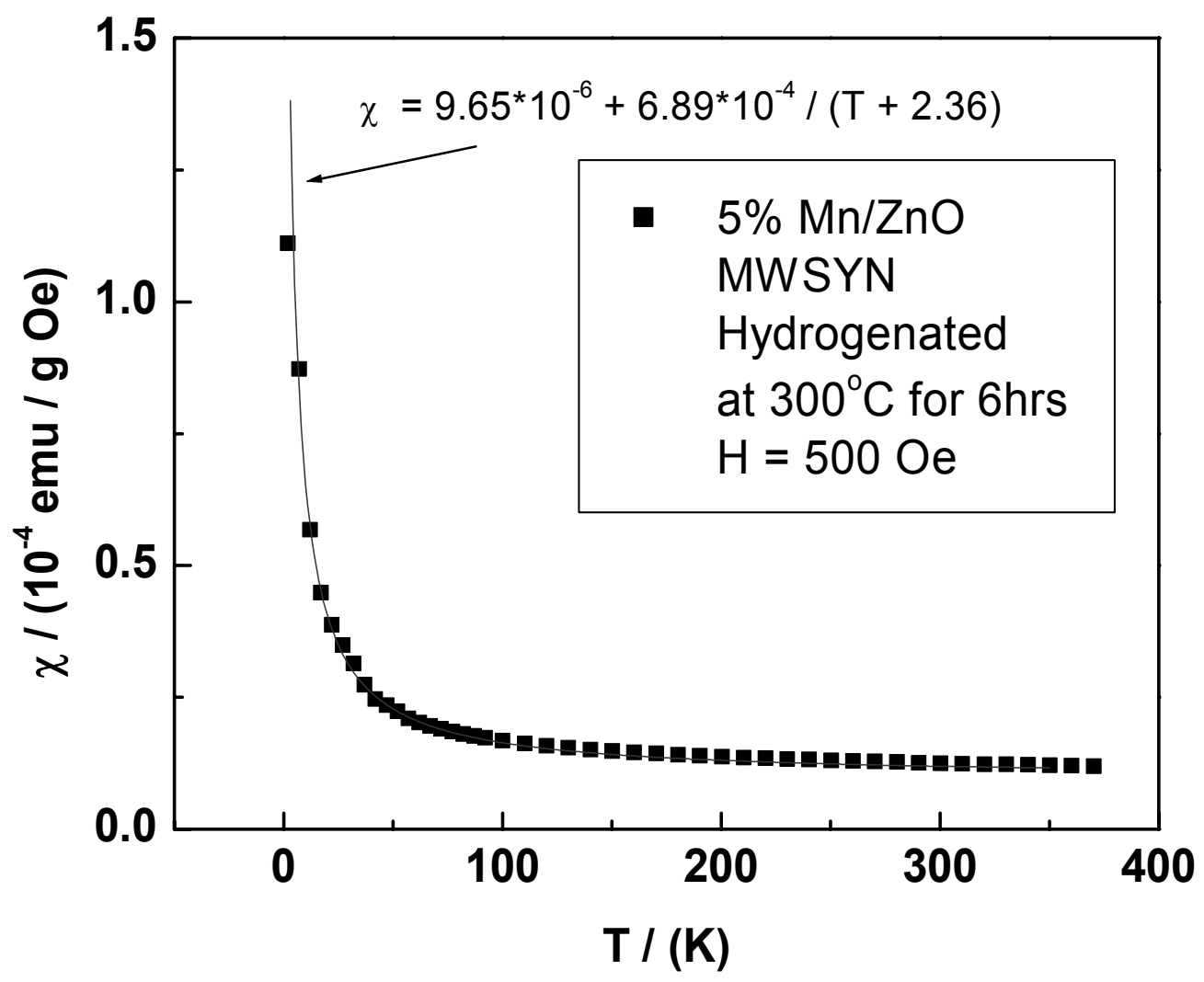

Figure 6-19. Temperature dependence of the magnetic susceptibility $(\chi)$ of the asprepared $5 \% \mathrm{Mn} / \mathrm{ZnO}$ hydrogenated for 6 hours. The solid line is fit to the equation shown. 


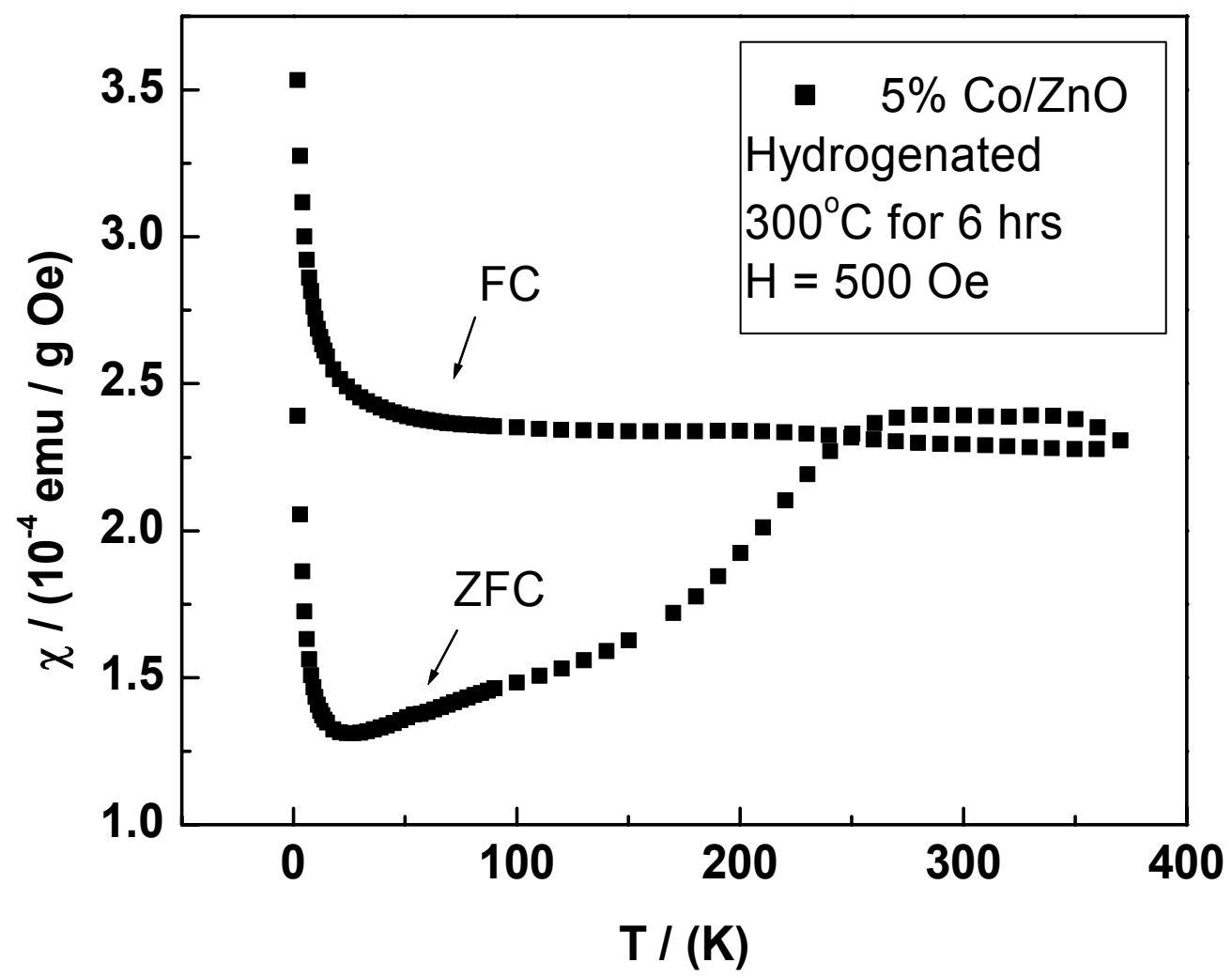

Figure 6-20. Temperature dependence of the magnetic susceptibility $(\chi)$ of the asprepared $5 \% \mathrm{Co} / \mathrm{ZnO}$ hydrogenated for 6 hours under zero-field-cooled and field-cooled conditions. 


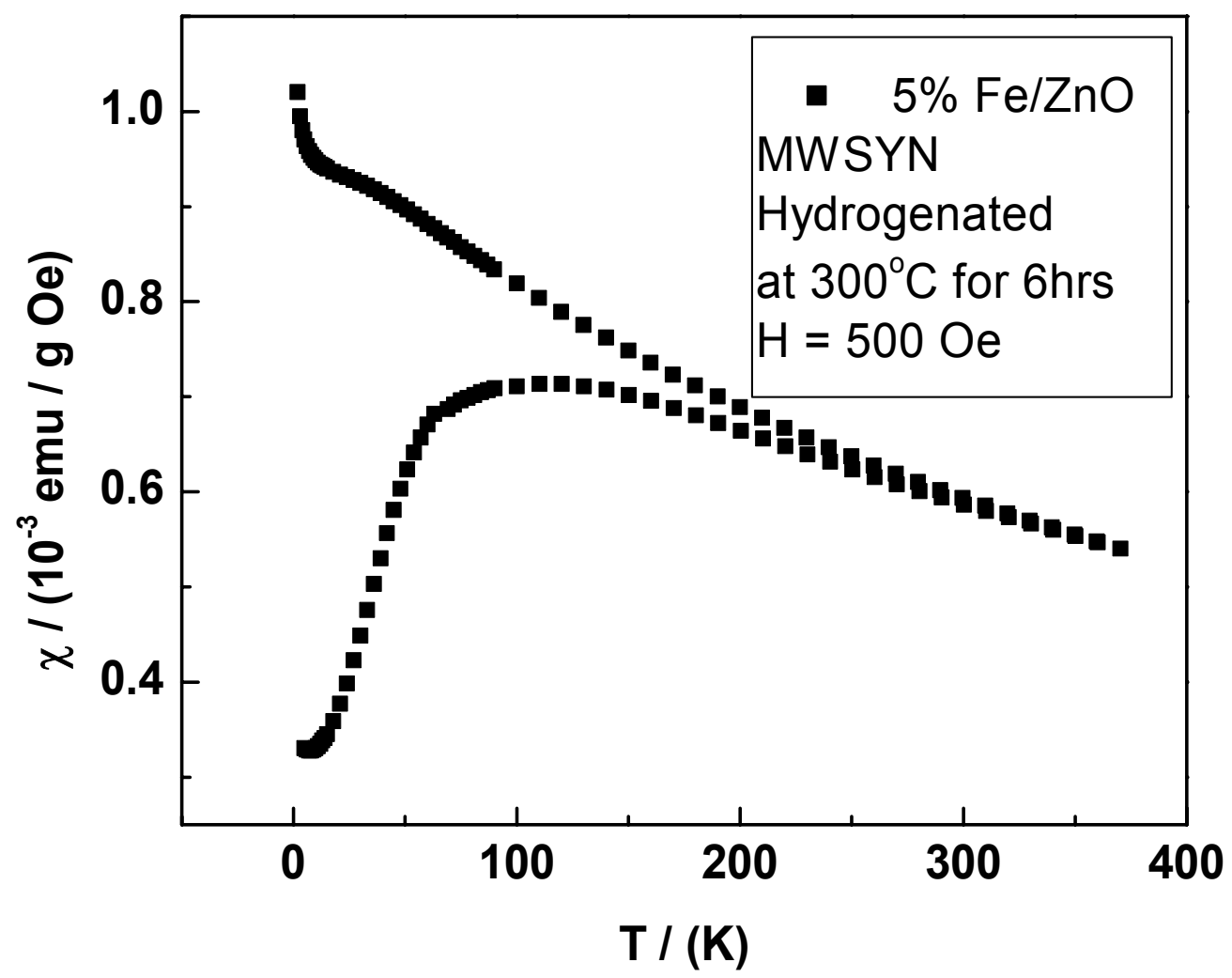

Figure 6-21. Temperature dependence of the magnetic susceptibility $(\chi)$ of the asprepared $5 \% \mathrm{Fe} / \mathrm{ZnO}$ hydrogenated for 6 hours under zero-field-cooled and field-cooled conditions. 

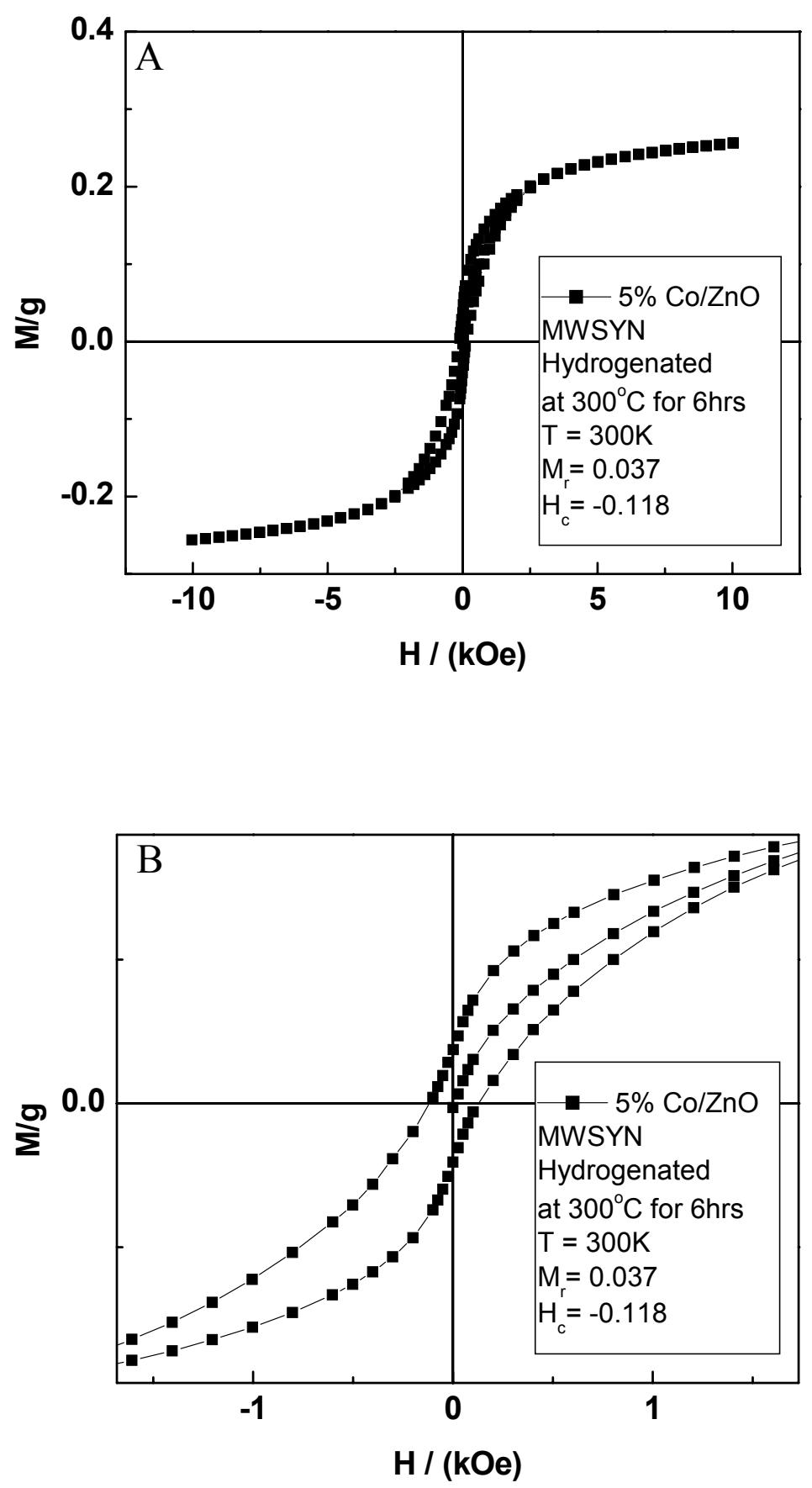

Figure 6-22. $M$ vs $H$ Variation of $5 \% \mathrm{Co} / \mathrm{ZnO}$ at $300 \mathrm{~K}(\mathrm{~A})$ and an expanded view (B). 

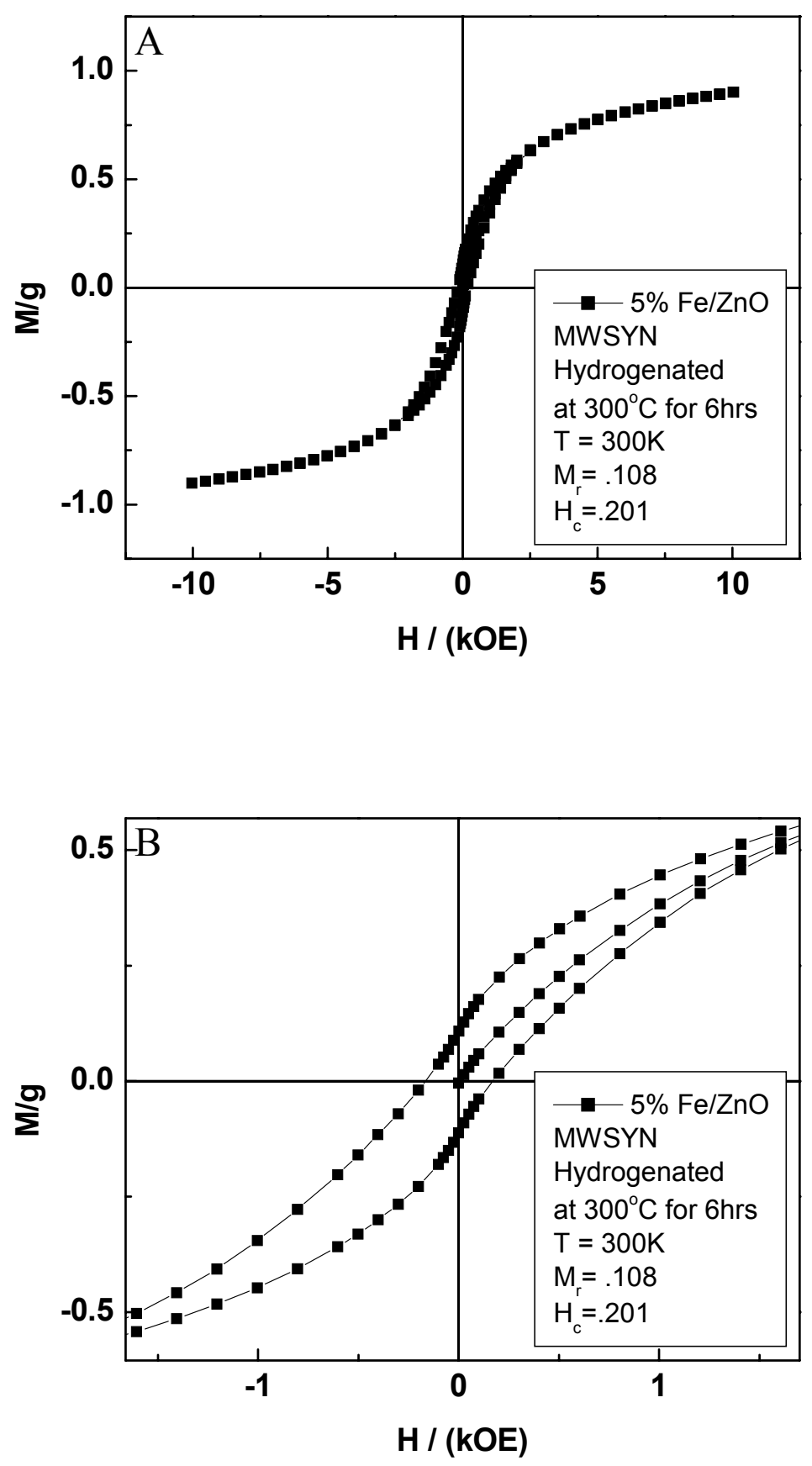

Figure 6-23. $M$ vs $H$ Variation of 5\% Fe/ZnO at $300 \mathrm{~K}(\mathrm{~A})$ and an expanded view (B). 


\section{Summary of Part II}

Samples of 1,5 , and $10 \%$ cobalt-doped $\mathrm{TiO}_{2}$ prepared by a sol gel technique are found to be paramagnetic at room temperature with the magnetic susceptibility following the Curie-Weiss Law. However, transformation from paramagnetic to room temperature ferromagnetism (RTFM) is observed for the 5\% and 10\% doped samples after hydrogenation of the samples at $573 \mathrm{~K}$. The increase in the hydrogenation time from 1 to $6 \mathrm{hr}$. increases the remanance and coercivity. X-ray photoelectron spectroscopy and high resolution transmission electron spectroscopy failed to detect the presence of cobalt nanoparticles suggesting that the observed RTFM may be intrinsic. This study was extended to include $10 \%$ iron, manganese, and nickel doped $\mathrm{TiO}_{2}$. Upon hydrogenation only the iron and manganese doped samples showed a single phase (anatase) in the XRD pattern. Magnetic measurements revealed that the manganese doped sample retains its paramagnetic behavior after hydrogenation while the iron sample acquires RTFM.

Transition metal-doped $\mathrm{ZnO}$ is also important for applications in spintronics. A

number of preparation methods, such as sputtering, chemical vapor deposition, sol-gel are commonly employed. In most of these methods, the nature of the produced material is amorphous and so an additional high-temperature processing step is required in order to obtain crystallinity. However, high temperature processes can lead to significant side effects, such as the formation of other phases. We have shown that $5 \% \mathrm{M}(\mathrm{M}=\mathrm{Cr}, \mathrm{Fe}$, $\mathrm{Mn}$, and $\mathrm{Ni}$ ) $\mathrm{ZnO}$ can be synthesized at room temperature. However after hydrogenation only the chromium and cobalt samples show a single phase of $\mathrm{ZnO}$ as determined by XRD. Magnetic measurements revealed that the chromium doped sample retains its 
paramagnetic behavior after hydrogenation while the cobalt sample acquires RTFM. We have extended this study to include $10 \% \mathrm{Co} / \mathrm{ZnO}$ which is also paramagnetic at room temperature, but hydrogenation at $573 \mathrm{~K}$ changes the magnetic behavior from paramagnetic to ferromagnetic.

Finally, we have also synthesized $5 \% \mathrm{M}(\mathrm{M}=\mathrm{Co}, \mathrm{Cr}, \mathrm{Fe}, \mathrm{Mn}$ and $\mathrm{Ni})$ doped zinc oxide using microwave irradiation. Microwave irradiation has several advantages over conventional methods including short reaction time, small particle size, narrow size distribution and high purity. Upon hydrogenation only the nickel doped sample exhibited multiple phases. Magnetic measurements reveal that only the cobalt and iron doped samples acquire RTFM after hydrogenation. 


\section{VITA}

Garry Glaspell was born to Garry and Carolyn Glaspell on February $7^{\text {th }} 1978$ in Fairmont, West Virginia. After graduating from Fairmont Senior High in 1996, He attended Fairmont University with a scholarship and graduated in 2000 with a B.S. in both Chemistry and Mathematics. He then entered the graduate program at West Virginia University with a Fellowship from the NSF under the supervision of Dr. Paul Jagodzinski working primarily on research involving nanoparticles. He is currently a candidate for the degree of Doctor of Philosophy in Analytical Chemistry at West Virginia University. 


\section{Publications}

Manivannan, A.; Glaspell, G.; Seehra, M. S. Controlled Transformation of Paramagnetism to Room-Temperature Ferromagnetism in Cobalt-Doped Titanium Dioxide. Journal of Applied Physics (2003), 94(10), 6994.

Glaspell, G.; Jagodzinski, P. W.; Manivannan, A. Formation of Cobalt Nitrate Hydrate, Cobalt Oxide, and Cobalt Nanoparticles Using Laser Vaporization Controlled Condensation (accepted - Journal of Physical Chemistry B).

Manivannan, A.; Glaspell, G.; Riggs, L.; Underwood, S.; Seehra, M. S. RoomTemperature Synthesis and Characterization of Pure and Co-Doped $\mathrm{ZnO}$ (accepted - MRS Symposium).

Glaspell, G.; Manivannan A.; Seehra, M. S. Sol-Gel Synthesis and Magnetic Studies of Titanium Dioxide Doped with 10\% M ( $\mathrm{M}=\mathrm{Fe}, \mathrm{Mn} \& \mathrm{Ni}$ ) (In preparation)

Glaspell, G.; Manivannan A.; Seehra, M. S. Novel One Step Synthesis of M (M = Co, Cr, $\mathrm{Fe}, \mathrm{Mn} \& \mathrm{Ni}$ ) Doped Zinc Oxide Nanoparticles Via Microwave Irradiation (In preparation)

Glaspell, G.; Manivannan A.; Seehra, M. S. Novel One Step Synthesis of Zinc Doped Copper Oxide Nanoparticles at Room Temperature (In preparation) 